ISSN 1916-9639 (Print)

ISSN 1916-9647 (Online)

APPLIED

PHYSICS

RESEARCH

Vol. 1, No. 2

November 2009

CCSE

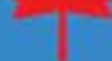

Canadian Center of Science and Education 


\section{Editorial Board}

Ahmad Mujahid Ahmad Zaidi Universiti Tun Hussein Onn Malaysia, Malaysia

Ajay K Pandey University of St Andrews, UK

Anne Brown Canadian Center of Science and Education, Canada

Christopher Andrew Hooley University of St Andrews, UK

Gang Sheng University of Alaska, USA

Harneet Thakur Deemed University, India

Hwee San Lim Universiti Sains Malaysia, Malaysia

Igor Meglinski Cranfield University, UK

Jing Zhang University of Alaska Fairbanks, USA

Kaza Venkata Ramana Rao University of Rajasthan, India

Khalid Omar Universiti sains Malaysia, Malaysia

Makbul Anwari Universiti Teknologi Malaysia, Malaysia

Mike Gibbs University of Sheffield, UK

Mohamed S. Gaafar National Institute of Standards (NIS), Egypt

Nikolaus Klaus Metzger University of St Andrews, UK

Patrick McNally Dublin City University, Ireland

Paul Alan Hatherly Open University, UK

Puramanathan Naidoo Mangosuthu University of Technology, South African

Riccardo Bartolini University of Oxford, UK

Stanislav Victorovich Shutov National Academy of Sciences of Ukraine, Ukraine

Stephen Daniels Dublin City University, Ireland

Yevgen Baganov Kherson National Technical University, Ukraine 


\section{Contents}

Ozone Generation by Pulsed Streamer Discharge in Air

Zolkafle Buntat, Ivor R.Smith \& Noor. A. M. Razali

Validation Process for Electrical Charge Tomography System Using Digital Imaging Technique

Mohd Daud Isa, Mohd Fua'ad Rahmat, Kamaruzaman Jusoff \& Tengku Ahmad Raja Hussin

The Hydration of Heavy Metal Salts Admixtured High Alumina Cement - A X-Ray Diffraction Study

R. Nithya, S.Barathan, M.Gopalakrishan, G.Sivakumar \& B.Gobinath

Nanoseconds Switching for High Voltage Circuit Using Avalanche Transistors

Abd Rahman Tamuri, Noriah Bidin \& Yaacob Mad Daud

Synthesis of LaMnO3 Nanofibers via Electrospinning

Jinxian Wang, Xiaoqiu Zheng, Xiangting Dong, Zhen Qu, Guixia Liu, Ran Xue \& Yudong Hao

Artificial Neural Network Based Prediction of Maximum and Minimum Temperature in the Summer

Monsoon Months over India

S. S. De \& A. Debnath

Assessment of Radiation Dose Rates in the High Terrestrial Gamma Radiation Area of Selama District, Perak, Malaysia

Ahmad Termizi Ramli, Nursama Heru Apriantoro \& Husin Wagiran

Study on the Experiment of Concentrating Coking Wastewaters by Air-blowing Vacuum Membrane

Distillation

Heng Zhao \& Huawei Sun

Effect of Fly Ash and Water in Hydrated Srpc-A Ftir Study

K.Thiruppathi, S.Barathan, N.Anandhan \& G.Sivakumar

Study on the Laser Hybrid Cladding Technology on the Surface of Copper Substrate

Fudong Zhu \& Yunshan Wang

Investigation on the Hydration Properties of the Rice Husk Ash Cement Using Ftir and Sem

G. Sivakumar \& R. Ravibaskar

Study on Wet Etching of AAO Template

Guofeng Hu, Haiming Zhang, Wenwen Di \& Tingting Zhao

Ionospheric Correction and Ambiguity Resolution in DGPS with Single Frequency

Norsuzila Ya'acob, Mardina Abdullah, Mahamod Ismail \& Kamaruzaman Jusoff

Target Strength for Fish Identification Using Echo Sounder

Sunardi, Jafri Din, Anton Yudhana \& Raja Bidin Raja Hassan

Study on Fault Diagnosis of Fuel Injection Based on Vibration Signal Analysis of High-pressure Fuel

Injection Pipe

Zhiqiang Wang 


\title{
Ozone Generation by Pulsed Streamer Discharge in Air
}

\author{
Zolkafle Buntat \\ Faculty of Electrical Engineering, Universiti Teknologi Malaysia \\ 81310 UTM Skudai, Johor, Malaysia \\ Ivor R.Smith (Corresponding author) \\ Department of Electronic and Electrical Engineering, Loughborough University \\ Loughborough, Leicestershire LE11 3TU, UK \\ Tel: 44-1509-227-005Ｅ-mail: i.r.smith@lboro.ac.uk
}

Noor. A. M. Razali

Faculty of Electrical Engineering, Universiti Teknologi Malaysia

81310 UTM Skudai, Johor, Malaysia

\begin{abstract}
Ozone is well established as an important oxidising agent in many industrial applications and the high-voltage pulsed streamer discharge technique has emerged as an efficient method for its production. The paper investigates the parameters that are important in this process, including the magnitude of the applied pulse voltage, the air flow rate and the electrode dimensions and spacing, when used in a plate-to-plate reactor configuration in which sheets of perforated aluminium are employed to enhance the degree of ionisation and soda lime glass dielectric barriers both to inhibit singular discharges and to promote the development of the streamer discharge. The highest ozone concentration achieved was $5995 \mathrm{ppmv}$ and the greatest yield was $144 \mathrm{~g} / \mathrm{kWh}$.
\end{abstract}

Keywords: Ozone generation, Pulsed power, Pulsed streamer discharge

\section{Introduction}

Arising from the increased concern with environmental protection, ozone attracts widespread attention as an important oxidising agent, finding use in a wide range of industrial applications. With three oxygen atoms bonded together, it is a powerful but unstable oxidant, although having a half life of only between about 7 and 20 minutes. Nevertheless, when compared with alternatives such as the chlorination process (Samaranayake W., 2000; Buntat Z, 2003; Chalmers I D, 1994; Namihira T, 2001), it offers a number of significant advantages, in particular its lower energy consumption (Samaranayake W., 2000; Buntat Z, 2003; Chalmers I D, 1994; Namihira T, 2001; Buntat Z, 2005; Chalmers I D, 1996; Samaranayake, 2001). As a consequence of its attractive properties, many methods of enhancing the production rate of ozone have been investigated.

Ozone is produced during an electrical discharge at room temperature and pressure, with air assisting in the two main processes of dissociation and formation (Samaranayake, 2000). Initially, an oxygen atom is dissociated in collisions between high energy electrons and oxygen molecules (equations (1) and (2) below), before ozone itself is formed in a three-body reaction process (equation (3)). $\mathrm{M}$, the third particle involved in the collision process, could in dry air be either $\mathrm{O}_{2}, \mathrm{O}_{3}$ or $\mathrm{N}_{2}$ (Samaranayake, 2000; Simek, 2002).

$$
\begin{aligned}
& \mathrm{e}+\mathrm{O}_{2} \rightarrow \mathrm{O}+\mathrm{O}+\mathrm{e} \\
& \mathrm{e}+\mathrm{O}_{2} \rightarrow \mathrm{O}+\mathrm{O}^{-} \\
& \mathrm{O}+\mathrm{O}_{2}+\mathrm{M} \rightarrow \mathrm{O}_{3}+\mathrm{M}
\end{aligned}
$$

Acceleration of excited electrons requires a high-voltage energy supply, which may however cause a spark breakdown to occur in a discharge chamber. Use of a pulsed streamer discharge [PSD] technique can alleviate this problem, since 
the energy in the short duration fast rising pulse required to accelerate the electrons will be insufficient to lead to a breakdown (Chalmers, 1994; Chalmers, 1996; Samaranayake, 2001; Simek, 2002; Samaranayake, p.849-854). As a consequence, an intense streamer discharge is produced by the very effective ozone generation process. Dielectric material may be added inside the chamber to distribute evenly the micro-discharges over the dielectric layer area (Buntat, 2003; Samaranayake, 2001; Samaranayake, p.849-854) and to prevent the propagation of a single discharge.

High electric field strength in the vicinity of the electrodes is important in ionizing the gas molecules and in producing both more energetic electrons and more streamers. The ozone formation that occurs in the streamers is increased if they are more intense and wider. In the experiments described in this paper a perforated aluminium sheet with an array of sharp edged holes was located next to the aluminium foil electrodes, to produce an increased electric field strength in the vicinity of the holes and so lead to a greater ozone production (Buntat, 2005; Buntat, 2007).

The pulsed voltage applied throughout the present investigation was of positive rather than negative polarity, since it is known (Samaranayake, 2000; Samaranayake, p.849-854) that the streamers then produced have more branches and more channels per unit length, and are likely to lead to a greater dissociation of oxygen molecules. The pulse duration of $120 \mathrm{~ns}$ used in the experiments was sufficiently short not to accelerate significantly any ions, and as a result the chamber temperature remained at the ambient level (Tamaribuchi, 2007). This avoids any need for a cooling system and the ozone deformation rate is reduced. In addition, operation at a frequency of 50 pps promotes new streamer growth within every new pulse (Shuhai, 2000).

The paper studies maximisation of the oxygen yield in a PSD experiment by maximising the various parameters that are involved, including the applied pulse voltage, the air flow rate, the gaseous gap spacing between the dielectric barrier and the length of the electrode chamber.

\section{Experimental arrangement}

Figure 1 shows the constructional details of the discharge reactor that was purpose built for the PSD experimentation. A plane-to-plane electrode structure was used, with the commercial zero grade dry air flowing axially along the reactor having a composition of nitrogen $78.08 \%$, oxygen $20.9 \%$, carbon dioxide $0.03 \%$ and argon $0.93 \%$, plus traces of neon, helium, methane, krypton, zenon, hydrogen and nitrous oxide. The flow rate of the gas was monitored before its entry into the reaction chamber, and was controlled to between 0.2 and $1 \mathrm{l} / \mathrm{m}$ at a constant pressure of $1 \mathrm{bar}$.

The gap spacing between the two dielectric barriers influences the electric field strength and the radius of the micro-discharge, and the electrode dimensions influence the gas ionisation and residence time. The variation of the gap spacing was therefore investigated between $1.5 \mathrm{~mm}$ and $3 \mathrm{~mm}$ and the electrode length between $100 \mathrm{~mm}$ and $220 \mathrm{~mm}$, but at a constant width of $16 \mathrm{~mm}$, since any variation in the electrode width has a similar effect to one in the length. The overall discharge volume thus ranged from $2.40 \times 10^{-6} \mathrm{~m}^{3}$ to $10.56 \times 10^{-6} \mathrm{~m}^{3}$, with the effective area being between 1.60 $\mathrm{x} 10^{-3} \mathrm{~m}^{2}$ and $3.52 \times 10^{-2} 1$

Figure 2 shows diagrammatically the perforated aluminium sheet that was placed in the discharge chamber between the aluminium foil electrodes and the dielectric barrier, causing high-energy electrons to be produced by the enhanced electric field in their vicinity. The sharp edged circular holes were $1.2 \mathrm{~mm}$ in diameter, which resulted in the removal of about $23 \%$ of the area of the sheet. Both dielectric barriers were a $1 \mathrm{~mm}$ sheet of soda lime glass having a relative permittivity of 7.75 , with the high pulse voltage supply obtained from a cable generator and supplied at the centre of the electrodes, as shown in Figure 1.

Figure 3 shows the overall experimental assembly. The ozone monitor recorded the ozone concentration on the basis of the ultraviolet absorption $(254 \mathrm{~mm})$ properties. After measurement, the ozone was destroyed in a catalytic ozone destroyer before being exhausted to air. The high-voltage positive-polarity pulses for the reactor were provided by the combination shown in Figure 4 of a double Blumlein pulse generator using three coaxial cables together with a rotary spark gap switch., and could be varied between 1 and $20 \mathrm{kV}$ at a fixed repetition rate of $50 \mathrm{pps}$. The pulse rise time was less than $50 \mathrm{~ns}$ and its duration was $120 \mathrm{~ns}$. A high-voltage probe (Tektronix P6015A, 1000x) with a $0.22 \mu \mathrm{F}$ capacitor connected in series to ground was used to measure the voltage supplied and a Rogowski coil with a Pearson current monitor (model 2877,1:1 V/A) to measure the current. Both signals were displayed on a digital storage oscilloscope (LeCroy 9344) with a bandwidth of $500 \mathrm{MHz}$ and a sample rate of $1 \mathrm{GS} / \mathrm{s}$. The power and the energy input to the discharge per pulse were computed from the two digitised signals.

\section{Experimental results and analysis}

During the PSD experimentation all measurements were taken before the electrical discharge turned into the arc stage, after which ozone formation ceases. The discharge process was left to run continuously for at least five minutes, by which time the concentration level in the ozone analyser had always reached a steady state. The power supply was then removed until the ozone analyser indicated a zero level, when the power supply was restored and the cycle repeated. 
Figure 5 shows waveforms of a typical positive polarity voltage pulse of about $14 \mathrm{kV}$ peak and a current of about $8 \mathrm{~A}$ peak fed to the reaction chamber. The small oscillations evident in the current are attributed to both stray inductance and reflected waves due to a slight impedance mismatch between the power supply and the reactor.

In ozone generation either the ozone concentration in parts per million or the ozone yield in $\mathrm{g} / \mathrm{kWh}$ is used as a figure of merit in assessing the efficiency of the process. Both are considered in the assessment below.

\subsection{Effect of peak pulsed voltage on ozone concentration at different air flow rates}

Figure 6 shows the variation of the ozone concentration as the peak pulsed voltage supplied to the maximum 3 mm long gap is increased from $13 \mathrm{kV}$, the lowest level at which ozone was produced, to $18 \mathrm{kV}$, beyond the normal breakdown voltage of the gap. This higher figure confirms the advantage of the higher voltage possible with the PSD approach in increasing the energy given to the electrons before a breakdown results. As the voltage is increased the higher electrical energy density in the discharge leads to more energy being transferred to the electrons, thereby increasing the possibility of collisions with the air in the chamber and giving an approximately linear increase in the ozone concentration. The effect of an increased flow rate on the ozone concentration is also evident in Figure 6, with the increased residence time producing a very much greater concentration at the lower flow rates.

\subsection{Effect of air flow rate on ozone concentration at different peak pulsed voltages}

The effect of the air flow rate on the ozone concentration is evident in Figure 7, with the concentration increasing with the voltage but decreasing with the flow rate The residence time of the gas in the reaction chamber is obviously inversely related to the air flow rate, with an increased residence time providing more time for a reaction to occur and a correspondingly higher ozone concentration to be produced.

\subsection{Effect of gaseous gap spacing on ozone concentration as a function of peak pulsed voltages}

Figure 8 shows that the effect of reducing the gaseous gap length from $3 \mathrm{~mm}$ to $1.5 \mathrm{~mm}$ is clearly for the generation of ozone to begin at an appreciably lower voltage and to have produced a significantly higher concentration at any given flow rate.

This is clearly related to the increased energy density as the gap is decreased, together with the increased number of oxygen molecule/electron collisions and the correspondingly increased combination of oxygen atoms with oxygen molecules. However, for the $1.5 \mathrm{~mm}$ gap length the ozone concentration increases at a progressively slower rate than with the $3 \mathrm{~mm}$ gap length, particularly as the voltage approaches the maximum $16 \mathrm{kV}$ that the shorter gap can sustain.

\subsection{Effect of electrode chamber length on ozone concentration as a function of peak pulsed voltages}

Figure 9 shows that the electrode chamber length has little effect on the ozone concentration at low peak pulsed voltages. In contrast, it has a marked effect at higher voltages above about $14 \mathrm{kV}$, with the increased residence time that accompanies the $60 \mathrm{~mm}$ increase in the chamber length being responsible for a $40 \%$ increase in the concentration at 18 $\mathrm{kV}$. However, the longer the ozone spends in the air-filled chamber the greater is the rate at which it becomes deformed. Electrons and various undesirable products such as the nitrogen oxide compounds (NOx) are also produced in the complex reaction processes, with these being the primary cause of the deformation.

\subsection{Effect of peak pulsed voltage on ozone yield at different air flow rates}

The ozone yield of a process clearly depends on both the concentration and the input electric energy density, with the efficiency $\eta$ in $\mathrm{g} / \mathrm{kWh}$ commonly being calculated from

$$
\eta=\left[\frac{C\left(O_{3}\right) f_{r}}{P}\right]
$$

where $C\left(\mathrm{O}_{3}\right)$ is the ozone concentration (ppmv), $f_{r}$, is the gas flow rate $(1 / \mathrm{min})$ and $P$ is the discharge power (kW). Figure 10 shows that initially the yield increased for all flow rates, reaching a peak at about $15 \mathrm{kV}$ before it decreased as the rate of ozone decomposition became higher than the rate of ozone formation at that particular energy input per cycle. Eventually, due to the greater and rapidly increasing energy input per cycle evident in Figure 11, the yield rises again, as shown in Figure 12 at voltages only the longer gap can withstand.

\subsection{Effect of peak pulsed voltage on ozone yield at different gap spacing}

Figure 12 shows that a maximum ozone yield is achieved, but that this is at the breakdown voltage for the smaller gap. For the larger gap the rapid increase in the energy input per pulse above about $15 \mathrm{kV}$ eventually more than compensates for the increased decomposition rate, with the yield again increasing after having fallen to a minimum at about $17 \mathrm{kV}$.

\subsection{Effect of peak pulsed voltage on ozone yield at different chamber length}

Figure 13 demonstrates that at lower peak pulsed voltages the shorter chamber length produces a higher yield, but that the situation reverses at the higher voltages when the longer chamber produces an appreciably greater yield. Together 
with figure 12, the results demonstrate that the maximum values of the yield are not obtained under conditions also giving the maximum concentration, and which one is optimised will depend on the particular application.

\section{Conclusions}

It has been confirmed that, as with other ozone production processes, concentration and yield are two different criteria that cannot be maximised simultaneously. The application for the ozone generation will be determined by which criteria is most important, and the PSD technique has been shown to be most useful when a high concentration rather than a high yield is required. It can also be concluded from the work that in general, the ozone concentration is increased by the use of a higher pulsed voltage, greater gaseous gap spacing and a longer electrode length but a slower air flow rate. On the other hand, the yield was generally found to be greatest at intermediate levels of these quantities with, for example the greatest concentration obtained when the electrode length was $220 \mathrm{~mm}$ whereas a length of $160 \mathrm{~mm}$ gave the greatest yield. Similarly, a greater gap spacing with higher input energy generates the highest yield of ozone at 15 $\mathrm{kV}$. However, the ozone deformation due to the residence time at higher voltages also needs to be considered. Faster air flow rates (above about $1 \mathrm{l} / \mathrm{m}$ will be investigated in future research, as the ozone yield shows a linear relationship with an increasing air flow

\section{Acknowledgements}

Dr Z Buntat and Miss N.A.M Razali are indebted to the Ministry of Higher Education of Malaysia and the University Malaysia Perlis for financial support received during the course of this investigations.

\section{References}

Buntat Z, Harry J E, and Smith I R. (2007). Generation of a homogenous glow discharge in air at atmospheric pressure. ELEKTRIKA, 9. 60-65

Buntat Z, Harry J E. and Smith I R. (2003). Application of dimensional analysis to ozone production by pulsed streamer discharge in oxygen. Phys. D: Appl. Phys, 36, 1553-1557.

Buntat Z. (2005). PhD Thesis Ozone generation using electrical discharges. Loughborough University, UK.

Chalmers I D, Zanella L and MacGregor S J. (1996). Ozone generation using pulsed corona in a wire/cylinder arrangement. IEE Colloquium on Pulsed Power, 7/1-7/5.

Chalmers I D, Zanella L, MacGregor S J, and Wray I A. (1994). Ozone generation by pulsed corona discharge in a wire cylinder arrangement. IEE Colloquium on Electro-technologies for waste processing and purification. 6/1-6/4.

Namihira T, Shinozaki K, Katsuki S, Hackam R, Akiyama H and Sakugawa T. (2001). Characteristic of ozonizer using pulsed power. IEEE Pulsed Power and Plasma Science, 2, 1090-1093.

Samaranayake W J M, Mihara Y, Namihira T, Katsuki S, Hackam R and Akiyama, H. Ozone production using pulsed dielectric barrier discharge in oxygen. IEEE, 7, No. 6, pp 849-854

Samaranayake W J M, Namihira T, Katsuki S, Miyahara, Y, Sakugawa T, Hackam R and Akiyama H. (2001). Pulsed power production of ozone using nonthermal gas discharges. IEEE Electrical Insulation Magazine, 17, No. 4, pp.17-25.

Samaranayake W. J. M, Miyahara Y, Namihira T, Katsuki S, Hackam R and Akiyama H. (2000). Pulsed streamer discharge characteristics of ozone production in dry air. IEEE Trans Dielectr. Electr. Insul, 7, 254-260.

Shuhai Liu and Manfred Neiger. (2000). Excitation of dielectric barrier discharges by unipolar submicrosecond square pulses. J.Phys. D: Appl.Phys, 34 1632-1638.

Simek M and Clupek M. (2002). Efficiency of ozone production by pulsed positive corona discharge in synthetic air. J.Phys. D: Appl.Phys. 35, pp.1171-1175.

Somerville I C, MacGregor S J and Farish O. (1990). An efficient stacked-Blumlein h.v pulse generator. Meas. Sci. Technol, 1, pp. 865-868.

Tamaribuchi H, Wang D, Namihira T, Sakugawa, S, Katsuki S and Akiyama H. (2007). Effect of pulse width on ozone generation in pulsed streamer discharge IEEE Pulsed Power Plasma Science Conference Record 333. 


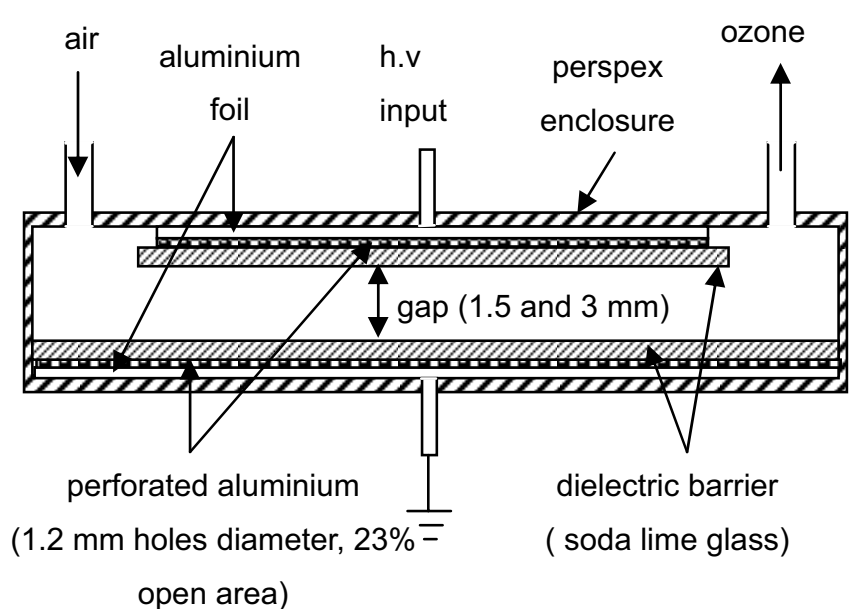

Figure 1. Reaction chamber (Buntat, 2005)

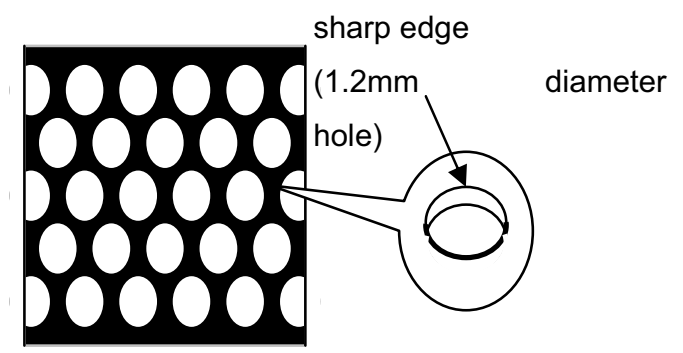

Figure 2. Perforated aluminium sheet (Buntat, 2007)

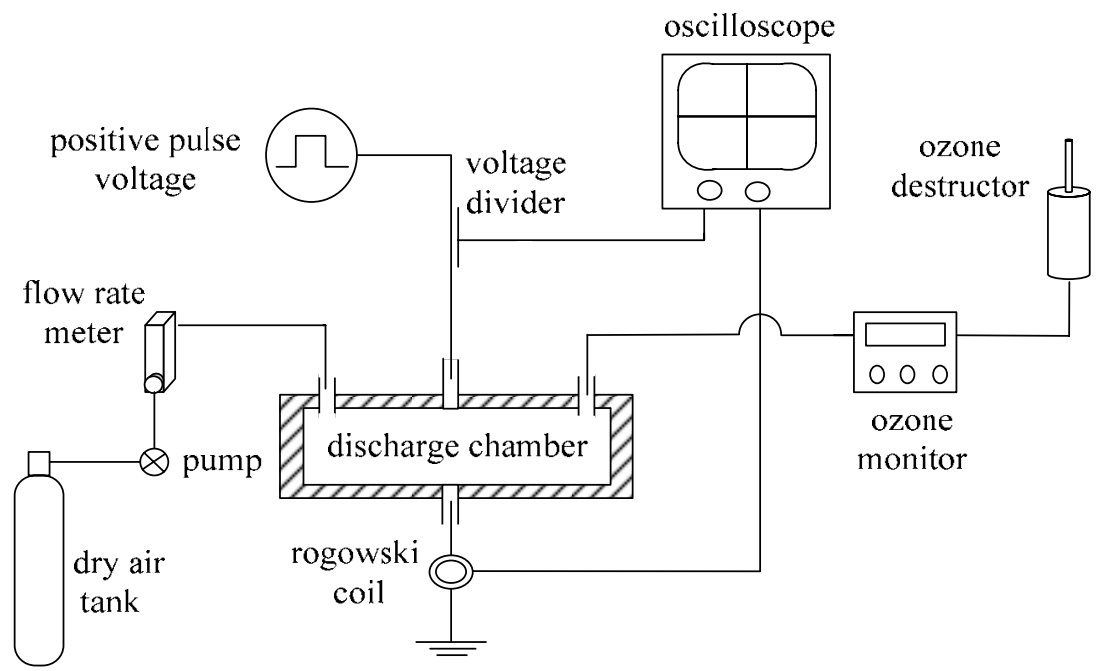

Figure 3. Block diagram of experimental assembly 


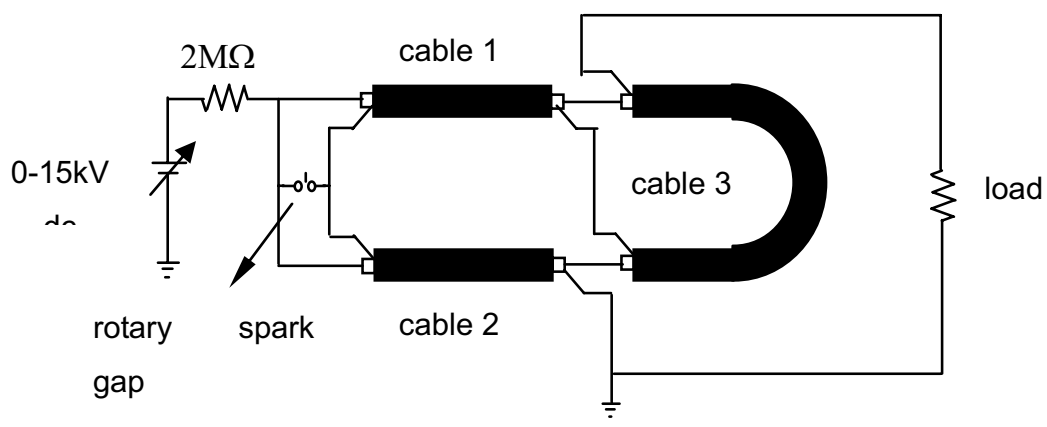

Figure 4. Pulse power supply of Blumlein configuration (Somerville, 1990)

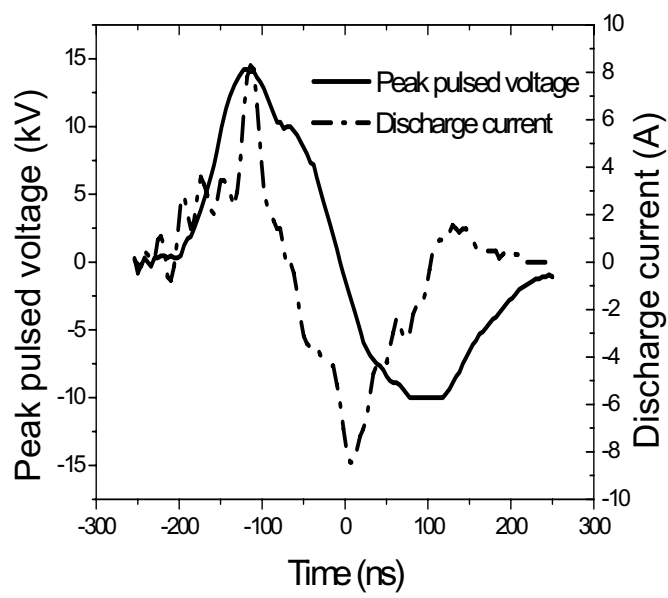

Figure 5. Typical voltage pulse and discharge current waveform. Gap spacing $=3 \mathrm{~mm}$, peak pulsed voltage $=14 \mathrm{kV}$, air flow rate $=0.21 / \mathrm{min}$, pulse repetitive rate $=50 \mathrm{pps}$, pulse duration $=120 \mathrm{~ns}$, and pressure $=1 \mathrm{bar}$.

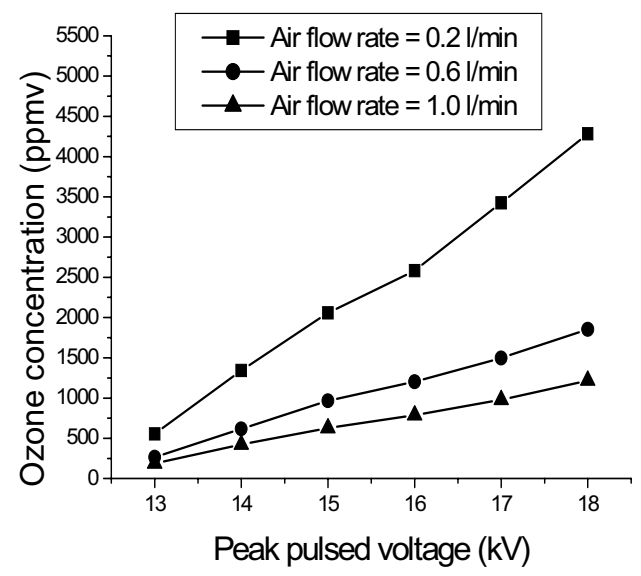

Figure 6. Effect of peak pulsed voltage on ozone concentration at different air flow rates. Gap length $=3 \mathrm{~mm}$, chamber length $=160 \mathrm{~mm}$, pressure $=1$ bar 


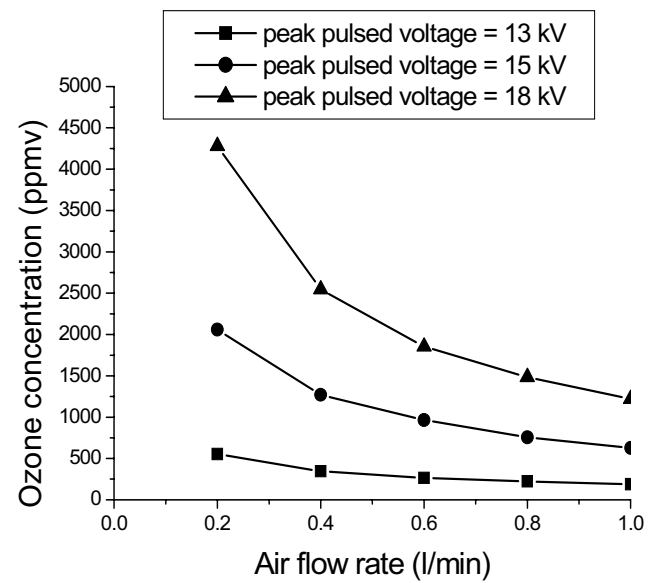

Figure 7. Effect of air flow rate on ozone concentration at different peak pulsed voltages. Gap length $=3 \mathrm{~mm}$, chamber length $=160 \mathrm{~mm}$, pressure $=1 \mathrm{bar}$

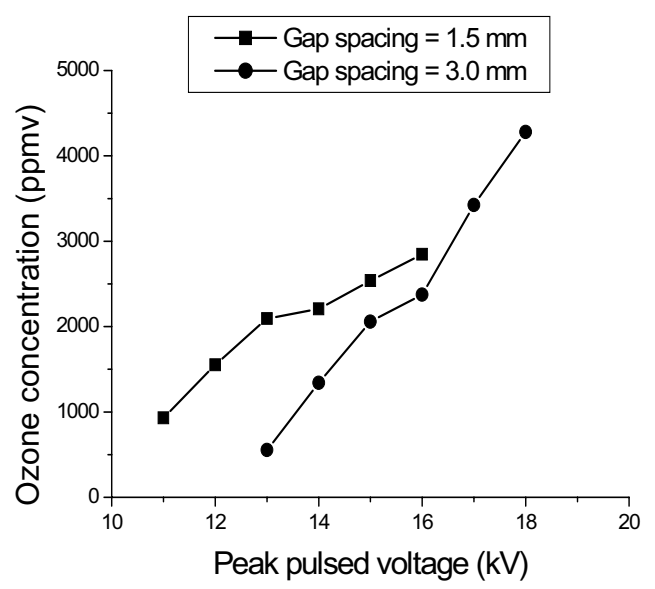

Figure 8. Effect of gap spacing on ozone concentration as a function of peak pulsed voltage. Chamber length $=160 \mathrm{~mm}$, air flow rate $=0.2 \mathrm{l} / \mathrm{min}$, pressure $=1 \mathrm{bar}$

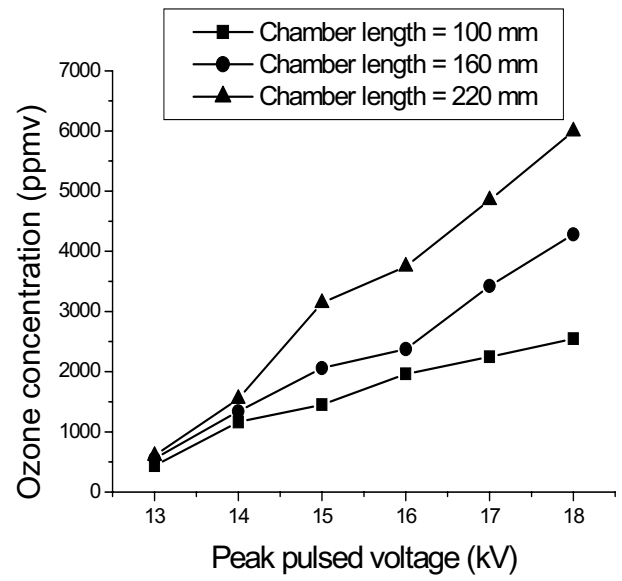

Figure 9. Effect of chamber length on ozone concentration as a function of peak pulsed voltage. Gap length $=3 \mathrm{~mm}$, air flow rate $=0.21 / \mathrm{min}$, pressure $=1 \mathrm{bar}$. 


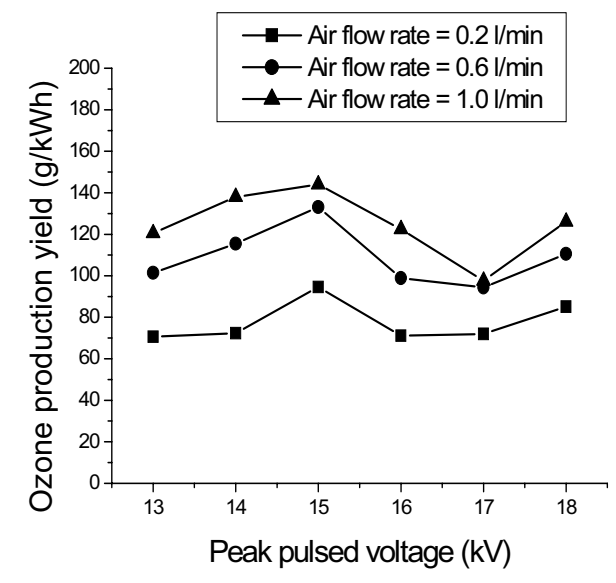

Figure 10. Effect of applied peak pulsed voltage on ozone yield at different air flow rates. Gap length $=3 \mathrm{~mm}$, chamber length $=160 \mathrm{~mm}$, pressure $=1 \mathrm{bar}$

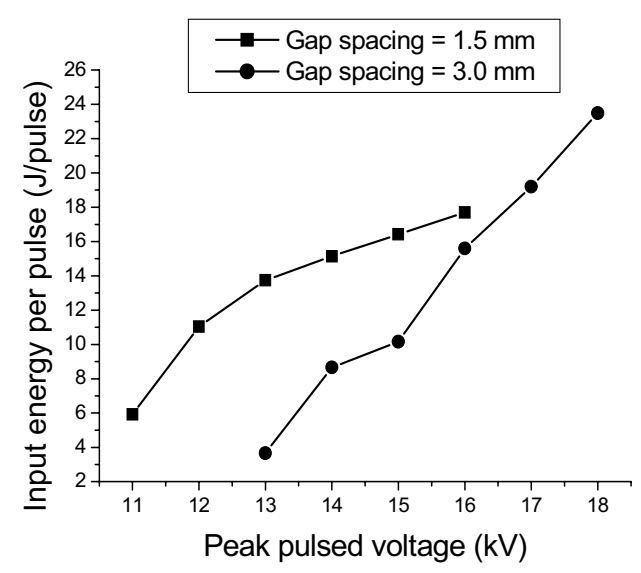

Figure 11. Effect of peak pulsed voltage on input energy into discharges/pulse.

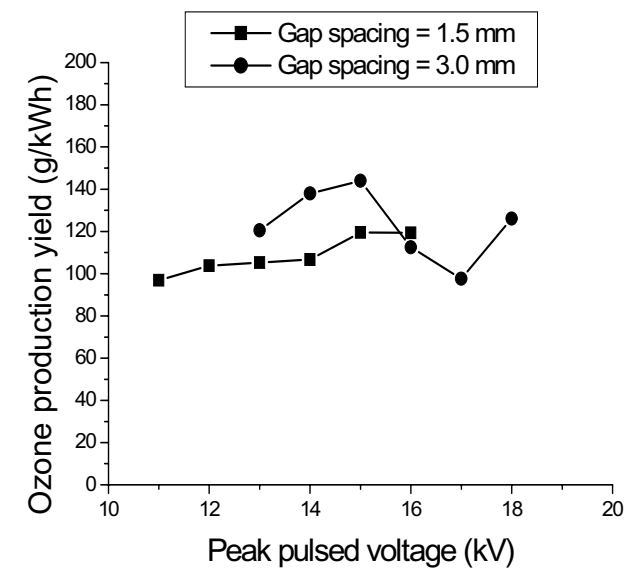

Figure 12. Effect of peak pulsed voltage on ozone yield at different gap spacing. air flow rate $=1.0 \mathrm{l} / \mathrm{min}$, pressure $=1$ bar. 


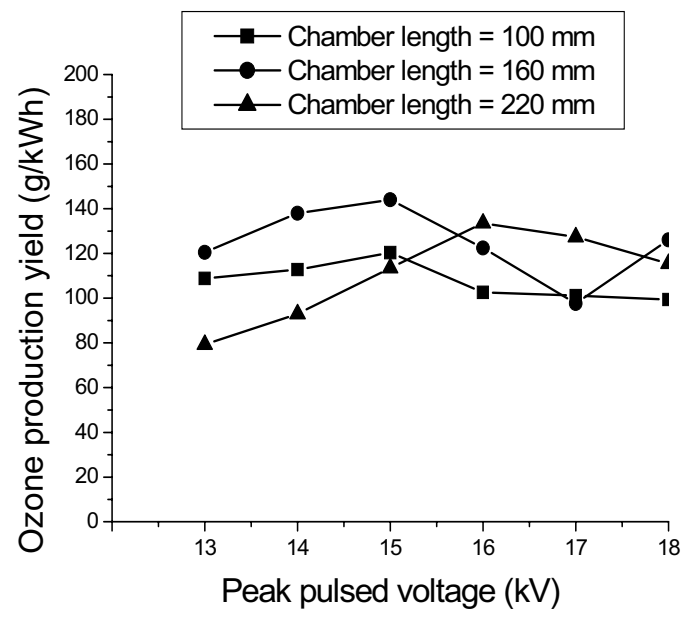

Figure 13. Effect of peak pulsed voltage on ozone yield at different. Gap length $=3 \mathrm{~mm}$,air flow rate $=1.0 \mathrm{l} / \mathrm{min}$, pressure $=1$ bar. 


\title{
Validation Process for Electrical Charge Tomography System Using Digital Imaging Technique
}

\author{
Mohd Daud Isa \\ Electrical Engineering Department, Politeknik Kota Bharu \\ KM.24 Kok Lanas, 16400 Ketereh, Kota Bharu, Kelantan, Malaysia \\ Tel: 60-9-788-9126 E-mail: peppkb@yahoo.com \\ Mohd Fua'ad Rahmat \\ Faculty of Electrical Engineering, University Technology Malaysia \\ 81310 Skudai, Johor Bharu, Johor, Malaysia \\ Tel:60-7553-5900Ｅ-mail: fuaad@fke.utm.my \\ Kamaruzaman Jusoff (Corresponding author) \\ TropAIR, Faculty of Forestry, Universiti Putra Malaysia \\ 43400 Serdang, Selangor, Malaysia \\ Tel: 60-3-8946-7176_E-mail: kjusoff@yahoo.com \\ Tengku Ahmad Raja Hussin \\ General Studies Department, Politeknik Kota Bharu \\ KM.24 Kok Lanas, 16400 Ketereh,Kota Bharu, Kelantan, Malaysia \\ Tel: 60-930-0198 E-mail: tabs2104@yahoo.com
}

This project is funded by Ministry of Higher Education, Malaysia (Sponsoring information)

\begin{abstract}
Electrical charge tomography (EChT) is a non-invasive imaging technique that is aimed to reconstruct the image of material being conveyed based on data measured by electrodynamics sensor installed around the pipe. The method to ensure the stability and accuracy of the image reconstruction should be applied to obtain a meaningful image reconstruction results. In this paper, Least square with regularization (LSR) method was introduced to reconstruct the cross-section image of material in gravity mode conveyor pipeline. Numerical analysis result based on data measured by sensor indicates that the algorithm is efficient to overcome the numerical instability. Instead of image reconstruction process, validation of the images is very important. It would be parts of verification process to the new image reconstruction method. In this system, digital imaging technique was used to interrogate the flow in pipeline around sensing area using CCD camera. It was found out that there is a good match between LSR method of image reconstruction and image capture by CCD camera due to the similarity of both images. This study implies that LSR method produced images that are stable and accurate as well as applicable for industrial use. It is suggested that another validation process should be conducted using duty ratio, signal to noise ration and structure correlation to validate the quality of image produced by LSR method.
\end{abstract}

Keywords: Tomography, Digital imaging technique, Least square, Validation, Regularization method

\section{Introduction}

Electrical charge tomography (EChT) is a non-invasive imaging technique that is aimed to reconstruct the image of material being conveyed in pipeline. Electrical tomography has many advantages over other tomography modes due to 
its high-speed, low-cost, non-intrusive sensors, no radiation, rapid response and robust as well as suitable for industrial applications (Yang \& Liu, 2000).

Many image reconstruction techniques have been extensively developed over the last two decades as reliable tools for electrical tomography. Examples are system linear back projection (Dyakowski, et. al., 1997), filter back projection (Isa et. al, 2008), singular value decomposition (SVD) (Hua, et. al. 2004). Tikhonov regularization (Jinchuang et. al. 2002), simultaneous algebraic reconstruction technique (Jiang et. al. (2003), landweber iteration (Yang et. al. 2003) and etc.

In electrical charge tomography, although there are numbers of work been done applying electrostatic charge carried by particles in solid/powder conveyor pipeline to tomographic imaging, only three methods were introduced - namely linear back projection (LBP), filter back projection (FBP) and least square method (Bidin et. al., 1995; Machida et. al. 200; Green et. al.,1997).

In this paper, novel algorithm for electrical charge tomography is presented. Basically, the previous method will be discussed and the advantages of the new method will be highlighted. All discussion will be based on similarity of the image being reconstructed by these methods as compared to image captured by CCD camera that has been processed using digital imaging technique.

\section{Methods \& materials}

\subsection{Background to EChT image reconstrcution}

EChT image reconstruction process involves two problems which have to be solved i.e. forward modeling problem solution and inverse problem solution. In electrical charge tomography, imaging forward modeling is pre-described as the theoretical of the system in sensing area. It is related to sensor's sensitivity to the three-dimensional charge which contains a uniformly distributed charge in coulomb per square meter $\left(\mathrm{C} / \mathrm{m}^{2}\right)$. Process tomography system by electrical charge is given one measurement from each of the sensors; the amount of information available is equal to the number of the sensors (Green et. al., 1997). Therefore, forward modeling of the pipe and the sensing area are mapped equally to the number of the sensor i.e sixteen by sixteen rectangular arrays consisting of 256 pixels or elements. The length between sensors is divided equally and located around the pipe at respective coordinates. The sensitivity map, S derived from the modeling and the summation of complete sensitivity map for sixteen sensors in two and three-dimensional is shown in Figure 2.

Inverse problem is the solution to provide an image of the charge concentration distribution within the sensing area. The data captured by 16 sensors is used to generate an image concentration. This image concentration is generated using analytical and statistical approaches such as linear back projection (LBP), filter back projection (FBP), and least square with regularization (LSR) methods.

\subsection{Linear Back Projection (LBP)}

Linear back projection is a straight forward solution which refers to the relationship between the distribution of charge, $\mathrm{q}$ and the detection of voltage by the detector as in equation (1).

$$
\mathbf{V}=\mathbf{S q}
$$

$\mathrm{S}$ is the sensitivity map or sensitivity matrix with a dimension of $16 \mathrm{X} 16$ (as discussed in section 2.0). The measurement data, $\mathrm{V}$ and the charge distribution $\mathrm{q}$ are unknown.

To reconstruct the images in this system, the inverse problem has to be solved using equation (1). However, there are some difficulties in calculating the inverse matrix of the sensitivity matrix S. The concept of general inverse has to be introduced. Moore proposed the concept of general inverse matrix, and Penrose gave the definition of Moore general inverse matrix in a definition form (Yong et. al., 2007). Thus, the equation (1) becomes $q=\mathbf{S}^{-1} \mathrm{~V}$, known as back projection. In practice, the concept of pseudo-inversion is used by assuming that $\mathbf{S}^{-1}=\mathbf{S}^{\mathrm{T}}$ (Dyakowski et. al., 2000). In the reality, $\mathrm{S}$ is a symmetry value, so this is formulated as equation (2).

$$
\mathbf{q}_{\mathbf{L B P}}=\mathbf{S V}
$$

\subsection{Filter Back Projection (FBP)}

The major limitation of linear back projection method arises due to the non-linear sensing mechanism of the electrostatic charge transducer. Filter can be determined by combining with the back projection method to provide filtered back projection. This filter provides weighting to individual pixels to provide a uniform concentration profile when the sensor has equal outputs (Green et. al.,1997).

The filter matrix is obtained by taking the maximum value of pixel divided by each value of pixel within the pipe mapping as shown in equation (3).

$$
\text { Filter }=\mathbf{S}_{\max } / \mathbf{S}_{\mathbf{i}}
$$

Filtered back projection is a result of linear back projection multiplied by filter matrix of S, written as equation (4). 


\subsection{Least Square with Regularization Method (LSR)}

$$
\mathbf{q}_{\mathrm{FBP}}=\mathbf{q}_{\mathrm{LBP}} \mathrm{X} \text { Filter }
$$

Least square (LS) method is almost the solution to the inverse problem of equation when measurement error are considered. It is meant to minimize the equation (1).

$$
\begin{gathered}
\text { Min }\|\mathbf{S q}-\mathbf{V}\|^{2} \\
\text { Where, } q=\left(\mathbf{S}^{\mathrm{T}} \mathbf{S}\right)^{-1} \mathbf{V}
\end{gathered}
$$

The solution of equation (6) is not unique. This is because the matrix $\left(\mathbf{S}^{\mathrm{T}} \mathbf{S}\right)^{-1}$ is not invertible. Therefore, the equation (6) is not a stable solution. A general principle of dealing with the instability of the problem is regularization (Yan et. al., 2001), imposing additional information about the solution. A penalty term can be added to the optimization problem as in equation below.

$$
\mathrm{E}(\mathrm{q})=\operatorname{argmin}|| \mathbf{S q}-\mathbf{V}\left\|^{2}+\beta^{2}\right\| \mathbf{R}\left(\mathrm{q}-\mathrm{q}_{\mathrm{o}}\right) \|^{2}
$$

A simple choice for the regularization penalty term is Tikhonov regularization (Jing et. al. 2008). The aim of this regularization is to dampen the contribution of small singular value in solution. The matrix $\mathrm{R}$ is a regularization matrix which penalizes extreme changes in parameter q, removing the instability in the reconstruction. The parameter $\beta$ called regularization parameter control the trade-off between the data fitting and violates the prior assumption. The solution of equation (7) would be written as a simple form of the standard Tikhonov where $\mathbf{R}=\mathbf{I}$ and assuming $\mathrm{q}_{0}=0$. Thus, equation (8) called Least square with regularization (LSR) method is introduced

$$
\mathbf{q}=\left(\mathbf{S}^{\mathbf{T}} \mathbf{S}+\beta^{2} \mathbf{I}\right)^{-1} \mathbf{S}^{\mathbf{T}} \mathbf{V}
$$

For the described algorithm, the choice of regularization is important. In general, a small value of $\beta$ gives a good approximation to the original problem but the influence of errors may make the solution physically unacceptable. Conversely, a large value of $\beta$ suppresses the data but increases the approximation error. At present, in most cases, $\beta$ is chosen empirically (Tarantola, 2004). The value of regularization parameter 0.025908 is obtained.

\subsection{Singular Value Decomposition (SVD)}

The SVD will reveal all the difficulties associated with the ill-conditioning of the matrix (Soleimani, 2005). Let K be the matrix of reconstructed image with $\mathrm{MXN}$ rectangular matrix where $\mathrm{M} \geq \mathrm{N}$, Then, the SVD of $\mathrm{K}$ is a decomposition of the form (Hansen, 2007);

$$
K=\sum_{i=1}^{\operatorname{Min}(m, n)} u_{i} \sigma_{i} v_{i}^{T}
$$

Where $\mathrm{U}_{\mathrm{i}}=\left(u_{1}, \ldots \ldots u_{\mathrm{n}}\right)$ and $\mathrm{V}_{\mathrm{i}}=\left(v_{1} \ldots \ldots v_{\mathrm{n}}\right)$ are matrices with orthonormal columns, $\mathrm{U}^{\mathrm{T}} \mathrm{U}=\mathrm{V}^{\mathrm{T}} \mathrm{V}=\mathrm{I}$, where $\Sigma=$ $\operatorname{diag}\left(\sigma_{\mathrm{i}} \ldots \ldots \sigma_{\mathrm{n}}\right) \cdot \sigma_{\mathrm{i}}$ are the singular values of $\mathrm{S}$, while $\mathrm{U}_{\mathrm{i}}$ and $\mathrm{V}_{\mathrm{i}}$ are the left and right singular vectors of $\mathrm{S}$.

Discrete ill-conditionings will be considered if condition number of $\mathrm{K}$ is large. The condition number is equal to the ratio as equation (10).

\subsection{Digital imaging technique by CCD camera}

$$
\operatorname{Cond}(\mathrm{S})=\sigma_{1} / \sigma_{\mathrm{n}}
$$

Other than the image reconstruction process, the validation of image is also very important. It would be part of verifying process of the new image reconstruction method. In this system digital imaging technique is used to interrogate the flow in pipeline around the sensing area using CCD camera. When materials or particles flow through a pipeline, it is possible to acquire images using CCD camera with suitable illumination light source (Carter et. al. 2003).

CCD camera is used to capture image of particles (Carter et. al. 2003; Sugita et. al., 2003; Cater et. al., 2005) for various purposes such as particle size analysis, particles size distribution, mass flow rate and etc. It is quite a simple matter to focus a CCD camera on this system and acquire digital images. This general concept is illustrated in Figure 2. CCD camera will capture video of materials moving through the pipe hole as shown in Figure 2. Meanwhile, the electrodynamics sensor will be induced with charge from the material that passes through the sensors. This charge will be converted into voltage by electrical conditioning circuit attached to the sensor. The voltage will be sent to image reconstruction of computer system through Keithely STA-1800HC data acquisition card. Image reconstruction process is conducted off-line using Matlab programming language. These two types of measurements will be treated separately. Video captured by CCD camera will be processed using digital image processing and measured data from the sensor will be used to reconstruct the cross-section image of the pipe through sensing area using LBP, FBP and LSR methods. Image reconstructed by these methods will be compared to image captured by CCD camera. Validation of the image reconstruction methods will be based on similarity to the image produced by the CCD camera. The length between the point of the video captured by the CCD camera and the point of the electrodynamics sensor location is very short. 
Therefore, image captured by the CCD camera and image reconstructed from the measured data by electrodynamics sensor are assumed similar.

The video captured by the CCD camera will go through several processes to produce a single image and to produce the concentration of particles in the pipeline. The processes involving algorithms for image processing are shown in Figure 3. Figure 3 shows the schematic flow of the algorithm for image processing. Materials being moved through the pipe are captured by a CCD camera. This is continuously recorded in videos with an image size of $1000 \mathrm{x} 1000$ pixels in color. The data measured by the electrodynamics sensor are also recorded with both processes occuring at the same time. All the preprocessing and processing stages of the image are done off-line. Preprocessing such as video framing, frame background selection and frame with particles selection are performed using Virtual Dub application program. Meanwhile, processes to produce image with absolute value and threshold are done using Matlab. The process to identify the sensing area, image conversion and scaling are done using Adobe Photoshop. Finally image is displayed using Matlab.

\section{Results \& discussion}

This section focuses on the digital image processing from the video data captured by CCD camera and image reconstruction processes based on LBP, FBP and LSR methods. Images produced by both techniques will be compared. Figure 4 shows the results obtained from the preprocessing and processing stages using digital imaging technique. Based on the data measured by the electrodynamics sensor, image reconstruction is performed using the LBP, FBP and LSR methods. Figure 5 shows the comparison among images captured by the CCD Camera and reconstructed by the LBP, FBP and LSR methods.

Figure 5 (a) shows the image captured by the CCD camera with the highest image concentration area at the middle and top of the image as shown in circle and labeled A. The other high concentration areas are shown in circles with labels B, $\mathrm{C}$ and $\mathrm{D}$. This means that in real situation the particles dropped in conveyor pipeline are scattered around the pipe with many concentration areas.

Figure 5 (b) shows high image concentration area for LSR method which is similar to the image recorded by the CCD camera area as being labeled A, B, C and D. It means that the LSR method is capable of differentiating between two or more charges in sensing area. It shows that charge concentration area detected by LSR method is scattered around the sensing area just like the image presented by the CCD Camera. Although the value of concentration is different, the pattern is almost similar. This is because of the different in sensitivity with every electrodynamics sensor, and also depends on the properties of the particles (size, shape, conductivity, chemical composition, moisture content and so on). To overcome the problem with the electrodynamics sensor, its design and fabrication should be made using high technology rather than using discrete electronic components and manual fabrication process.

Figure 5(c) shows that the image reconstructed using FBP method is accurate in detecting the high concentration area which is almost similar to image shown by label A in Figure 5 (a). However, it is detected as a huge point. Another problem with FBP is it produces high concentration near the sensor while reducing the value away toward the centre. As a result, FBP cannot be differentiated between two or more charges in the sensing area.

In Figure 5(d), image reconstructed using LBP method shows that the high concentration values of the image are not focusing on the area as shown by real image in Figure 5 (a). Instead the values focus on sensors 16, 1, 2 and 3. It means that LBP method is not suitable to reconstruct the image for electrical charge tomography because of its non-linearity to the sensing mechanism.

Stability analysis of the images is conducted using singular value decomposition (SVD) method. Table 1.0 shows the condition number of ill-posed for every method. From the result, it shows that LSR produces the lowest condition number with 224.53. The result reflects that LSR method produces better image stability than any other methods including CCD camera.

\section{Conclusion}

The results from image reconstruction processes by LBP, FBP and LSR methods and validation process above have highlighted some information. Firstly, the image reconstructed using least square with regularization method is similar with the image captured by CCD-camera whereby condition number obtained by LSR method is better than others. Secondly, the image reconstructed using FBP is accurate in detected the location of the charge but it did not distinguish between two separately charge in sensing area. But LSR method has capability to solve this problem. Finally, the mage reconstructed using LBP is focused on the sensor location. It means that LBP method is not suitable to reconstruct the image for electrical charge tomography because of its non-linearity to the sensing mechanism. Thus, it shows that LSR method provides good promising result in terms of accuracy and stability of the image being reconstructed. It means that this paper is success to achieve their objective as mention earlier. The image produced by LSR method is better in terms of its accuracy, stability and suitability to be used in industries. In addition, more work should be done in validating the proposed algorithm such as computation of image error and quality of the image using duty ratio, signal 
to noise ration and structure correlation as well as improving ill-posed of sensitivity matrix in mathematical modeling. For this system to be used in real industry environment, more work on hardware and software systems should be carried out to warranty their data and algorithm is well organized and developed.

\section{References}

Bidin, A.R., Green, R.G., Shackleton, M.E, Stoot, A.L. and Tylor, R.W. (1995). Electrodynamic sensors for process tomography, in Process Tomography: Principles, Techniques and Application. Butterworth-Heunemann Ltd.

Carter R. M., Yan Y. (2003). On-line particle sizing of pulverized and granular fuels using digital imaginf techniques. Measurement Sci. Technology, 14, p. 1099-1109.

Cater T.M., Yann Y, Cameron S.D. (2005). On-line measueremnt of particle size distribution and mass flow rate of particles in pneumatic suspension using combined imaging and electrostatics sensor. Flow measurement and instrumentation, 16, p.309-314.

Dyakowski T., Laurent F.C. (2000). Application of electrical tomography for gas-solid and liquid-solids flows - a review. Power technology, 112, p.174-192.

Dyakowski, T., R.B. Edwards, \& C.G. Xie, R.A. William. (1997). Application of capacitance tomography to gas-solid flows. Chemical engineering science, Vol. 52, No. 13, p.2009-2110.

Green, R.G., Rahmat, M.F., Evans, K., Goulde, A., Hennry, M., and Stone, J.A.R. (1997). Concentration Profiles of dry powders in a gravity conveyor using an electrodynamics tomography system. measurement Science of Technology, Vol. 8, No. 2, p.192-197.

Hansen P. C. (2007). Regularization tools: A MATLAB package for analysis and solution of discrete ill-posed problem, Version 4.0. Numerical Algorithms, 46, p.103-120.

Hua Y. Chunting L. Jing G. (2004). Electrical Capacitance tomography reconstruction based on singular value decomposition. Proceeding of $5^{\text {th }}$ word congress on intelligent control and automation, Jun 15-19, China, p. 3783-3786.

Isa, M.D., Rahmat M.F. (2008). Image reconstruction algorithm based on least square with regularization for process tomography system using electrical charge carried by particles. Proceeding of 2008 student conference on research and development (SCOReD 2008), 26-27 Nov. Johor, Malaysia. p.98(1-4).

Jiang M. Wang G. (2003). Convergence of the simultaneous algebraic reconstruction technique (SART). IEEE transaction on image processing, Vol. 12, No. 8, August.

Jinchuang Z., Wenli F., Taoshen L., Shi W. (2002). An image reconstruction algorithm based on a revised regularization method for electrical capacitance tomograpgy. measurement science and technology, 13, p.638-640.

Jing L., Shi L., Zhihong L. Inaki S. Meng S. (2008). An image reconstruction algorithm based on new objective function for electrical capacitance tomography. Measurement science and technology. 19015505 (5pp).

Machida, M., Scarlett, B. (2005). Process Tomography System by Electrical Charge Caried by Particle, IEEE Sensors JournaL, Vol. 5, No. 2, April, p.252-259.

Soleimani M. (2005). Numerical modeling and analysis of the forward and invee problems in electrical capacitance tomography. International journal of information and system sciences, Vol. 1 No. 1, p.193-207.

Sugita T., Kamimura M., Kitayama Y. (2003). A particles size distribution measuring method for pulverized particle, SICE Anuual conference in Fukui, August 4-6.

Tarantola A. (2004). Inverse problem theory and methods for model parameter estimation. SIAM.

Yan H., Hiu L J etc. (2001). Image Reconstruction in Electrical Capacitance Tomography Using Multi Linear Regression and Regularization, Measurement. Science and technology, 12, p.575-581.

Yang, W.Q, \& Liu, S. (2000). Role of tomography in gas/solid flow measurement. Flow measurement and Instrumentation, 1:237-244.

Yang, W.Q, Lihui P. (2003). Review Article: Image reconstruction Algorithms for Electrical Capacitance Tomography. Measurement Science and Technology. Institute of Physics Publishing. 14, p.1-13

Yong W. D., Dong F. (2007). An Image Reconstruction Algorithm Based On Regularization Optimization For Process Tomography. Proceeding of sixth International Conference on Machine Learning and Cybernetics, Hong Kong, 8, p.19-22. 
Table 1. Condition number from various regularization parameter $\beta$ for LSR images

\begin{tabular}{ll}
\hline Images & Condition Numbers of ill-posed \\
\hline Image captured by CCD camera & $1.63 \times 10^{3}$ \\
Image reconstructed by LSR & 224.53 \\
Image reconstructed by FBP & $5.15 \times 10^{5}$ \\
Image reconstructed by LBP & $7.63 \times 10^{5}$ \\
\hline
\end{tabular}

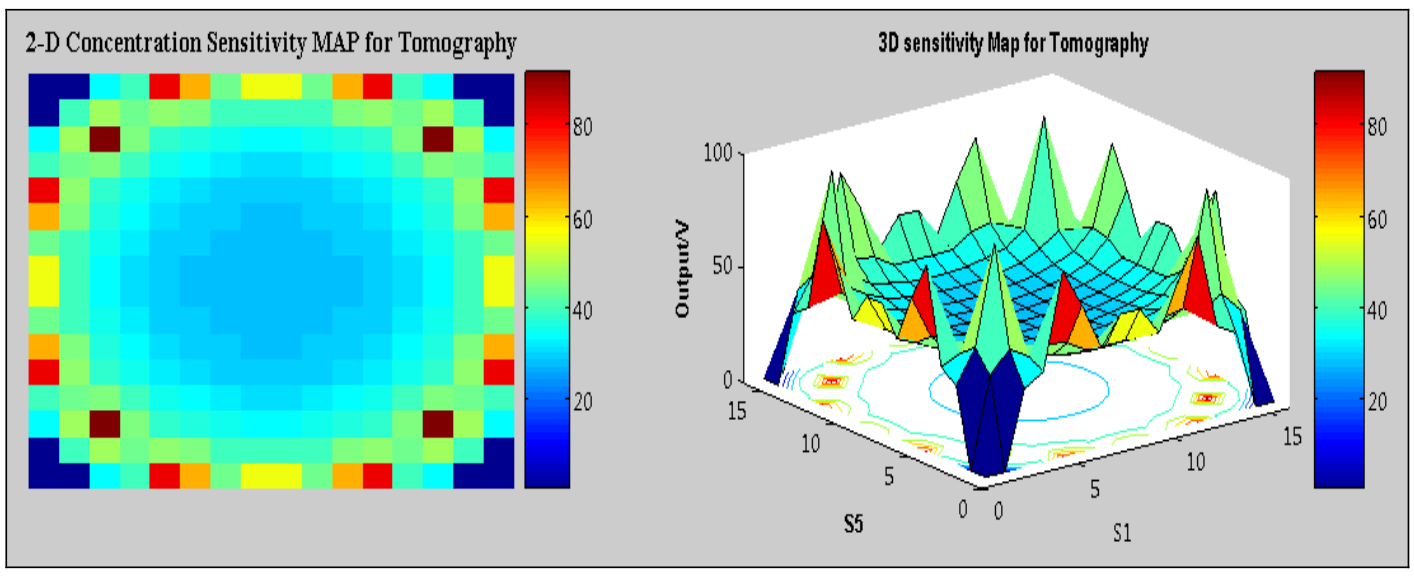

Figure 1. Two and three-dimensional Total Sensitivity map, S.

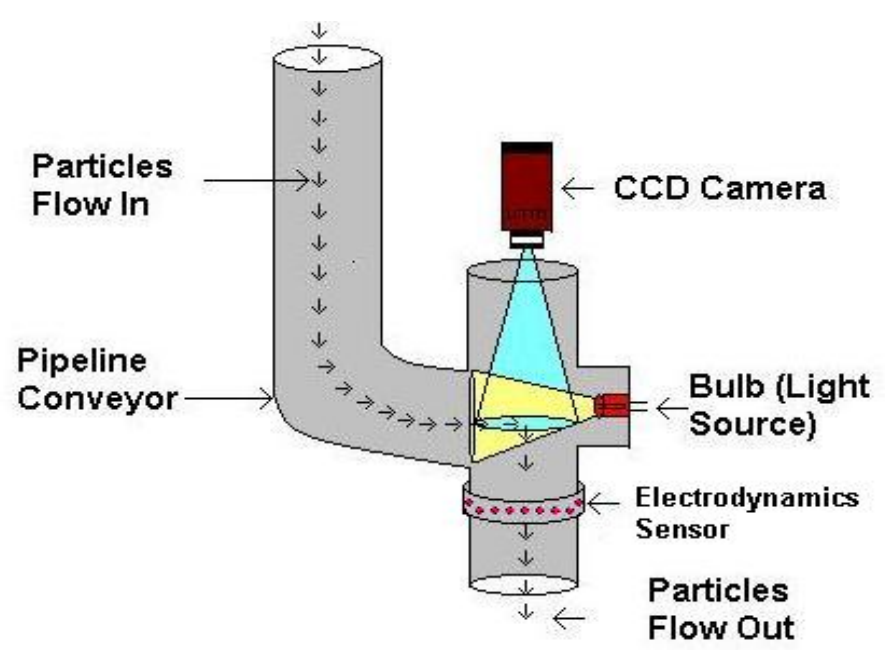

Figure 2. Particles imaging technique 


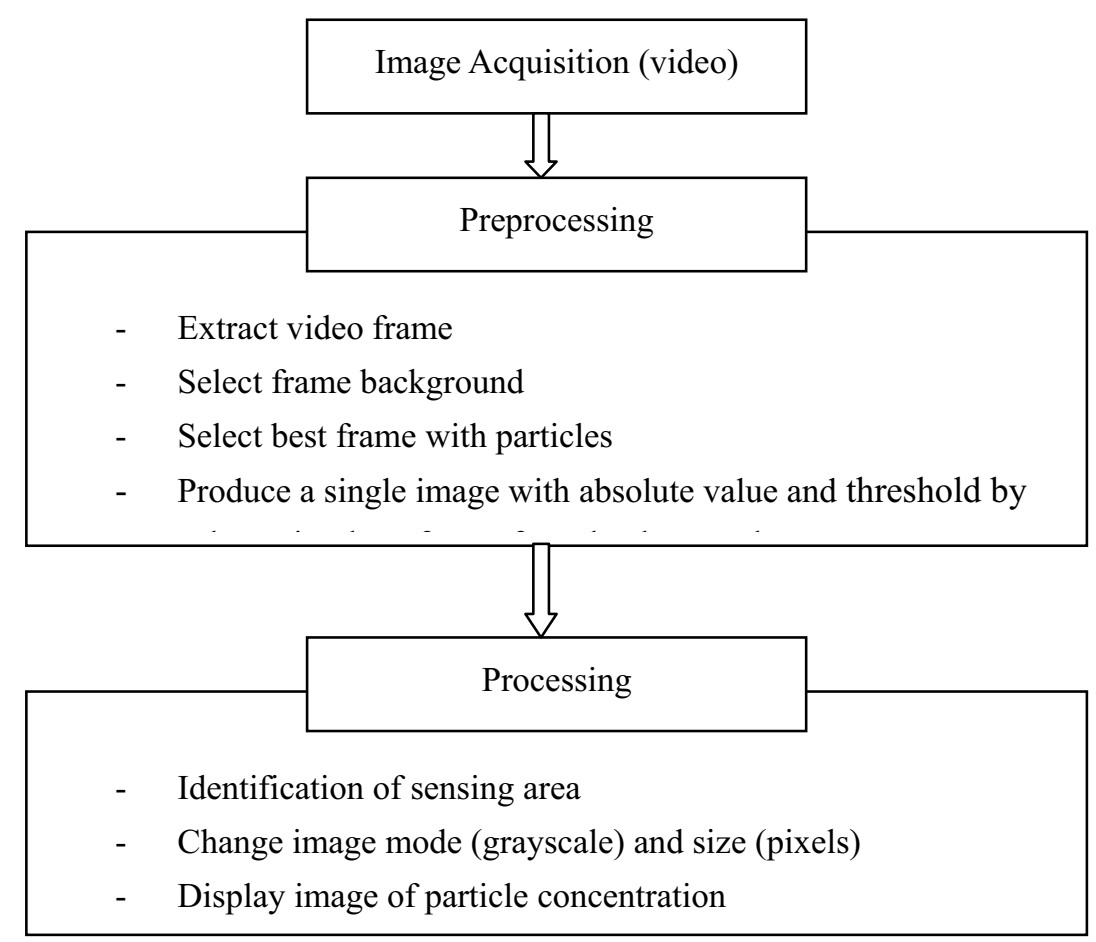

Figure 3. Schematic flow of the algorithm for image processing

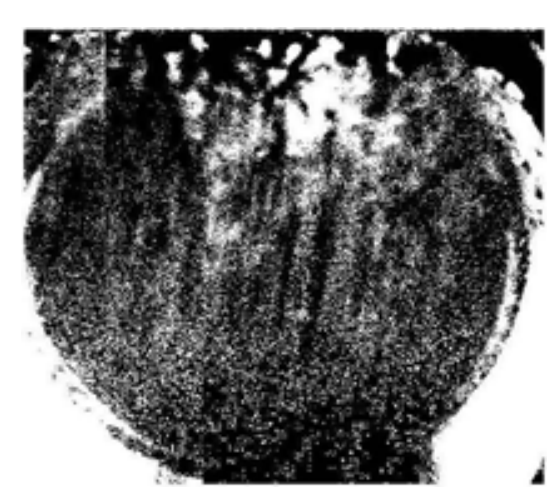

(a) Image with absolute value and threshold

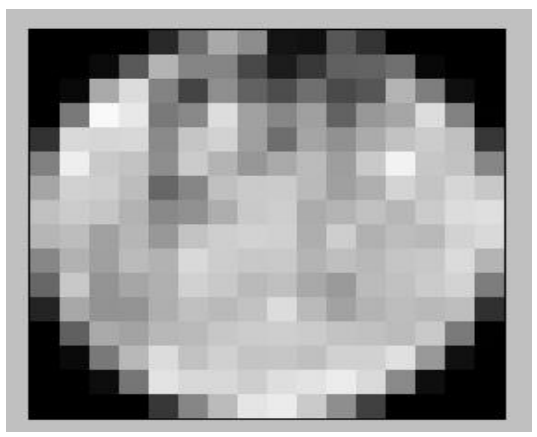

(c) Image with mode (grayscale) and size (16 X 16 Pixels)

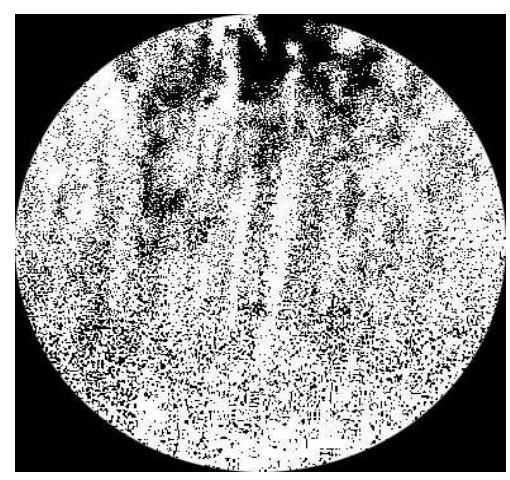

(b) Image with identified sensing area

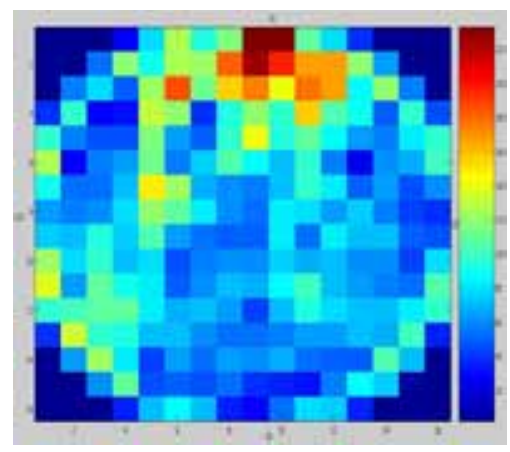

(d) Image of particle concentration

Figure 4. Images produced from preprocessing and processing stages 


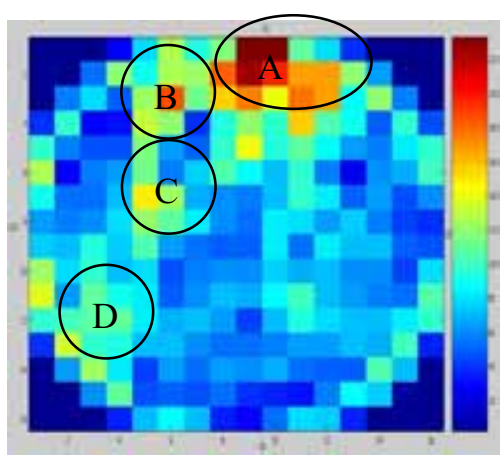

(a) Image captured by CCD Camera

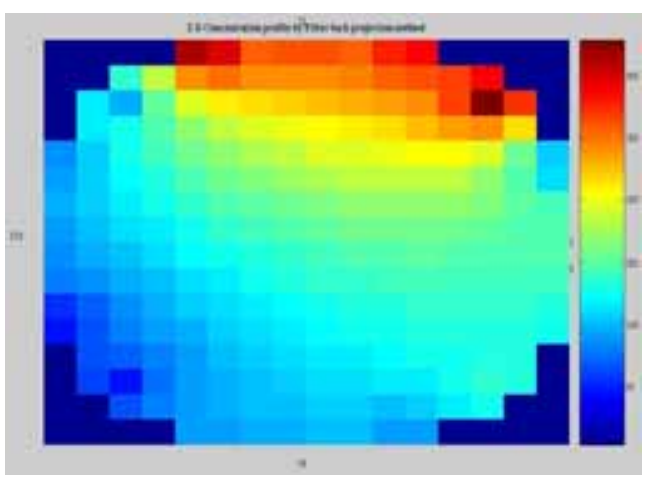

(c) Image reconstructed by FBP method

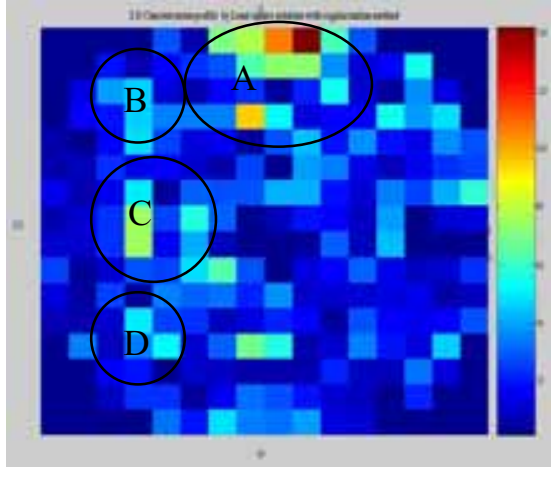

(b) Image reconstructed by LSR method

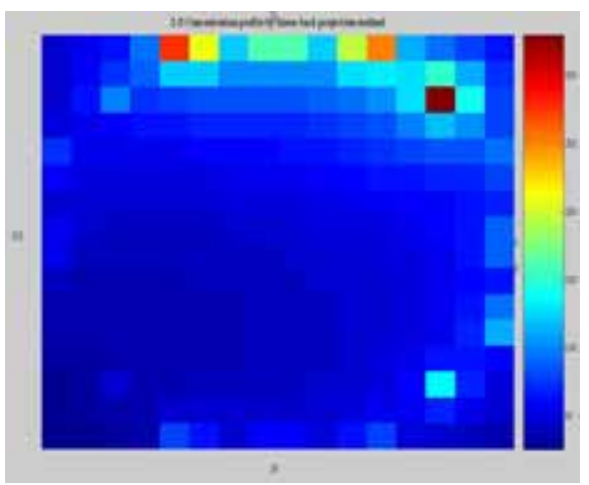

(d) Image reconstructed by LBP method

Figure 5. Image being compared: (a) Image recorded by CCD Camera (b) Image reconstructed by LSR method (c) Image reconstructed by FBP method and (d) Image reconstructed by LBP method 


\title{
The Hydration of Heavy Metal Salts Admixtured High Alumina Cement - A X-Ray Diffraction Study
}

\author{
R. Nithya \\ Department of Physics, Annamalai University \\ Annamalainagar 608 002, Tamilnadu, India \\ E-mail: nivelan_15@yahoo.com \\ S.Barathan (Corresponding author) \\ Department of Physics, Annamalai University \\ Annamalainagar 608 002, Tamilnadu, India \\ E-mail: sbarathan.au@rediffmail.com \\ M.Gopalakrishan \\ Department of Chemistry, Annamalai University \\ Annamalainagar 608 002, Tamilnadu, India \\ E-mail: profmgk@yahoo.co.in \\ G.Sivakumar \\ Department of Physics, Annamalai University \\ Annamalainagar 608 002, Tamilnadu, India \\ E-mail: gsk_cisl@yahoo.com \\ B.Gobinath \\ Department of Physics, Annamalai University \\ Annamalainagar 608 002, Tamilnadu, India \\ E-mail: gobinathb@yahoo.com
}

\begin{abstract}
The XRD, Setting time and Compressive strength results of the hydration of High Alumina Cement (HAC) with different concentrations of $\mathrm{Cr}, \mathrm{Cd}, \mathrm{Pb}, \mathrm{Zn}$ and $\mathrm{Mg}$ as impurities are presented. The heavy metal salts are doped from 100 to $15000 \mathrm{ppm}$ in various steps. The hydration products are investigated both qualitatively and quantitatively by X-ray powder diffraction. The initial, final setting time and strength of heavy metal salts doped HAC, which are measured and compared with the phases at different time intervals are discussed. The results show that various concentrations of heavy metal salts doped HAC can play an effective role in conversion reactions (i.e.) from metastable to stable hydrates imparting setting time and strength. It is observed that a lower concentration of industrial waste metal ions do not affect the characteristics of the blend.
\end{abstract}

Keywords: HAC, Heavy metal ions, XRD, Mechanical properties 


\section{Introduction}

The cost of High Alumina Cement (HAC) is higher than any Ordinary Portland Cement (OPC) due to its ingredients. Though its competeness with OPC in everyday application is almost nil, due to its higher strength it gives a helping hand when OPC's function and performanance are insufficient in certain applications. In general a parallel practical utility can be obtained by admixturing it with suitable metal ions in certain conditions.

The main difference between OPC and HAC lies in the nature of their active phases that lead to setting and hardening. HAC develops substantially higher strength than OPC. The high early strength characteristics of HAC take facility in emergency repair work due to its quick setting. Monocalcium aluminate (CA) is the principal active phase in HAC. When mixed with water, depending on the metal ion concentration available in water, the properties of the products vary. Chromium $(\mathrm{Cr})$, Lead $(\mathrm{Pb})$, Cadmium $(\mathrm{Cd})$, Zinc $(\mathrm{Zn})$ and Magnesium $(\mathrm{Mg})$ are the major metal ions that are dissolved in ground water either through industrial pollution or through environmental factors. On hydration, the effects of these metal ions by their product are noteworthy.

The hydration reaction of High Alumina Cement at environmental temperature produces metastable hexagonal hydrated calcium aluminates $\mathrm{CAH}_{10}\left(\mathrm{CaAl}_{2} \mathrm{O}_{14} \mathrm{H}_{2} \mathrm{O}\right)$ and $\mathrm{C}_{2} \mathrm{AH}_{8}\left(\mathrm{Ca}_{2} \mathrm{Al}_{2} \mathrm{O}_{13} \mathrm{H}_{16}\right)$. However the stable phases are $\mathrm{C}_{3} \mathrm{AH}_{6}$ $\left(\mathrm{Ca}_{3} \mathrm{Al}_{2}(\mathrm{OH})_{12}\right)$ and $\mathrm{AH}_{3}\left(\mathrm{Al}(\mathrm{OH})_{3}\right)$ and other phases inevitably gets converted to these (Ana Hidalgo et al., 2009).

The conversion reactions are shown schematically below

$$
\begin{array}{ll}
3 \mathrm{CAH}_{10} \rightarrow & \mathrm{C}_{3} \mathrm{AH}_{6}+2 \mathrm{AH}_{3}+18 \mathrm{H} \\
3 \mathrm{C}_{2} \mathrm{AH}_{8} \rightarrow(1) & \rightarrow \mathrm{C}_{3} \mathrm{AH}_{6}+\mathrm{AH}_{3}+9 \mathrm{H} \rightarrow(2)
\end{array}
$$

The aim of the present work is to study the hydration properties of HAC with heavy metal salts namely Cadmium Carbonate $\left(\mathrm{CdCO}_{3}\right)$, Zinc Sulphate $\left(\mathrm{ZnSO}_{4} \cdot 7 \mathrm{H}_{2} \mathrm{O}\right)$, Magnesium Sulphate $\left(\mathrm{MgSO}_{4} \cdot \mathrm{H}_{2} \mathrm{O}\right)$, Lead Nitrate $\left(\mathrm{Pb}\left(\mathrm{NO}_{3}\right)_{2}\right)$ and Potassium dichromate $\left(\mathrm{K}_{2} \mathrm{Cr}_{2} \mathrm{O}_{7}\right)$ which are major pollutants from Industries. The water soluble salts of the above metals are dissolved using groundwater in different concentrations from 100 to $15000 \mathrm{ppm}$ to study the effect on setting time and strength of the paste. The mechanical measurement has revealed that the concentration of $2000 \mathrm{ppm}$ is optimum. The XR diffractograms for the admixed paste were recorded at different time intervals of hydration and compared with mechanical measurements. This has been substantiated by workability, flowability and consistence measurements.

\section{Experimental Methods}

Commercially available HAC and heavy metal salts of higher purity (E-Merck) (Cd, Mg, $\mathrm{Pb}, \mathrm{Zn}$ and $\mathrm{Cr}$ ) are used. The heavy metal salts say $(2000 \mathrm{ppm})$ on a metal basis are first dissolved in one liter ground water whose water analysis have been carried out and made to a solution. This is added to HAC whose chemical composition is given in Table. 1 in a water/cementitious ratio of 0.4 , allowed to hydrate and dehydrated at different time intervals after proper curing, wherever necessary. This procedure is carried out with different metal ions in different concentrations $(100,500,1000$, $2000,3000,5000,10000$ and $15000 \mathrm{ppm}$ ) at a temperature of $30^{\circ} \mathrm{C}$, using the standard procedure adopted by various workers (Stephan, et al., 1999). The Consistency, Flowability and Workability were also measured using standard procedure.

The Initial Setting Time (IST) and Final Setting Time (FST) of the paste containing heavy metal salts are measured using Vicat's apparatus with a consistency sample as per Standard Procedure and are shown in non linear scale (Fig.1). The compressive strength of all the samples is measured after adopting, standard procedure and proper curing (Waldemar, et al., 2002). For the sake of convenience the $28^{\text {th }}$ day strength alone is presented and is shown in a non linear scale (Fig. 2). Though the XRD pattern for various hydrated time intervals are recorded, $28^{\text {th }}$ day strength is prominent for analysis, it is preferred for a concentration of 2000ppm and are shown in Fig.3.

The Quantitative estimation of these important phases were also carried out using the Rietveld method (Guirado, et al., 2000) and reported (Table. 2) for the $28^{\text {th }}$ day diffractogram only.

The XRD pattern of all the samples were recorded using PANalytical (Philip - Netherlands) at Pondicherry University, Pudhucherry with $\mathrm{CuK}_{\alpha}$ radiation $(\lambda=1.5460 \AA)$ at $40 \mathrm{kV}$ and $30 \mathrm{~mA}$. The patterns were recorded from $2 \theta=10$ to $60^{\circ}$ in the range $2^{\circ} / \mathrm{min}$. The intensities were calculated with the help of $X^{\prime}$ pert software available with the instrument.

\section{Results and Discussion}

A close scrutiny of the (Table.2) reveals that the change in weight percentage of the phases depending on time helps one to identify the reactions and its consequences.

A close scrutiny of the Fig. $1 \& 2$ suggests that 2000ppm of metal ions is an optimum concentration for both Setting time and Strength. For all the salt added pastes, depending on metal ions the variations in setting time can be arranged in the order $\mathrm{Cd}>\mathrm{Zn}>\mathrm{Pb}>\mathrm{Mg}>\mathrm{Cr}$. The observed compressive strength (Fig. 2) indicates that the addition of heavy 
metal salts does not alter the value very much except $\mathrm{Zn}$ added paste compared to HAC's value at this concentration of $2000 \mathrm{ppm}$.

The assignment of different X-ray peaks to the compounds in HAC (Fig.3) is fixed on the lines of Harchand et al. It is evidenced from hydrated HAC diffractograms that $\mathrm{C}_{12} \mathrm{~A}_{7}$ and $\mathrm{C}_{2} \mathrm{AS}$ go on reducing as time elapses and at one week, these phases are converted to $\mathrm{CA}$ (Harchand, et al., 1984). At 1 day, XRD reveals that $\mathrm{C}_{2} \mathrm{AH}_{8}$ is the main hydration product. There is some $\mathrm{CAH}_{10}$. No $\mathrm{C}_{3} \mathrm{AH}_{6}$ could be detected. After 7 days the phases of $\mathrm{CAH}_{10}, \mathrm{C}_{2} \mathrm{AH}_{8}$ and $\mathrm{C}_{3} \mathrm{AH}_{6}$ have appeared. The proportion of intensity has increased is higher in $\mathrm{C}_{2} \mathrm{AH}_{8}$. Various peaks trace of $\mathrm{C}_{3} \mathrm{AH}_{6}\left(2 \theta=44^{\circ}: \mathrm{d}=2.04\right.$ $\AA), \mathrm{CAH}_{10}\left(2 \theta=20^{\circ}: \mathrm{d}=4.36 \AA\right), \mathrm{AH}_{3}\left(2 \theta=31^{\circ}: \mathrm{d}=2.85 \AA\right)$ are present with variation in intensity at $28^{\text {th }}$ day spectra. The growth of the metastable phases $\mathrm{CAH}_{10}$ on $\mathrm{C}_{2} \mathrm{AH}_{8}$ in the later hydration periods is indicative of its slightly higher compressive strength. A trace of gibbsite is also noticed.

XRD spectrum of $\mathrm{Cd}$ added $\mathrm{HAC}$ paste shows a reduction in intensity of the phases $\mathrm{CAH}_{10}$ and $\mathrm{C}_{2} \mathrm{AH}_{8}$ in early hydrated diffractogram. This indicates an increase in early compressive strength. The increasing $\mathrm{C}_{3} \mathrm{AH}_{6}$ peak observed at $28^{\text {th }}$ day is indicative of reduction in strength. A close scrutiny of the spectra at different time intervals reveals that the presence of $\mathrm{Cd}$ delays the formation of $\mathrm{C}_{3} \mathrm{AH}_{6}$ phase (Murat and Sorrentino et al., 1996). This may retard the setting time but does not modify the strength very much. Additional calcium chloroaluminate and calcium alumino ferrite peaks are also detected (Sanjuan, et al., 1997).

A close scrutiny of the $\mathrm{Zn}$ added diffractograms and its quantative estimation of phases at different time frames reveal a non linear reduction of the phases of $\mathrm{C}_{2} \mathrm{AH}_{8}$ and $\mathrm{CAH}_{10}$ and non uniform increase of phases is noticed. This implies that the presence of $\mathrm{Zn}$ slightly accelerates the hydration reaction and the rate of formation of $\mathrm{C}_{3} \mathrm{AH}_{6}$ hydrate increases. This probably causes the setting time to decrease rapidly but the strength is found to be lower than control. Some additional peak of calcium chloroaluminates, ferrite and zinc aluminates are observed in hydrated $28^{\text {th }}$ day spectrum (Stephan, et al., 1999).

The mix with $\mathrm{Pb}$ addition in the $28^{\text {th }}$ day spectra shows, a reduction in intensity of the peak at $\mathrm{CAH}_{10}$ and an increase in the peak at $\mathrm{C}_{2} \mathrm{AH}_{8}$ and $\mathrm{C}_{3} \mathrm{AH}_{6}$. A close watch on the XRD patterns of $\mathrm{Pb}$ added paste and the quantitative estimation of the phases suggest that a normal and gradual change might have been occurred for the phase $\mathrm{CAH}_{10}$. In other words, $\mathrm{CAH}_{10}$ phases compensate the faster reaction of the other phase and have a setting time almost equal to that of control. On the other hand, an increase in intensity and hence the amount of these phases $\mathrm{C}_{2} \mathrm{AH}_{8}$ and $\mathrm{C}_{3} \mathrm{AH}_{6}$ increases. Comparing the amount of the phases with control, it is observed that the loss in strength created through $\mathrm{C}_{3} \mathrm{AH}_{6}$ is compensated by $\mathrm{C}_{2} \mathrm{AH}_{8}$ phases (Table 2). In addition peaks observed for calcium chloroaluminates and gehlenite at $28^{\text {th }}$ day is also compensated by $\mathrm{C}_{2} \mathrm{AH}_{8}$ phase thereby making the strength almost equal to control (Murat, et al., 1996).

The XRD patterns of $\mathrm{Cr}$ added HAC paste and its quantitative estimation of phases at various time intervals indicates that the $\mathrm{C}_{3} \mathrm{AH}_{6}$ phase is proceeding faster than $\mathrm{C}_{2} \mathrm{AH}_{8}$ and $\mathrm{CAH}_{10}$ phases. The increase in amount of $\mathrm{C}_{3} \mathrm{AH}_{6}$ and decrease in the amount of phases $\mathrm{C}_{2} \mathrm{AH}_{8}$ and $\mathrm{CAH}_{10}$ are indicative of delayed setting time and lower strength than the control. An increase in $\mathrm{Cr}$ concentrations in HAC indicates a reduction in strength than control (Minocha, et al., 2003).

The $28^{\text {th }}$ day diffractogram of the $\mathrm{Mg}$ mixed sample shows an increased intense peak for $\mathrm{C}_{3} \mathrm{AH}_{6}$ and decreased intense peak for $\mathrm{CAH}_{10}$. The observed variations are similar to that of other studied metal ions. The observed additional peaks were identified as $\mathrm{MgAl}_{2} \mathrm{O}_{4}$ (Prodjosantoso and Kennedy, 2003). The Observed flowability and workability supports all the results discussed above.

The final concentrations of various metals have been verified through quantitative chemical analysis and the final result is well within the experimental errors.

\section{Conclusion}

XRD is the most primary investigative technique in cement chemistry to identify and estimate the constituent phases. The qualitative and quantitative estimation of phases reveal that the addition $(2000 \mathrm{ppm})$ of heavy metal salts $(\mathrm{Cd}, \mathrm{Cr}$, $\mathrm{Pb}, \mathrm{Zn}$ and $\mathrm{Mg}$ ) to $\mathrm{HAC}$ is optimum at $30^{\circ} \mathrm{C}$. This produces cementitious mixture that does not alter very much from control compressive strength except $\mathrm{Zn}$. $\mathrm{Zn}$ has a deleterious effect on $\mathrm{HAC}$ compared to $\mathrm{Cr}, \mathrm{Pb}, \mathrm{Cd}$ and $\mathrm{Mg}$ and hence cannot be added even in small quantity. The effect of the addition of metal ions on compressive strength of HAC may be placed as $\mathrm{Cd}>\mathrm{Zn}>\mathrm{Pb}>\mathrm{Mg}>\mathrm{Cr}$.

\section{References}

Ana Hidalgo, J., Garcia, L., Cruz Alonso, M., Fernandez, L. \& Carmen Andrade. (2009). Microstructure development in mixes of calcium aluminate cement with silica fume or fly ash. Journal of Thermal Analysis and Calorimetry, 49(2), $1-10$.

Guirado, F., Gali, S., \& Chinchon, S. (2000). Quantative Rietveld analysis of aluminous cements clinker phases Cement and Concrete Research, 30, 1023-1029. 
Harchand, K.S., Vishwamitter., \& Chandra, K. (1984). A study of the iron phase and its hydration behavior in alumina cement. Cement and Concrete Research, 17, 19-24.

Minocha, A.K., Neeraj Jain, \& Verma, C.L. (2003). Effect of inorganic materials on the solidification of heavy metal sludge. Cement and Concrete Research, 33, 1695-1701.

Murat, M., \& Sorrentino, F. (1996). Effect of Large additions of Cd, Pb, Cr, Zn to raw meal on the composition and the propertities of the clinker and the cement. Cement and Concrete Research, 26(3), 377-385.

Prodjosantoso, A.K., \& Kennedy, B.J. (2003) Heavy metals in cement phases: on the solubility of $\mathrm{Mg}, \mathrm{Cd}, \mathrm{Pb}$ and $\mathrm{Ba}$ in $\mathrm{Ca}_{3} \mathrm{Al}_{2} \mathrm{O}_{6}$. Cement and Concrete Research, 33, 1077-1084.

Sanjuan, M.A. (1997). Formation of chloroaluminates in calcium aluminate cements cured at high temperatures and exposed to chloride solutions. Journal of Materials Science, 32, 6207-6213.

Stephan, D., Mallmann, R., Knofel, D., \& Hardtl, R. (1999). High intakes of Cr, Ni and Zn in Clinker Part II Influence on the hydration properties. Cement and Concrete Research, 29, 1959-1967.

Waldemar, A., Klemmm, Javed, L., \& Bhatty. (2002). Fixation of heavy metals as Oxyanion-Substituted Ettringites. Portland cement Association.

Table 1. Percentage Chemical composition of HAC

\begin{tabular}{cccccccccccc}
\hline $\mathrm{CaO}$ & $\mathrm{Al}_{2} \mathrm{O}_{3}$ & $\mathrm{SiO}_{2}$ & $\mathrm{Fe}_{2} \mathrm{O}_{3}$ & $\mathrm{FeO}$ & $\mathrm{TiO}_{2}$ & $\mathrm{MgO}$ & $\mathrm{Na}_{2} \mathrm{O}$ & $\mathrm{Mn}_{2} \mathrm{O}_{3}$ & $\mathrm{P}_{2} \mathrm{O}_{5}$ & $\mathrm{SO}_{3}$ & $\mathrm{Traces}$ \\
\hline 38.5 & 39.0 & 4.5 & 10.0 & 4.0 & 2.5 & 0.4 & 0.1 & 0.1 & 0.2 & 0.15 & 0.35 \\
\hline
\end{tabular}

Table 2. Weight Percent of Phases (28 ${ }^{\text {th }}$ day)

\begin{tabular}{lccccccc}
\hline & $\mathbf{2 \theta}$ & CONTROL & CHROMIUM & LEAD & CADMIUM & ZINC & MAGNESIUM \\
\hline $\mathbf{C A H}_{\mathbf{1 0}}$ & $20^{\circ}$ & 14.75 & 10.23 & 14.75 & 11.76 & 14.25 & 12.46 \\
\hline $\mathbf{C}_{\mathbf{2}} \mathbf{A H}_{\mathbf{8}}$ & $18^{\circ}$ & 8.74 & 11.93 & 4.63 & 13.66 & 9.24 & 10.65 \\
\hline $\mathbf{A H}$ & $31^{\circ}$ & 55.14 & 55.14 & 55.14 & 55.14 & 55.14 & 55.14 \\
\hline $\mathbf{C}_{\mathbf{3}} \mathbf{A H}_{\mathbf{6}}$ & $44^{\circ}$ & 21.37 & 22.70 & 25.48 & 19.44 & 21.37 & 21.75 \\
\hline
\end{tabular}




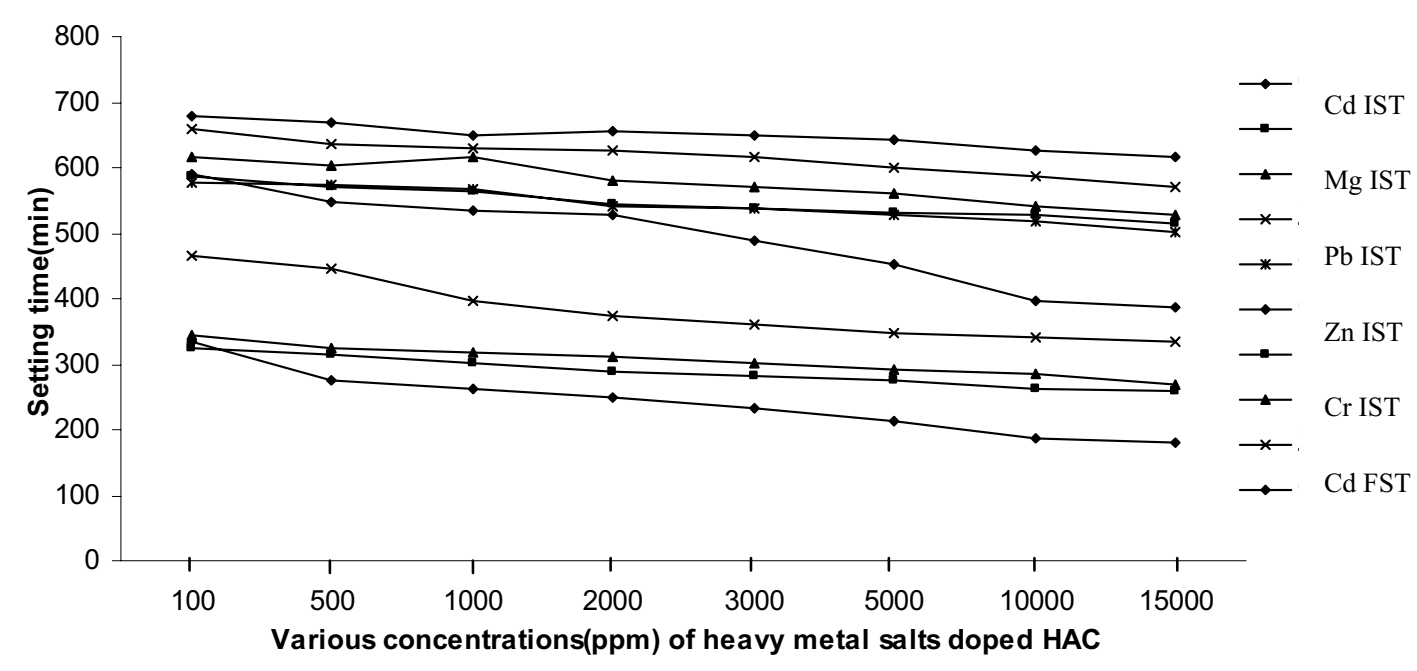

Figure 1. Setting time (IST and FST) of different metal salts doped HAC

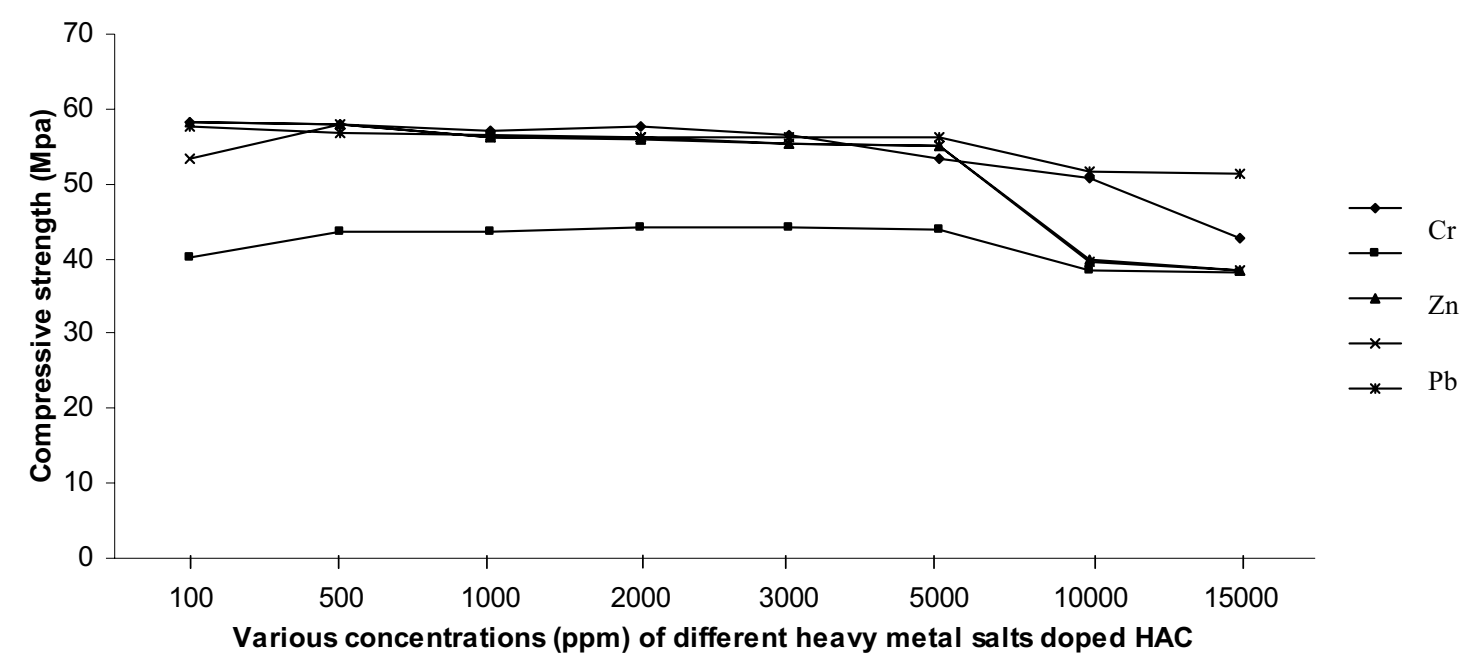

Figure 2. Compressive strength of heavy metal salts doped HAC at $28^{\text {th }}$ day 


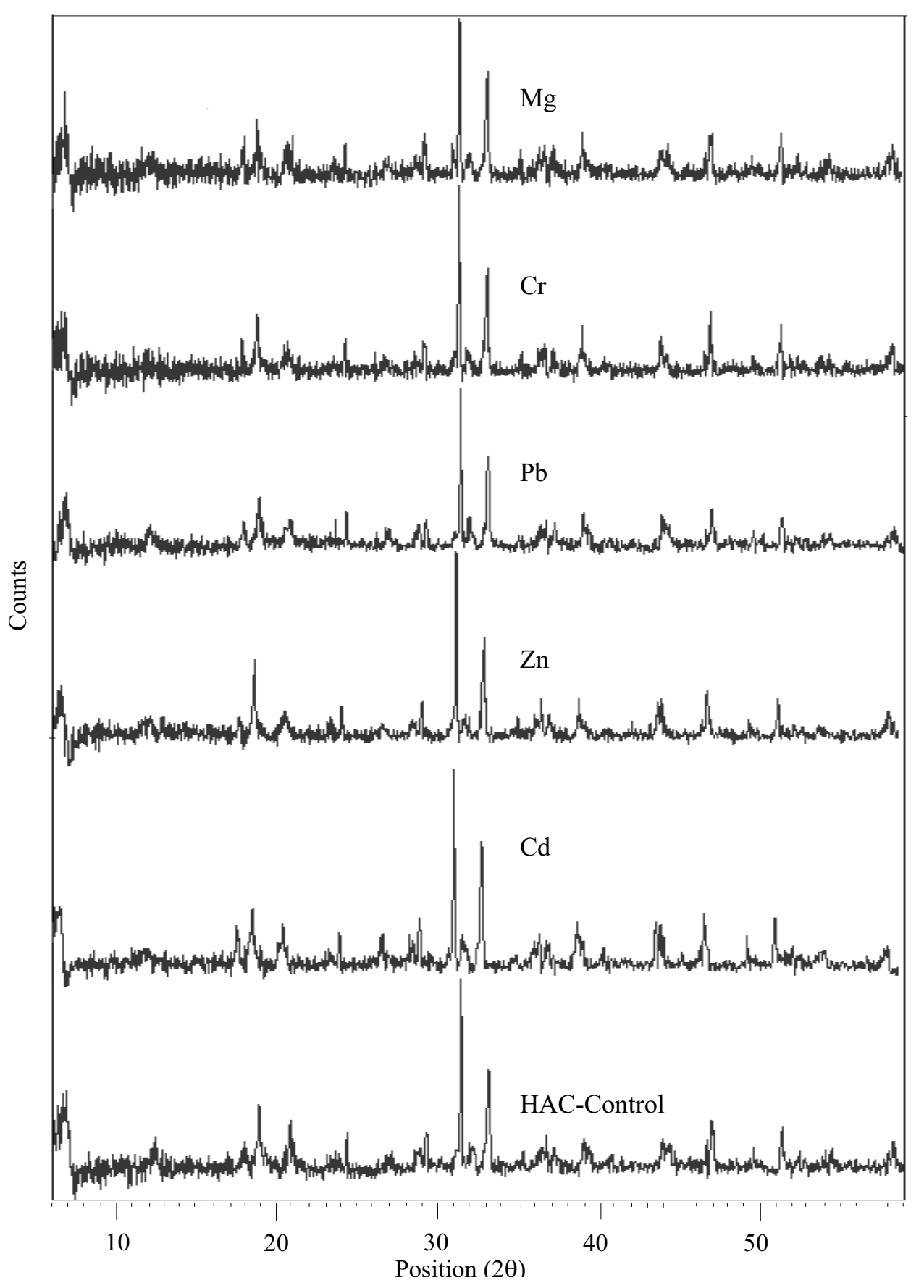

Figure 3. XRD pattern of heavy metal salts doped HAC hydrated at $28^{\text {th }}$ day 


\title{
Nanoseconds Switching for High Voltage Circuit Using Avalanche Transistors
}

\author{
Abd Rahman Tamuri (Corresponding author) \\ Laser Technology Laboratory \\ Physics Department, Faculty of Science \\ Universiti Teknologi Malaysia, 81310, Skudai \\ Johor Bharu, Johor, Malaysia
}

Tel: 60-7-553-4096 E-mail: rahman_t@hotmail.com

\author{
Noriah Bidin \\ Head of Physics Department, Faculty of Science \\ Universiti Teknologi Malaysia, 81310, Skudai \\ Johor Bharu, Johor, Malaysia
}

Tel: 60-7-553-4009 E-mail: noriah@utm.my

Yaacob Mad Daud

Physics Department, Faculty of Science

Universiti Teknologi Malaysia, 81310, Skudai

Johor Bharu, Johor, Malaysia

Tel: 60-7-553-4096 E-mail: ymd@dfiz2.fs.utm.my

\begin{abstract}
The avalanche transistor is suitable for switching high voltage in kilovolts region. In this paper, a simple switching circuit consists of avalanche transistor is demonstrated. Sixteen of ZTX 415 avalanche transistors were used to switch a high voltage circuit up to $4.5 \mathrm{kV}$. A PIC16F84 microcontroller was utilized as control unit to generate input trigger. The result shows that the developed circuit was able to switch applied voltage up-to $4.5 \mathrm{kV}$ with an average falling time is $2.89 \mathrm{~ns}$.
\end{abstract}

Keywords: Avalanche transistor, High voltage, Microcontroller

\section{Introduction}

The operation of an electro-optically Q-switched laser requires fast switching of voltages in the multi-kilovolt regime (Chadderton, 19961; W. Koechner, 2006). Nanosecond scale high-voltage pulse generator or driver requires extremely high switching speeds. It is also capable of producing current outputs far in excess of that obtained from conventional circuits. In particular, the half-voltage of $\mathrm{KD}^{*} \mathrm{P}$ crystal Pockels cell is about $5.9 \mathrm{kV}$ and needs the voltage to switch to zero within few nanoseconds in order to produce a short laser pulse (W. Koechner, 2006).

The common switching techniques include the use of MOSFETs (Alton and Sundararaja, 2004), SCRs and avalanche transistors (W. G Maguson, 1962; Molina et al, 2002, Jankee and Navathe, 2006, Lui Jinyuan et al, 1998). Each switch has its advantages and applications. The avalanche transistor mode is ideally suitable for this operation and has wide applications in laser Q-switching (Chadderton, 1996; E. S. Fulkerson \& R. Box; C. Alton and R. Sundararajan, 2004 ; E. S. Fulkerson et al, 1997; ZTX 415 Datasheet,). Avalanche transistors are normally connected in series and operated close to their avalanche breakdown voltage. When triggered, all the transistors are switched on, and the transient pulse 
switching appears on Pockels cell. This effect changes the polarization state of Pockels cell which blocks or deflects light from passing through the crystal. The speed of switching and voltage applied across the crystals will determine the pulse duration of the laser output (W. Koechner, 2006)

In this paper, a simple circuit of avalanche transistors was developed to switch in the kilovolt regime. A series avalanche transistor was designed to switch up to $4.5 \mathrm{kV}$ within few nanoseconds.

\section{High Voltage Switching Circuit Design}

The circuit shown in Figure (1) was designed to drive a Pockels Cell for a Q-switched Nd:YAG laser within a $0-4.5$ $\mathrm{kV}$ DC voltage. This circuit includes three main components, high voltage power supply, trigger unit and control unit. The high voltage power supply provides DC voltage to Pockels Cell in the range of $4.5 \mathrm{kV}$. The trigger unit was used to chop the DC voltage to zero when initiated by control unit. The trigger unit circuit consists of a series of avalanche transistors such as illustrated in Figure (1).

The high voltage power supply is connected to trigger unit through two, series $1 \mathrm{MOhm}$ resistors. The avalanche

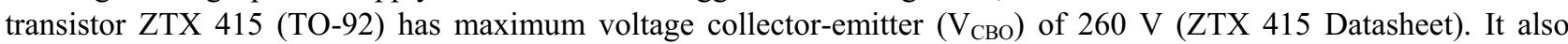
possess high peak collector current of about $60 \mathrm{~A}$ with a pulse width shorter than $20 \mathrm{~ns}$. Each avalanche transistor base is directly connected to emitter except the last one $\left(\mathrm{Q}_{1}\right)$. Transistor $\mathrm{Q}_{1}$ is triggered via a control unit connected through a $100 \mathrm{Ohm}$ resistor.

Initially transistor $\mathrm{Q}_{1}$ is triggered, through the collector near the ground potential; resulting in about $300 \mathrm{~V}$ between the collector and emitter voltage across the second transistor $\mathrm{Q}_{2}$. This second transistor, $\mathrm{Q}_{2}$ experiences a nondestructive avalanche breakdown due to this over voltage. Consequently each transistor in turn experienced an even greater overvoltage due to a faster rise time and a shorter delay. Finally, transistor $\mathrm{Q}_{16}$ is turn to experience the high voltages, fast fall time.

The control unit was designed to operate in two modes, single and repetitive mode. For calibration purposes, the control unit was set to operate in a single mode. A single push button connected to PIC16F84A microcontroller was employed to perform this task. When, the push button is pressed, the microcontroller produced a single $10 \mu$ s pulse. This pulse was then triggered a BC547 transistor. The output of this transistor was used to trigger the first avalanche transistor.

\section{Methodology}

In this experiment a developed avalanche transistor circuit was calibrated. A Tektronix TDS 3054B digital oscilloscope with a bandwidth of $500 \mathrm{MHz}$ and sampling rate of $5 \mathrm{GS} / \mathrm{s}$ was used to display and to measure the electronic signal. A high-voltage probe (Tektronix P6015A) with the maximum voltage of $20 \mathrm{kV} \mathrm{DC}$ or $40 \mathrm{kV}$ for pulse was utilized to measure the high voltage supplied across the circuit. The flow chart of the measurement is shown as in Figure (2). The variable high voltage DC power supply in the range of 0 to $4.5 \mathrm{kV}$ was connected directly to the developed circuit. For safety reason as well as to eliminate noise and to avoid electric shock the experimental setup was arranged properly. When the high speed switching occurs in kilovolt regime, electromagnetic induction (EMI) is expected to occur. This effect was avoided by designing the circuit on one layer of printed circuit board (PCB) and all the components were soldered and sealed properly. All the components and circuit are kept in isolated plastic case such illustrated as in Figure (3). The parameters such as the voltage switching, falling time and pulse duration were measured using the high voltage probe and oscilloscope.

\section{Result and Discussion}

The typical high voltage switching signal measured by Tektronix oscilloscope is shown in Figure (4). The input signal from control unit via PIC16F84A generated 10 microseconds pulse (bottom signal in Figure (4)). After the high voltage supply is switched to ground, the voltage is raised again within 90 microseconds (upper signal of Fig. 4). In this experiment, the maximum supply of DC voltage was $4.5 \mathrm{kV}$. Figure 5 shows the switching signal at $4.36 \mathrm{kV}$ with a time scale of $4 \mathrm{~ns}$ time/division. The voltage reached its ground level within 3.04 nanoseconds. The falling time of high voltage switching was measured using Tektronix high voltage probe and Tektronix oscilloscope $5 \mathrm{GHz}$ sampling rate.

The collected data of falling time were recorded. Figure (6) shows a graph of the switching falling time versus applied voltage. A nonlinear graph is obtained with the average of switching falling time of $2.89 \mathrm{~ns}$. The developed circuit also produced negative voltage and small ripple in nanoseconds scale. The maximum negative voltages were measured and represented in Figure (7). The negative voltages were in linear relationship with the applied voltage. In certain case, this voltage could increase the Q-switching efficiency due to the full retardation of laser beam. For commercial purpose, the circuit should produce sharp pulse with small ripple. The high voltage supplied to the avalanche transistor caused it to change its shape due to the piezoelectric effect. This effect could be eliminated by adding RC component in the circuit. Furthermore, by using PIC microcontroller, the pulse duration of trigger signal easily adjusted and controlled. In addition, the developed circuit also able to operate in high repetition rate mode up to $1 \mathrm{MHz}$. 


\section{Conclusion}

A simple high-voltage pulse switching circuit using avalanche transistor and PIC16F84A microcontroller was successfully developed and characterized. The maximum operation voltage was $4.5 \mathrm{kV}$ with average falling time of switching pulse is $2.89 \mathrm{~ns}$.

\section{Acknowledgment}

The authors would like to express their thanks to Universiti Teknologi Malaysia and the Government of Malaysia for the financial support for this project.

\section{References}

C. Alton \& R. Sundararajan. (2004). Simple MOSFET-Based High-Voltage Nanosecond Pulse Circuit. IEEE Transactions on Plasma Science, Vol. 32, No. 5, Oct 2004.

E. S. Fulkerson \& R. Box. Design of reliable high voltage avalanche transistor pulsers. Lawrence Livermore National Laboratory.

E. S. Fulkerson, D. C. Norman \& R. Booth. (1997). Driving Pockels Cell Using Avalanche Transistor Pulsers. 11 ${ }^{\text {th }}$ IEEE International Pulse Power Conference, Baltimore, Maryland.

L. L. Molina, A. Mar, F. J. Zutavern, G. M. Loubriel \& M. W. O’Malley. (2002). Sub-nanosecond avalanche transistor drivers for low impedance pulsed power applications. IEEE, pp 178-181

Lui Jinyuan, Shan Bing \& Chang Zenghu. (1998). High Voltage fast ramp pulse generation using avalanche transistor. Review of Scientific Instruments, Vol. 69, No. 8, 3066-3067

N. Chadderton. (1996). The ZTX 415 Avalanche Mode Transistor: An Introduction to Characteristics, Performance and Application. Application Note, Issue 2

(1995). NPN Silicon planar avalanche transistor ZTX 415: Datasheet, Issue 4 - Nov 1995.

U. Jankee \& C. P. Navathe. (2006). A fast high-voltage pulse generator with variable amplitude and duration. Design Note, Meas. Sci. Technol., 17, N25-N28.

W. Koechner. (2006). Solid State Laser Engineering. 6th Edition, United State of America, Springer Science-Business Media. pp 514-516.

W.G. Magnuson. (1962). Variable-width pulse generation using avalanche transistor. IEEE Transactions on Instrumentation and Measurement, Sep, pp 56-64.

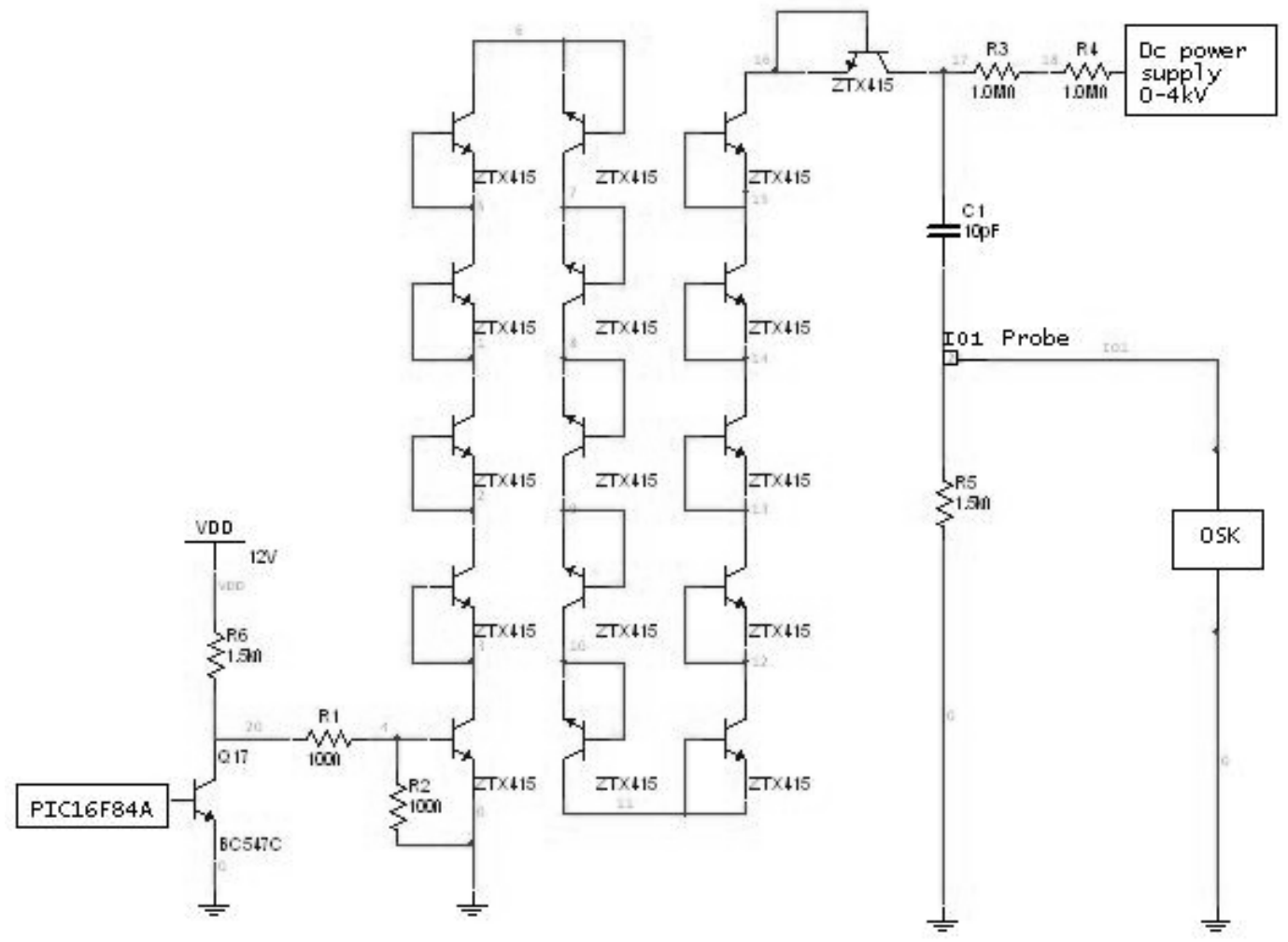

Figure 1. Schematic diagram of high voltage avalanche transistor trigger circuit 


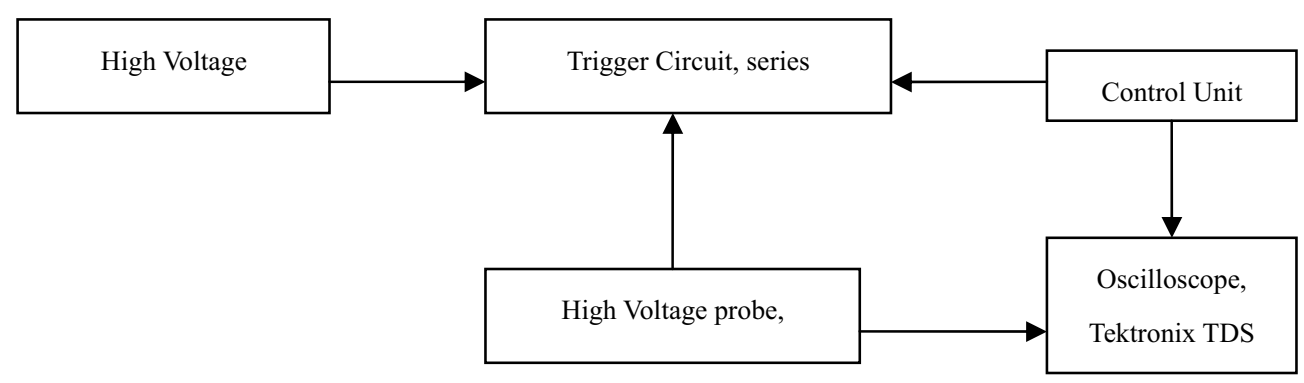

Figure 2. The flow chart of experimental work

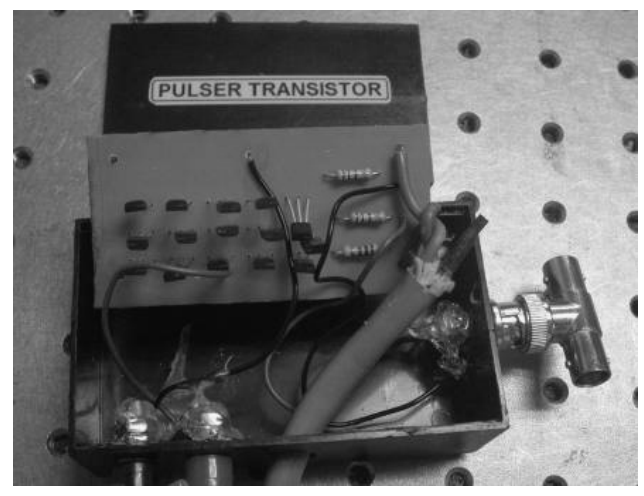

Figure 3. The developed avalanche transistor circuit on PCB in the plastic case

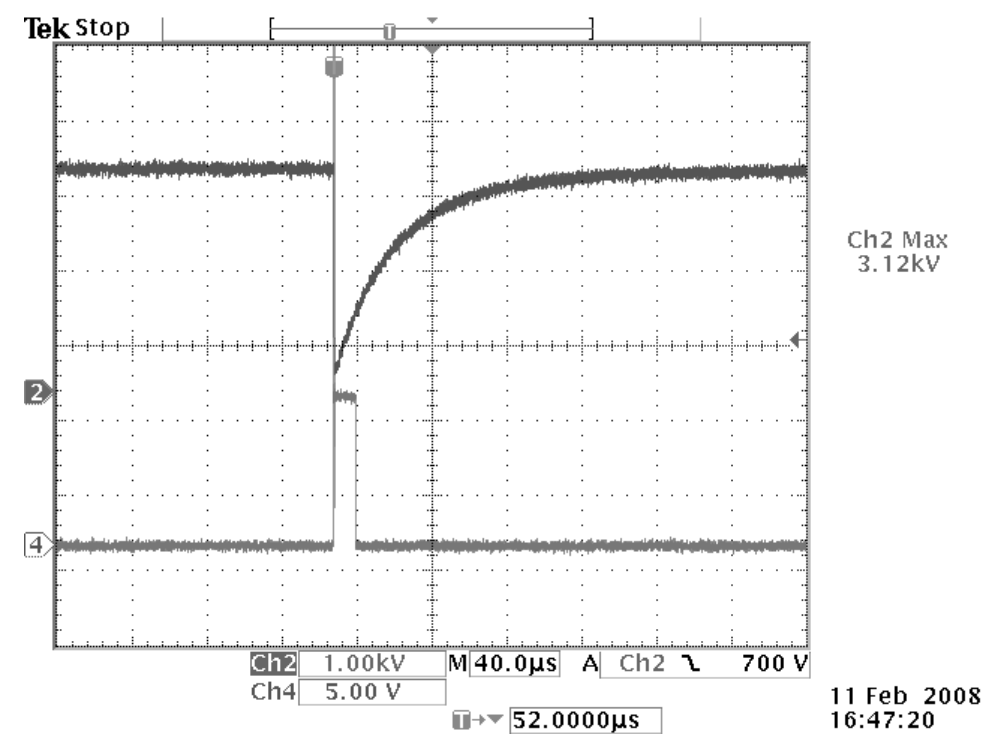

Figure 4. High voltage switching signal 


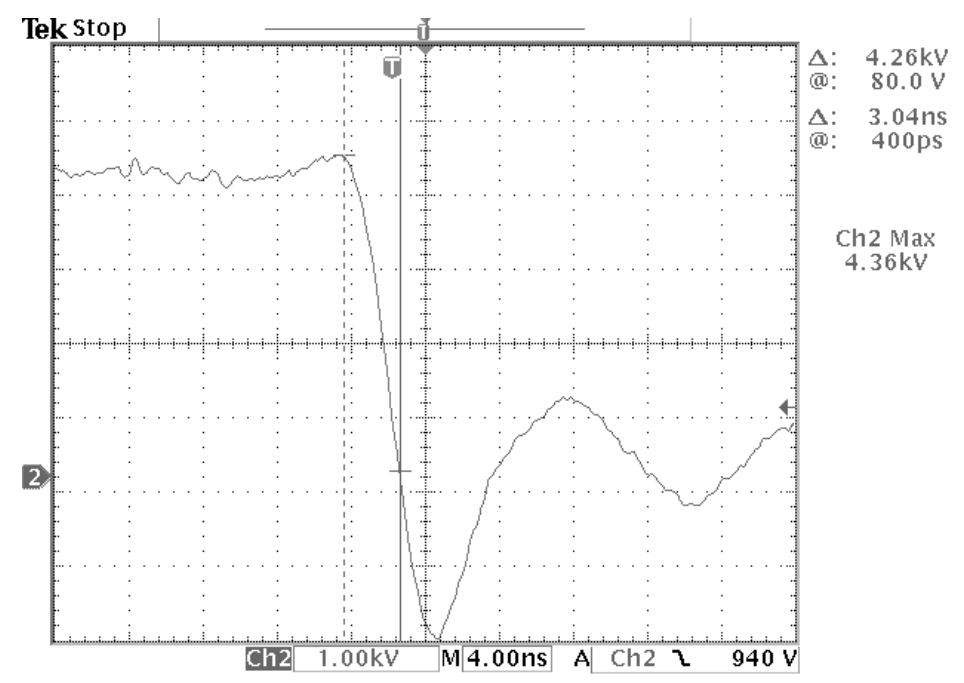

Figure 5. Typical result of nanosecond pulse

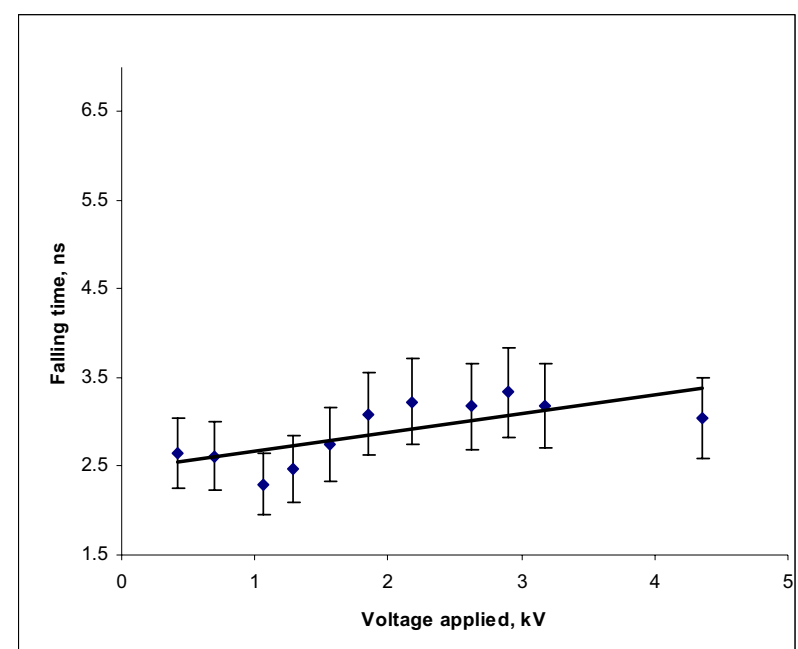

Figure 6. The graph of falling time versus applied voltage.

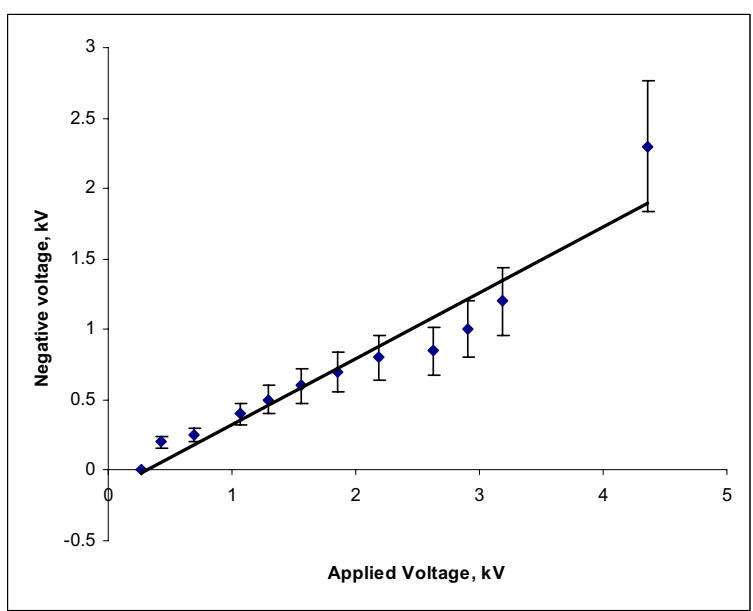

Figure 7. Negative voltage of high voltage switching 


\title{
Synthesis of $\mathrm{LaMnO}_{3}$ Nanofibers via Electrospinning
}

\author{
Jinxian Wang, Xiaoqiu Zheng, Xiangting Dong (Corresponding author), Zhen Qu \& Guixia Liu \\ School of Chemistry and Environmental Engineering \\ Changchun University of Science and Technology \\ Changchun 130022, Jilin, China \\ Tel: 86-431-8558-2574Ｅ-mail: dongxiangting888@yahoo.com.cn
}

\author{
Ran Xue \& Yudong Hao \\ School of Life Science, Jilin University \\ Changchun 130012, Jilin, China
}

\begin{abstract}
This work was financially supported by the Science and Technology Development Planning Project of Jilin Province (Grant Nos. 20040125, 20060504, 20070402), Key Research Project of Science and Technology of Ministry of Education of China(Grant No.207026), the Science and Technology Planning Project of Changchun City(Grant No. 2007045), the Scientific Research Planning Project of the Education Department of Jilin Province (Under grant Nos. 200224, 2005109, 2007-45) and the Scientific Research Project of Environment Protection Bureau of Jilin Province(No. 2006-24)
\end{abstract}

\begin{abstract}
Polyvinyl alcohol(PVA)/[La( $\left.\left(\mathrm{NO}_{3}\right)_{3}+\mathrm{Mn}\left(\mathrm{CH}_{3} \mathrm{COO}\right)_{2}\right]$ composite nanofibers were fabricated by electrospinning, and polycrystalline $\mathrm{LaMnO}_{3}$ nanofibers were prepared by calcination of the PVA/[La( $\left.\left.\mathrm{NO}_{3}\right)_{3}+\mathrm{Mn}\left(\mathrm{CH}_{3} \mathrm{COO}\right)_{2}\right]$ composite nanofibers at $600^{\circ} \mathrm{C}$ for $10 \mathrm{~h}$. The samples were characterized by using thermogravimetric-differential thermal analysis (TG-DTA), X-ray diffraction spectrometry(XRD), scanning electron microscopy(SEM) and Fourier transform infrared spectrometry(FTIR). The results show that PVA/[La( $\left.\left(\mathrm{NO}_{3}\right)_{3}+\mathrm{Mn}\left(\mathrm{CH}_{3} \mathrm{COO}\right)_{2}\right]$ composite nanofibers are amorphous in structure, and pure phase $\mathrm{LaMnO}_{3}$ nanofibers are orthorhombic with space group Pbnm. The surface of as-prepared composite nanofibers is smooth, and the diameter is about $150 \mathrm{~nm}$. The diameter of $\mathrm{LaMnO}_{3}$ nanofibers is smaller than that of the relevant composite fibers. The surface of the $\mathrm{LaMnO}_{3}$ nanofibers becomes coarse with the increase of calcination temperatures. The diameter of $\mathrm{LaMnO}_{3}$ nanofibers is ca. $100 \mathrm{~nm}$, and the length is greater than $100 \mu \mathrm{m}$. The mass of the sample remains constant when the temperature is above $450^{\circ} \mathrm{C}$, and the total mass loss percentage is $94.6 \%$. Possible formation mechanism of $\mathrm{LaMnO}_{3}$ nanofibers is preliminarily proposed.
\end{abstract}

Keywords: $\mathrm{LaMnO}_{3}$, Nanofibers, Electrospinning

\section{Introduction}

The science and technology of nanostructured materials is advancing at a rapid pace (Yang, 2009, Gao, 2009, Mohapatra, 2008 \& Zhang, 2007). Over the past decade, the preparation and functionalization of one-dimensional nanostructured materials has become one of the most highly energized research fields ( $\mathrm{Hu}, 2008$ \& Kar, 2006). One-dimensional nanostructured materials, such as nanowires, nanorods, nanowhiskers and nanofibers, have stimulated great interest due to their importance in basic scientific research and potential technological applications (Huynh, 2002 $\&$ Duan, 2003). They are expected to play an important role as both interconnects and functional components in the fabrication of nanoscale electronic and optoelectronic devices. In order to obtain these materials, various preparation methods have been developed including arc discharge, laser ablation, template, precursor thermal decomposition, and other methods (Iijima, 1991, Morales, 1998, Shi, $2001 \&$ Pan, 2001). Electrospinning technique is widely applied to prepare polymers nanofibers( $\mathrm{Li}, 2004,1151-1170)$. Recently, some inorganic compounds nanofibers have been prepared by electrospinning technique using electrospun fibers of polymer/inorganic composite as the precursor $(\mathrm{Li}$, 2004, Zhang, 2008 \& Shao, 2004). This processing involved the following three steps: (1) Preparation of a sol with 
suitable inorganic precursor and proper polymer, and achieving the right rheology for electrospinning process; (2) Electrospinning of the sol to obtain fibers of polymer/inorganic precursors composite; (3) Calcinations of the composite fibers to obtain final oxide fibers. It is important; however, to control all of the above three steps in order to obtain high quality fibers with the desired final properties. $\mathrm{LaMnO}_{3}$ has attracted much interest recently due to their specific electrical and catalytic properties (Dong, 1994, Weng, 2001, Yang, 2003 \& Deng, 2006). A few methods on the preparation of $\mathrm{LaMnO}_{3}$ nanocrystalline materials were reported (Maglia, 2008, Krupicka, 2002, Zhu, 2002 \& Jeffrey, 2004). In this paper, $\mathrm{LaMnO}_{3}$ nanofibers were fabricated by calcination of the electrospun fibers of $\mathrm{PVA} /\left[\mathrm{La}\left(\mathrm{NO}_{3}\right)_{3}+\mathrm{Mn}\left(\mathrm{CH}_{3} \mathrm{COO}\right)_{2}\right]$ composite, and some new results were obtained.

\section{Experimental}

\subsection{Chemicals}

Polyvinyl alcohol (PVA)(Mr=80000) was bought from the Third Chemical Reagents Factory of Tianjin, and manganese acetate tetrahydrate $\left[\mathrm{Mn}\left(\mathrm{CH}_{3} \mathrm{COO}\right)_{2} \cdot 4 \mathrm{H}_{2} \mathrm{O}\right]$ were purchased from Tianjin Kermel Chemical Reagents Development Center. Lanthanum nitrate hexahydrate $\left[\mathrm{La}\left(\mathrm{NO}_{3}\right)_{3} \cdot 6 \mathrm{H}_{2} \mathrm{O}\right]$ was obtained from Tianjin Guangfu Institute of Fine Chemicals. All chemicals were analytically pure and directly used as received without further purification. Distilled water was used as solvent.

\subsection{Preparation of $\mathrm{PVA} /\left[\mathrm{La}\left(\mathrm{NO}_{3}\right)_{3}+\mathrm{Mn}\left(\mathrm{CH}_{3} \mathrm{COO}\right)_{2}\right]$ composite sol}

$\mathrm{PVA} /\left[\mathrm{La}\left(\mathrm{NO}_{3}\right)_{3}+\mathrm{Mn}\left(\mathrm{CH}_{3} \mathrm{COO}\right)_{2}\right]$ composite solution was prepared by dissolving an amount of PVA powders, $\mathrm{La}\left(\mathrm{NO}_{3}\right)_{3} \cdot 6 \mathrm{H}_{2} \mathrm{O}$ and $\mathrm{Mn}\left(\mathrm{CH}_{3} \mathrm{COO}\right)_{2} \cdot 4 \mathrm{H}_{2} \mathrm{O}$ in distilled water, and stirring for $5 \mathrm{~h}$, then remaining motionlessly for $2 \mathrm{~h}$. Thus, a viscous sol of PVA/[ $\left.\mathrm{La}\left(\mathrm{NO}_{3}\right)_{3}+\mathrm{Mn}\left(\mathrm{CH}_{3} \mathrm{COO}\right)_{2}\right]$ composite containing $9 \%(\mathrm{wt} \%) \mathrm{PVA}, 3 \%$ (wt $\left.\%\right)$ metallic salts, $88 \%(\mathrm{wt} \%) \mathrm{H}_{2} \mathrm{O}$, and the molar ratio $1: 1$ of $\mathrm{La}^{3+}$ to $\mathrm{Mn}^{2+}$ was obtained for electrospinning processing.

\subsection{Synthesis of PVA/[La( $\left.\left(\mathrm{NO}_{3}\right)_{3}+\mathrm{Mn}\left(\mathrm{CH}_{3} \mathrm{COO}\right)_{2}\right]$ composite nanofibers and $\mathrm{LaMnO}_{3}$ nanofibers}

The setup used for electrospinning was indicated in Figure 1. The above composite sol of PVA, $\mathrm{La}\left(\mathrm{NO}_{3}\right)_{3}$, $\mathrm{Mn}\left(\mathrm{CH}_{3} \mathrm{COO}\right)_{2}$ and $\mathrm{H}_{2} \mathrm{O}$ mixture was contained in a plastic syringe with a stainless steel needle on its top, and the diameter of the needle was $1 \mathrm{~mm}$. A copper wire connected to a DC high-voltage power supply was placed in the sol, and the sol was kept in the syringe by adjusting the angle between syringe and horizon, and the angle was kept at $15^{\circ}$. A grounded aluminum foil served as counter electrode and collector plate. The distance between the needle tip and the collector was fixed to $15 \mathrm{~cm}$. Electrospinning experiments were performed when ambient temperature was greater than $18^{\circ} \mathrm{C}$ and relative air humidity was $50 \%-60 \%$. A voltage of $20 \mathrm{kV}$ was applied to the composite sol and a sprayed dense web of fibers was collected on the aluminum foil. The collected fibers were PVA/[La( $\left.\left(\mathrm{NO}_{3}\right)_{3}+\mathrm{Mn}\left(\mathrm{CH}_{3} \mathrm{COO}\right)_{2}\right]$ composite nanofibers. The prepared composite nanofibers were dried initially at $70^{\circ} \mathrm{C}$ for $12 \mathrm{~h}$ under vacuum, and then calcined at a heating rate of $2^{\circ} \mathrm{C} / \mathrm{min}$ and remained for $10 \mathrm{~h}$ at $300^{\circ} \mathrm{C}, 600^{\circ} \mathrm{C}$ and $900^{\circ} \mathrm{C}$, respectively. Thus, $\mathrm{LaMnO}_{3}$ nanofibers were obtained when calcination temperature was $600^{\circ} \mathrm{C}$.

\subsection{Characterization methods}

XRD analysis was performed with a Y-2000 X-ray diffractometer made by Dandong Aolong Radiative Instrument Co. $\mathrm{Ltd}$ using $\mathrm{Cu} \mathrm{K} \alpha$ radiation and $\mathrm{Ni}$ filter, the working current and voltage were $20 \mathrm{~mA}$ and $40 \mathrm{kV}$, respectively. Scans were made from $20^{\circ}$ to $75^{\circ}$ at the speed of $3 \% \mathrm{~min}$, and step was $0.02^{\circ}$. The morphology and size of the fibers were observed with a S-4200 scanning electron microscope made by Japanese Hitachi company. TG-DTA analysis was carried out with a SDT-2960 thermal analyzer made by American TA Instrument Company at a temperature-rising rate of $10^{\circ} \mathrm{C} / \mathrm{min}$ under stable air conditions. FTIR spectra of the samples were recorded on BRUKER Vertex 70 Fourier transform infrared spectrophotometer made by Germany Bruker company, and the specimen for the measurement was prepared by mixing the sample with $\mathrm{KBr}$ powders and then the mixture was pressed into pellets, the spectrum was acquired in a wave number range from $4000 \mathrm{~cm}^{-1}$ to $400 \mathrm{~cm}^{-1}$ with a resolution of $4 \mathrm{~cm}^{-1}$.

\section{Results and discussion}

\subsection{XRD patterns}

In order to investigate the lowest crystallizing temperature and the variety of phases, the $\mathrm{PVA} /\left[\mathrm{La}\left(\mathrm{NO}_{3}\right)_{3}+\mathrm{Mn}\left(\mathrm{CH}_{3} \mathrm{COO}\right)_{2}\right]$ composite fibers and samples obtained by calcining the composite fibers at different temperatures for $10 \mathrm{~h}$ were characterized by $\mathrm{XRD}$, as indicated in Figure 2 . The results showed that the $\mathrm{PVA} /\left[\mathrm{La}\left(\mathrm{NO}_{3}\right)_{3}+\mathrm{Mn}\left(\mathrm{CH}_{3} \mathrm{COO}\right)_{2}\right]$ composite fibers were amorphous in structure, only a broad peak was located around $22^{\circ}$, it was the typical peak of the amorphous polymer, indicating that the composite fibers were amorphous in structure. The sample was partly crystallized at $300^{\circ} \mathrm{C}$. The polycrystalline $\mathrm{LaMnO}_{3}$ nanofibers with single phase were synthesized when calcination temperature was in the range of $600-900^{\circ} \mathrm{C}$, the $\mathrm{d}($ spacing between crystallographic plane)values and relative intensities of $\mathrm{LaMnO}_{3}$ were consistent with those of JCPDS standard card(35-1353), and the crystal structure of the prepared $\mathrm{LaMnO}_{3}$ was orthorhombic system with space group Pbnm. 


\subsection{SEM images}

In order to study the morphology and size of the as-synthesized fibers, the prepared fibers were investigated by SEM, as shown in Figure 3. As seen from Figure 3, the morphology and size of the fibers varied strongly with the increase of calcination temperatures. The surface of the PVA/[La( $\left.\left(\mathrm{NO}_{3}\right)_{3}+\mathrm{Mn}\left(\mathrm{CH}_{3} \mathrm{COO}\right)_{2}\right]$ composite nanofibers was very smooth, and the diameter of the composite fibers was about $150 \mathrm{~nm}$. The diameter of the fibers was ca. $120 \mathrm{~nm}$ at $300^{\circ} \mathrm{C}$. The surface morphology of $\mathrm{LaMnO}_{3}$ nanofibers became coarse with the increase of calcination temperatures. The diameter of the synthesized $\mathrm{LaMnO}_{3}$ nanofibers was ca. $100 \mathrm{~nm}$ at $600^{\circ} \mathrm{C}$, and their lengths were greater than $100 \mu \mathrm{m} . \mathrm{The}$ diameters of $\mathrm{LaMnO}_{3}$ nanofibers were smaller than those of the $\mathrm{PVA} /\left[\mathrm{La}\left(\mathrm{NO}_{3}\right)_{3}+\mathrm{Mn}\left(\mathrm{CH} \mathrm{COO}_{2}\right]\right.$ composite nanofibers owing to the decomposition and evaporation of $\mathrm{PVA}, \mathrm{NO}_{3}{ }^{-}, \mathrm{CH}_{3} \mathrm{COO}^{-}$. The fibers were broken at $900^{\circ} \mathrm{C}$. Therefore, $\mathrm{LaMnO}_{3}$ nanofibers with good morphology should be prepared at low calcination temperature.

\subsection{TG-DTA analysis}

TG and DTA curves of the PVA/[ $\left.\mathrm{La}\left(\mathrm{NO}_{3}\right)_{3}+\mathrm{Mn}\left(\mathrm{CH}_{3} \mathrm{COO}\right)_{2}\right]$ composite fibers were indicated in Figure 4. It was noted that there were mainly three stages of weight loss. The first weight loss step $(7.6 \%)$ was in the range of $29^{\circ} \mathrm{C}$ to $127^{\circ} \mathrm{C}$ accompanied by a small endothermic peak near $71.08^{\circ} \mathrm{C}$ in the DTA curve caused by the loss of the surface absorbed water or the residual water molecules in the composite fibers. The second weight loss step (50\%) was noticed between $127^{\circ} \mathrm{C}$ and $248^{\circ} \mathrm{C}$ accompanied by an exothermic peak near $229^{\circ} \mathrm{C}$ in the DTA curve due to the decomposition of the acetate, nitrate and side-chain of PVA. The last weight loss was $37 \%$ from $248^{\circ} \mathrm{C}$ to $450^{\circ} \mathrm{C}$. In the DTA curve, a wide exothermic peak was located at $363.07^{\circ} \mathrm{C}$. This was likely to be the oxidation combustion of the PVA main chain. And above $450^{\circ} \mathrm{C}$, the TG and DTA curves were all stable, indicating that water, organic compounds, nitrate and acetate in the composite fibers were completely volatilized and inorganic compounds nanofibers could be obtained above $450^{\circ} \mathrm{C}$. The total weight loss rate was $94.6 \%$. This result tallied with the XRD analysis.

\subsection{FTIR spectra analysis}

Pure PVA, PVA/[La( $\left.\left.\mathrm{NO}_{3}\right)_{3}+\mathrm{Mn}\left(\mathrm{CH}_{3} \mathrm{COO}\right)_{2}\right]$ composite nanofibers and $\mathrm{LaMnO}_{3}$ nanofibers(obtained by calcination of the relevant composite nanofibers at $600^{\circ} \mathrm{C}$ for $10 \mathrm{~h}$ ) were analyzed by FTIR, as shown in Figure 5. As seen from Figure 5, pure PVA(Figure 5a) and $\mathrm{PVA} /\left[\mathrm{La}\left(\mathrm{NO}_{3}\right)_{3}+\mathrm{Mn}\left(\mathrm{CH}_{3} \mathrm{COO}\right)_{2}\right]$ composite nanofibers(Figure 5b) had the identical spectra, but absorption peaks intensity of spectrum for PVA/[La( $\left.\left.\mathrm{NO}_{3}\right)_{3}+\mathrm{Mn}\left(\mathrm{CH}_{3} \mathrm{COO}\right)_{2}\right]$ composite nanofibers was lower than those of spectrum for pure PVA. This resulted from the lower content of PVA in the $\mathrm{PVA} /\left[\mathrm{La}\left(\mathrm{NO}_{3}\right)_{3}+\mathrm{Mn}\left(\mathrm{CH}_{3} \mathrm{COO}\right)_{2}\right]$ composite nanofibers. All absorption peaks were attributed to PVA at $3334 \mathrm{~cm}^{-1}$, $2945 \mathrm{~cm}^{-1}, 1704 \mathrm{~cm}^{-1}, 1488 \mathrm{~cm}^{-1}, 1305 \mathrm{~cm}^{-1}, 1091 \mathrm{~cm}^{-1}, 815 \mathrm{~cm}^{-1}$ corresponding to the stretching vibrations of hydroxyl $\operatorname{group}\left(v_{\mathrm{O}-\mathrm{H}}\right)$, C-H bond $\left(v_{\mathrm{C}-\mathrm{H}}\right)$, carbonyl group $\left(v_{\mathrm{C}=\mathrm{O}}\right)$, C-H bond $\left(v_{\mathrm{C}-\mathrm{H}}\right)$, C-C bond $\left(v_{\mathrm{C}-\mathrm{C}}\right)$, C-O bond $\left(v_{\mathrm{C}-\mathrm{O}}\right)$, and O-H bond $\left(v_{\mathrm{O}-\mathrm{H}}\right)$, respectively. It was seen from Figure $5 \mathrm{c}$ that all peaks of PVA disappeared, and at low wave number range, a new absorption peak at $614 \mathrm{~cm}^{-1}$ appeared. The new absorption peak was ascribed to the vibration of metal-oxygen bond, indicating that $\mathrm{LaMnO}_{3}$ was formed. The results of FTIR analysis were in good agreement with XRD results.

\subsection{Possible formation mechanism of $\mathrm{LaMnO}_{3}$ nanofibers}

Possible formation mechanism of $\mathrm{LaMnO}_{3}$ nanofibers was indicated in Figure $6 . \mathrm{La}\left(\mathrm{NO}_{3}\right)_{3} \cdot 6 \mathrm{H}_{2} \mathrm{O}, \mathrm{Mn}\left(\mathrm{CH} \mathrm{COO}_{2} \cdot 4 \mathrm{H}_{2} \mathrm{O}\right.$ and PVA were mixed with distilled water to form sol with certain viscosity. PVA acted as template during the formation processing of $\mathrm{LaMnO}_{3}$ nanofibers. $\mathrm{La}^{3+}, \mathrm{Mn}^{2+}, \mathrm{CH}_{3} \mathrm{COO}^{-}$and $\mathrm{NO}_{3}{ }^{-}$were mixed with or absorbed onto PVA molecules to fabricate PVA/[ $\left.\mathrm{La}\left(\mathrm{NO}_{3}\right)_{3}+\mathrm{Mn}\left(\mathrm{CH}_{3} \mathrm{COO}\right)_{2}\right]$ composite fibers under electrospinning. During calcination treatment of the composite fibers, solvent water would remove to the surface of the $\mathrm{PVP} /\left[\mathrm{La}\left(\mathrm{NO}_{3}\right)_{3}+\mathrm{Mn}\left(\mathrm{CH}{ }_{3} \mathrm{COO}\right)_{2}\right]$ composite fibers and eventually evaporated from the composite fibers. With the increasing in calcination temperature, PVA molecular chains were broken, $\mathrm{PVA} \mathrm{CH}_{3} \mathrm{COO}^{-}$, and $\mathrm{NO}_{3}{ }^{-}$would oxidize and volatilize gradually, $\mathrm{La}^{3+}$ and $\mathrm{Mn}^{2+}$ were oxidized into $\mathrm{LaMnO}_{3}$ crystallites in air, and many crystallites were sintered to form small $\mathrm{LaMnO}_{3}$ nanoparticles, these small nanoparticles were combined into big particles, and these particles were mutually connected to generate $\mathrm{LaMnO}_{3}$ nanofibers.

\section{Conclusions}

4.1 PVA/[La( $\left.\left(\mathrm{NO}_{3}\right)_{3}+\mathrm{Mn}\left(\mathrm{CH}_{3} \mathrm{COO}\right)_{2}\right]$ composite nanofibers were fabricated by electrospinning. Polycrystalline $\mathrm{LaMnO}_{3}$ nanofibers were synthesized by calcining the relevant composite fibers at $600^{\circ} \mathrm{C}$.

4.2 TG-DTA analysis showed that the mass of the PVA/[La( $\left.\left.\mathrm{NO}_{3}\right)_{3}+\mathrm{Mn}\left(\mathrm{CH}_{3} \mathrm{COO}\right)_{2}\right]$ composite fibers remained constant when the temperature was above $450^{\circ} \mathrm{C}$, and the total mass loss percentage was $94.6 \%$.

4.3 XRD analysis revealed that the composite fibers were amorphous in structure. The crystal structure of $\mathrm{LaMnO}_{3}$ nanofibres was orthorhombic system with space group Pbnm.

4.4 SEM images indicated that the surface of the prepared composite fibres was smooth, and the diameters of the composite nanofibres were about $150 \mathrm{~nm}$. The diameters of $\mathrm{LaMnO}_{3}$ nanofibers were smaller than those of the composite nanofibers. The surface of the $\mathrm{LaMnO}_{3}$ nanofibers became coarse with the increase of calcination 
temperatures. The diameter of $\mathrm{LaMnO}_{3}$ nanofibers was ca. $100 \mathrm{~nm}$, and their lengths were greater than $100 \mu \mathrm{m}$.

\section{References}

Deng, J. G., Wang, G. Z., Zhang, Y. J., et al. (2006). Advancement of preparation strategies and photocatalytic performance of perovskite-type oxides. J. Chin. Rare Earth Soc., 24(z2), 80-93.

Dong, X. T., Guo, Y. Z., Yu, D. C., et al. (1994). Study of synthesis and electrical conductivity of $\mathrm{LaMnO}_{3}$ ultrafine powders. Rare Metal Mater. \& Eng., 23(2), 60-63.

Duan, X. F., Huang, Y., Agarwal, R., Lieber, C. M. (2003). Single-nanowire electrically driven lasers. Nature, 421, 241-245.

Gao, X. B., Dong X. T., Fan L. J. et al. (2009). Fabrication and Characterization of $\mathrm{Nd}^{3+}$ :YAG Nanofibers. Chinese Journal of Lasers, 36(6): 1517-1522.

Hu, X. K., Qian, Y. T., Song, Z. T., et al. (2008). Comparative study on $\mathrm{MoO}_{3}$ and $\mathrm{H}_{x} \mathrm{MoO}_{3}$ nanobelts: structure and electric transport. J. Chem Mater, 20(4), 1527-1533.

Huynh, W. U., Dittmer, J. J., Alivisatos, A. P. (2002). Hybrid nanorod-polymer solar cells. Science, 295, 2425-2427.

Iijima, S. (1991). Helical microtubules of graphitic carbon. Nature, 354, 56-58.

Jeffrey, J. U., Lian, O. Y., Moon, H. J., et al. (2004). Synthesis of single-crystalline $\mathrm{La}_{1-\mathrm{x}} \mathrm{Ba}_{\mathrm{x}} \mathrm{MnO}_{3}$ nanocubes with adjustable doping levels. Nano Lett., 4(8), 1547-1550.

Kar, S., Chaudhuri, S. (2006). Shape selective growth of CdS one-dimensional nano-structures by a thermal evaporation process. J. Phys. Chem. B, 110(10), 4542-4547.

Krupicka, E., Reller, A., Weidenkaff, A. (2002). Morphology of nanoscaled $\mathrm{LaMO}_{3}$-particles (M=Mn,Fe,Co,Ni) derived by citrate precursors in aqueous and alcoholic solvents. Crystal Engineering, 5, 195-202.

Li, D., Xia, Y. N. (2004). Direct fabrication of composite and ceramic hollow nanofibers by electrospinning. Nano Lett., 4(5), 933-938.

Li, D., Xia, Y. N. (2004). Electrospinning of Nanofibers: Reinventing the Wheel. Adv. Mater., 16(14), 1151-1170.

Maglia, F., Malavasi, L., Camurlu, H. E., et al. (2008). Synthesis and characterization of pure and doped (Na, Ca, Sr) nanograined $\mathrm{LaMnO}_{3}$ magnetoresistive ceramics. J. Nanosci. Nanotechnol., 8(2), 846-853.

Mohapatra, S. K., Misra, M., Mahajan, V. K., et al. (2008). Synthesis of Y-branched $\mathrm{TiO}_{2}$ nanotubes. Materials Letters, 62, 1772-1774.

Morales, A. M., Lieber, C. M. (1998). A laser ablation method for the synthesis of crystalline semiconductor nanowires. Science, 279, 208-211.

Pan, Z. W., Dai, Z. R., Wang. E.L. (2001). Nanobelts of semiconducting oxides. Science, 291, 1947-1949.

Shao, C. L., Guan, H. Y., Liu, Y. C., et al. (2004). A novel method for making $\mathrm{ZrO}_{2}$ nanofibres via an electrospinning technique. J. Crystal Growth, 267, 380-384.

Shi, W. S., Zheng, Y. F., Wang, N., et al. (2001). A general synthetic route to III-V compound semiconductor nanowires. Adv. Mater., 13, 591-594.

Weng, D., Ding, H. M., Wu, X. D., et al. (2001). Catalytic Performance of Rare Earth Nanometer Materials LaMnO ${ }_{3+\lambda}$. Acta Physico-Chimica Sinica, 17(3), 248-251

Yang, Q. H., Fu, X. X. (2003). Analysis of photocatalytic oxidation activity of nano-LaMO $(\mathrm{M}=\mathrm{Cr}, \mathrm{Mn}, \mathrm{Fe}, \mathrm{Co})$ compounds. J. Chin. Ceram. Soc., 31(3), 254-256.

Yang, X. F., Dong, X. T. Wang, J. X., et al. (2009). Glycine-assisted hydrothermal synthesis of $\mathrm{YPO}_{4}: \mathrm{Eu}^{3+}$ nanobundles. Materials Letters, 63, 629-631.

Zhang, S. H., Dong, X. T., Xu, S. Z., et al. (2007). Preparation and characterization of $\mathrm{TiO}_{2} @ \mathrm{SiO}_{2}$ submicron-scaled coaxial cables via a static electricity spinning technique. Acta Chimica Sinica, 65(23), 2675-2679.

Zhang, S. H., Dong, X. T., Xu, S. Z., et al. (2008). Preparation and characterization of $\mathrm{TiO}_{2} / \mathrm{SiO}_{2}$ composite hollow nanofibers via an electrospinning technique. Acta Materiae Compositae Sinica, 25(3), 138-143.

Zhu, D., Zhu, H., Zhang, Y. (2002). Hydrothermal synthesis of $\mathrm{La}_{0.5} \mathrm{Ba}_{0.5} \mathrm{MnO}_{3}$ nanowires. Appl. Phys. Lett., 80, 1634-1636. 


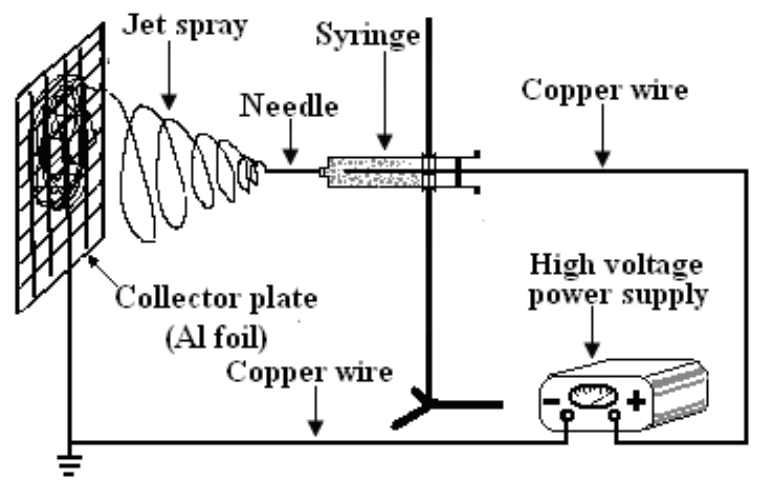

Figure 1. Schematic diagram of electrospinning setup

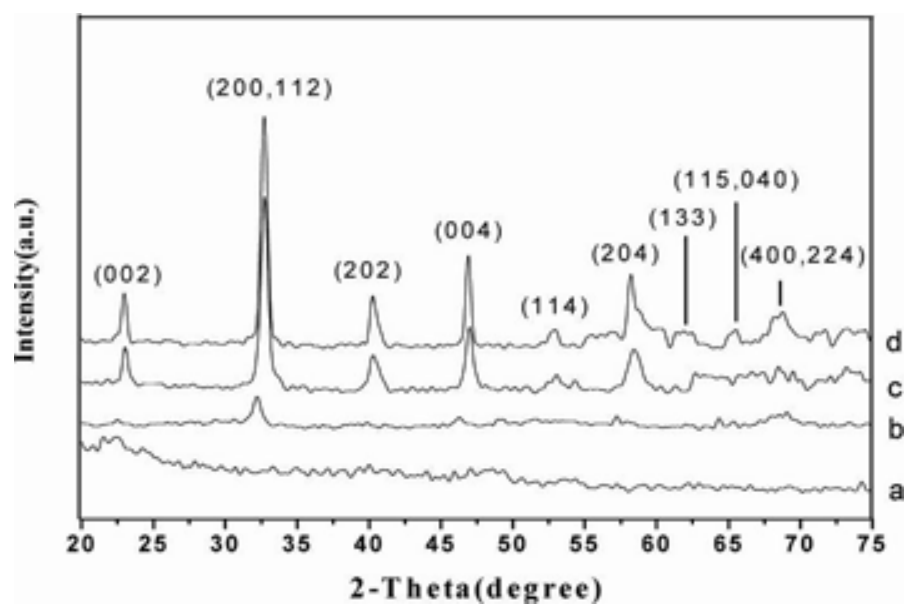

Figure 2. XRD patterns of samples

a. $\mathrm{PVA} /\left[\mathrm{La}\left(\mathrm{NO}_{3}\right)_{3}+\mathrm{Mn}\left(\mathrm{CH}_{3} \mathrm{COO}\right)_{2}\right]$ composite fibers $\quad$ b. $300^{\circ} \mathrm{C} \quad$ c. $600^{\circ} \mathrm{C} \quad$ d. $900^{\circ} \mathrm{C}$

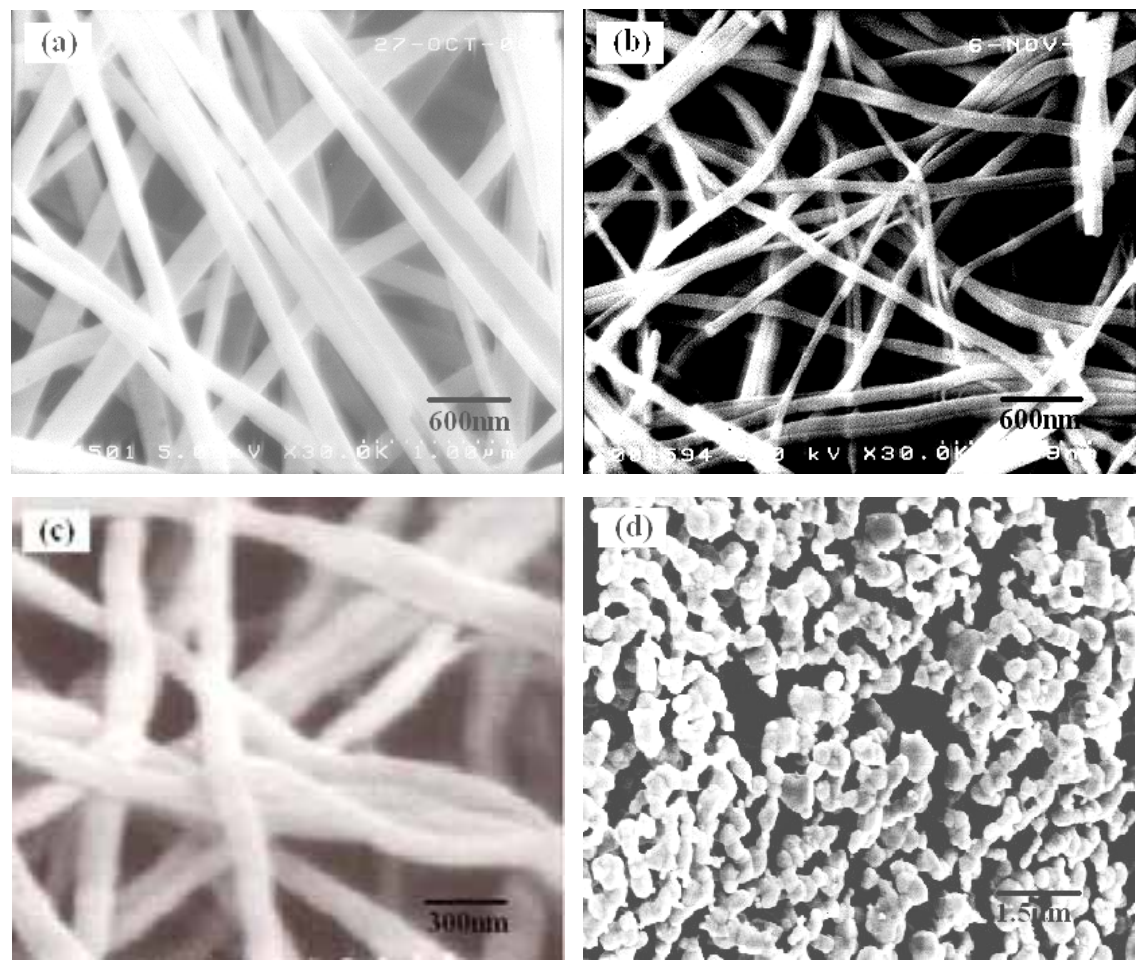

Figure 3. SEM images of the fibers obtained at different temperatures
(a) PVA/[La( $\left.\left(\mathrm{NO}_{3}\right)_{3}+\mathrm{Mn}\left(\mathrm{CH}_{3} \mathrm{COO}\right)_{2}\right]$ composite fibers
(b) $300^{\circ} \mathrm{C}$
(c) $600^{\circ} \mathrm{C}$
(d) $900^{\circ} \mathrm{C}$ 


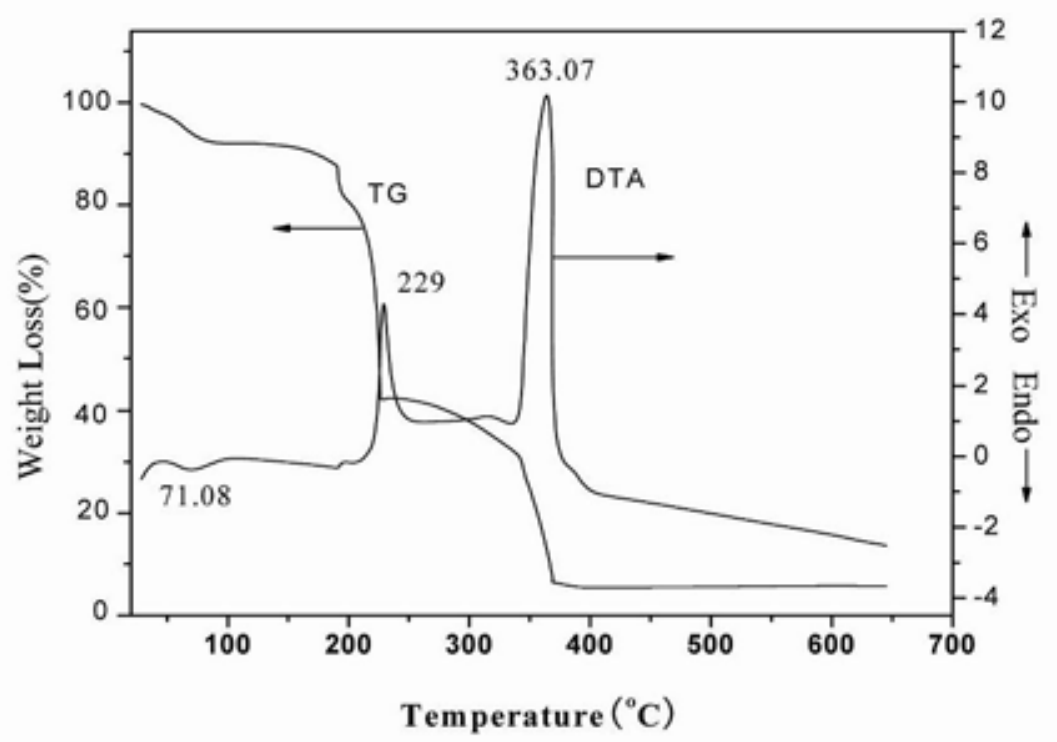

Figure 4. TG-DTA curves of PVA/[La( $\left.\left(\mathrm{NO}_{3}\right)_{3}+\mathrm{Mn}\left(\mathrm{CH}_{3} \mathrm{COO}\right)_{2}\right]$ composite fibers

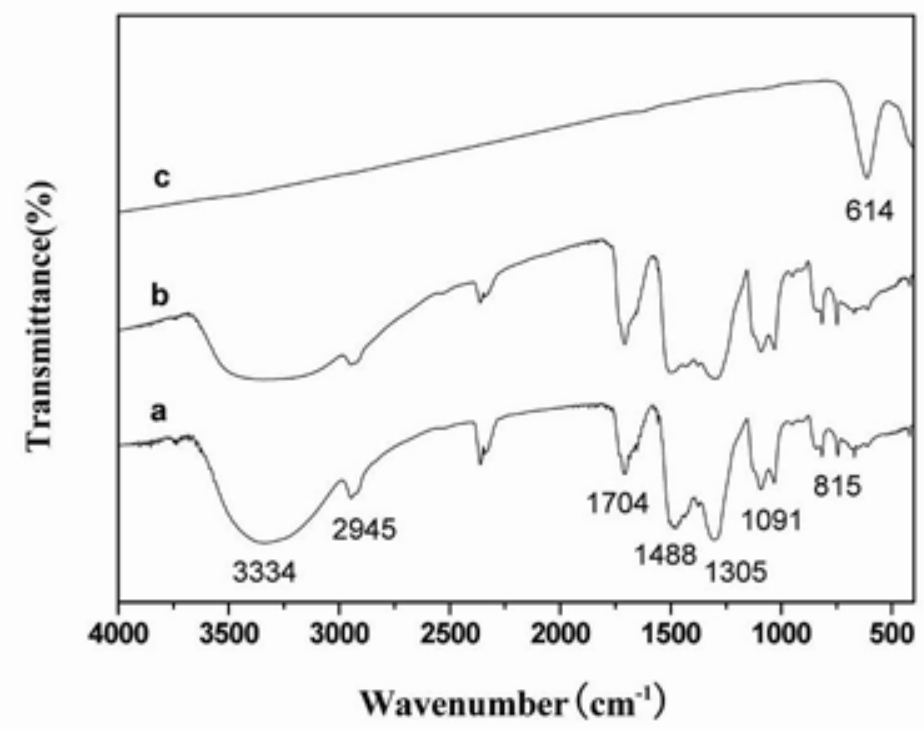

Figure 5. FTIR spectra of the samples
a. Pure PVA
b. $\mathrm{PVA} /\left[\mathrm{La}\left(\mathrm{NO}_{3}\right)_{3}+\mathrm{Mn}\left(\mathrm{CH}_{3} \mathrm{COO}\right)_{3}\right]$ composite fibers
c. $\mathrm{LaMnO}_{3}$ nanofibers 


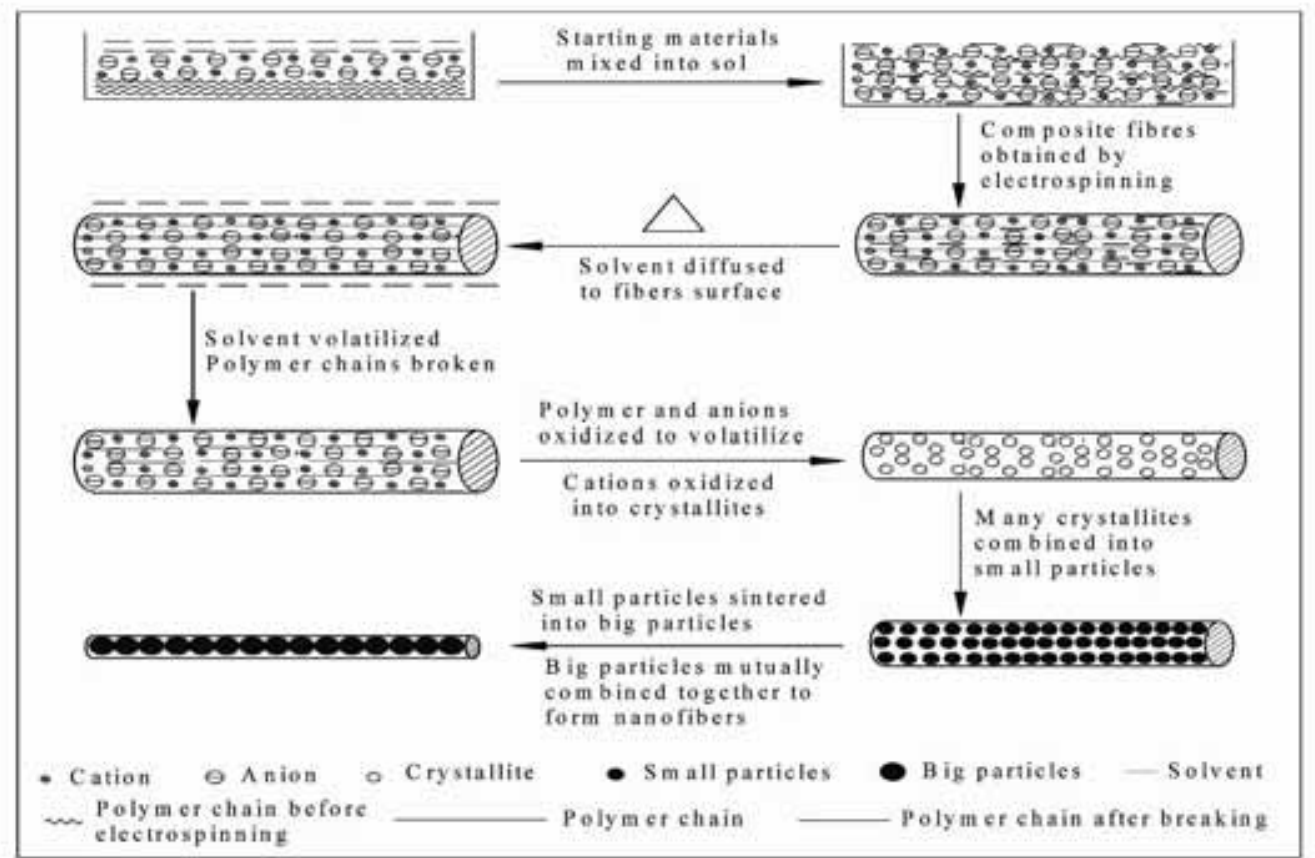

Figure 6. Illustrative diagram of possible formation mechanism of $\mathrm{LaMnO}_{3}$ nanofibers 


\title{
Artificial Neural Network Based Prediction of Maximum and Minimum Temperature in the Summer Monsoon Months over India
}

\author{
S. S. De (Corresponding author) \\ Centre of Advanced Study in Radio Physics and Electronics, University of Calcutta \\ 1, Girish Vidyaratna Lane, Kolkata 700 009, India \\ E-mail: de_syam_sundar@yahoo.co.in
}

A. Debnath

132/ S, Raja Rajendralal Mitra Road, Kolkata 700 085, India

\begin{abstract}
In the present paper, Artificial Neural Network has been adopted to forecast the maximum and minimum temperature monsoon months. The temperature of June, July, August has been predicted with the help of January to May temperature. In both the cases, maximum and minimum temperature is greatly predicted in the month of August. In the largest part of the cases, prediction error lies below $5 \%$.

In formulating the ANN-based predictive model, three-layer network has been constructed. The data published by Indian Institute of Tropical Meteorology (http://www.tropmet.res.in) are explored to develop the predictive model. The analysis is found to produce a forecast with small prediction error.
\end{abstract}

Keywords: Temperature prediction, Monsoon months, Artificial Neural Network, Prediction error

\section{Introduction}

Meteorological Parameter forecast is one of the most significant tasks all over the world (Holton, 1972; Gadgil et al., 2005). Weather condition is a very much complex system and nonlinear. Soft computing techniques have opened up new avenues to the complex system researches. It has three basic components, e.g., Artificial Neural Network (ANN), Fuzzy Logic, and Genetic Algorithm. Here ANN has been adapted for predicting the proposed purpose.

Artificial Neural Network (ANN), a component of Soft Computing, is highly suitable for the situations where the underlying processes exhibit chaotic features (Nagendra and Khare, 2006). The concept of ANN is originated from the attempt to develop a mathematical model capable of recognizing complex patterns on the same line as biological neuron work (Hornik, 1991; Maqsood et al., 2002). It is useful in the situations where underlying processes / relationships display chaotic properties. ANN does not require any prior knowledge of the system under consideration and are well suited to model dynamical systems on a real-time basis. It is, therefore, possible to set up systems so that they would adapt to the events which are observed and for this, it is useful in real time analyses, e.g., weather forecasting, different fields of predictions, etc.

The problem of generating predictions of meteorological events is more complex than that of generating predictions of planetary orbits. This is because the atmosphere is unstable and the systems responsible for the events are the culmination of the instabilities and involve nonlinear interaction between different spatial scales from kilometres to hundreds of kilometres (Holton, 1972; Gardner and Dorling, 1998). Sahai et al. (2000, 2003) showed that the variability in the Indian monsoon rainfall depends heavily upon the sea surface temperature anomaly over the Indian Ocean. As the extra tropical circulation anomalies display energy dispersion away from the region of anomalous tropical convection, 
they have been interpreted as a Rossby wave response to latent heat release is associated with the tropical convection. In regions of anomalous tropical heating, there is a dynamical response with anomalous large-scale ascent and upper tropospheric divergence, which acts as a Rossby wave source for extratropical waves. Conversely, in regions of reduced convection and anomalous cooling, the tropical response is one of anomalous descent and upper-tropospheric convergent inflow. Thus, it is obvious that surface temperature influences the monsoon rainfall to a large extent (Gardner and Dorling, 1998; Sahai et al., 2000, 2003). The present paper aims to look into the patterns of temperature over India during the monsoon months using Artificial Neural Network (ANN). The surface temperature is extremely related to the monsoon rainfall. So, the prediction of surface temperature in the monsoon months is essential for developing any predictive model for the summer monsoon rainfall that influences the agro-based Indian economy to a large extent (Gardner and Dorling, 1998; Hsieh and Tang, 1998). Here January to May maximum and minimum temperature is used as input parameter to predict the temperature of the monsoon months.

\section{Data used in the present paper}

In India, the months June, July and August are identified as the summer-monsoon months. The present study explores the data of these three months for the period 1901-2003. This paper develops ANN model step-by-step to predict the maximum and minimum temperature over India during summer-monsoon by exploring the data available at the website http://www.tropmet.res.in, published by Indian Institute of Tropical Meteorology.

\section{ANN based prediction of summer-monsoon temperature in India}

The model building process consists of four sequential steps:

(i) Selection of the input and output for the supervised Backpropagation learning

(ii) Selection of the activation function

(iii) Training and testing of the model

(iv) Testing the goodness of fit of the model

The Backpropagation Algorithm (BP) and the method of steepest descent, opened up application of Multilayered ANN for many problems of practical interest (Sahai et al., 2000, 2003; Kamarthi and Pittner, 1999; Sejnowski and Rosenberg, 1987; Widrow and Lehr, 1990). A multilayered ANN contains three basic type of layers: input layer, hidden layer and output layer. Basically, the Backpropagation learning involves propagation of error backwards from the output layers to the hidden layers in order to determine the update for the weights leading to the units in the hidden layer.

Kartalopoulos (1996) and Perez (2000) showed that the generalized delta rule is one of the most commonly used learning rules for feed forward Multilayered ANN. For a given input vector, the output vector is compared to the correct result. If the difference is zero, no learning takes place; otherwise, the weights are adjusted to reduce this difference. The learning is done by least-square-error minimization. The least-square-error (E) between the target output ( $\mathrm{T}$ ) and actual output (O) can be given by (Yegnanarayana, 2000)

$$
O_{i}^{l+1}(k)=f\left(\sum_{j=1}^{N_{t}} w_{j i}^{l} O_{j}^{l}(k)-\theta_{i}^{l+1}\right)
$$

where, $w_{j i}^{l}=$ weight between node $i$ of layer $l-1$ and node $j$ of layer $l$.

$O_{j}^{l}(k)=$ actual output (for pattern $k$ of the $j^{\text {th }}$ node in layer $l$ (after nonlinearity)).

$\theta_{i}{ }^{l+1}=$ bias of neuron $i$, that can be considered as weight of an input having value 1 . The bias is also called the 'free parameter'.

The total error $E$ for the network and for all patterns $\mathrm{k}$ is defined as the sum of squared differences between the actual network output and the target output at the output layer $L$. It is given by

$$
E=\sum_{k=1}^{k} E_{k}=\sum_{k=1}^{k}\left(\frac{1}{2} \sum_{i=1}^{N_{L}}\left[T_{i}(k)-O_{i}^{l}(k)\right]^{2}\right)
$$

The goal is to evaluate a set of weights in all layers of the network that minimizes $E$. The ultimate weight update equation for the $m^{\text {th }}$ step would be

$$
w_{j i}^{h}(m+1)=w_{j i}^{h}(m)+\Delta w_{j i}^{h}(m)
$$

The purpose of the present paper is to forecast the mean monthly surface temperature in the monsoon months (June, July and August) over India. An ANN model has been developed using the supervised training procedure to predict the 
said weather parameter over the study period. Since three months are the target months, the model is generated in a supervised manner with three desired outputs. From the whole dataset, the input and the desired output matrices are generated. The input data are separated into training and test set. The training set consists of $75 \%$ of the whole data and the remaining $25 \%$ constitutes the test set. The input matrix contains six columns that correspond to the average monthly temperature over the study period and pertains to the months of December, January, February, March, April and May. The ANN model generated here is a single-hidden-layer model, and the hidden layer contains 2 nodes. After running the model up to 500 epochs, the results are validated for the test set. The outcomes of the validation phase are presented in the next section.

\section{Results and discussion}

The learning rate $\eta$ is taken to be 0.9. A three-layered feed forward neural net is now designed. Three models are generated for both maximum and minimum temperature. There are three outputs in both the three models. The first model is for June maximum and minimum temperature prediction, second for July and third for August. In both models, the initial weights are chosen randomly from -0.5 to +0.5 . After training iterations, the network is tested for its performance on validation data set. The training process is stopped when the performance reached the maximum on validation data set. After training and testing, the prediction error values are computed for each model. The results are schematically presented in Figs. 1-3 and 5-7. In the month of August the PE is very low (Figs. 4 \& 8), and the actual and predicted graphs of temperature are significantly associated (Figs. 3 \& 7) in both maximum and minimum temperature. Also in the month of August, the percentage of prediction error is below 5\% in both maximum and minimum temperature (Figs. $9 \& 10$ ). The results show that the third model produces the lowest prediction error among the three possible predictive models.

\section{Conclusion}

In the present paper, Artificial Network with Backpropagation learning has been implemented to predict average summer monsoon temperature over India. Six predictors have been explored to generate the input matrix for the Neural Net. After 500 epochs, the Artificial Neural Network has been found to produce a forecast with small prediction error. The study, therefore, establishes that the third model is the best predictive model over the other two models.

\section{References}

Gadgil, S., Rajeevan, M., \& Nanjundiah, R. (2005). Monsoon prediction - Why yet another failure? Current Science, 88, 1389.

Gardner, M. W., \& Dorling, S. R. (1998). Artificial Neural Network (Multilayer Perception) - A review of applications in atmospheric sciences. Atmo. Environ., 32, 2627.

Holton, J. R. (1972). An Introduction to Dynamic Meteorology (Academic Press, San Diego, USA).

Hornik, K. (1991). Approximation capabilities of multiplayer feedforward networks. Neural Networks, $4,251$.

Hsieh, W. W., \& Tang, T. (1998). Applying Neural Network Models to prediction and data analysis in meteorology and oceanography. Bull. Am. Meteor. Soc., 79, 1855.

Kamarthi, S. V., \& Pittner, S. (1999). Accelerating neural network training using weight extrapolation. Neural Networks, 12,1285 .

Kartalopoulos, S. V. (1996). Understanding Neural Networks and Fuzzy Logic - Basic Concepts and Applications (Prentice Hall, New Delhi, INDIA).

Maqsood, I., Muhammad, R. K., \& Abraham, A. (2002). Neurocomputing based Canadian weather analysis: Computational Intelligence and Applications (Dynamic Publishers Inc., USA), 39.

Nagendra, S. M. S., \& Khare, M. (2006). Artificial neural network approach for modelling nitrogen dioxide dispersion from vehicular exhaust emissions. Ecological Modelling, 190, 99.

Perez, P., Trier, A., \& Reyes, J. (2000). Prediction of PM2.5 concentrations several hours in advance using neural networks in Santiago, Chile. Atmosph. Environ., 34, 1189.

Sahai, A. K., Soman, M. K., \& Satyam, V. (2000). All India summer monsoon rainfall prediction using an artificial neural network. Climate Dynamics, 16, 291.

Sahai, A. K., Patanik, D. R., Satyam, V., \& Grimm, A. M. (2003). Teleconnections in recent time and prediction of Indian summer, monsoon rainfall. Meteorology and Atmos. Phys., 84, 217.

Sejnowski, T. J., \& Rosenberg, C. R. (1987). Parallel networks that learn to pronounce English text. Complex Systems, 1, 145 .

Widrow, B., \& Lehr, M. A. (1990). 30 years of Adoptive Neural Networks; Perceptron, Madaline, and Back propagation. Proc. IEEE, 78, 1415. 
Yegnanarayana, B. (2000). Artificial Neural Network (Prentice Hall, New Delhi, INDIA).

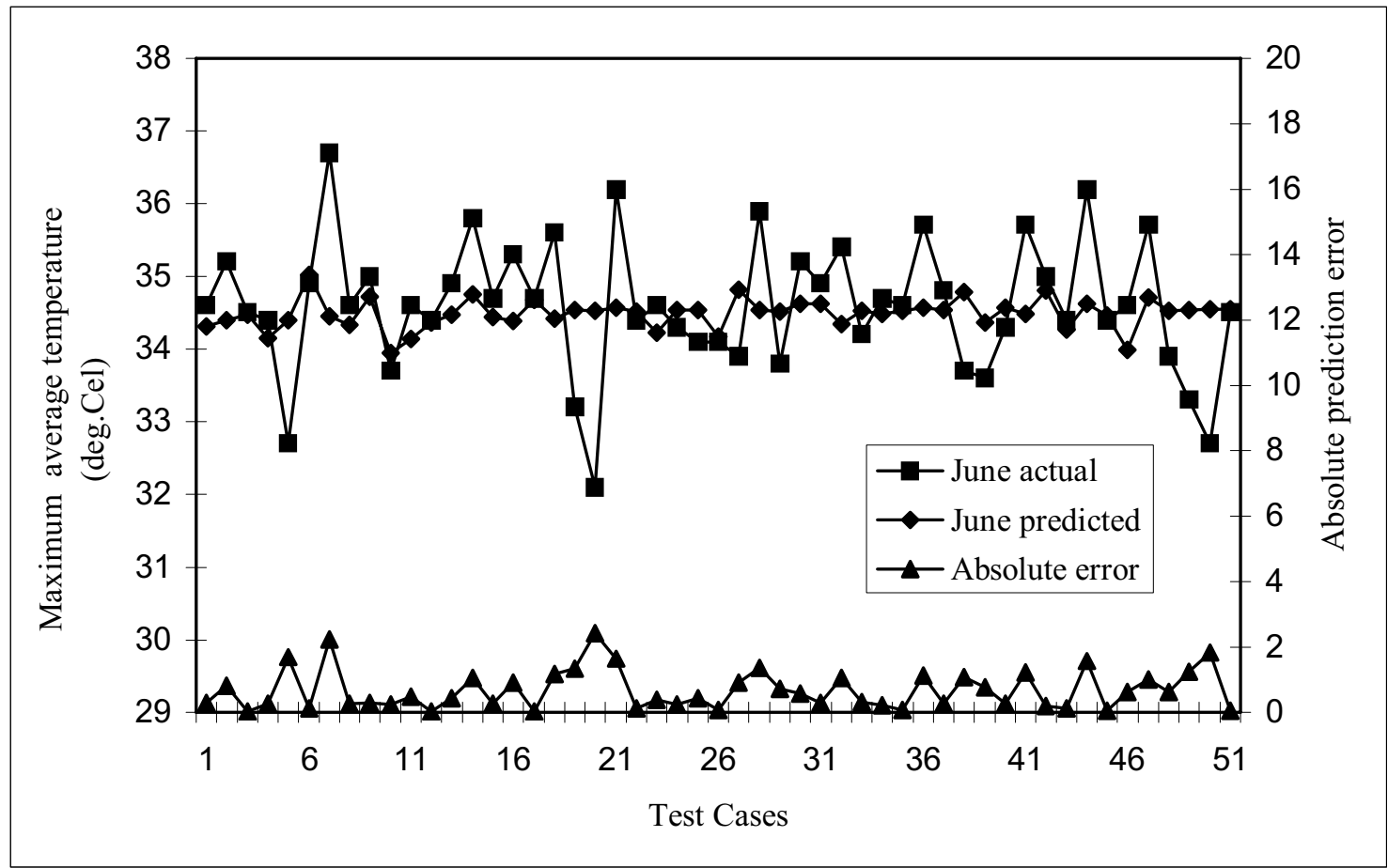

Figure 1. The figure shows that the actual and predicted maximum temperature and the absolute prediction error graph for the month of June.

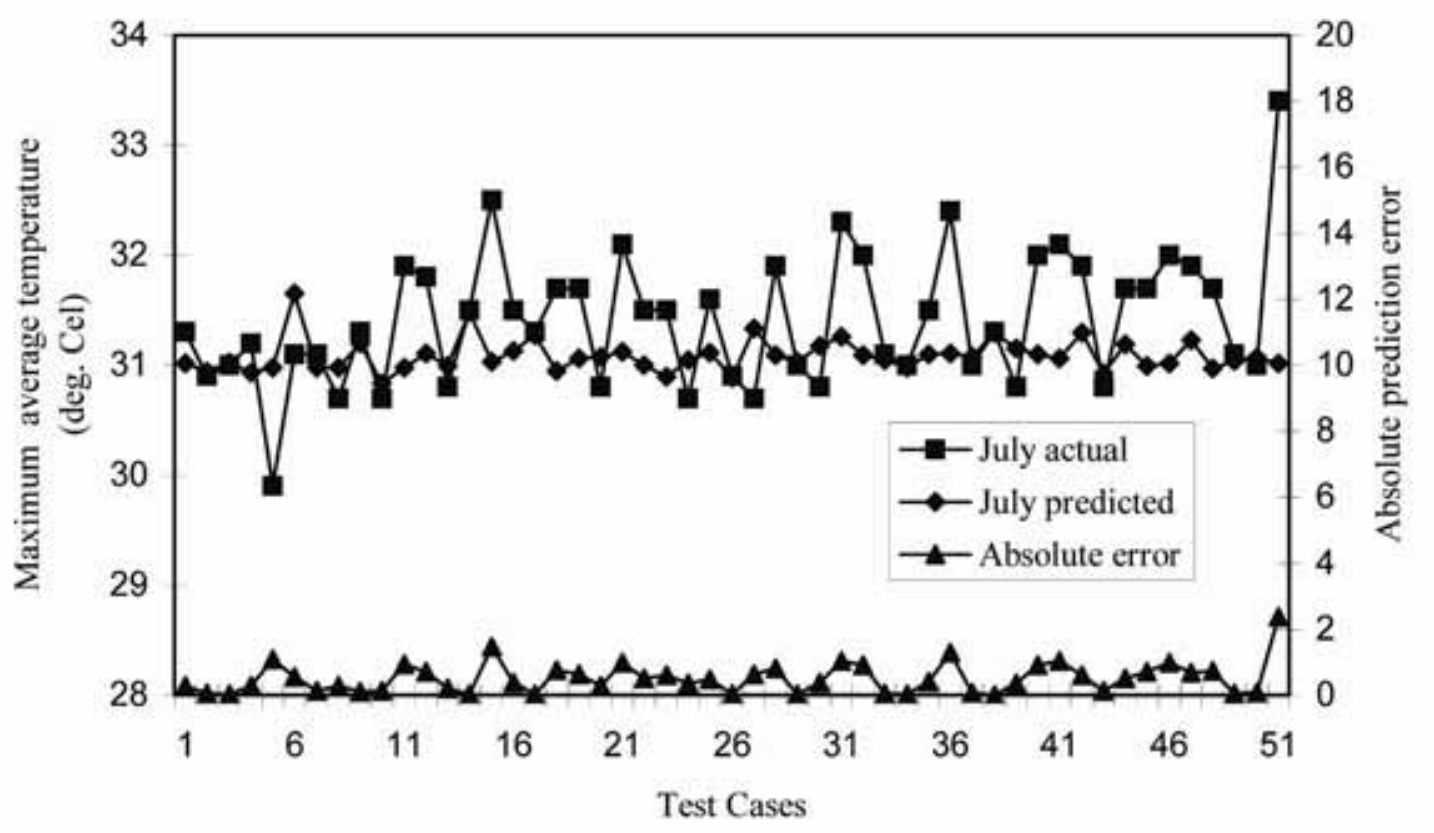

Figure 2. It depicts the actual and predicted maximum temperature and the absolute prediction error graph for the month of July. 


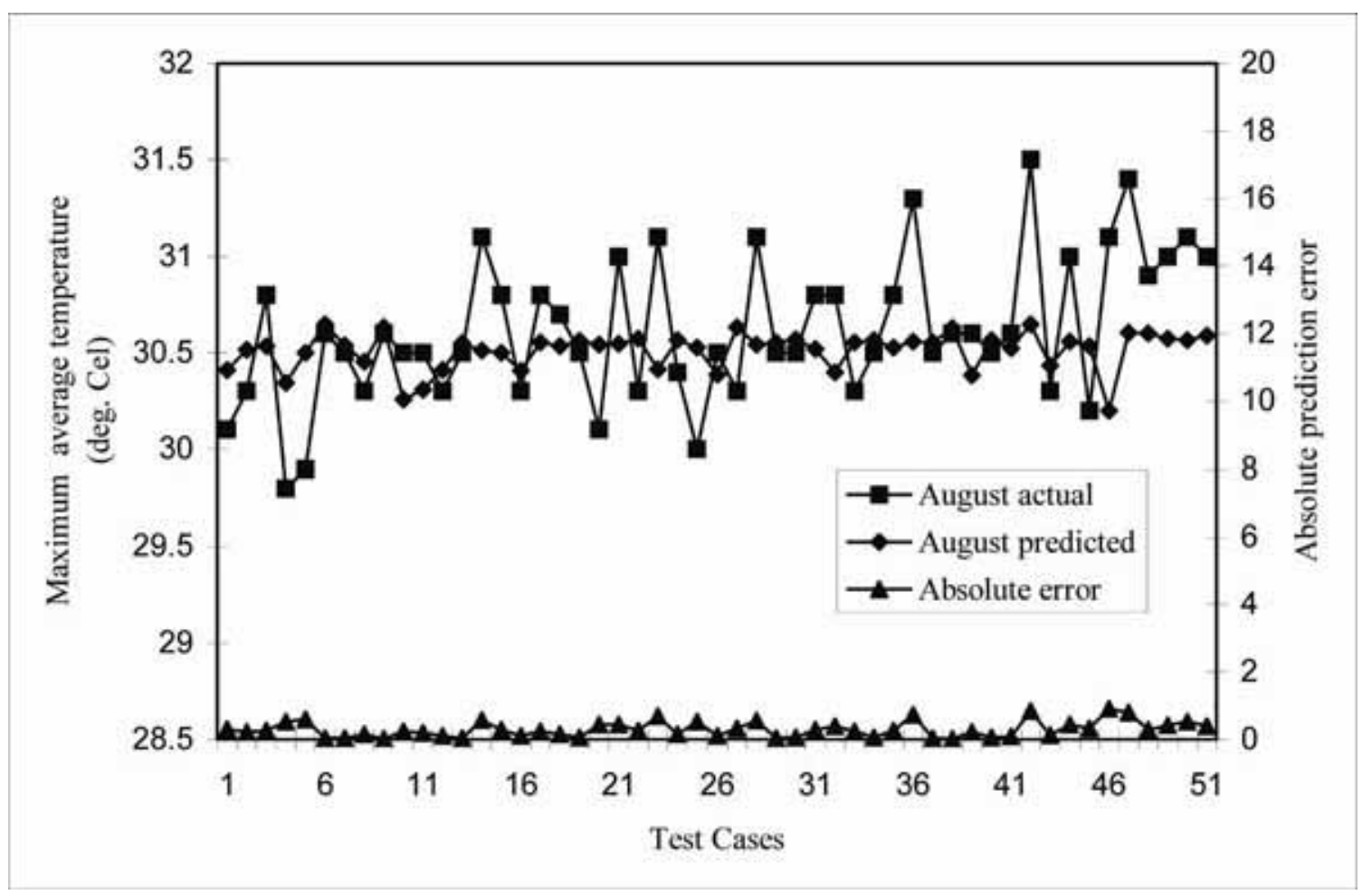

Figure 3. The actual and predicted maximum temperature and the absolute prediction error graph for the month of August are shown.

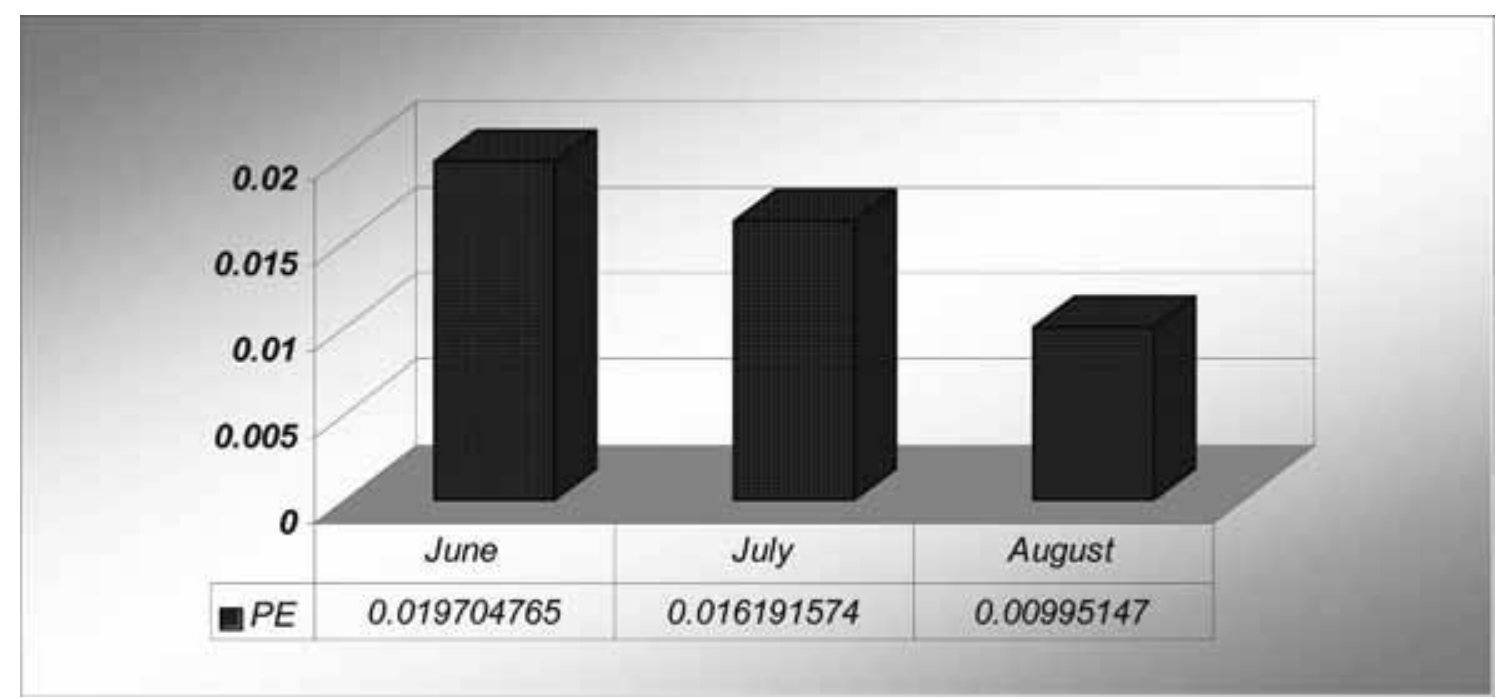

Figure 4. Relative comparison of the prediction errors (PE) produced by the three output models in predicting maximum temperature over India. The computation is made over the test cases. 


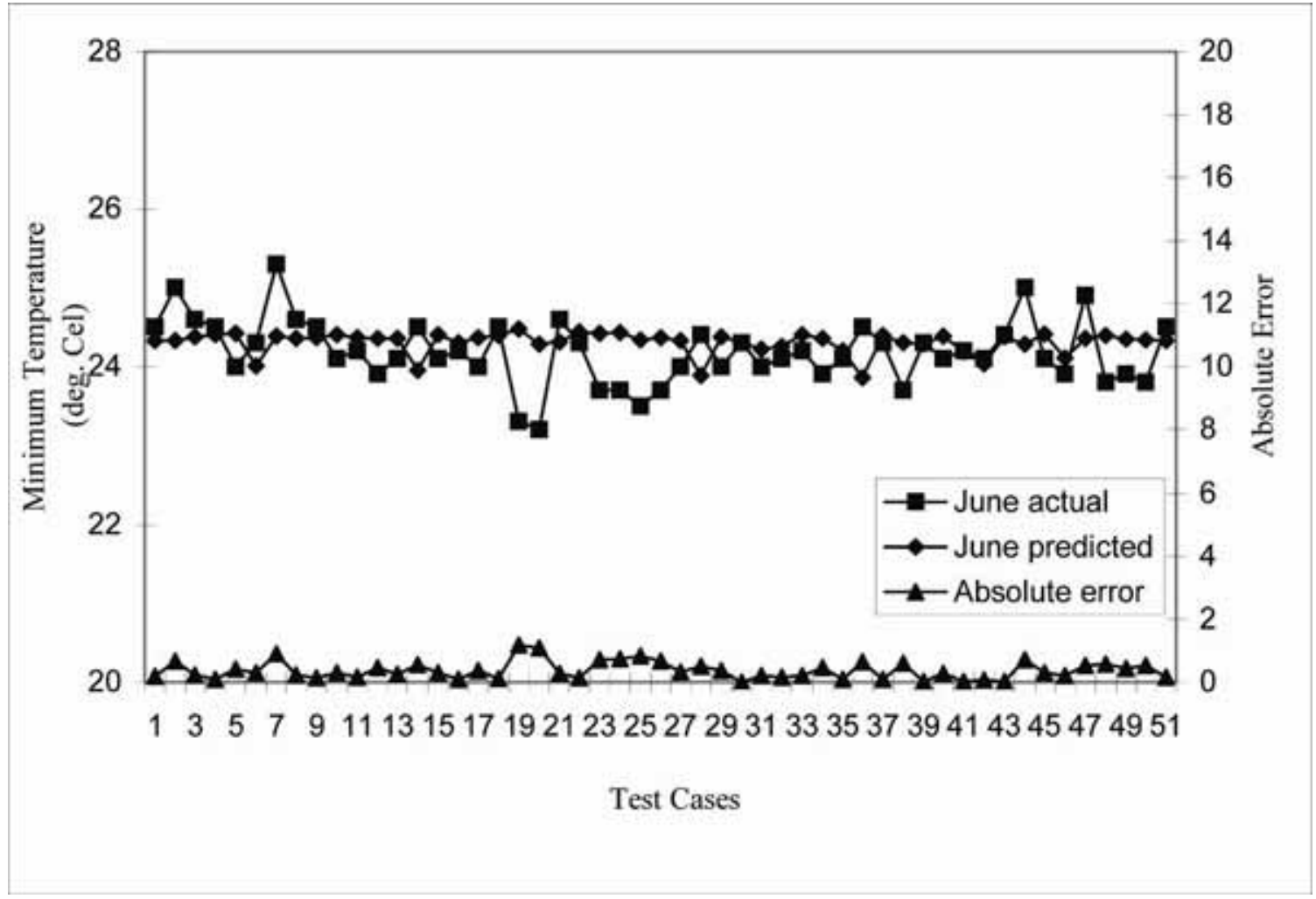

Figure 5. The figure represents the actual and predicted minimum temperature and the absolute prediction error graph for the month of June.

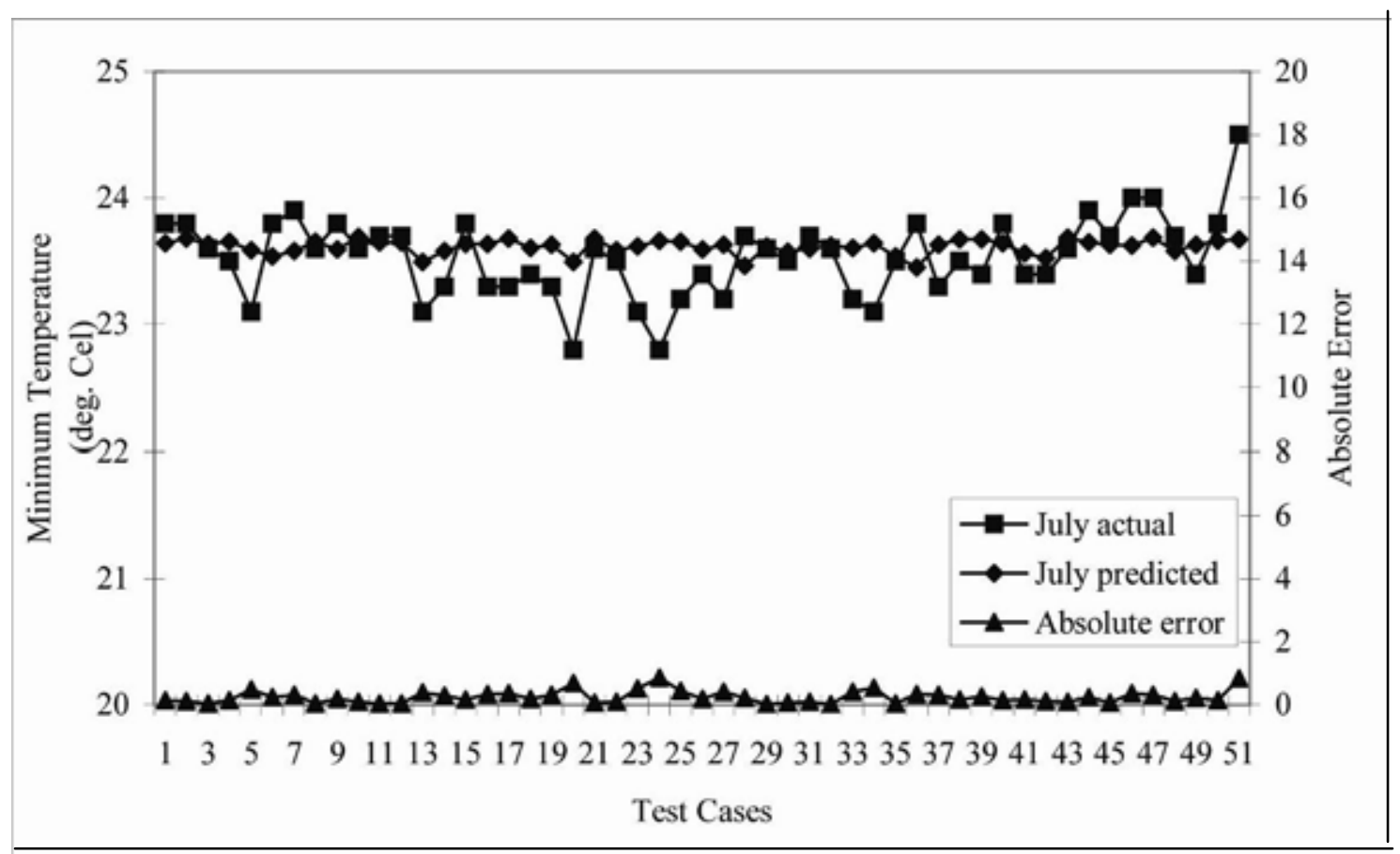

Figure 6. The actual and predicted minimum temperature and the absolute prediction error graph for the month of July. 


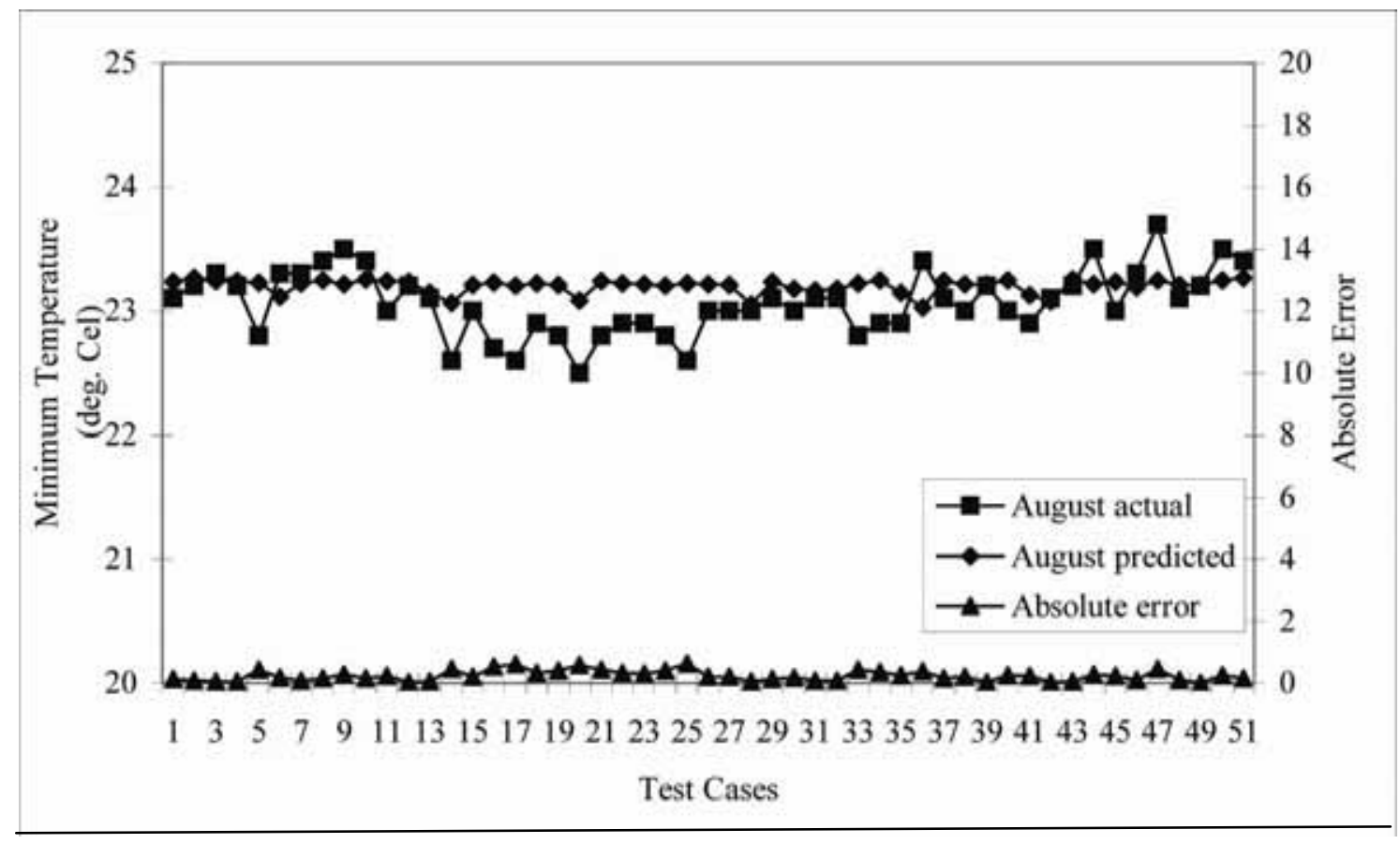

Figure 7. The figure depicts the actual and predicted minimum temperature and the absolute prediction error graph for the month of August.

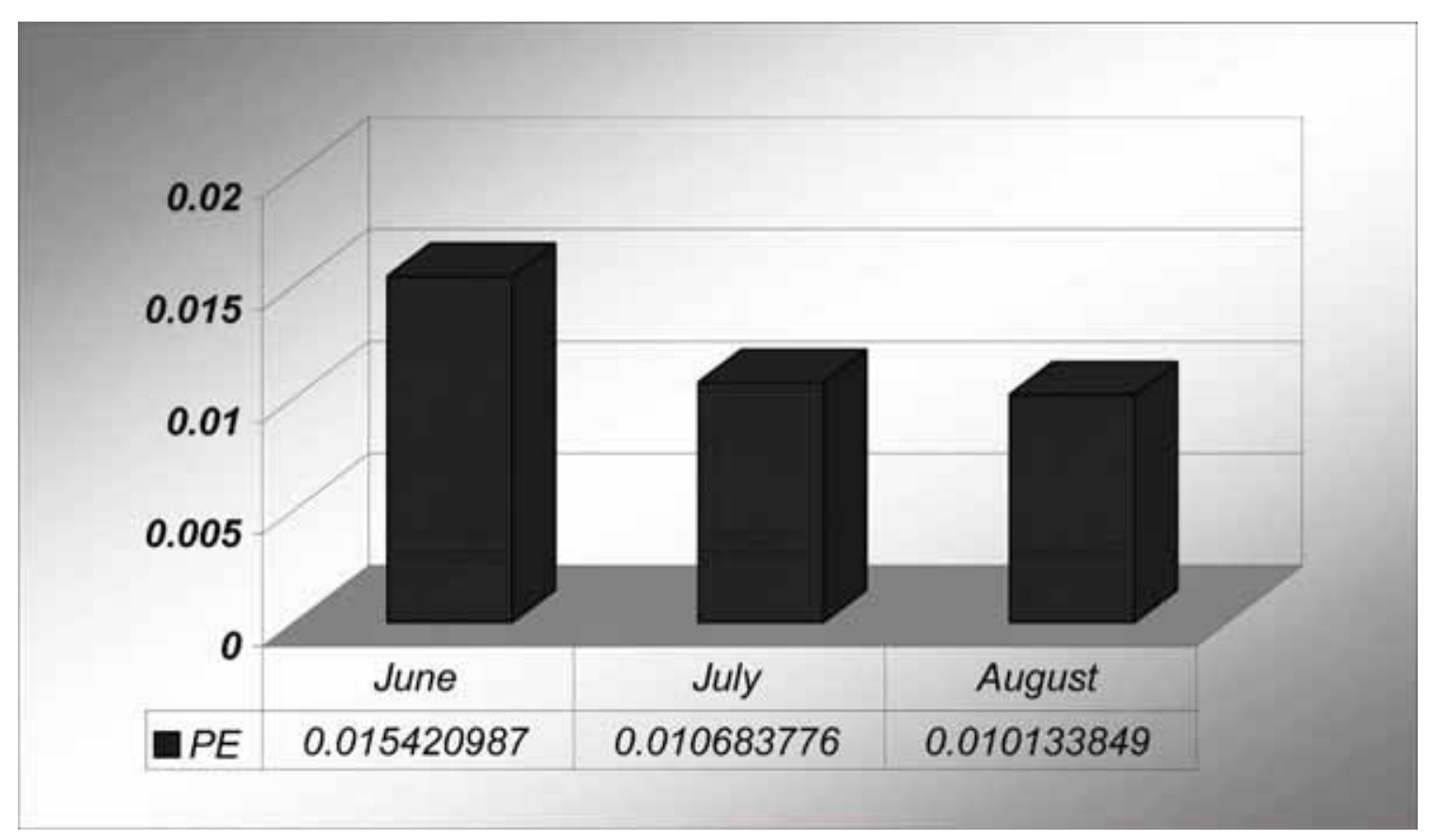

Figure 8. Relative comparison of the prediction errors (PE) produced by the three output models in predicting minimum temperature over India. The computation is made over the test cases. 


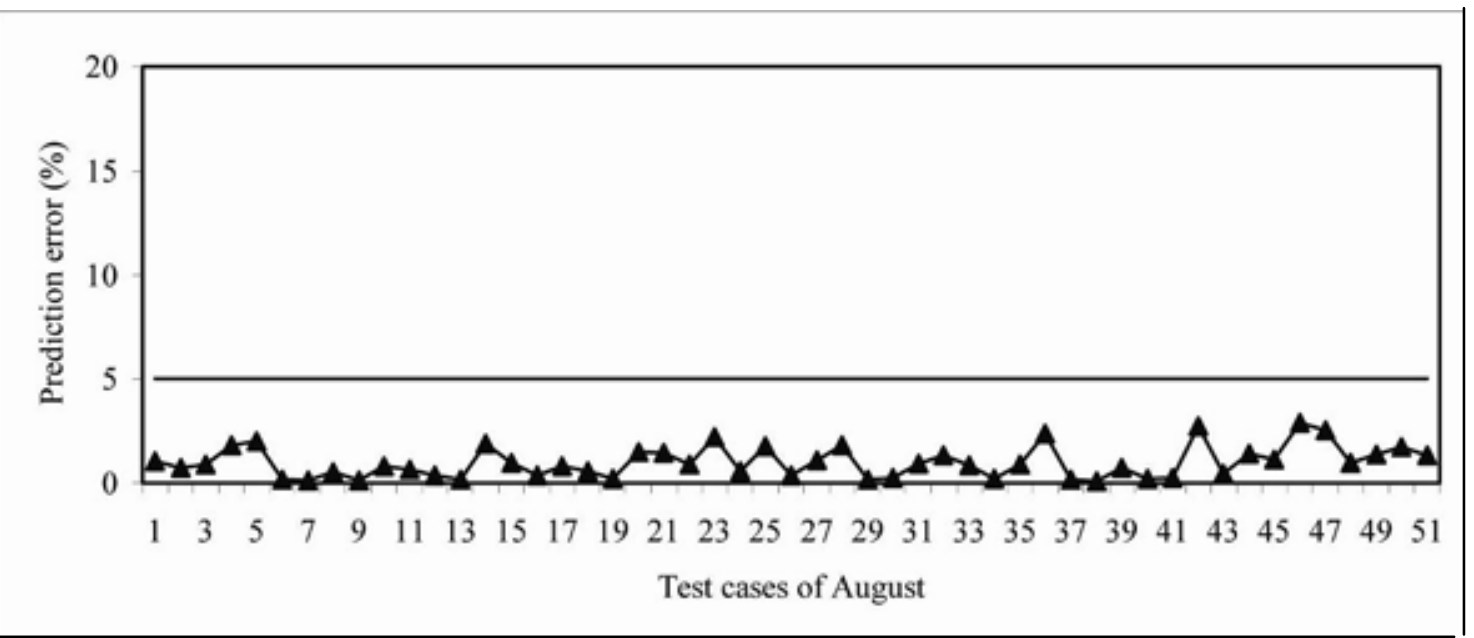

Figure 9. This figure shows the percentage of prediction error is below 5\% in the month of August maximum temperature.

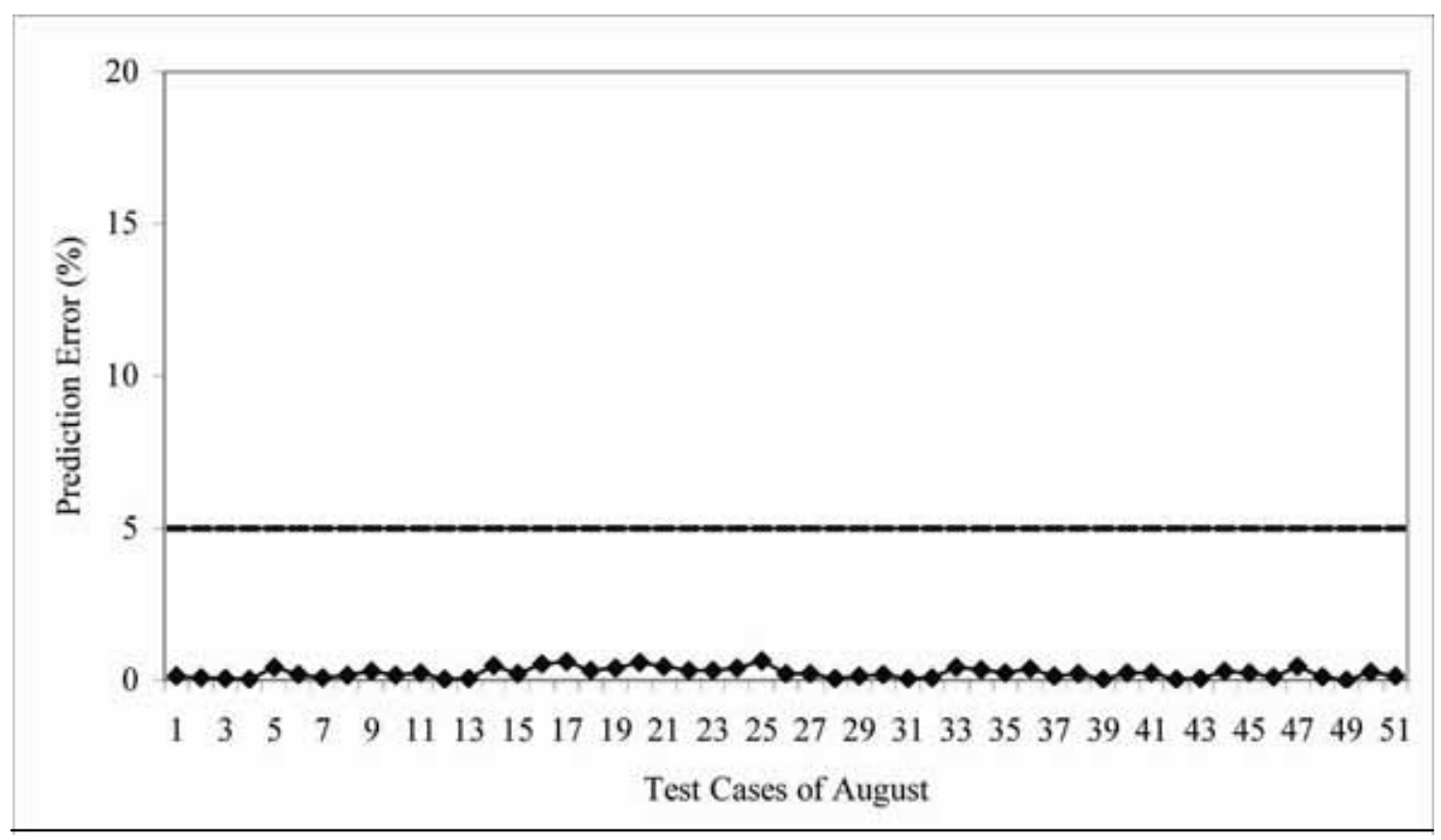

Figure 10. The percentage of prediction error is below 5\% in the month of August minimum temperature. 


\title{
Assessment of Radiation Dose Rates in the High Terrestrial Gamma Radiation Area of Selama District, Perak, Malaysia
}

\author{
Ahmad Termizi Ramli \\ Department of Physics, Faculty of Science \\ Universiti Teknologi Malaysia, Johor 81310, Malaysia \\ Tel: 60-1-9725-8470 E-mail:a_hma_d2003@yahoo.co.uk \\ Nursama Heru Apriantoro (Corresponding author) \\ Department of Physics, Faculty of Science \\ Universiti Teknologi Malaysia, Johor 81310, Malaysia \\ Tel: 60-1-6704-5707 E-mail: nursama_91@yahoo.co.id \\ Husin Wagiran \\ Department of Physics, Faculty of Science \\ Universiti Teknologi Malaysia, Johor 81310, Malaysia
}

This project is funded by The Atomic Energy Licensing Board of Malaysia (Vot no. 68876). This project also used various facilities provided by Universiti Teknologi Malaysia and the Malaysian Nuclear Agency.

\begin{abstract}
Survey of terrestrial gamma radiation (TGR) dose rates have been conducted in Selama district, Perak, Malaysia. The mean value of TGR dose rate outdoor in Selama is $(273 \pm 133) \mathrm{nGy} \mathrm{h}^{-1}$. For the habited land, the mean TGR dose rates outdoor and indoor are $(205 \pm 59) \mathrm{nGy} \mathrm{h}^{-1}$ and $(212 \pm 64) \mathrm{nGy} \mathrm{h}^{-1}$ respectively. They contribute fatal cancer risk of $6.4 \mathrm{x}$ $10^{-5}$ per year to an individual in the area. The activity concentrations of ${ }^{238} \mathrm{U},{ }^{232} \mathrm{Th}$, and ${ }^{40} \mathrm{~K}$ in the soil samples were analysed using a high resolution co-axial HPGe gamma ray spectrometer system. The values obtained range from $57 \mathrm{~Bq}$ $\mathrm{kg}^{-1}$ to $364 \mathrm{~Bq} \mathrm{~kg}^{-1}$ with the mean value of $(178 \pm 95) \mathrm{Bq} \mathrm{kg}^{-1}$ for ${ }^{238} \mathrm{U} ; 207 \mathrm{~Bq} \mathrm{~kg}^{-1}$ to $625 \mathrm{~Bq} \mathrm{~kg}^{-1}$ with the mean value of $(353 \pm 143) \mathrm{Bq} \mathrm{kg}^{-1}$ for ${ }^{232} \mathrm{Th}$, and $26 \mathrm{~Bq} \mathrm{~kg}^{-1}$ to $601 \mathrm{~Bq} \mathrm{~kg}^{-1}$ with the mean values of $(273 \pm 133) \mathrm{Bq} \mathrm{kg}^{-1}$ for ${ }^{40} \mathrm{~K}$.
\end{abstract}

Keywords: TGR dose rate, ${ }^{238} \mathrm{U},{ }^{232} \mathrm{Th},{ }^{40} \mathrm{~K}$, radiation risk

\section{Introduction}

Naturally occurring radioactive materials (NORM) existing in soil could pose potential health physics risk (Wilson, 1993), especially if assisted by natural processes such as weathering deposition and wind erosion (Elles et al., 1997). The radiological impact of NORM to the human populations is due to terrestrial gamma radiation, inhalation of air contaminated with radon gas and other radionuclide particulate, consumption of the agricultural products, water and their products (Kryshev et al., 1996). The terrestrial gamma radiation dose rate is influenced by soil types, geological features and geographical condition (Florou \& Kritidis., 1992; Ramli, 1997). Human beings are exposed outdoors to the natural terrestrial radiation that originates predominantly from the upper $30 \mathrm{~cm}$ of the soil (Narayana et al., 1994). The high terrestrial gamma radiation dose rates are mostly found in areas with soils originating from granitic rocks (Kogan et al., 1969). The concentration of uranium and thorium in the soil in the area is also high. The world average values for terrestrial gamma radiation dose rates outdoor for the world and Malaysia are $57 \mathrm{nGy} \mathrm{h}^{-1}$ and $75 \mathrm{nGy} \mathrm{h}^{-1}$ respectively (UNSCEAR, 2000). The highest concentrations of radioactive minerals in soil are found in Brazil (Radhakrishna et al., 1993). 
Selama has an area of $746 \mathrm{~km}^{2}$ and population of about 36405 (Selama District Council, 2009). It is one of 10 districts of Perak state. Its capital is also called Selama. It is located between the latitudes $5^{\circ} 05^{\prime}$ to $5^{\circ} 26^{\prime}$ North, and the longitudes $100^{\circ} 37^{\prime}$ to $100^{\circ} 57^{\prime}$ East. It is bordered on the north by Kedah State, on the east by Hulu Perak district, on the south by Larut Matang district and to the west by Kerian district. $66 \%$ of the district is covered by forest (hills, mountains) and the main land use is for agriculture. The climate is tropical with temperature between $28^{\circ} \mathrm{C}$ to $32^{\circ} \mathrm{C}$. Selama can be divided into four major geological groups of different geological ages (Director General of Geological Survey, 1985) as shown in Figure 1, that are Quaternary (mainly recent alluvium), Triassic-Jurassic (sediments rocks with conglomerates), Silurian (sediments rocks with associated lava and tuff), and acid and undifferentiated (granitic rocks). Granite based geological features is most abundant in Selama, it cover about $75 \%$ of the area, and followed by Silurian (12\%), Triassic (9\%), and Quaternary (4\%). Selama is overlaid by five types of soil as classified by FAO /UNESCO (Director General of Agriculture Peninsular Malaysia, 1973). The soil types present according to FAO/UNESCO classification are Haplic Acrisol (locally are refered as Holyrood, Harimau), Dystric Fluvisol-Haplic Arenosol-Dystric Cabisol (Aluvium Tempatan- Telemong-Akob), Haplic Acrisol-Ferric Acrisol (Rengam-Bukit Temiang), Haplic Acrisol-Haplic Ferralsol (Serdang-Munchong) and steep land (miscellaneous soils). Soil types in Selama are shown in Figure 2.

The results obtained for this area can be used to determine the natural radiological background and can be used as one of the baseline data in the assessments of the environmental impacts of amang deposits and nuclear accidents.

\section{Materials and Methods}

\subsection{Terrestrial gamma radiation (TGR) dose rates}

The terrestrial gamma radiation dose rate was measured 1 meter above the ground by using two identical gamma-ray detectors and the average value was recorded. The detector used was model 19, micro roentgen ( $\mu \mathrm{R}$ ) meter, manufactured by Ludlum, USA. It uses $1^{\prime \prime} \times 1 "\left(2.54 \times 2.54 \mathrm{~cm}^{2}\right)$ sodium iodide $(\mathrm{NaI})$ crystal doped with thallium $(\mathrm{Tl})$. The instrument was calibrated by Malaysia Nuclear Agency, it is a Secondary Standard Dosimetry Laboratory (SSDL). The terrestrial gamma radiation (TGR) dose rates were measured from locations with different soil types and geological backgrounds randomly, the results of TGR dose rate measurements are presented as an isodose contour map. The isodose map was drawn by using software surfer and modified according to soil type, geological background, and topological information. It is shown in Figure 3.

\subsection{Concentration of ${ }^{238} U,{ }^{232}$ Th and ${ }^{40} \mathrm{~K}$ in soil samples}

Soil samples were collected from locations with different terrestrial gamma radiation dose rates, soil types and geological features. All samples were dried by placing them in an oven at $110^{\circ} \mathrm{C}$ for 24 hours then crushed and ground to fine powder by using a grinding mill (Herzog-D4500/type HSM 100, No. 62B/529, German-made). The samples were sieved by passing through a $200 \mathrm{~mm}$ test sieve/150 microns to be homogenized in size. Samples were sealed in plastic containers and left for at least one month, before gamma spectrometric analysis, to ensure secular equilibrium (Mollah et al.,1987; Ibrahim et al., 1993). The specific activity in soil (in $\mathrm{Bq} \mathrm{kg}^{-1}$ ) due to radionuclide $i$ and for a peak at energy $E$, is given by Equation (1) (IAEA 1989),

$$
A_{E i}=\frac{N_{E i}}{\varepsilon_{E i} t \gamma_{E i} M}
$$

where $N_{E i}$ is the net peak area at energy $E_{i}$ of radionuclide i, $\varepsilon_{E \mathrm{i}}$ is the detection efficiency at energy $E, t$ is the counting time, $\gamma_{E i}$ is the number of gammas per nuclear transformation of the radionuclide at energy $E$, and $M$ is the mass in $\mathrm{kg}$ of the measured sample. The minimum detectable activity for counting time $10,800 \mathrm{~s}$ were estimated to be $4 \mathrm{~Bq} \mathrm{~kg}^{-1}, 9 \mathrm{~Bq}$ $\mathrm{kg}^{-1}$ and $19 \mathrm{~Bq} \mathrm{~kg}{ }^{-1}$ for ${ }^{238} \mathrm{U},{ }^{232} \mathrm{Th}$ and ${ }^{40} \mathrm{~K}$ respectively.

Gamma ray spectrometric analysis of radionuclides were carried out by using a coaxial high purity germanium (HPGe) detector. The concentration of the radionuclide considered was determined from the peaks at $239 \mathrm{keV}\left({ }^{212} \mathrm{~Pb}\right), 583 \mathrm{keV}$ $\left({ }^{208} \mathrm{Tl}\right)$ and $911 \mathrm{keV}\left({ }^{228} \mathrm{Ac}\right)$ for ${ }^{232} \mathrm{Th}$, the peaks at $352 \mathrm{keV}\left({ }^{214} \mathrm{~Pb}\right)$ and $609 \mathrm{keV}\left({ }^{214} \mathrm{Bi}\right)$ for the ${ }^{238} \mathrm{U}$ and the peak at 1 $460 \mathrm{keV}$ for ${ }^{40} \mathrm{~K}$. The standard samples IAEA SL-14 and IAEA SL- 2 were used as reference materials and were mixed with $\mathrm{SiO}_{2}$ in Marinelli beakers. For calibration, the IAEA reference materials ${ }^{133} \mathrm{Ba},{ }^{22} \mathrm{Na},{ }^{137} \mathrm{Cs}$, ${ }^{60} \mathrm{Co}$ and ${ }^{152} \mathrm{Eu}$, were used. To determine the detection efficiency of gamma energies from $200 \mathrm{keV}$ to $2000 \mathrm{keV}$, Equation (2) was used,

$$
\operatorname{Ln} \varepsilon=1.09-0.79 \operatorname{Ln} E
$$

where $\varepsilon$ is the detection efficiency and $E$ is the gamma ray energy in $\mathrm{keV}$. The minimum detectable activity for counting time of $10800 \mathrm{~s}$ were estimated to be $4 \mathrm{~Bq} \mathrm{~kg}^{-1}, 9 \mathrm{~Bq} \mathrm{~kg}^{-1}$ and $19 \mathrm{~Bq} \mathrm{~kg}^{-1}$ for ${ }^{238} \mathrm{U},{ }^{232} \mathrm{Th}^{2}$ and ${ }^{40} \mathrm{~K}_{\text {respectively. }}$

\section{Results and discussion}

The mean value of terrestrial gamma radiation dose rates in Selama and other areas in Malaysia and the world are 
presented in Table 1. The value of terrestrial gamma radiation dose rates measured from the 140 outdoor locations, ranged from $64 \mathrm{nGy} \mathrm{h}^{-1}$ to $715 \mathrm{nGy} \mathrm{h}^{-1}$, with the mean value of $(273 \pm 133) \mathrm{nGy} \mathrm{h} \mathrm{h}^{-1}$. This value is higher than the world and the Malaysian average as reported by UNSCEAR 2000. The mean TGR dose rate value in this area is higher than other areas of Perak, except for the area of Kg. Sg. Durian (Ramli et al., 2009, in communication). For the habited land in Selama, the mean TGR outdoor dose rate value is $(205 \pm 59) \mathrm{nGy} \mathrm{h}^{-1}$. For the forested areas, the mean TGR dose rate outdoor is $(351 \pm 152) \mathrm{nGy} \mathrm{h}^{-1}$.

TGR dose rates indoor for concrete houses in the high TGR dose rate areas were calculated using Equation (3) (Ramli, et al, 2009, in communication).

$$
D_{\text {in }}=0.33 D_{\text {out }}+144
$$

where $D_{\text {in }}$ and $D_{\text {out }}$ are TGR dose rate indoor and outdoor respectively. The indoor mean value for Selama district is estimated to be $(212 \pm 64) n G y h^{-1}$ for concrete houses.

The mean values of terrestrial gamma radiation dose rates for the five soil types and four geological backgrounds found in Selama are presented in Table 2. The steep lands and Haplic Acrisol-Ferric Acrisol (Rengam, Bukit Temiang) appear to have the higher mean TGR dose rates values. The steep lands mean value is $(379 \pm 143) \mathrm{nGy} \mathrm{h}^{-1}$ with values ranging from $234 \mathrm{nGy} \mathrm{h}^{-1}$ to $696 \mathrm{nGy} \mathrm{h}^{-1}$, and the Haplic Acrisol-Ferric Acrisol mean value is $(306 \pm 161) \mathrm{nGy} \mathrm{h}^{-1}$ with values ranging from $64 \mathrm{nGy} \mathrm{h}^{-1}$ to $715 \mathrm{nGy} \mathrm{h}^{-1}$. These soils were formed with granite as parent material. The highest mean TGR dose rate value based on geological background was found in acid undifferentiated areas. The mean value is (337 $\pm 16) \mathrm{nGy} \mathrm{h}{ }^{-1}$ and ranged from $165 \mathrm{nGy} \mathrm{h}^{-1}$ to $715 \mathrm{nGy} \mathrm{h}^{-1}$. The area are igneous acidic and extensively intruded by granitic rocks. The granite is relatively rich in radioactive minerals (UNSCEAR, 2000).

The mean values of ${ }^{238} \mathrm{U},{ }^{232} \mathrm{Th}$ and ${ }^{40} \mathrm{~K}$ activity concentration in different soil samples are presented in Table 3 . The activity concentration of the 15 soil samples for ${ }^{238} \mathrm{U}$ ranged from $57 \mathrm{~Bq} \mathrm{~kg}^{-1}$ to $364 \mathrm{~Bq} \mathrm{~kg}^{-1}$, the mean value is $(178 \pm$ 95) $\mathrm{Bq} \mathrm{kg}{ }^{-1} ; 207 \mathrm{~Bq} \mathrm{~kg}^{-1}$ to $625 \mathrm{~Bq} \mathrm{~kg}^{-1}$ for ${ }^{232} \mathrm{Th}$, the mean value is $(353 \pm 143) \mathrm{Bq} \mathrm{kg}^{-1}$; and $36 \mathrm{~Bq} \mathrm{~kg}^{-1}$ to $601 \mathrm{~Bq} \mathrm{~kg}^{-1}$ for ${ }^{40} \mathrm{~K}$, the mean value is $(296 \pm 184) \mathrm{Bq} \mathrm{kg}^{-1}$. The average activity concentrations of ${ }^{238} \mathrm{U}$ and ${ }^{232} \mathrm{Th}$ in the soils of these areas are higher than the world average as reported in UNSCEAR 2000, but the activity concentration for ${ }^{40} \mathrm{~K}$ is lower than world average value of $400 \mathrm{~Bq} \mathrm{~kg}^{-1}$. The most abundant primordial radionuclide is thorium $\left({ }^{232} \mathrm{Th}\right)$. It is about $43 \%$ of the total $\left({ }^{232} \mathrm{U}+{ }^{232} \mathrm{Th}+{ }^{40} \mathrm{~K}\right) .{ }^{238} \mathrm{U}$ is $21 \%$ and ${ }^{40} \mathrm{~K}$ is $36 \%$. The correlation between gamma dose rate in situ with the activity concentration of ${ }^{232} \mathrm{U},{ }^{232} \mathrm{Th}$ and ${ }^{40} \mathrm{~K}$ in soil samples are given in Figure. 4.

Using the conversion coefficient factor for the absorbed dose in air to effective dose of $0.7 \mathrm{~Sv} \mathrm{~Gy}^{-1}$, as recommended by UNSCEAR 2000 and the outdoor occupancy factor of 26\% (Ramli et al., 2009, in communication), the annual effective dose $\left(H_{E}\right)$ is calculated by using Equation (4),

$$
H_{E}\left(\mathrm{mSv} \mathrm{y}^{-1}\right)=\text { Dose rate }\left(\mathrm{nGy} \mathrm{h}^{-1}\right) \text { x } 24 \text { hours } \mathrm{x} 365 \text { days } \mathrm{x} O F \mathrm{x} 0.7 \mathrm{x} 10-6
$$

where $H_{E}$ is annual effective dose in $\mathrm{mSv}$, and $O F$ is occupancy factor that is 0.74 and 0.26 for indoor and outdoor respectively.

The average annual effective dose equivalent received in habited areas of Selama District are $0.96 \mathrm{mSv}$ and $0.33 \mathrm{mSv}$ for indoor (concrete houses) and outdoor respectively. The world annual effective dose equivalent average value are $0.41 \mathrm{mSv}$ indoor and $0.07 \mathrm{mSv}$ outdoor (UNSCEAR, 2000). The annual effective dose rate outdoor will be higher for steep lands, and areas with acid undifferentiated geological background; its mean value is $1.17 \mathrm{mSv}$. But these areas are not populated being mostly pristine jungle.

To estimate the fatal cancer risk to an individual $\hat{R}_{i}$, Equation (5) is used (Alvarez, 1997):

$$
\hat{R}_{i}=a \sum H_{E} \text {, or } \hat{R}_{i}=a\left(H_{E_{\text {in }}}+H_{\text {Eout }}\right)
$$

where $a$ is the risk factor, that is 0.05 death per sievert (ICRP 1990). $H_{E i n}$ and $H_{E o u t}$ are effective dose rates indoor and outdoor respectively. The value of fatal cancer risk is about 6.4. $\times 10^{-5}$ per year to each individual living in habited land of Selama.

\section{Conclusion}

The mean terrestrial gamma radiation dose rate in Selama is about 3 times higher than the Malaysian average and about 5 times higher than the world average value. Eventhough the mean TGR dose rate is relatively high but the higher dose rate areas are mostly in unhabited areas, therefore the annual effective dose rate is less than the expected value based on the mean value for the Selama district. Nevertheless the average total fatal cancer risk of $6.4 \times 10^{-5}$ per year to each individual in the Selama district is too small to cause alarm.

The higher values of terrestrial gamma radiation dose rate are associated with soils of granitic origin, which are Haplic Acrisol-Ferric Acrisol and steep land. These soils were formed with granite as parent material. The highest TGR dose 
rate values based on geological background are found in acid undifferentiated (acid intrusive) areas, they are granitic. Granite is relatively rich in radioactive minerals. The most abundant radionuclide in the study areas is thorium- 232 .

\section{References}

Abdul Rahman, A.T. \& Ramli, A.T. (2007). Radioactivity levels of ${ }^{238} \mathrm{U}$ and ${ }^{232} \mathrm{Th}$, the $\alpha$ and $\beta$ activities and associated dose rates from surface soil in Ulu Tiram, Malaysia. Journal of Radio analytical and Nuclear Chemistry, 273 (3), 653-657.

Alvarez, JL. (1997). Ionizing Radiation Risk Assessment, in: Molak, V (eds.), Fundamental of Risk Analysis and Risk Management. CRC Press. pp. 163-175.

Director General of Geological Survey. (1985). Map of Geological Features in Peninsular Malaysia. Ipoh.

Director General of Agriculture Peninsular Malaysia. (1973). Map of Soil Types in Peninsular Malaysia. $1^{\text {st }}$ Edition. Kuala Lumpur.

Elless, MP., Armstrong, AQ. \& Lee, SY. (1997). Characterization and solubility measurements of uranium-contaminated soils to support risk assessment. Journal of Health Phyics, 72, 716-726.

Florou, H., \& Kritidis, P. (1992). Gamma radiation measurements and dose rate in the coastal areas of a volcanic island, Aegean Sea, Greece. Journal of Radiation Protection Dosimetry, 45, 277-279.

Ibrahim, N.M., Abd El Ghani, A.H., Shawky, E.M., Ashraf, E.M., \& Farouk, M.A. (1993). Measurement of radioactivity levels in soils in the Nile Delta and Middle Egypt. Journal of Health Physics, 64, 620-627.

ICRP. (1990). Recommendations of the International Commission on Radiological Commission. ICRP Publication 60. Pergamon Press: New York.

Kogan, R.M., Nazarov, I.M., \& Fridman, S.D. (1969). Gamma Spectrometry of Natural Environments and Formation : Theory of The Method Application to Geology dan Geophysics. Keter Press: Jerusalem.

Kryshev, I.I., Sazykina, T.G., \& Isaeva, L.N. (1996). Risk assessment from contamination of aquatic ecosystem in the areas of Chernobyl. Journal of Radiation Protection Dosimetry, 64, 103-107.

Lee, S.K., Wagiran, H., Ramli., A.T., Apriantoro, N.H., \& Wood., A.K. (2009). Radiological monitoring : terrestrial natural radionuclides in Kinta District, Perak, Malaysia. Journal of Environmental Radioactivity, 100, 368-374.

Mollah, S., Rahman, N.M., Kodlus, M.A., \& Husain, S.R. (1987). Measurement of high natural background radiation level by TLD at Cox and Bazar coastal areas in Bangladesh. Journal of Radiation Protection Dosimetry, 18, 39 - 41.

Narayana, Y., Somashekarappa, H.M., Radhakrishna, A.P., Balakrishna, K.M., \& Siddappa,K. (1994). External gamma radiation dose rate in coastal Karnataka. Journal of Radiology Protection. 14, 257-264.

Radhakrishna, A.P., Somashekarappa, H.M., Narayana, Y., \& Siddappa, K. (1993). A new natural background radiation area on the southwest coast of India. Journal of Health Physics, 65, 390 - 395.

Ramli, A,T. (1997). Environmental Terrestrial Gamma Radiation Dose and its Relationship with Soil Type and Underlying Geological Formation in Pontian District, Malaysia. Journal of Applied Radiation and Isotopes, 48, 407-412.

Ramli, A,T., Apriantoro, N,H., Wagiran, H., Lee, S.K., \& Wood, A.K. (2009). Health Risk implications of high background radiation dose rate in Kampung Sungai Durian, Kinta District, Perak, Malaysia. Global Journal of Health Science 1 (2), 140 - 149

Ramli, A.T., Abdel Wahab, M. A., \& Lee, M.H. (2001). Geological influence on terrestrial gamma radiation dose rate in the Malaysian State of Johore. Journal Applied Radiation and Isotopes, 54 (2), 327-333.

Ramli, A.T., Abdul Rahmana, A.T., \& Lee, M.H. (2003). Statistical prediction of terrestrial gamma radiation dose rate based on geological features and soil types in Kota Tinggi district, Malaysia. Journal of Applied Radiation and Isotopes, 59 (5-6), 393-405.

Ramli, A.T., Sahrone., S \& Wagiran, H. (2005). Terrestrial gamma radiation dose study to determine the baseline for environmental radiological health practices in Melaka state, Malaysia. Journal of Radiological Protection, 25, 435-450.

Selama District Council, (2009). Official website of Selama District Council. [Online] Available: http://www.mdselama.gov.my/homestay

UNSCEAR. (2000). Sources and effect of ionising radiation. United Nation Scientific Committee of the Effect Atomic Radiation Report on The General Assembly, United Nation; New York.

Willson, M.J. (1993). Anthropogenic and naturally occurring radioactive materials detected on radiological survey of properties in Monticello, Utah. Environmental Health Physics; $26^{\text {th }}$ midyear topical meeting, 24-28 January. pp. 564. 
Table 1. TGR dose rate in Selama compared with the other parts of Malaysia and the world.

\begin{tabular}{lccl}
\hline State/District in Malaysia & $\begin{array}{c}\text { Mean } \pm \mathrm{Sd} \\
\left(\mathrm{nGy} \mathrm{h}^{-1}\right)\end{array}$ & $\begin{array}{c}\text { Range } \\
\left(\mathrm{nGy} \mathrm{h}^{-1}\right)\end{array}$ & Reference \\
\hline Selama district, Perak & $273 \pm 133$ & $64-715$ & Present Study \\
Johor State & $163 \pm 122$ & $9-1262$ & Ramli et al., 2001 \\
Melaka State & $183 \pm 54$ & $54-378$ & Ramli et al., 2005 \\
Kinta district, Perak & $222 \pm 191$ & $39-1039$ & Lee et al., 2009 \\
Pontian district, Johor & 67 & $50-230$ & Ramli, 1997 \\
Kota Tinggi district, Johor & $180 \pm 20$ & $9-1262$ & Ramli et al., 2003 \\
Ulu Tiram, Johor & 200 & $98-409$ & Abdul Rahman, A.T. \& Ramli, 2007 \\
Kg Sungai durian, Perak & $458 \pm 295$ & $78-1039$ & Ramli et al., 2009 \\
Malaysia & 92 & $55-130$ & UNSCEAR, 2000 \\
World & 57 & $18-93$ & UNSCEAR, 2000 \\
\hline
\end{tabular}

Table 2. Terrestrial gamma radiation dose rate from different soil types and geological background in Selama, Perak

\begin{tabular}{|c|c|c|c|c|c|c|c|}
\hline \multirow{2}{*}{ Soil type and Geological background } & \multirow{2}{*}{$\begin{array}{c}\mathrm{N} \\
\text { sample }\end{array}$} & \multirow{2}{*}{$\begin{array}{c}\text { Mean } \\
\left(\text { nGy h}^{-1}\right)\end{array}$} & \multirow{2}{*}{ Std Dev } & \multicolumn{2}{|c|}{$\begin{array}{l}95 \% \text { Confidence } \\
\text { Interval for Mean }\end{array}$} & \multirow{2}{*}{ Min } & \multirow{2}{*}{ Max } \\
\hline & & & & Lower & Upper & & \\
\hline \multicolumn{8}{|l|}{ Soil types (FAO/UNESCO) } \\
\hline Haplic Acrisol-Haplic Acrisol & 23 & 241 & 63 & 213 & 268 & 129 & 357 \\
\hline \multicolumn{8}{|l|}{ Dystric fluvisol-Haplic Arenosol - } \\
\hline Dystric Cabisol & 30 & 220 & 46 & 203 & 237 & 123 & 311 \\
\hline Haplic Acrisol-Ferric Acrisol & 46 & 306 & 161 & 259 & 354 & 64 & 715 \\
\hline Haplic Acrisol-Haplic Ferralsol & 16 & 158 & 40 & 137 & 179 & 116 & 246 \\
\hline Steep land (Miscellaneous soils) & 25 & 379 & 143 & 320 & 438 & 234 & 696 \\
\hline \multicolumn{8}{|l|}{ Geological background } \\
\hline Acid and undifferentiated & 78 & 337 & 143 & 304 & 369 & 165 & 715 \\
\hline Quaternary & 12 & 155 & 38 & 131 & 179 & 121 & 233 \\
\hline Silurian & 36 & 222 & 44 & 207 & 237 & 116 & 278 \\
\hline Triassic-Jurassic & 14 & 152 & 59 & 118 & 186 & 64 & 311 \\
\hline Present study & 140 & 273 & 133 & 251 & 295 & 64 & 715 \\
\hline Malaysian average (UNSCEAR 2000) & & 92 & & & & & \\
\hline World average (UNSCEAR 2000) & & 57 & & & & & \\
\hline
\end{tabular}


Table 3. Concentration of ${ }^{238} \mathrm{U},{ }^{232} \mathrm{Th}$ and ${ }^{40} \mathrm{~K}$ in soil sample and the corresponding TGR dose rate in air $1 \mathrm{~m}$ above the ground

\begin{tabular}{|c|c|c|c|c|c|c|}
\hline \multirow{2}{*}{$\begin{array}{c}\text { Soil } \\
\text { sample }\end{array}$} & \multirow{2}{*}{ Soil Types (FAO/UNESCO) } & \multirow{2}{*}{ Geological Background } & \multicolumn{3}{|c|}{ Concentration $\left(\mathrm{Bq} \mathrm{kg}{ }^{-1}\right)$} & \multirow{2}{*}{$\begin{array}{l}\text { TGR dose rate } \\
\text { at The point } \\
\text { sampling }\end{array}$} \\
\hline & & & ${ }^{238} \mathrm{U}$ & ${ }^{232} \mathrm{Th}$ & ${ }^{40} \mathrm{~K}$ & \\
\hline S 1 & Haplic Acrisol-Haplic Acrisol & Quartenary & 126 & 252 & 290 & 260 \\
\hline S 2 & Haplic Acrisol-Haplic Acrisol & Acid undifferentiated & 117 & 625 & 60 & 330 \\
\hline S 3 & $\begin{array}{l}\text { Dystric Fluvisol-Haplic Arenosol } \\
\text { - Dystric Cabisol }\end{array}$ & Silurian & 139 & 272 & 291 & 273 \\
\hline $\mathrm{S} 4$ & Haplic Acrisol-Ferric Acrisol & Triassic-Jurassic & 57 & 207 & 198 & 130 \\
\hline S 5 & Haplic Acrisol-Ferric Acrisol & Triassic-Jurassic & 65 & 384 & 215 & 142 \\
\hline S 6 & Haplic Acrisol-Ferric Acrisol & Acid undifferentiated & 158 & 459 & 378 & 390 \\
\hline S 7 & Haplic Acrisol-Ferric Acrisol & Acid undifferentiated & 152 & 245 & 251 & 260 \\
\hline S 8 & Haplic Acrisol-Ferric Acrisol & Acid undifferentiated & 140 & 211 & 464 & 234 \\
\hline S 9 & Haplic Acrisol-Ferric Acrisol & Acid undifferentiated & 206 & 507 & 104 & 429 \\
\hline $\mathrm{S} 10$ & Haplic Acrisol-Ferric Acrisol & Acid undifferentiated & 166 & 247 & 579 & 311 \\
\hline S 11 & Haplic Acrisol-Ferric Acrisol & Acid undifferentiated & 247 & 276 & 439 & 364 \\
\hline $\mathrm{S} 12$ & Haplic Acrisol-Ferric Acrisol & Acid undifferentiated & 364 & 521 & 36 & 520 \\
\hline $\mathrm{S} 13$ & Steep land & Acid undifferentiated & 286 & 566 & 78 & 559 \\
\hline S 14 & Haplic Acrisol-Haplic Ferralsol & Acid undifferentiated & 357 & 297 & 601 & 325 \\
\hline S 15 & $\begin{array}{l}\text { Dystric Fluvisol-Haplic Arenosol } \\
\text { - Dystric Cabisol }\end{array}$ & Silurian & 96 & 224 & 455 & 273 \\
\hline \multicolumn{2}{|c|}{ Present Study } & & $178 \pm 95$ & $353 \pm 143$ & $296 \pm 184$ & $273 \pm 133$ \\
\hline \multicolumn{2}{|c|}{ Malaysia average (UNSCEAR, 2000) } & & $66(49-86)$ & $82(63-110)$ & $310(170-430)$ & $92(55-130)$ \\
\hline \multicolumn{3}{|c|}{ World average (UNSCEAR, 2000) } & $35(16-110)$ & $30(11-64)$ & $400(140-850)$ & $57(18-93)$ \\
\hline
\end{tabular}

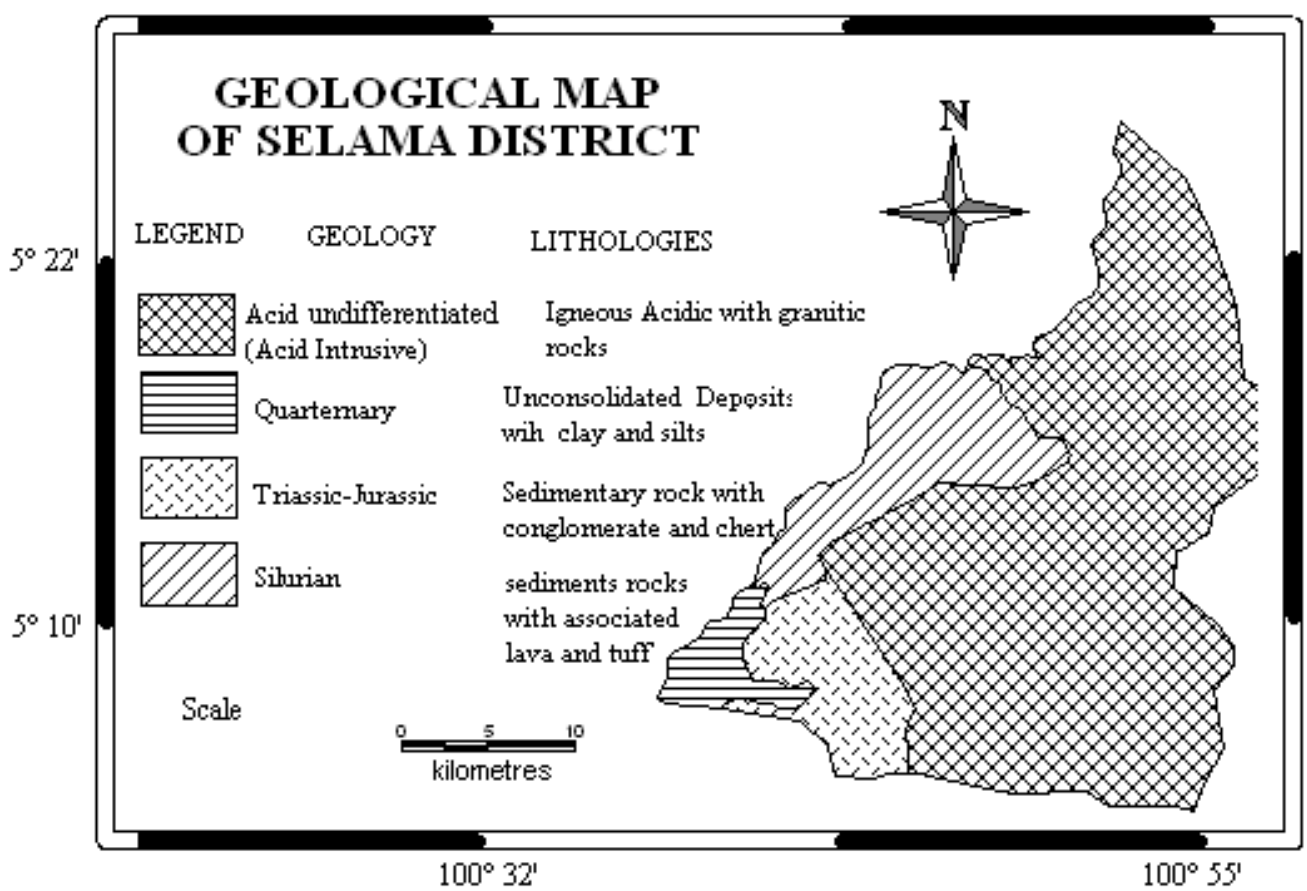

Figure 1. Map of geological features and its lithologies in Selama district, Perak, Malaysia (Director General of Geological Survey 1985) 


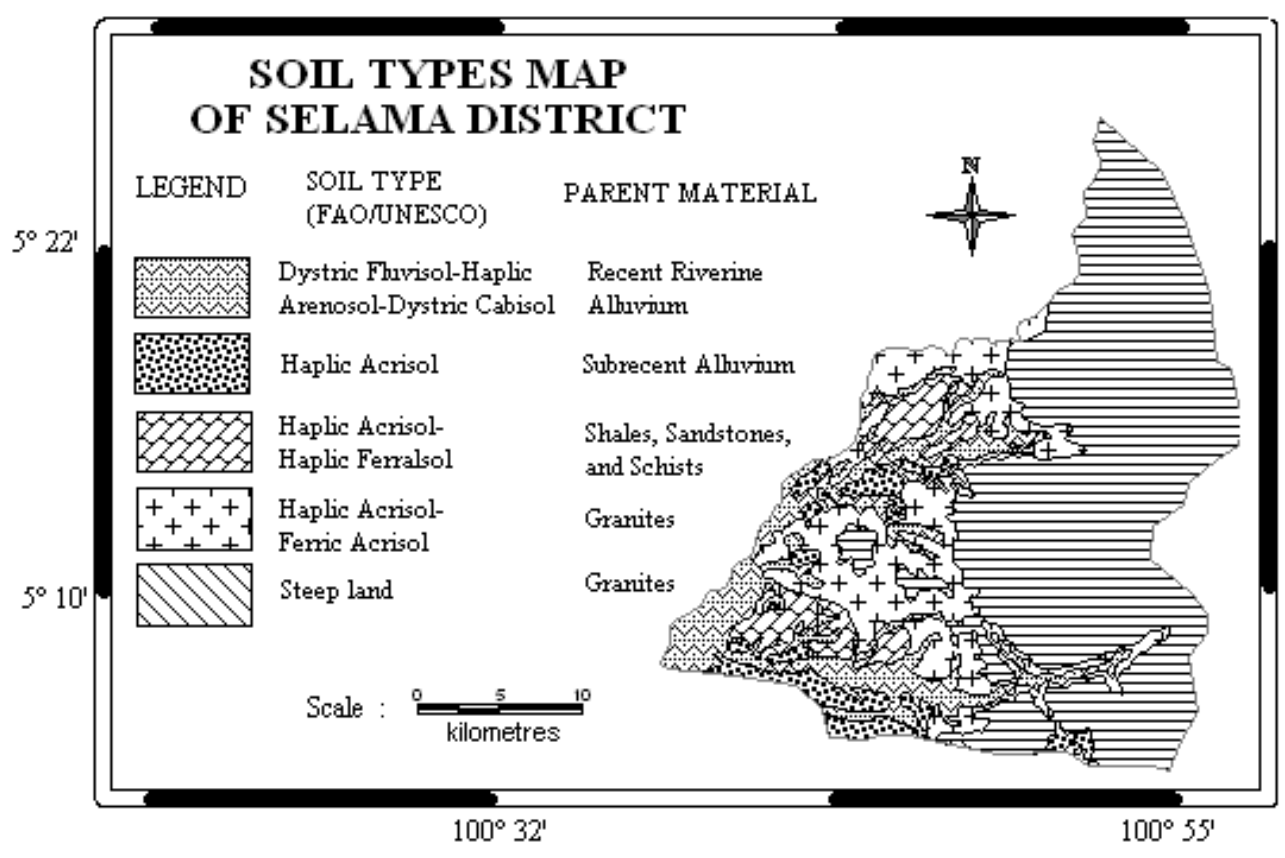

Figure 2. Map of soil types and its parent materials in Selama district, Perak, Malaysia (Directorate of National Mapping Malaysia, 1970).

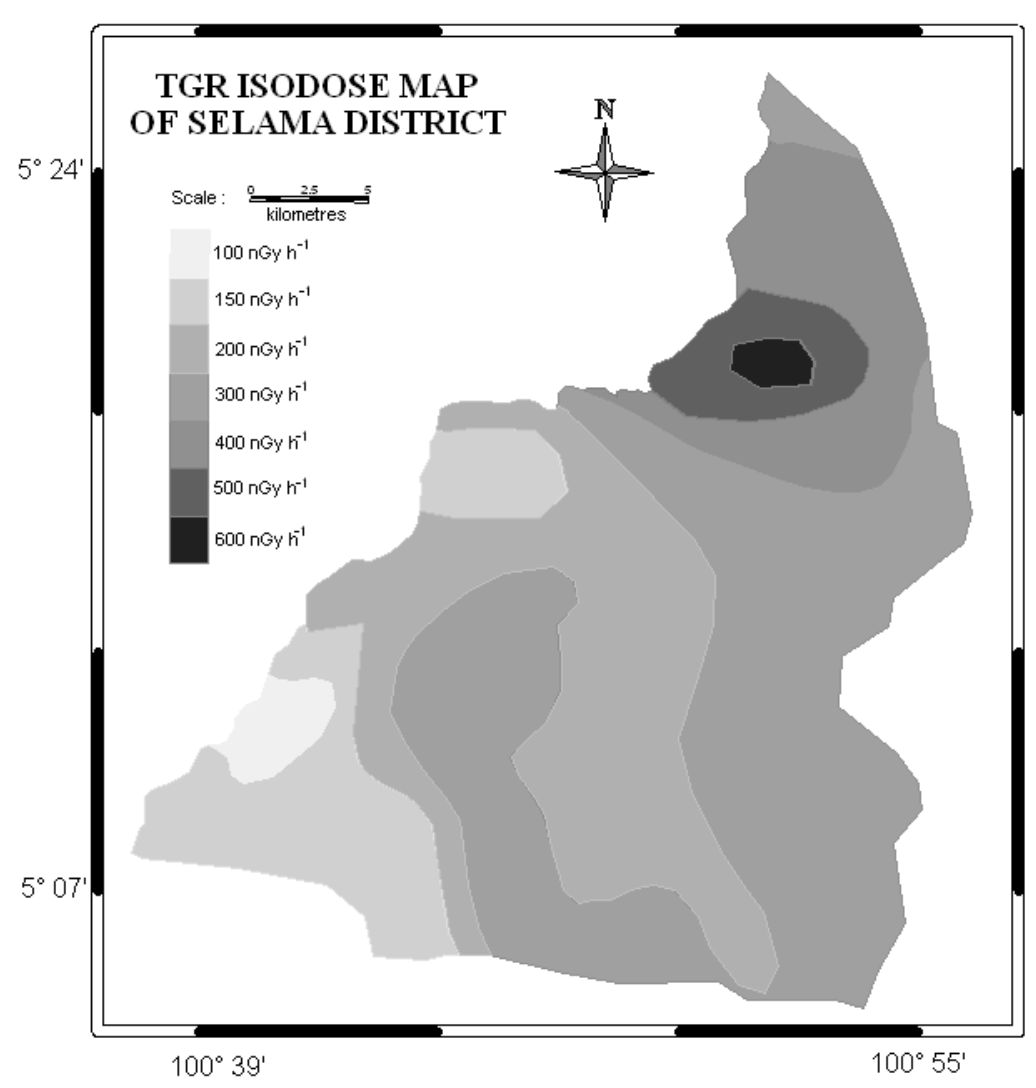

Figure 3. Map of terrestrial gamma radiation dose rates $\left(\mathrm{nGy} \mathrm{h}^{-1}\right)$ in Selama District, Perak, Malaysia 


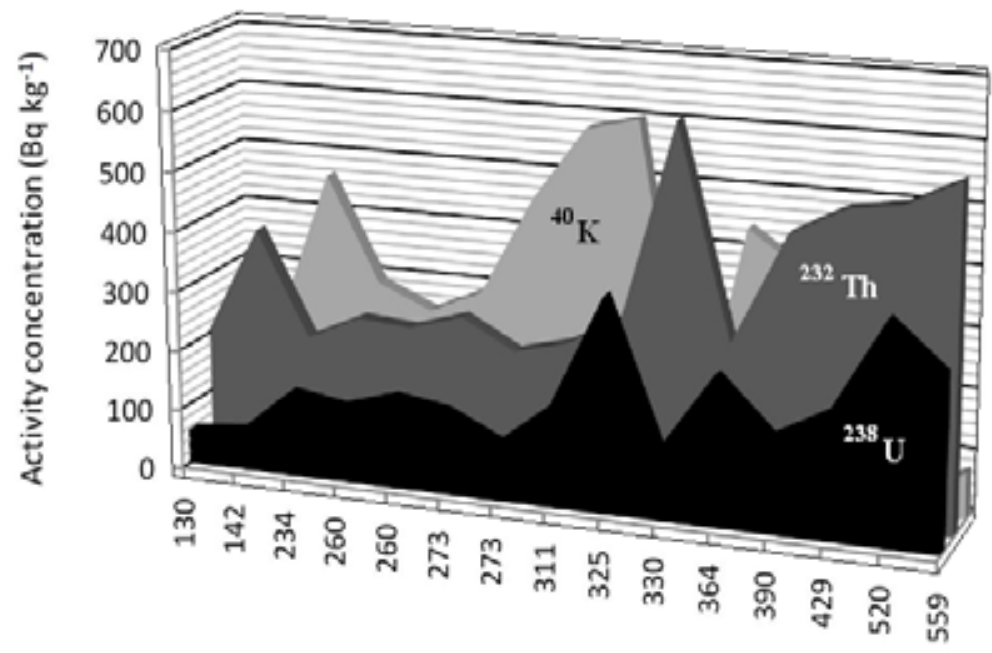

TGR dose rates (nGy h $h^{-1}$ )

Figure 4. The TGR dose rate versus activity concentration of ${ }^{238} \mathrm{U},{ }^{232} \mathrm{Th}$, and ${ }^{40} \mathrm{~K}$ in soil samples 


\title{
Study on the Experiment of Concentrating Coking Wastewaters
}

\section{by Air-blowing Vacuum Membrane Distillation}

\author{
Heng Zhao \& Huawei Sun \\ Key Laboratory of Hollow Fibre Membrane Materials \& Membrane Process Founded by Ministry of Education \\ Biological Chemical Research Institute of Tianjin Polytechnic University, Tianjin 300160, China \\ E-mail: hengheng924315@126.com
}

\begin{abstract}
In the article, a new air-blowing vacuum membrane distillation (AVMD) process is proposed, and it forms the air-liquid flows in the membrane by forcedly blowing airs to the hot feed liquids circularly flowing in the hollow fiber membrane, and forms the AVMD system to enhance the turbulent degree of the liquids. The intense disturbance of air bubbles and the strong cutting power at the surface of membrane can reduce the depth of the boundary layer of liquids, the temperature and the concentration polarization of the membrane surface, and enhance the speed of heat and mass transfer to enhance the membrane distillation flux and control the membrane pollution. By the process that the optimized AVMD process is used in the coking wastewater treatment process of certain enterprise, the influence of the pretreatment technique of the wastewater on the removal effect of COD is studied in the article, and the influences of the vacuum membrane distillation (VMD) and the AVMD process on the wastewater concentrating treatment effect and efficiency are also respectively researched in the article.
\end{abstract}

Keywords: Air-blowing vacuum membrane distillation (AVMD), PVDF, Hollow membrane, Hydrophobic membrane, Wastewater treatment

\section{Introduction}

The membrane distillation (MD) is the membrane separation process combining the membrane technology with the distillation process, and it possesses high interception ratio, and it can realize the distillation process when the negative pressure and the temperature of the feed liquids are very low, and treat reverse osmosis wastewaters with high concentration (Wu, 2003, p.67-75). Most existing researches only aim at the study about the mass transfer process of the steam permeation side, which emphasized to reduce the mass transfer resistance of the membrane/liquid interface of the steam permeation side or enhance the driver of the mass transfer, and few of them study the mass transfer process of the hot side and its strengthening method. J. Phattaranawid and Ma Runyu et al strengthened the turbulent degree of the liquids of the hot side and increased the membrane flux by the pulse feeding method and the feed-liquid-mixing method (M.N. Chernyshov, 2005, P.363-374 \& J. Phattaranawik, 2001, P.193-201).

Based on large numbers of theoretical and experimental researches, the AVMD process is designed, and it blows low-pressure compressed airs to the pipes in front of subassembly of the raw water inlet hydrophobic membrane, mixes and forms the two-phase liquids including airs and liquids to enter the subassembly of the hydrophobic membrane, and connects the negative pressure system outside the exit of the producing airs of the hydrophobic membrane subassembly. Taking the demineralization and recycle of the coking wastewaters as the target, and taking the AVMD process as the core, the wastewater treatment process integrating the AVMD process, the chemical flocculation and the super-filtering technology is developed in the article.

\section{Experiment}

\subsection{Main experiment materials and instruments}

The main experiment materials and instruments include the PVDF hollow fiber hydrophobic membrane (the interior radius is $0.8 \mathrm{~m}$, the exterior radius is $1.1 \mathrm{~mm}$, the aperture is $0.160 \mu \mathrm{m}$, and the porosity is $85 \%$ ) which is made by the research institute, the hollow fiber membrane subassembly (the effective length is $21 \mathrm{~cm}$, the loading rate is $1.51 \%$ and the effective membrane area is about $0.025 \mathrm{~m}^{2}$ ), the analytical reagent of sodium chloride which is made by the Tianjin Chemical Reagent Factory, the tap water (the conductance value if $230 \mu \mathrm{s} / \mathrm{cm}$, and the water hardness if $15 \mathrm{mg} / \mathrm{L}$ ), the 
electronic balance which is made by Tianjin Tianma Instruments Factory, and the DDS-11A conductivity meter which is made by Shanghai Rex Instrument Factory.

\subsection{Experiment method and data processing}

The AVMD process is seen in Figure 1, and the system can be divided into two parts, i.e. the hot side and the cold side, and the hot side is composed by the constant temperature water bathing, the magnetic pump, the liquid flowmeter, the pressure meter, and the subassembly of membrane distillation, which blows airs to the hot feed liquid inlet of the membrane subassembly, and the stable airs controlled by the air valuator enter into the hollow fiber membrane along the flow direction of the hot feed liquid through the air flowmeter. The cold side is composed by the glass condenser, the catchment flume and the vacuum pump.

Heat the feed waters (tap water) to the scheduled temperature in the constant temperature batching, turn on the cycle pumps and the vacuum pumps of the hot side and the cold side, and adjust the flux (flow velocity) of the liquids and the quantity of the airs to the scheduled values. When the temperatures of the inlet and the outlet of two sides of the membrane subassembly are stable, begin clocking and collect the produced waters. Stop the experiment when the quantity of the produced water achieves about $250 \mathrm{ml}$, note the time and measure the conductance rate of the produced water, and respectively compute the membrane distillation flux $J$ and the desalination rate $R_{j}$ according to the formula (1) and formula (2).

$$
\begin{gathered}
J=\frac{W}{S * t} \\
R_{j}=\frac{C_{f}-C_{p}}{C_{f}} * 100 \%
\end{gathered}
$$

Where, $J\left(\mathrm{~kg} / \mathrm{m}^{2} \cdot \mathrm{h}\right)$ is the membrane flux, $W(\mathrm{~kg})$ is the quality of the distillated liquids, $S\left(\mathrm{~m}^{2}\right)$ is the effective area of membrane, $t$ is the collection time, and $C_{f}, C_{p}(\mathrm{~g} / \mathrm{L})$ respectively are the salt concentrations of the raw feed liquids and the produced waters.

For the air-liquid two phases liquids,

$$
\operatorname{Re}=\frac{U_{m} D}{V_{1}}=\frac{\left(q V_{Q}+q V_{L}\right) D}{A V_{1}}
$$

Where, $U_{m}(\mathrm{~m} / \mathrm{s})$ is the average flow velocity of the air-liquid two-phase liquids, $\mathrm{qV}_{\mathrm{Q}}(\mathrm{L} / \mathrm{h})$ is the volume flux of the air phase, $\mathrm{qV}_{\mathrm{L}}(\mathrm{L} / \mathrm{h})$ is the volume flux of the liquid phase, $\mathrm{A}\left(\mathrm{m}^{2}\right)$ is the flux area of the pipe section, $\mathrm{V}_{1}(\mathrm{~Pa} \cdot \mathrm{s})$ is the movement viscidity of the liquid phase, and $\mathrm{D}(\mathrm{m})$ is the equivalent diameter.

\section{Results and discussions}

\subsection{Influence of the air-blowing quantity on the performance of VMD}

Under the conditions that the feed liquid temperature is $70^{\circ} \mathrm{C}$, the vacuum degree is $0.085 \mathrm{MPa}$, and the flux of the membrane distillation liquids is $120 \mathrm{~L} / \mathrm{h}$, the influence of air-blowing intension on the performance of membrane distillation process is studied, and the result is seen in Figure 2.

From Figure 2, with the increase of air-blowing quantity, the flux of AVMD process increases significantly. The air-blowing quantity increases from 0 to $70 \mathrm{~L} / \mathrm{h}$, and the flux enhances double times, from $22 \mathrm{~kg} / \mathrm{m}^{2} \mathrm{~h}$ to $45 \mathrm{~kg} / \mathrm{m}^{2} \mathrm{~h}$. When the liquid flux is fixed, to blow airs to the liquids and form the air-liquid two-phase flow can effectively enhance the turbulent degree of the liquids. According to change of the Reynolds number obtained by the computation method (formula 3) in the air-liquid two-phase flow proposed by Nicklin with the air-blowing quantity (the right coordinate in Figure 2), with the increase of air-blowing quantity, the Reynolds number of the mixed liquids ascend linearly, and when the air-blowing quantity enhances from 0 to $70 \mathrm{~L} / \mathrm{h}$, the value of Re increases from 2655 to 4204 , and the laminar flow develops gradually to the turbulent flow. By the interfering function of air-blowing, the turbulent degree of liquids in the membrane increases, and the cutting forces of the membrane surface are enhanced, and the depth of the boundary layer of the liquids is reduced, and the concentration and the temperature polarization are reduced, so the process flux is enhanced.

At the same time, in the heat transfer process, the boiling heat transfer coefficient is obviously higher than the single phase heat transfer coefficient. According to the reports in the articles (Mandhane J M, 1974, P.537-553 \& Kenning D B R, 1972, P.1709-1717), the air-blowing in the convection heat transfer liquids, the heat transfer coefficient can be enhanced for $400 \%$, and the main reason is that the intense interference induced by large numbers of air bubbles can improve the heat exchange of the cold and heat liquids. Because of the analogy character of the heat transfer and the mass transfer, the interfering function of the air bubbles can increase the turbulent degree of liquids, strengthen the 
cutting force of membrane surface, control the concentration polarization, reduce the membrane pollution and increase the membrane flux.

\subsection{Research of the directly concentrating process of coking wastewaters}

Under the conditions that the vacuum degree is $0.085 \mathrm{MPa}$, the temperature of the raw water is $70^{\circ} \mathrm{C}$ and the flow velocity is $1.0 \mathrm{~m} / \mathrm{s}$, when the air-water ratios respective are 0 and 0.5 , the change performances of the AVMD process with the concentrating time of coking wastewater, the changes of the produced water conductance and $\mathrm{PH}$ value in the concentrating process are seen in Figure 3.

From Figure 3, after 900min AVMD concentrating experiment, concentrate the coking waters to initial 5 times concentration, and keep the produced water conductance under $50 \mathrm{uS} / \mathrm{cm}$, and the membrane flux descends significantly from $23.7 \mathrm{~kg} / \mathrm{m}^{2} \mathrm{~h}$ to $16.0 \mathrm{~kg} / \mathrm{m}^{2} \mathrm{~h}$. With the increase of concentrating times, the conductance of the concentrating liquids is kept in $35 \mathrm{uS} / \mathrm{cm}$ to $45 \mathrm{uS} / \mathrm{cm}$. But the extent of the PH value of concentrating water changes little relatively, only from 10 to 9.38 .

\subsection{COD removal and its concentrating process of coking wastewaters}

To reduce the organic matters' accumulation in the concentrated coking wastewater to pollute the membrane and reduce the flux and produce CODcr, in this experiment, different flocculating agents are appended to the coking wastewaters to removal CODcr, and the results are seen in Figure 4 and Figure 5.

From Figure 4, with the increase of PFS quantity, the CODcr value of the raw water descends, and when the quantity achieves $100 \mathrm{mg} / 1$, the value of COD is $700 \mathrm{mg} / 1$, and the removal rate of corresponding COD is $64.7 \%$. From Figure 5 , with the increase of PAC quantity, the COD value of raw waters first decreases and then ascends, and when the quantity of PAC is $75 \mathrm{mg} / 1$, the value of COD is $500 \mathrm{mg} / 1$, and the corresponding COD removal rate is $74.7 \%$. So, under normal temperature, when the appended quantities are same, the removal effect of PAC for raw water COD is better than PFS.

The optimal appended quantity of PAC is $75 \mathrm{mg} / \mathrm{l}$, and under the conditions that the vacuum is $0.085 \mathrm{MPa}$, the temperature of raw water is $70^{\circ} \mathrm{C}$, the flow velocity is $1.0 \mathrm{~m} / \mathrm{s}$, and the air-blowing intension if $50 \mathrm{~L} / \mathrm{h}$, the results of the AVMD concentrating experiment for removing CODcr in coking wastewaters are seen in Figure 6 and Figure 7.

From Figure 6 and Figure 7, in the initial of the AVMD concentrating process, the membrane flux descends slowly, and after 700min's concentrating, the wastewaters removing CODcr are concentrated five times, the produced water conductance in the concentrating process is kept under $10 \mu \mathrm{S} / \mathrm{cm}$, and the membrane flux descends from initial $29.1 \mathrm{~kg} / \mathrm{m}^{2} \mathrm{~h}$ to $18.2 \mathrm{~kg} / \mathrm{m}^{2} \mathrm{~h}$. With the increase of concentrating times, in the process that the raw waters are concentrated five times, the conductance of concentrated water decrease from initial $50 \mathrm{uS} / \mathrm{cm}$ to $28 \mathrm{uS} / \mathrm{cm}$. In the concentrating process, the COD of concentrating water ascends from $500 \mathrm{mg} / \mathrm{L}$ to $2300 \mathrm{mg} / \mathrm{L}$, and the CODcr of produced waters is stabilized in $1.7 \mathrm{mg} / \mathrm{L}-2.1 \mathrm{mg} / \mathrm{L}$ because the raw waters contain certain volatile low-molecule organic matters which can enter into the produced waters through the membrane holes.

In conclusion, the decrease of the VMD flux may come from the influence of the descending steam pressure, and the mass transfer driver of the membrane distillation process is the water steam pressure difference between two sides of the membrane, and when the distillation object is watery liquids, the influence of the descending steam pressure can be ignored, but when the concentration of the liquids is high, the descending steam pressure of the liquids will reduce the water steam pressure difference between two sides of the membrane, which will reduce the VMD flux. On the other hand, in the VMD concentrating process, the concentration of the inorganic-salt and the organic matters in the concentrating waters increase, and because of the increase of the concentration difference polarization effect, the membrane flux will decrease even the membrane pollution will be induced. But in the AVMD process, the air-liquid two-phase flow formed by air-blowing will change the laminar flows of the membrane cavity to the turbulent flows, and the high-effective convection mass transfer will replace single molecule diffusion, and the heat transfer process is changed from heat exchange to heat flow transfer, and the boundary layer and the temperature boundary layer effect will be minified, so the membrane flux will be reduced and the membrane pollution will be reduced.

\section{Conclusions}

The PVDF hollow fiber hydrophobic micro-hole membrane is adopted to design the AVMD process in the article, and the concrete process is that: blow low-pressure compressed airs to the pipes in front of subassembly of the raw water inlet hydrophobic membrane, mix and form the two-phase liquids including airs and liquids to enter the subassembly of the hydrophobic membrane, and connect the negative pressure system outside the exit of the producing airs of the hydrophobic membrane subassembly. Comparing with general VMD process, the blowing function of the compressed air can change the mass transfer principle of the water steam of two sides of the hydrophobic membrane in the membrane subassembly, which can enhance the membrane penetration transfer speed of the water steam and the flux of the membrane distillation.

The research result shows that the self-made high-flux PVDF hollow fiber hydrophobic micro-hole membrane can be 
used to treat the coking wastewaters in the AVMD process. The organic matter content in the wastewaters is higher, which is the main reason to reduce the flux in the AVMD process, and the proper treatment can remove CODcr and keep the membrane flux. Under the conditions that the vacuum degree is $0.085 \mathrm{MPa}$, the temperature of the raw water is $70^{\circ} \mathrm{C}$ and the flow velocity is $1.0 \mathrm{~m} / \mathrm{s}$, the AVMD process flux of the pretreated coking wastewaters can achieve $30.8 \mathrm{~kg} / \mathrm{m}^{2} \mathrm{~h}$, and when the concentration achieves 5 times, the flux is kept in $18.6 \mathrm{~kg} / \mathrm{m}^{2} \mathrm{~h}$, and the conductance of produced waters is kept under $10 \mu \mathrm{S} / \mathrm{cm}$, and the CODcr of produced water is stabilized in $2 \mathrm{mg} / \mathrm{L}-4 \mathrm{mg} / \mathrm{L}$.

\section{References}

Fabre J, Line A. (1996). International Encyclopedia of Heat and Mass Transfer. Innodate Corp. P.1015-1021.

J. Phattaranawik, R. Jiraratananon, A.G. Fane, C. Halim. (2001). Mass flux enhancement using spacer filled channels in direct contact membrane distillation. Journal of Membrane Science, No. 9 (2). P.193-201.

Kenning D B R, Kao Y S. (1972). Convective heat transfer to water containing bubbles: enhancement not dependent on thermo capillary. Journal of Membrane Science, No. 15(3). P.1709-1717.

M.N. Chernyshov, G.W. Meindersma, A.B. de Haan. (2005). Comparison of spacers for temperature polarization reduction in air gap membrane distillation. Desalination, No.31(9). P.363-374.

Mandhane J M, Gregory G A, Aziz Z. (1974). A flow pattern map for gas-liquid flow in horizontal pipes. Journal of Membrane Science, No. 1(9). P.537-553.

Wu, Yonglie. (2003). Advance of Membrane Distillation Technology and the Application. Technology of Water Treatment, No. 23(4). p.67-75.

Yang, Zurong. (2004). Principle of Chemical Industry. Beijing: Chemical Industry Press. P.76-80.

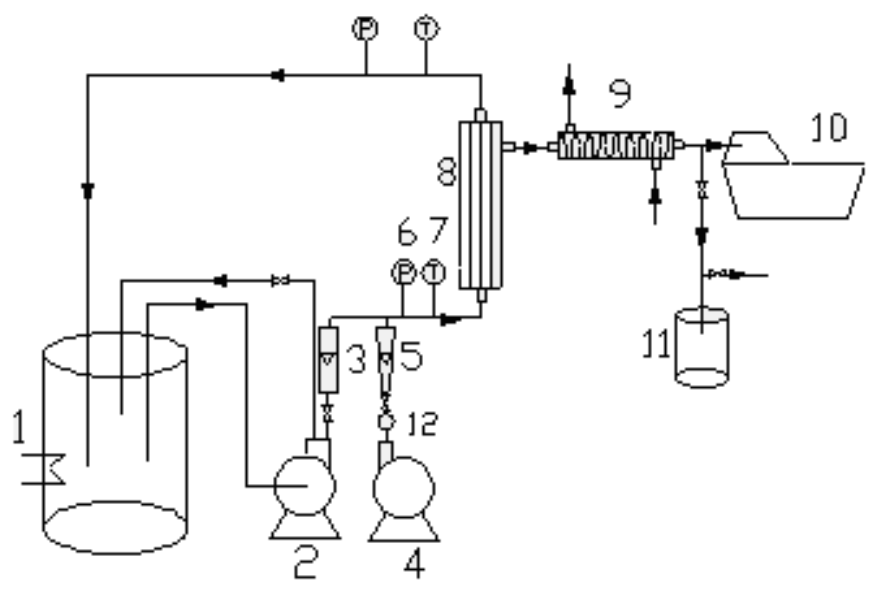

Figure 1. Experimental Apparatus for AVMD Process

(1: Flume of materials, 2: Magnetic pump, 3: Liquid flowmeter, 4: Air pump, 5: Air flowmeter, 6: Pressure meter, 7: Thermometer, 8: Subassembly of hollow fabre membrane, 9: Condensation pipe, 10: Vacuum pump, 11: Catchment flume, 12: Valuator) 


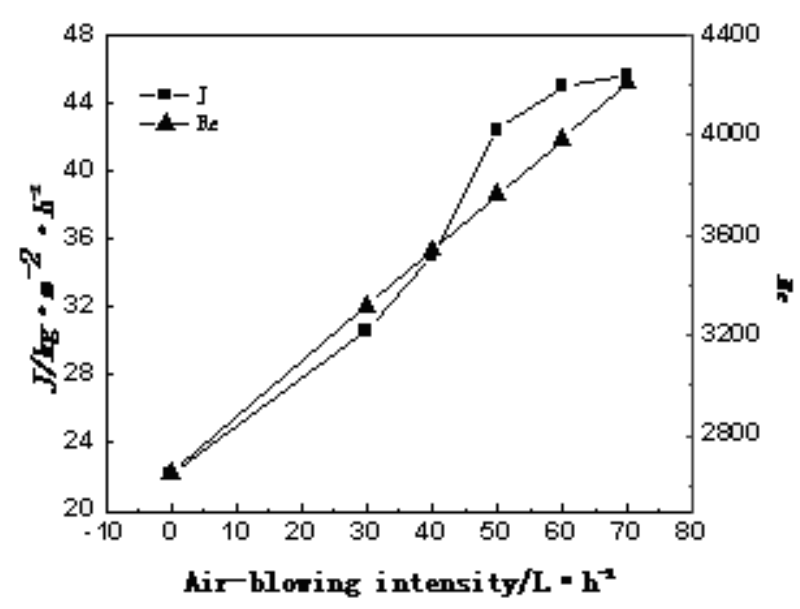

Figure 2. Influence of Air-blowing Quantity on the Membrane Distillation Performance

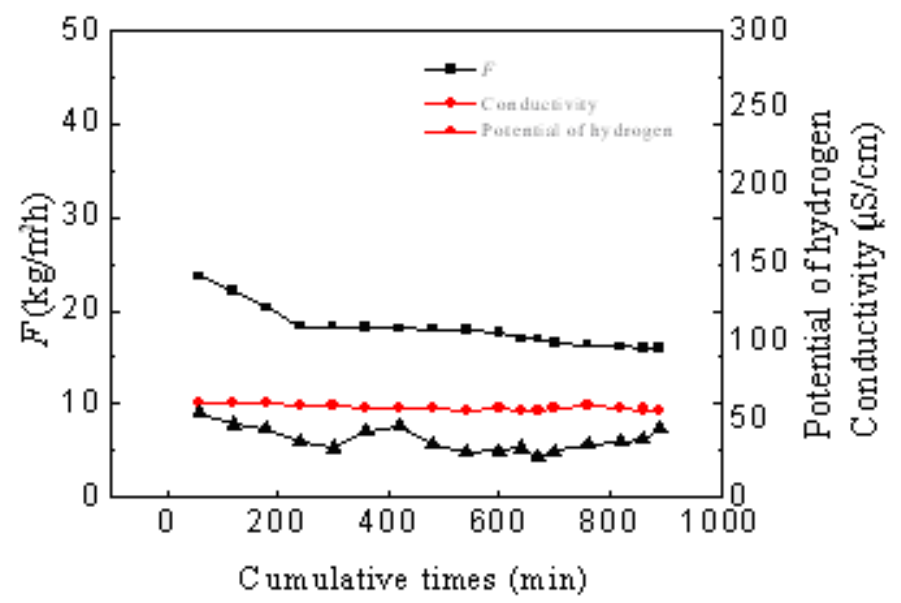

Figure 3. Influence of Operation Time on the AVMD Process

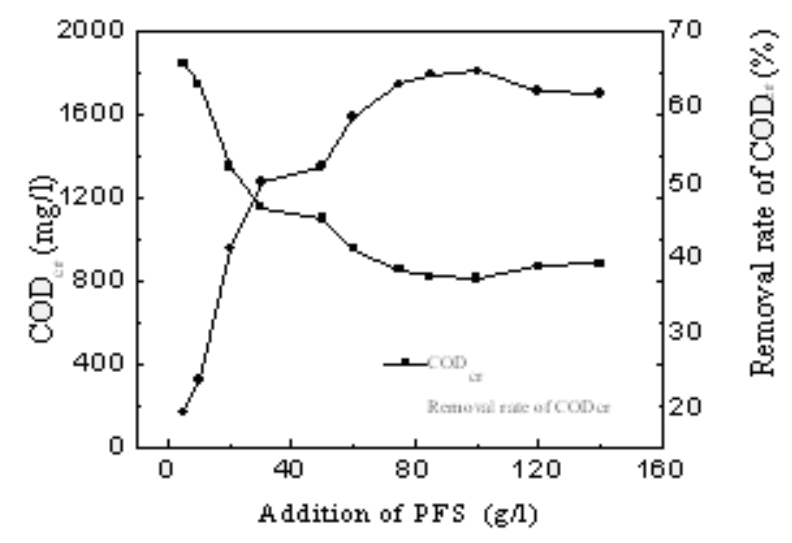

Figure 4. Influence of PFS Quantity on the value of CODcr and the removal rate of CODcr 


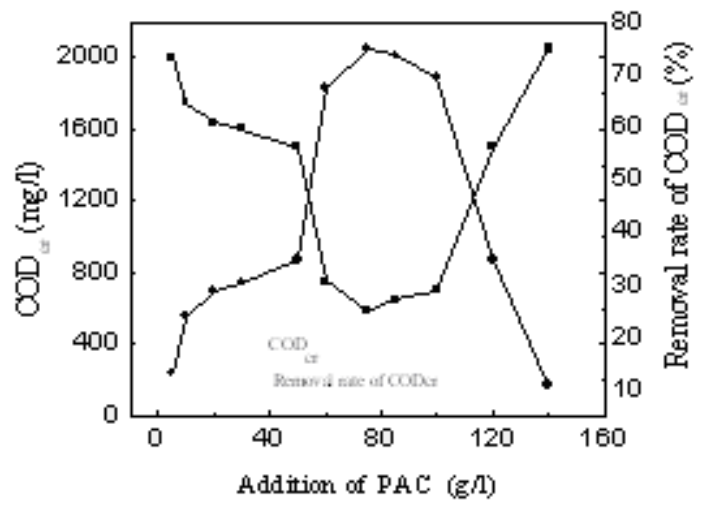

Figure 5. Influence of PAC Quantity on the value of CODcr and the removal rate of CODcr

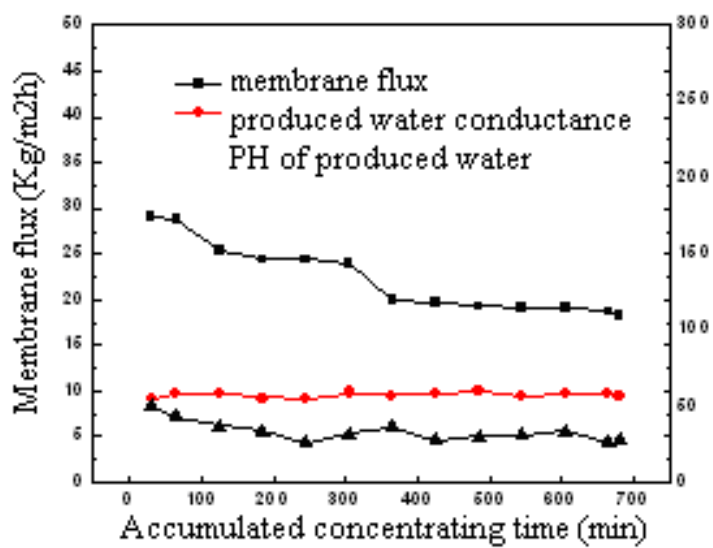

Figure 6. Condensing Five Times after Appending the Flocculating Agent PAC

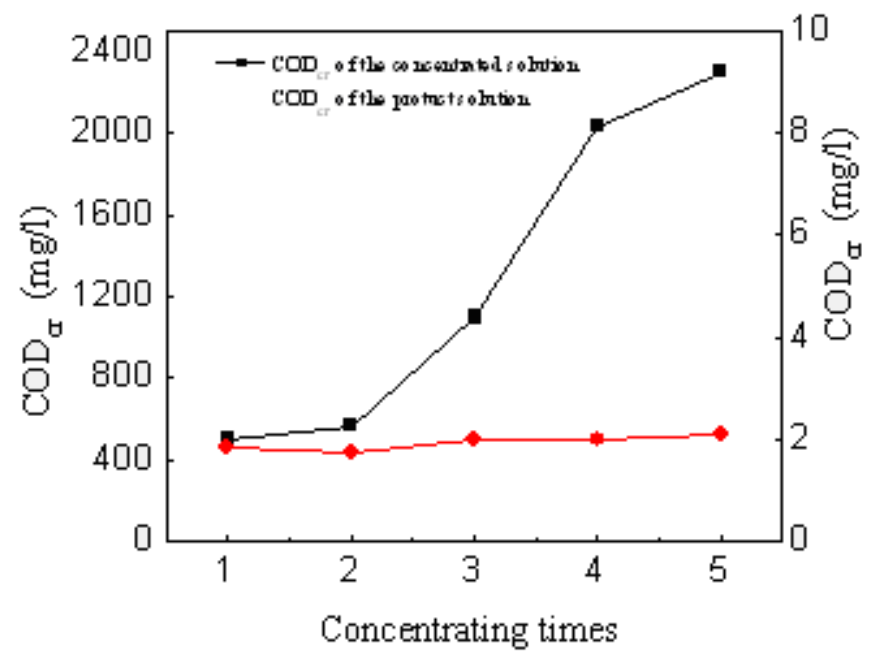

Figure 7. Changes of CODcr of the Produced Water and the Concentrated Water 


\title{
Effect of Fly Ash and Water in Hydrated Srpc-A Ftir Study
}

\author{
K.Thiruppathi \\ Department of Physics, AMET University \\ Chennai, TamilNadu, India \\ E-mail: thiruraj_ka@rediffmail.com \\ S.Barathan (Corresponding author) \\ Department of Physics, Annamalai University \\ Annamalainagar 608 002, Tamilnadu, India \\ E-mail: sbarathan_au@rediffmail.com \\ N.Anandhan \\ Department of Physics, SRM University \\ Chennai, 603 203, Tamilnadu, India \\ E-mail: anandhan_kn@rediffmail.com \\ G.Sivakumar \\ Department of Physics, Annamalai University \\ Annamalainagar 608 002, Tamilnadu, India \\ E-mail: gsk_cisl@yahoo.com
}

\begin{abstract}
The present investigation, deals with the study of both hydrated Sulfate Resisting Portland Cement (SRPC) and fly ash (fly ash 20\%,30\% and 50\%) composite with two different waters. Among the three percentages of fly ash addition, 30\% addition is found to be optimum. The samples (SRPC and 30\% fly ash) were analyzed using the Fourier Transform Infrared Spectroscopy (FTIR) spectra. The relationship between compressive strength and molecular vibration changes were discussed using FTIR spectra. Also, the setting time is identified with the FTIR spectra and proper explanation with available literature for the kinetics is presented. It is inferred that increasing the fly ash concentration reduce the setting time. This is due to the calcium sulfoaluminate (CSA) present in the fly ash. Result of this study indicates that the blended paste better perform than the control paste hydrated with distilled water and effluent water.
\end{abstract}

Keywords: Fly ash, Cement, FTIR, Hydration, Setting

\section{Introduction}

Cement is an energy-intensive component of concrete. The unit cost of concrete can be reduced either by addition or partial replacement of cement with fly ash (Rafat Siddique, 2004). Recently the use of fly ash has dramatically increased due to an increase in environmental awareness and durability. 
The ASTM C 595 define pozzolan as, "a silicious or silicious and aluminous materials, which itself possess little or no cementitious value, but will, in finely divided form and in the presence of moisture, chemically react with $\mathrm{Ca}(\mathrm{OH})_{2}$ at ordinary temperature to form compounds possessing cementitious properties (pozzolanic activity)". Fly ashes mainly consist of $\mathrm{SiO}_{2}, \mathrm{Al}_{2} \mathrm{O}_{3}, \mathrm{Fe}_{2} \mathrm{O}_{3}$ and $\mathrm{CaO}$ and some impurities. According to ASTM C 618, fly ash belongs to class $\mathrm{C}$ if $\left(\mathrm{SiO}_{2},+\mathrm{Al}_{2} \mathrm{O}_{3}+\mathrm{Fe}_{2} \mathrm{O}_{3}\right)>70 \%$. Usually class $\mathrm{C}$ fly ashes have a higher content of $\mathrm{CaO}$ and exhibit pozzolanic properties (Papadakis and Tsimas, 2002).

The variations in the property of the fly ash blended system through different concentrations under Indian condition are meager. Also the utility of the effluent water in the mixture is of considerable interest. The use of FTIR better characterize the amorphous and poorly crystalline phases that occur in the blended cement. Hence, the present study is aimed at in evaluating the performance of fly ash in blended cement paste using distilled water (DW) and Effluent water (EW) and finds the relationship between compressive strength and molecular vibrational changes.

\section{Materials and Methods}

ASTM Type V Sulfate Resisting Portland Cement (SRPC) and Fly ash (FA) collected from Neyveli Lignite Corporation, Neyveli, Tamil Nadu, India were used in this study and their chemical analysis are given below.

\begin{tabular}{lllllllllll} 
Composition $\mathrm{CaO} \mathrm{SiO}_{2}$ & $\mathbf{A l}_{2} \mathbf{O}_{3}$ & $\mathbf{F e}_{2} \mathbf{O}_{3}$ & $\mathbf{S O}_{3}$ & $\mathbf{M g O}$ & \multicolumn{2}{c}{$\mathbf{N a}_{2} \mathbf{O}$} & $\mathbf{K}_{2} \mathbf{O}$ & LOI Others \\
SRPC & 65.08 & 22.20 & 3.47 & 4.08 & 1.25 & 0.88 & 0.27 & 0.76 & 1.90 & 0.11 \\
Fly ash & 7.64 & 53.38 & 27.40 & 3.04 & 1.69 & 4.03 & 0.74 & 0.12 & 1.70 & 0.26
\end{tabular}

The fly ash was mixed with SRPC in 20\%, 30\% and 50\% quantity on weight addition basis. The control (SRPC) and blended samples (with fly ash) were hydrated with distilled water and effluent water in a water to solid ratio of (w/s) 0.4 at different intervals like 1 hour,setting times, 1day, 7days, 28days.

The pelletised sample with $\mathrm{KBr}$ was made use of for recording FTIR spectra (4000-400 $\left.\mathrm{cm}^{-1}\right)$ using Perkin Elmer-RX1 FTIR spectrometer available at Centralised Instrumentation and Service Laboratory (CISL), Annamalai University. Setting time and compressive strength of DW and EW pastes were carried out using ASTM C 191 and 109 procedure and the results are given in figure 1 and 2 (Lee and Van Deventer, 2002 and Natalaya Shannhan and Abla Zayed, 2007).

\section{Results and Discussion}

\subsection{Setting time and Compressive strength study}

Figure 1 and 2 shows the setting time and compressive strength of SRPC and fly ash composites (DW and EW). From the figure, the fly ash composite $(20 \%, 30 \%$ and $50 \%)$ has a shorter setting time than the SRPC. This is due to $\mathrm{C}_{4} \mathrm{~A}_{3} \mathrm{~S}$ which is responsible for producing more ettringite and erttringite to monosulfate conversion and also CSH gel. Hence strength of the paste at early age is increased. The result coincides well with the many observers (Malhotra and Ramezianpour, 1994, Raungrut Cheerarot and Chai Jaturapitakkul, 2004). The EW hydrated pastes have quick setting than DW due to the presence of accelerating ions in EW (Ghorab et al., 1990). The compressive strength of SRPC performs better than SRPC blend up to $7^{\text {th }}$ days of hydration. This suggests that fly ash do not contribute notably for early strength development of the cement system. The results after $28^{\text {th }}$ day indicate that there is a continuous and significant improvement in strength in the case of SRPC blend. This increase in strength may be due to the continuous production of CSH, the inert nature of fly ash particle and hence pozzolanic activity. The effluent water hydrated samples get an accelerating trend in early periods (up 7 days). At 28 days, the strength of EW control paste decreases whereas the strength of DW fly ash blend increases. From the result $30 \%$ fly ash blend gives a maximum compressive strength and hence it has been investigated through FTIR.

\subsection{FTIR study}

The spectra of Distilled water (DW) and effluent water (EW) hydrated Control (SRPC) and blended cement (SRPC+30\%FA) are shown in the Fig.3-6.

\subsubsection{DW Hydrated control}

In cement hydration, water, carbonate, sulphate and silicate are the major bands identified through FTIR.

- FTIR spectra of DW hydrated control are shown in figure 3. In 1 hour spectrum (Fig.3a), a medium intensity band around $3428 \mathrm{~cm}^{-1}$ and $1640 \mathrm{~cm}^{-1}$ may be assigned to the $v_{1}$ and $v_{2}$ water stretching and bending vibration respectively. A shoulder is emerging at $3640 \mathrm{~cm}^{-1}$ may be due to the formation of $\mathrm{Ca}(\mathrm{OH})_{2}$ (Abdul Aziz A Khalil, 1982). At $8^{\text {th }}$ hour (Fig.3b), the $v_{1}$ and $v_{2}$ water bands are having a stronger intensity with a shift to higher wave number around $3430 \mathrm{~cm}^{-1}$ and $1642 \mathrm{~cm}^{-1}$. The $\mathrm{Ca}(\mathrm{OH})_{2}$ peak is strong and sharp at $3640 \mathrm{~cm}^{-1}$. At 15 hour (Fig. $3 \mathrm{c}$ ) a growth in $v_{1}$ and $v_{2}$ bands and $\mathrm{Ca}(\mathrm{OH})_{2}$ are observed. As hydration time passes, the $\mathrm{Ca}(\mathrm{OH})_{2}$ peak increases in intensity up to $7^{\text {th }}$ day (Fig.3e) and there after a constant intensity is observed. The $v_{1}$ and $v_{2}$ bands have a broad and strong intensity up to $28^{\text {th }}$ day.

- In 1hour, a strong band near $1440 \mathrm{~cm}^{-1}$ is assigned to asymmetric stretching vibration of carbonate $\left(v_{3} \mathrm{CO}_{3}^{2-}\right)$ band. After 1hour (up to $7^{\text {th }}$ day), the $v_{3}$ band at $1440 \mathrm{~cm}^{-1}$ has an increasing intensity and a new peak is observed (1day) at $873 \mathrm{~cm}^{-1}$ 
due to out-of-plane bending vibration $\left(v_{4} \mathrm{CO}_{3}^{2-}\right)$ of carbonate. The carbonation reactions are rapid but later $\left(28^{\text {th }}\right.$ day $)$ almost constant (Van Gervan, 2004).

- In 1hour, a strong triplet band appearing between 1105 and $1137 \mathrm{~cm}^{-1}$ can be assigned to asymmetric stretching vibration of sulphate $\left(v_{3} \mathrm{SO}_{4}^{2-}\right)$. Also, a weak doublet observed in lower region (around $600 \mathrm{~cm}^{-1}$ and $670 \mathrm{~cm}^{-1}$ ) are due to in-plane bending $\left(v_{2} \mathrm{SO}_{4}^{2-}\right)$ and out-of-plane bending $\left(v_{4} \mathrm{SO}_{4}^{2-}\right)$ vibrations of sulphate (Rai and Singh, 2005). After 1hour (at 15 hour), the $v_{3}$ triplet merges to form a singlet at $1124 \mathrm{~cm}^{-1}$. As time passes $\left(28^{\text {th }}\right.$ day), the bands are absent. The changes suggest that the sulphate reaction is rapid between 1 hour and 1day.

- In 1 hour, a strong and broad band around $925 \mathrm{~cm}^{-1}$ is due to asymmetric stretching vibration $\left(\mathrm{v}_{3} \mathrm{SiO}_{4}^{4-}\right)$ of $\mathrm{C}_{3} \mathrm{~S}$ and a medium intensity peak observed at $846 \mathrm{~cm}^{-1}$ is due to $\mathrm{C}_{2} \mathrm{~S}$. In lower region a strong and sharp peak observed at $520 \mathrm{~cm}^{-1}$ is due to out-of-plane-bending $\left(v_{4} \mathrm{SiO}_{4}^{4-}\right)$ vibration of $\mathrm{C}_{2} \mathrm{~S}$ and a weak peak observed at $465 \mathrm{~cm}^{-1}$ is due to in-plane-bending $\left(v_{2} \mathrm{SiO}_{4}^{4-}\right.$ ) vibration of $\mathrm{C}_{3} \mathrm{~S}$ (Ghosh and Handoo, 1980, Mollah et al., 2000). At $15^{\text {th }}$ hour (Fig.3c), the band at $925 \mathrm{~cm}^{-1}$ shifts to higher wave number at $970 \mathrm{~cm}^{-1}$ which indicate control gets setting (Fig.1a) (Mollah et al., 1999). From 1 day spectrum (Fig.3d), the $v_{3}$ band grown stronger in intensity. At $28^{\text {th }}$ days (Fig. $\left.3 \mathrm{f}\right)$, the $v_{4}$ peak $\left(520 \mathrm{~cm}^{-1}\right)$ decreases whereas the $v_{2}$ peak $\left(465 \mathrm{~cm}^{-1}\right)$ increases in intensity. The relative intensity change between $v_{4}$ and $v_{2}$ peak is faster. It indicates that the silicate polimerization and control gets strength and well coincide with the strength observation (Fig.1b) (Mollah et al., 1999). As hydration time passes the $v_{4}$ peak is totally consumed at $180^{\text {th }}$ day. In $28^{\text {th }}$ day spectrum (Fig. $3 f$ ), the $v_{2}$ and $v_{3}$ band $\left(469\right.$ and $\left.990 \mathrm{~cm}^{-1}\right)$ has strong intensity.

\subsubsection{Hydrated FA Blends SRPC}

Comparing the figures 3-6, the hydration reaction of 30\%FA blends (Fig.4) and EW pastes (Figs.5 and 6) seems to be similar as that of DW control with a variation in reaction rate which are given below.

The strong and broad band (Fig.4a) observed at $1110 \mathrm{~cm}^{-1}$ and a small peak at $641 \mathrm{~cm}^{-1}$ are due to $v_{3} \mathrm{SiO}_{4}^{4-}$ and CSA stretching vibration of characteristic fly ash band (Benarchid et al., 2005 and Cheng Xin et al., 2001, Malhotra and Ramezanianpour, 1994). From $7^{\text {th }}$ day (Fig.4e), the $\mathrm{Ca}(\mathrm{OH})_{2}$ peak gets a decrease in intensity, which may be due to starting of pozzolanic reaction of fly ash. The $\mathrm{Ca}(\mathrm{OH})_{2}$ peak is totally consumed within $28^{\text {th }}$ day (Fig. $4 \mathrm{f}$ ) spectrum. The water bands $\left(v_{1}\right.$ and $\left.v_{2}\right)$ have a higher intensity up to $28^{\text {th }}$ day.

The carbonate bands are in increasing trend up to $7^{\text {th }}$ day (Fig.4e) and beyond the band reduce in intensity as time elapses. The sulphate bands $\left(v_{2}\right.$ and $\left.v_{4}\right)$ doublet merges to form a singlet exhibiting the setting of the blend. This result coincides with setting time observation (Fig.1b). After 1day (Fig. 4d), the $v_{2}$ and $v_{4}$ peaks has continuous decreasing in intensity similar as that of SRPC.

At $9^{\text {th }}$ hour the $v_{3}$ silicate band shifts to higher wave number with higher intensity than control. The characteristic fly ash band (at $1110 \mathrm{~cm}^{-1}$ ) gets a stronger intensity up to $7^{\text {th }}$ day (Fig.4e) spectrum. After $7^{\text {th }}$ day a decreasing trend in intensity is observed indicate the starting of fly ash's reaction. The relative intensity changes between $v_{4}$ and $v_{2}$ are also faster. In $28^{\text {th }}$ day, the $v_{2}$ and $v_{3}$ bands ( 465 and $990 \mathrm{~cm}^{-1}$ ) gets an increased intensity than control. This may be due to higher rate of pozzolanic reaction with packing effect which increases the strength (Fig.1b).

In effluent water hydrated control (Fig.5), the $v_{3}$ silicate band shifts from $925 \mathrm{~cm}^{-1}$ to higher wave number $985 \mathrm{~cm}^{-1}$ and is stronger in intensity and the relative intensity variation between $v_{4}$ and $v_{2}$ silicate are also faster than DW control at $7^{\text {th }}$ day (Fig.5d). It indicates that the control paste gets a faster setting and strength (Fig.2a). After $7^{\text {th }}$ day, the $v_{2}$ and $v_{3}$ silicate band has lesser intensity than (Fig.5d) DW control. This indicates that the EW control has a lesser strength than DW control and coincides with the compressive strength observation (Fig.2b).

In effluent water hydrated fly ash blend (Fig.6), the $v_{3}$ silicate band shifts to higher frequency with intensity lesser than EW control (1day to $7^{\text {th }}$ day) and also greater than DW fly ash blend. After $7^{\text {th }}$ day, the $v_{3}$ silicate band has a stronger intensity and the relative intensity changes between $v_{4}$ and $v_{2}$ band is faster than EW control.

\section{Discussion}

The sulphate band change indicate that the ettringite formation of the paste. It is indicative of early faster dissolution of gypsum and other alkali sulphates, and according to the equation (1).

$$
3 \mathrm{CaO} . \mathrm{Al}_{2} \mathrm{O}_{3}+3 \mathrm{CaSO}_{4} \cdot 2 \mathrm{H}_{2} \mathrm{O}+26 \mathrm{H}_{2} \mathrm{O} \rightarrow 3 \mathrm{CaO} . \mathrm{Al}_{2} \mathrm{O}_{3} \cdot 3 \mathrm{CaSO}_{4} \cdot 32 \mathrm{H}_{2} \mathrm{O}
$$

\section{(Ettringite)}

The shift of water bands (lower to higher wave number) indicates that conversion of ettringite to monosulphate (equation 2). 


$$
2\left(3 \mathrm{CaO} \cdot \mathrm{Al}_{2} \mathrm{O}_{3} \cdot \mathrm{CaSO}_{4} \cdot 12 \mathrm{H}_{2} \mathrm{O}\right)+\mathrm{Ca}^{2+}+\mathrm{SO}_{4}^{2-}+8 \mathrm{H}_{2} \mathrm{O} \quad \rightarrow
$$

(Monosulphate)

This is indication of the control paste being converted from plastic to hardened state and coincides with the setting time (Fig.1\&2) (Tong Liang and Yang Nantu, 1994). The shift of silicate band $\left(920\right.$ to $\left.975 \mathrm{~cm}^{-1}\right)$ indicates the formation of CSH and $\mathrm{Ca}(\mathrm{OH})_{2}$ (equation 3 and 4) (Puertas and Fernández-Jiménez, 2003).

$$
\begin{aligned}
& 2 \mathrm{Ca}_{3} \mathrm{SiO}_{5}+6 \mathrm{H}_{2} \mathrm{O} \rightarrow 3 \mathrm{CaO} .2 \mathrm{SiO}_{2 .} 3 \mathrm{H}_{2} \mathrm{O}+3 \mathrm{Ca}(\mathrm{OH})_{2} \\
&(\mathrm{CSH}-\mathrm{gel}) \\
& 2 \mathrm{Ca}_{2} \mathrm{SiO}_{4}+4 \mathrm{H}_{2} \mathrm{O} \rightarrow 3 \mathrm{CaO} . \mathrm{SiO}_{2 .} 3 \mathrm{H}_{2} \mathrm{O}+\mathrm{Ca}(\mathrm{OH})_{2}
\end{aligned}
$$

$30 \%$ fly ash composite (Fig.4f) has higher content of CSH due to the pozzolanic reaction. When fly ash is mixed with water, together with cement, it induces pozzolanic reaction, in which glass phase silica and alumina progressively react with $\mathrm{Ca}(\mathrm{OH})_{2}$, forming hydrates of $\mathrm{CSH}$ as given in eqn. 5 .

$$
2 \mathrm{SiO}_{2}+3 \mathrm{Ca}(\mathrm{OH})_{2} \rightarrow 3 \mathrm{CaO} .2 \mathrm{SiO}_{2} 3 \mathrm{H}_{2} \mathrm{O} \quad(\mathrm{CSH} \text { gel })
$$

The reduction in $\mathrm{Ca}(\mathrm{OH})_{2}$ with fly ash content, increases the $\mathrm{CSH}$ gel, are responsible for the formation of the structure of hardened cement. Therefore, in paste containing fly ash, the hydration of cement forms the hardened structure and the pozzolanic reaction of fly ash improves the structure, ensuring strength development at a longer time.

In effluent water control, the early hydration is accelerated due to chloride ions present in the $\mathrm{EW}$. The $\mathrm{Ca}(\mathrm{OH})_{2}$ content is slightly less after 7 day. It is due to the control paste had suffered sulphate, magnesium ions etc., attack. Consequently, brucite (eqn.6), and recrystallisation of gypsum, ettringite $\left(670 \mathrm{~cm}^{-1}\right)$ are also formed (Lee et al., 2005). It may cause the deterioration of the paste. Brucite is produced by the reaction with $\mathrm{Mg}^{2+}$ ions and $\mathrm{Ca}(\mathrm{OH})_{2}$.

$$
\mathrm{MgSO}_{4}+\mathrm{Ca}(\mathrm{OH})_{2}+2 \mathrm{H}_{2} \mathrm{O} \rightarrow \mathrm{Mg}(\mathrm{OH})_{2}+\mathrm{CaSO}_{4}+2 \mathrm{H}_{2} \mathrm{O}
$$

The effluent water hydrated fly ash (30\%) composite has higher strength than EW control paste. This result is well supported by the earlier reports of Sunil Kumar (2000) who showed that the blending fly ash in OPC has higher strength than control and increased resistance against sea water. This may be due to chloride ion diffusion of paste decreases with increasing replacement of OPC. The decrease may be attributed to change in pore size distribution, increasing CSH gel formation and increasing alumina level enabling more chloride to be fixed as Friedel's salt $\left(\mathrm{C}_{3} \mathrm{~A} \cdot \mathrm{CaCl}_{2} .10 \mathrm{H}_{2} \mathrm{O}\right)(\mathrm{Leng}$ et al., 2000). EW hydrated fly ash composite has lesser strength than DW hydrated fly ash blends composite but higher than EW control paste.

\section{Conclusion}

The EW control has faster setting because of the formation of higher amount of ettringite than DW control. Fly ash blend reduces cementitious materials and hence slow hydration and less strength at early periods. After $7^{\text {th }}$ day, pozzolanic activity of DW hydrated fly ash blend produces more amount of CSH than control. EW hydrated fly ash composite also has higher strength (28 days) than EW control. The 30\% fly ash is a suitable percentage against sulphate attack as well as strength gain in SRPC. Its seems that suitable addition of fly ash and reduction of chloride ions concentration may bring an equivalent paste that of SRPC both in character and strength.

\section{References}

Abdul Aziz A. Khalil. (1982). Infrared spectroscopic studies of the hydration products of the system $\mathrm{CaO}-\mathrm{Al}_{2} \mathrm{O}_{3}-\mathrm{CaSO}_{4}-\mathrm{SiO}_{2}$. Cem. Concr. Res., 12:21-24.

Benarchid, My.Y., J. Rogez, A. Diouri, A. Boukhari and J. Aride. (2005). Formation and hydraulic behavior of chromium-phosphorus doped calcium sulfoaluminate cement. Thermochimica Acta, 433, 183-186.

Cheng Xin, Chang Jun, Lu Ling Chao, Liu Futian and Teng Bing. (2001). Study of Ba-bearing calcium sulphoaluminate minerals and cement. Cem. Concr. Res., 30, 77-81.

Ghorab, H.Y., M.S. Hilal and A.Antal. (1990). Effect of mixing and curing waters on the behavior of cement pastes and concrete. Part2: properties of cement paste and concrete. Cem. Concr. Res., 20:69-72.

Ghosh, S.N and S.K. Handoo. (1980). Infrared and Raman spectral studies in cement and concrete (review). Cem. Concr. Res., 10: 771-782.

Lee, S.T., H.Y. Moon and R.N. Swamy. (2005). Sulphate attack and role of silica fume in resisting strength loss. Cem. Concr.Compo., 27:65-76.

Lee, W.K.W and J.S.J. Van Deventer. (2002). The effect of ionic contaminants on the early age properties of alkali-activated flyash-based cements. Cem. Concr.Res., 32: 577-584. 
Leng, F., N. Feng and X.Liu. (2000). An experimental study on the properties of resistance to diffusion of chloride ions of flyash and blast furnace slag concrete. Cem. Concr. Res., 30(6):989-992.

Malhotra, V.M. and A.A. Ramezanianpour. (1994). Fly ash in Concrete, CANMET, second Edition, Canada.

Mollah, M.Y.A., Felix Lu, Robert Schennach and D.L.Cocke. (1999). An XRD, FTIR and SEM/EDS investigation of the effect of sodium lignosulfonate super plasticizer on the hydration of the hydration of Portland cement type V. Polym.-Plast. Technol. Eng., 38(5):849-868.

Mollah, M.Y.A., Wenhong Yu, Robert Schennach and D.L.Coke. (2000). FTIR spectroscopic investigation of the early hydration of Portland cement and the influence of sodium lignosulfonate. Cem. Concr. Res., 30:267-273.

Natalaya Shannhan and Abla Zayed. (2007). Cement composition and sulfate attack, Cem. Concr. Res., 37: 618-623.

Papadakis, V.G and S.Tsimas. (2002). Supplementary cementing materials in concrete part 1: efficiency and design. Cem. Concr. Res., 32: 1525-1532.

Puertas, F and A. Fernández-Jiménez. (2003). Mineralogical and microstructral characterization of alkali-activated flyash/slag pastes. Cem. Concr. Compo., 25: 287-292.

Rafat Siddique. (2004). Performance characteristics of high volume class F flyash concrete. Cem. Concr. Res., 34: 487-493.

Rai, U.S and R.K.Singh. (2005). Effect of polycrylamide on the different properties of cement and mortar. Mater. Sci. and Eng. A., 392:42-50.

Raungrut Cheerarot and Chai Jaturapitakkul. (2004). A study of disposed fly ash from landfill to replace Portland cement. Waste Management, 24: 701- 709.

Sunil Kumar. (2000). Influence of water quality on the strength of plain and blended cement concrete in marine environments. Cem. Concr. Res., 30:345-350.

Tong Liang and Yang Nantu. (1994). Hydration products of calcium sulfoaluminate in the presence of gypsum. Cem. Concr. Res., 24:150-158.

Van Gervan,T., Johnny Moors, Veroniek Dutre and Carlo Vandecasteele. (2004). Effect of $\mathrm{CO}_{2}$ on leaching from a cement stabilized MSWI flyash. Cem. Concr. Res., 34:1103-1109.
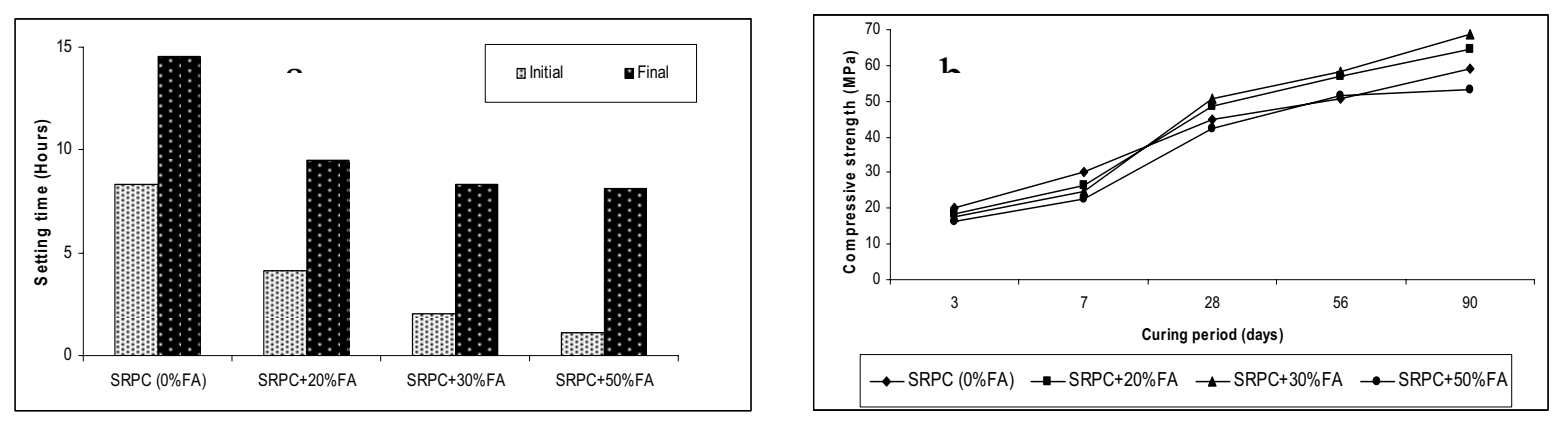

Figure 1. (a) Setting time and (b) Compressive strength of DW-Control and blended SRPC
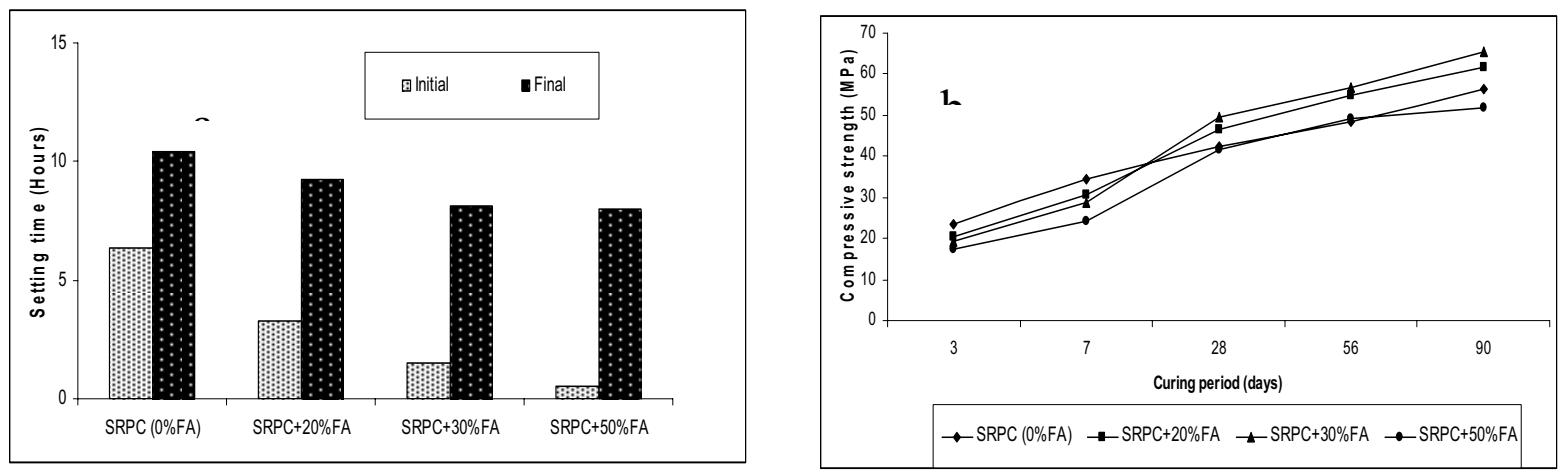

Figure 2. (a) Setting time and (b) Compressive strength of EW-Control and blended SRPC 


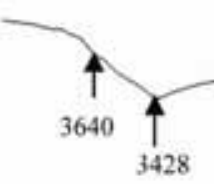

a

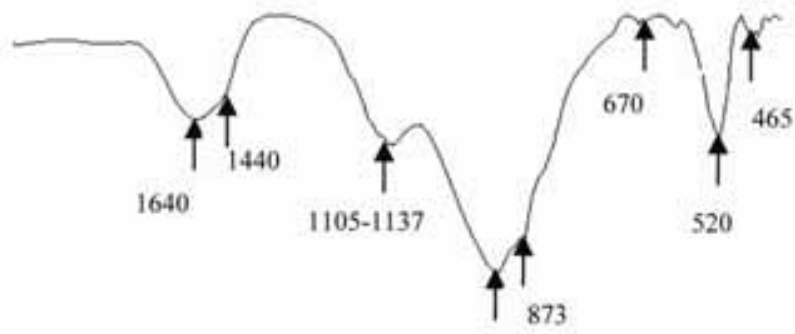

b
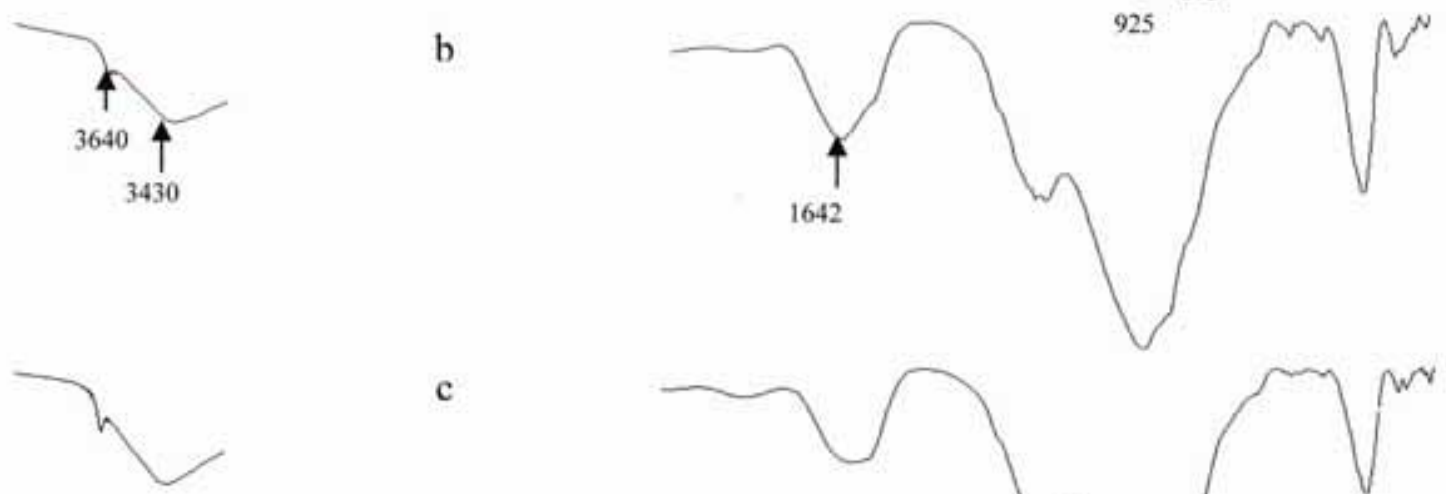

c
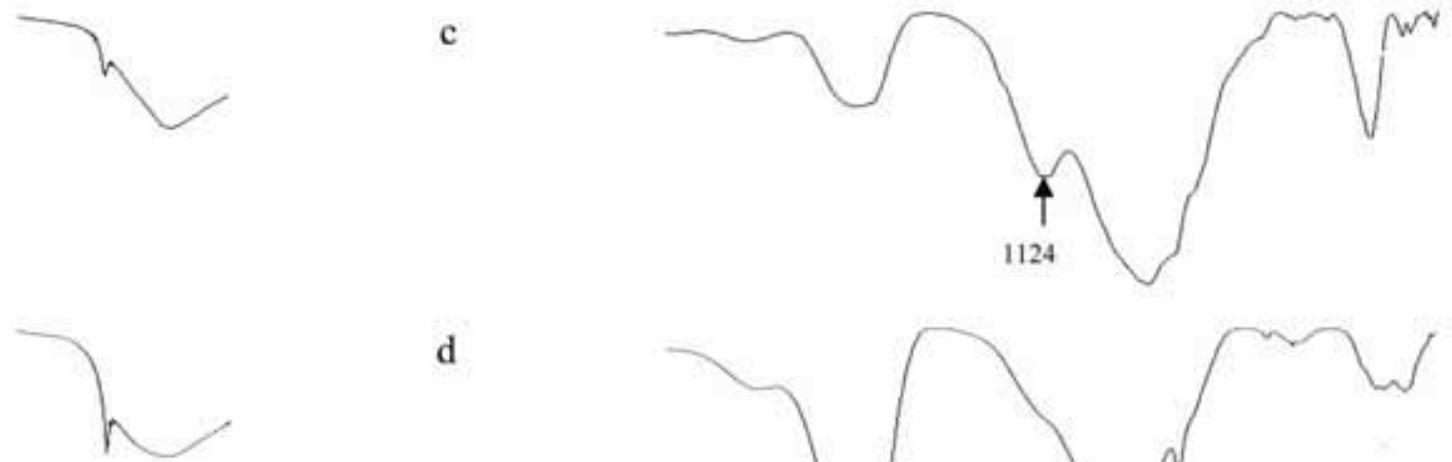

d
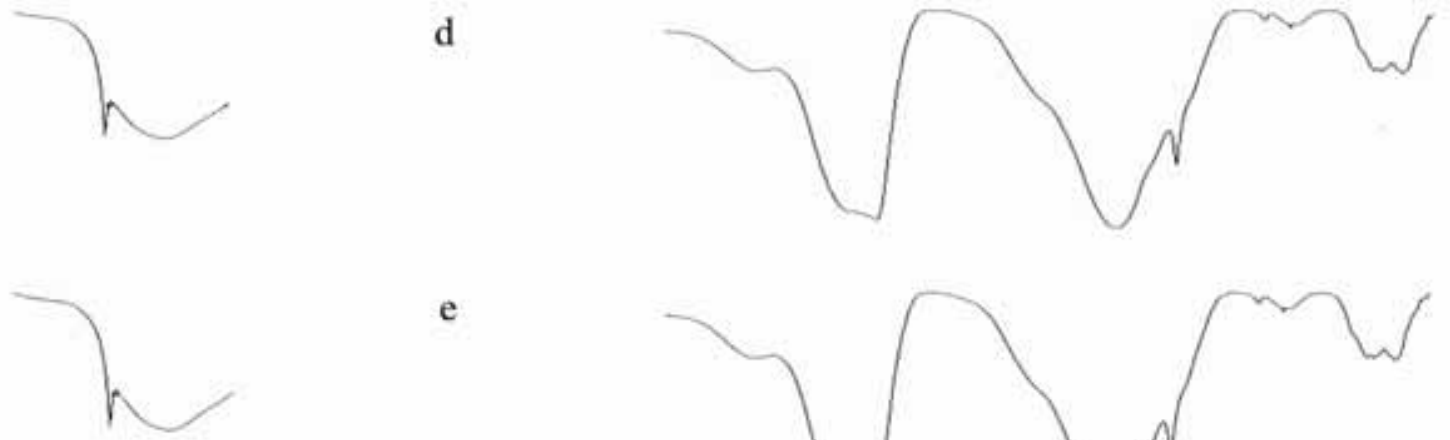

e
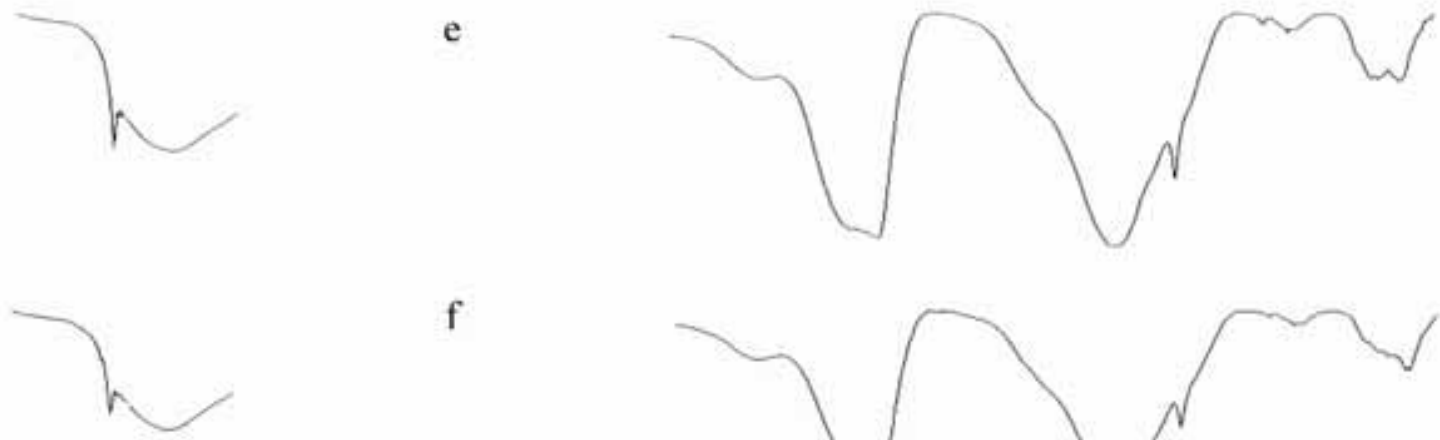

f
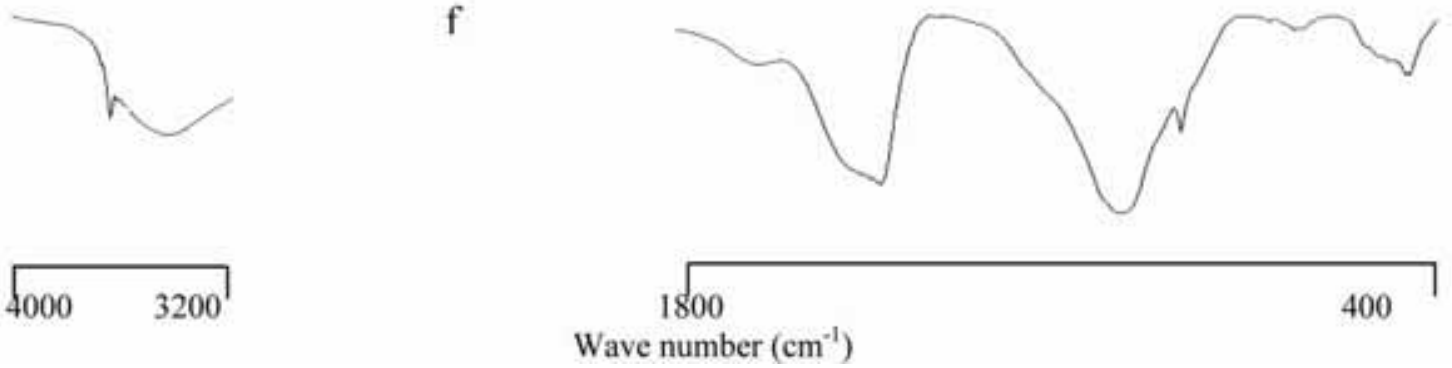

Figure 3. FTIR spectra of SRPC hydrated with DW for (a) 1 hour (b) 8 hours (c) 15 hours (d) 1 day (e) 7 days (f) 28 days 


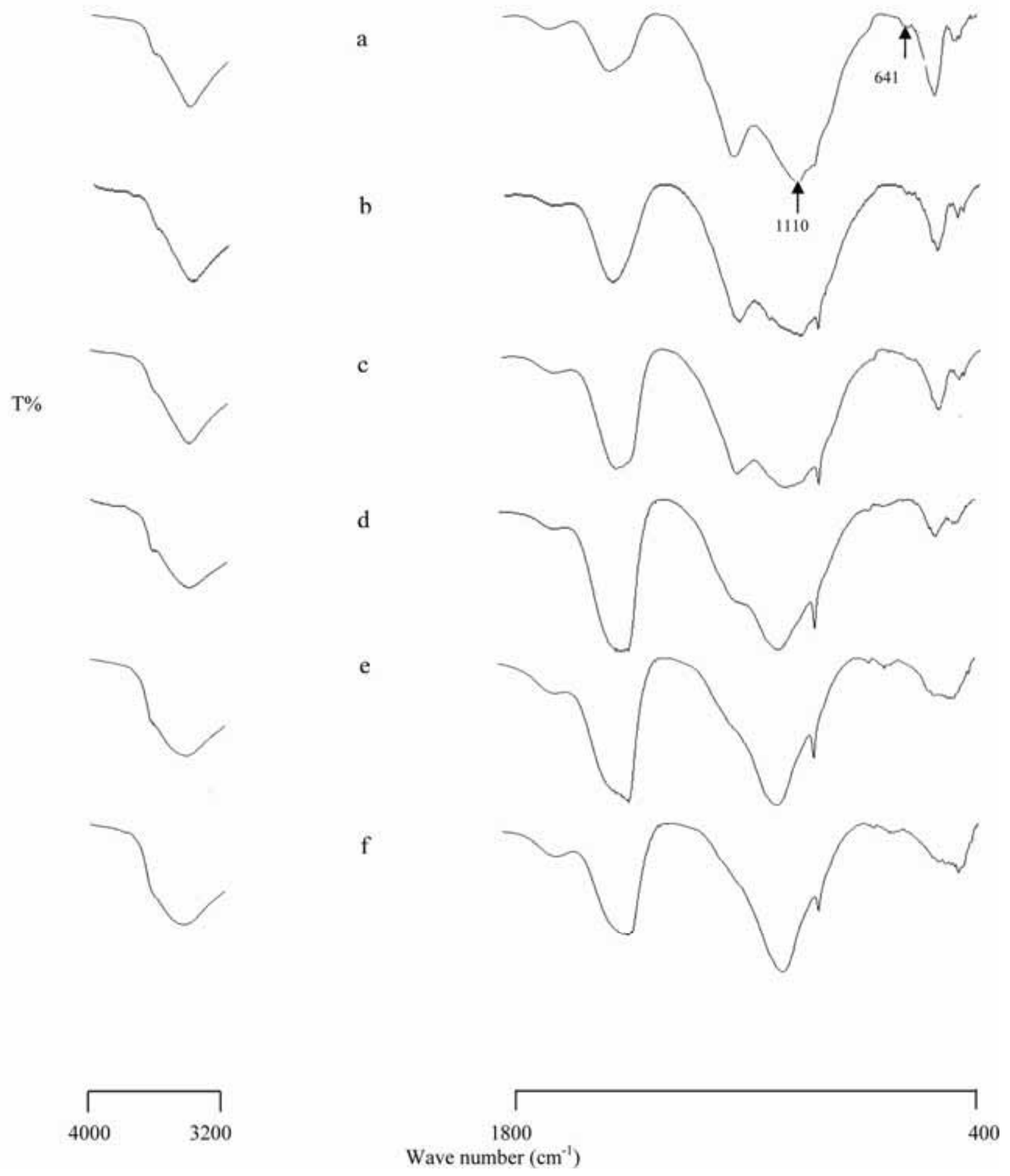

Figure 4. FTIR spectra of SRPC $+30 \%$ FA hydrated with DW for (a) 1 hour (b) 2 hours (c) 9 hours (d) 1 day (e) 7 days (f) 28 days 


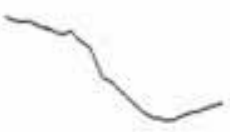

a

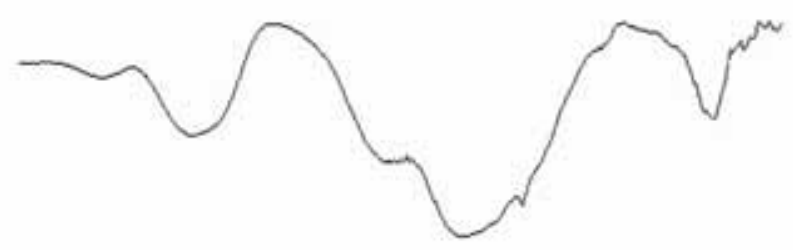

b

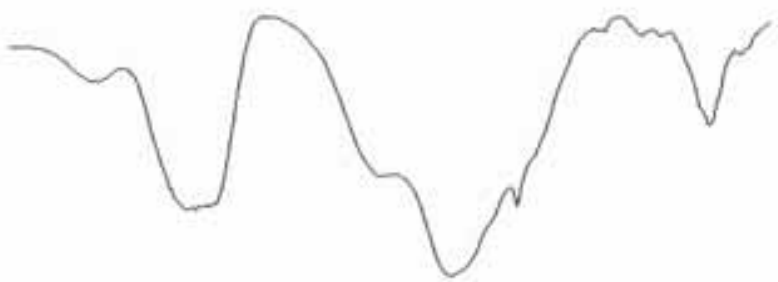

c
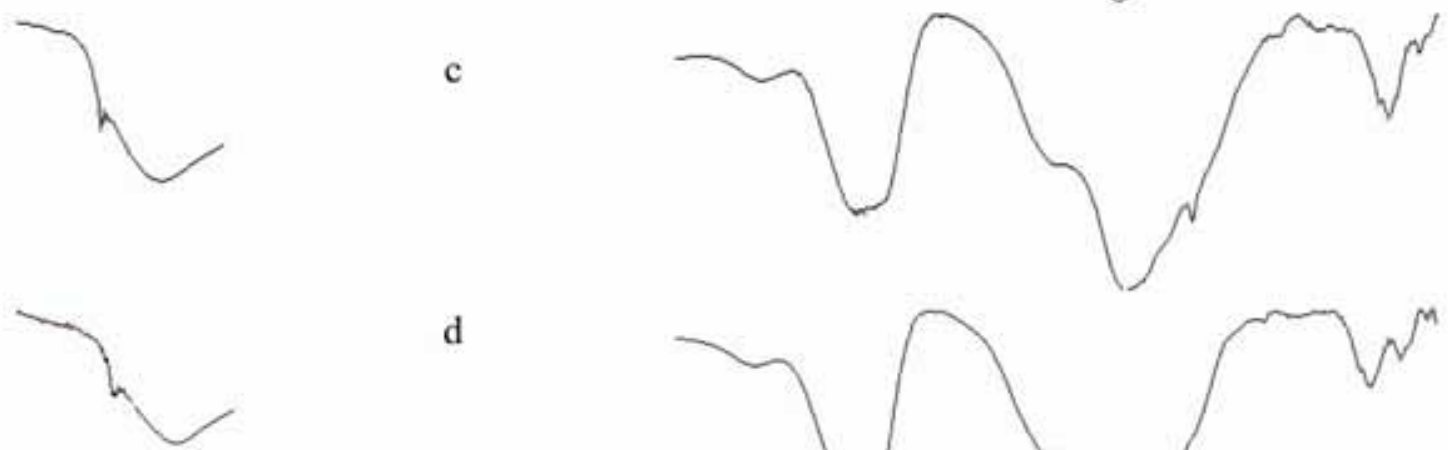

d

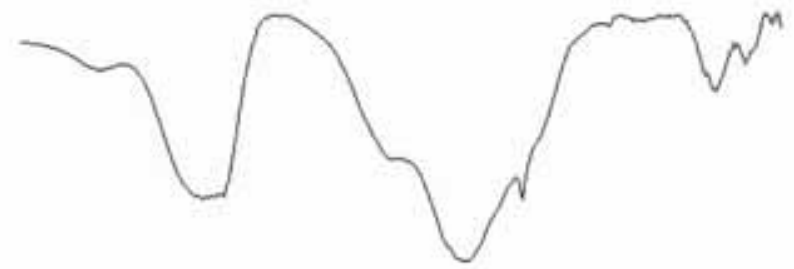

e
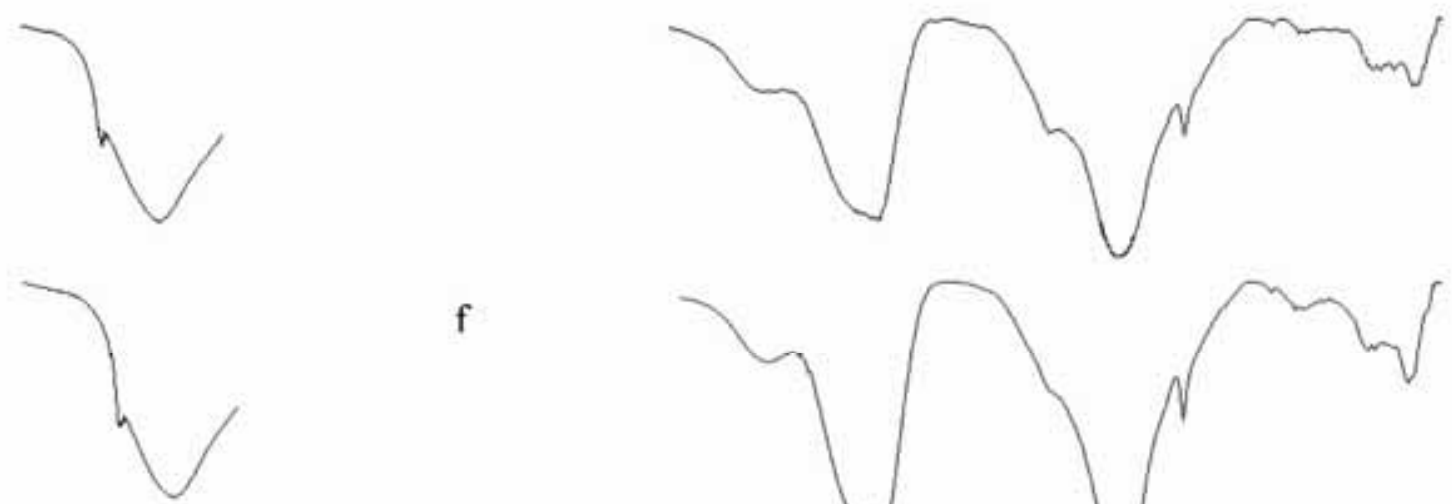

f

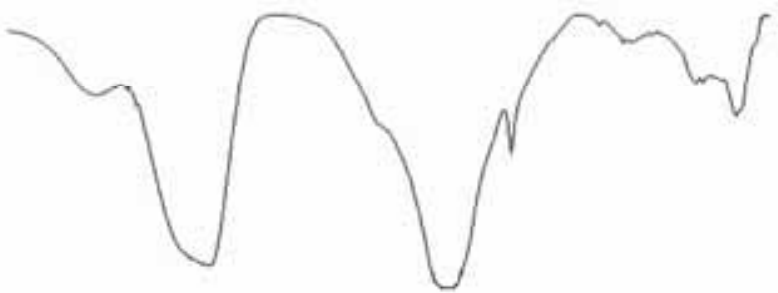

1800

Wave number $\left(\mathrm{cm}^{-1}\right)$
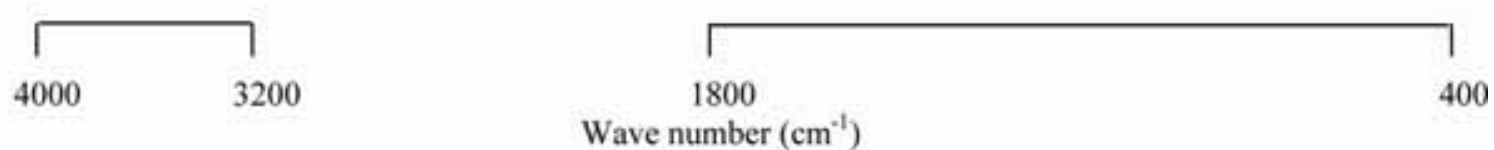

Figure 5. FTIR spectra of SRPC hydrated with EW for (a) 1 hour (b) 6 hours (c) 11 hours (d) 1 day (e) 7 days (f) 28 days 

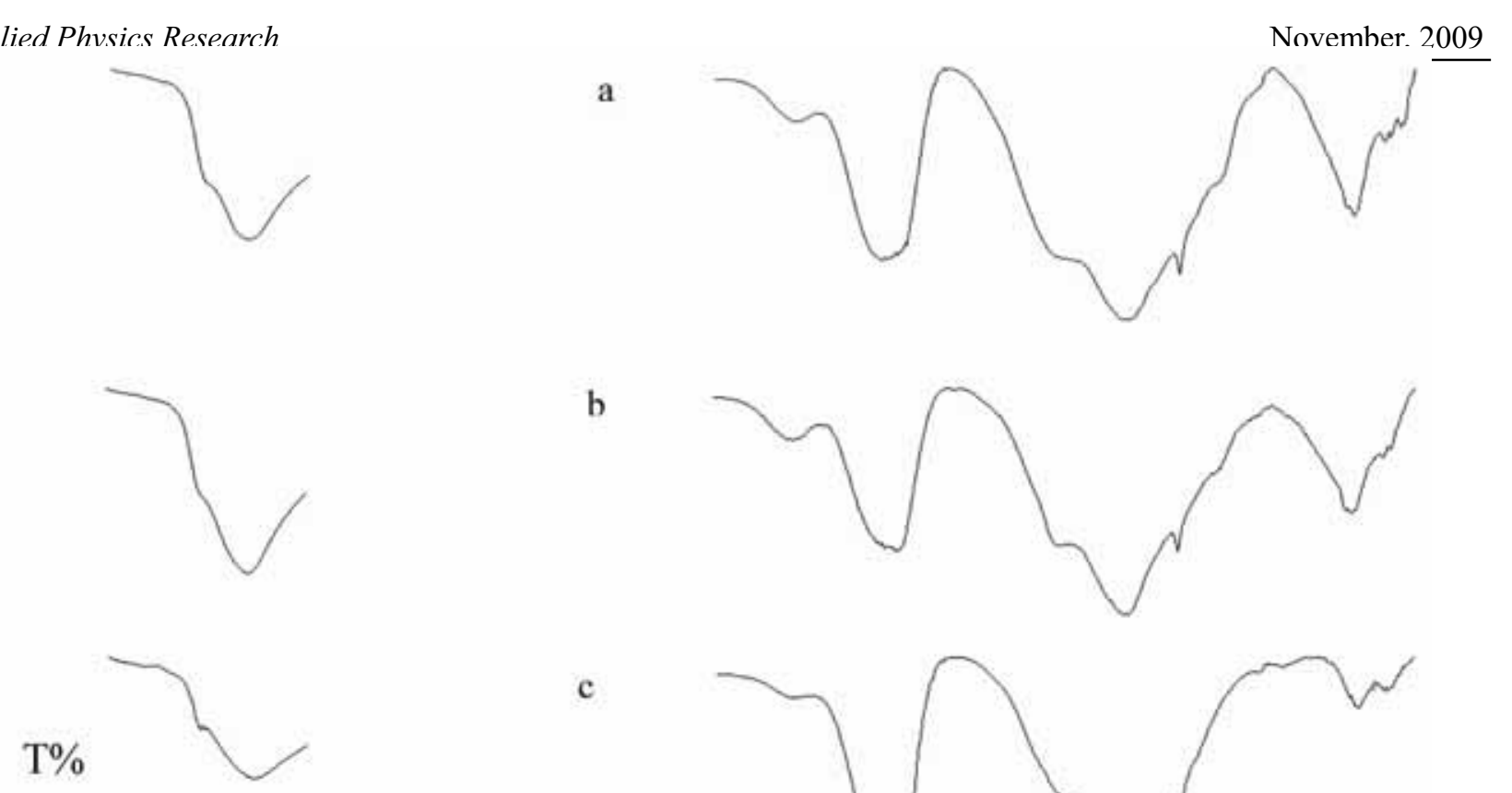

b

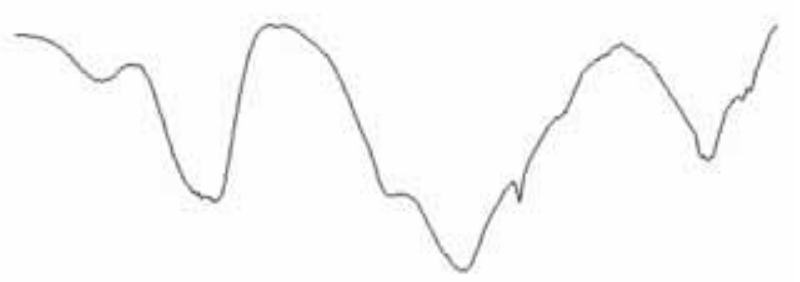

c
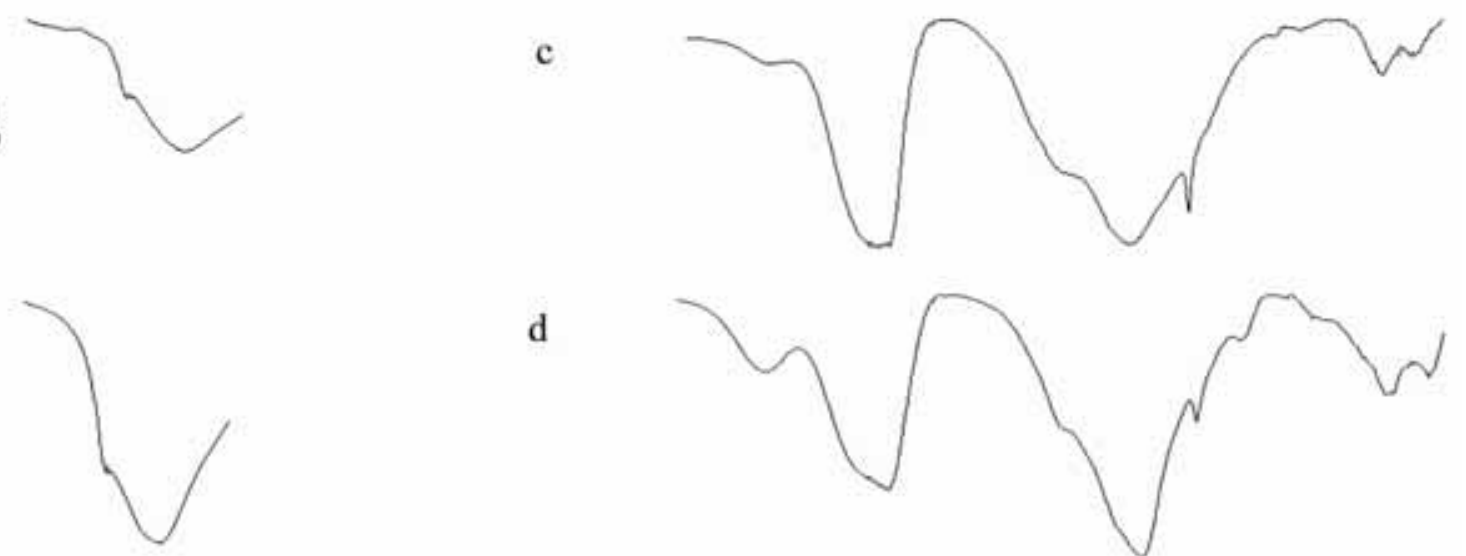

d
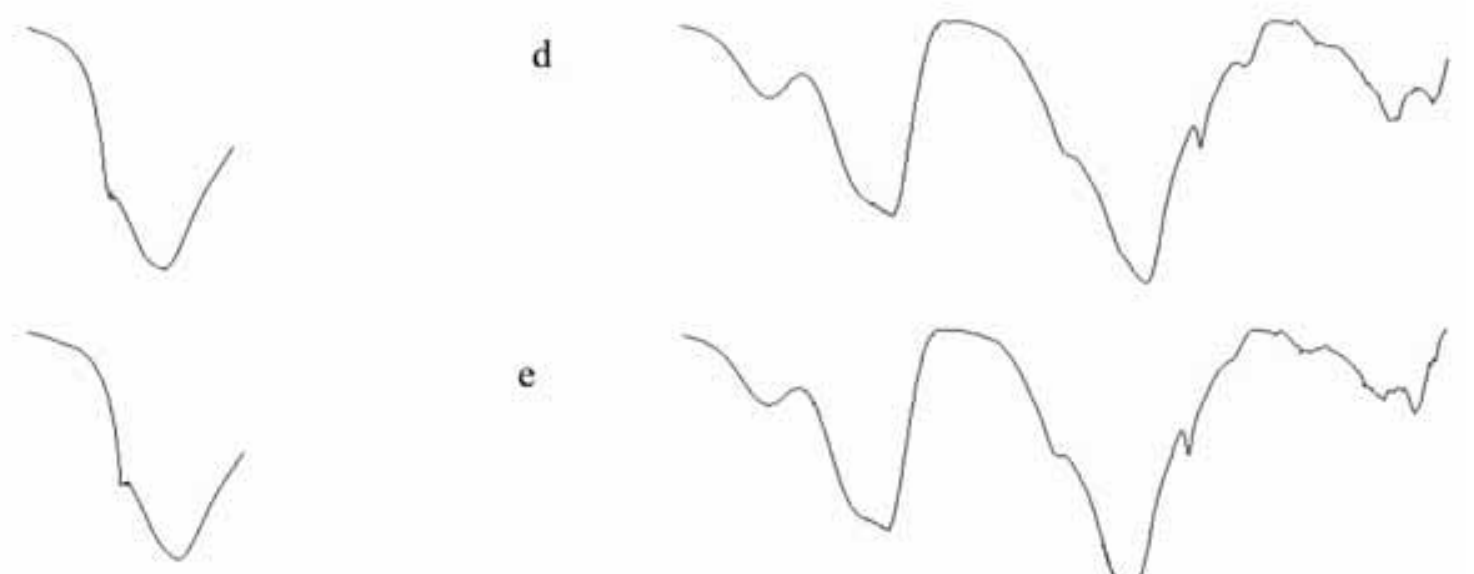

e
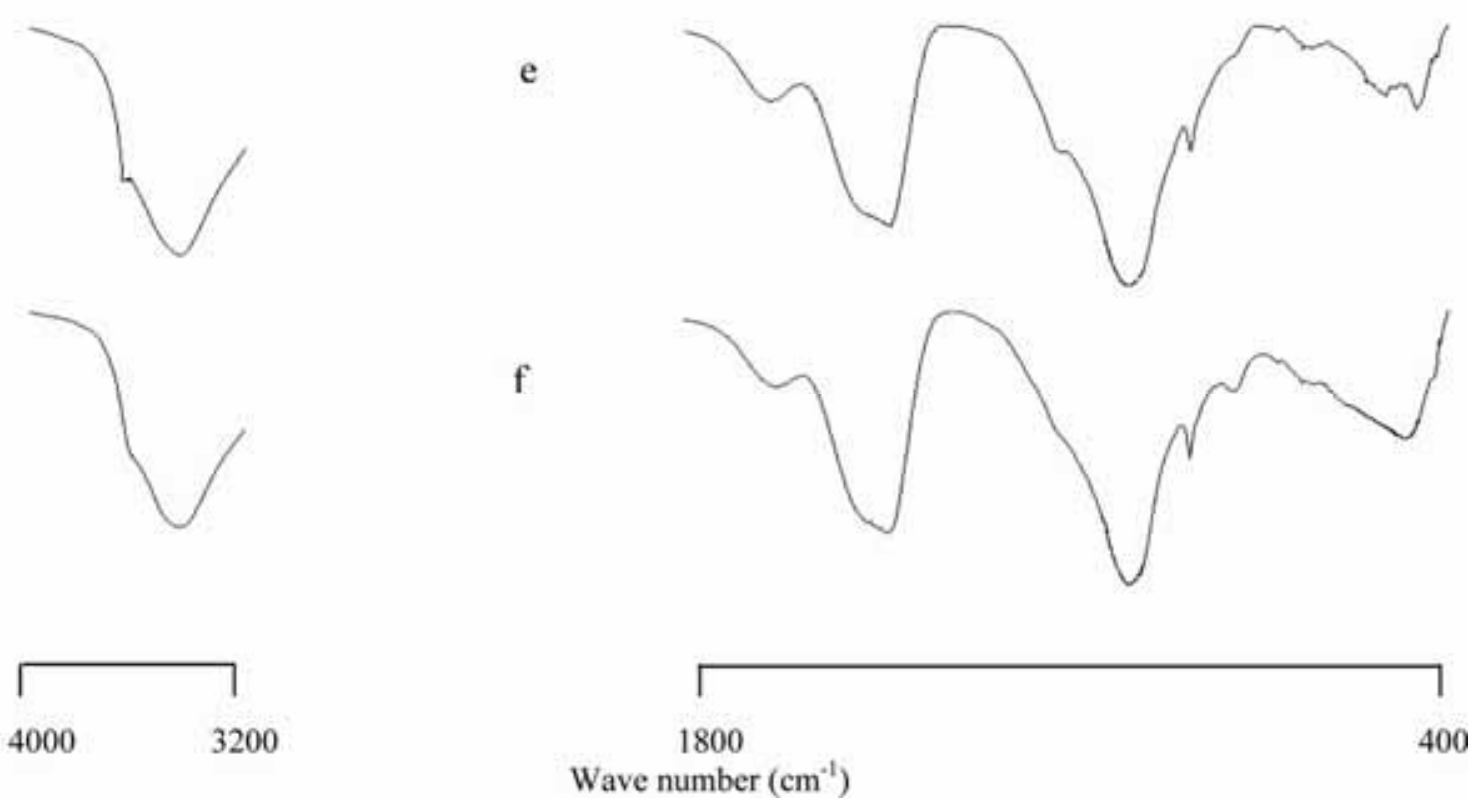

Figure 6. FTIR spectra of SRPC $+30 \% \quad$ hydrated with EW for (a) 1 hour (b) 2 hours (c) 8 hours $\quad$ (d) 1 day (e) 7 days (f) 28 days 


\title{
Study on the Laser Hybrid Cladding Technology
}

\section{on the Surface of Copper Substrate}

\author{
Fudong Zhu \& Yunshan Wang \\ Laser Processing Center, Tianjin Polytechnic University, Tianjin 300160, China \\ E-mail: pb701@163.com
}

The research is financed by the Science Foundation of Tianjin (No. 08JCYBJC09200). (Sponsoring information)

\begin{abstract}
To enhance the staying quality of the surface of the copperplate, the laser hybrid cladding technology can be used to clad Ni-Cr alloy on the surface of the copperplate. By the traditional laser cladding technology, it is hard to directly form good coat on the surface of the copperplate. In the article, the coat is made on the surface of the copperplate by the laser hybrid cladding technology, and the staying quality tests are made for samples by several methods, and the micro-hardness and the staying quality of the coat are far higher than the cooper substrate, and coat has good roughness of surface. And the test result indicates that the method adopting the laser hybrid cladding technology can prepare the alloy coat on the surface of the deep copperplate.
\end{abstract}

Keywords: Surface technology, Laser hybrid cladding, Induction cladding, Thermal spraying, Micro-arc Deposition

\section{Introduction}

At present, coppers and copper alloys have been widely applied in the industrial production. The continuous molten technology occupies the leading status in Chinese metallurgy industry, and its key component, crystallizer, is mainly made by coppers. Most traditional methods adopt the surface coating or the copper alloy to make the crystallizer to strengthen the staying quality, but the coat is thin and easy to be frayed after long time use. The laser cladding technology is a kind of new improved surface technology, and the steel surface cladding, especially the steel surface alloy powder cladding, has been widely used in commercial application (E.H Beyer, 2004, P.1-6). But it is more difficult to clad metals on the copper surface than to clad metals on the steel surface, because, first, the reflectivity of the copper to the $\mathrm{CO}_{2}$ laser is very high, second, the coppers have good thermal conduction, third, the heat expansion coefficient of coppers is very high, and cracks will easily occur when forming the coat with most cladding materials, therefore, it is very theoretically and practically meaningful to study the laser hybrid cladding on the surface of copper substrate.

The laser cladding technology adds the cladding materials on the substrate, heats and melts the cladding materials and the surface coat of the substrate by the high-energy density laser radiation, and realizes quick agglomeration through the chilling action of the substrate, so the cladding coat combined with metallurgy will form on the surface of substrate (Guan, 1998, No.265). The laser cladding technology can improve the hardness, the staying quality, the anti-corrosion and the anti-oxidation of the surface performance of the materials, and it has been an effective method to strengthen the surface of the material. This technical method can not only enhance the surface performance of the material, but also save many expensive metals, and it can not only modify the surface, but also repair the surface (Shepeleva L, 2000, P.45-48), so its application foreground is very wide.

The traditional surface modified technique and the laser cladding technology have their own limitations, and the laser hybrid cladding technology can combine with the advantages of these two technologies, and compensate the deficiencies in these two technologies, which makes the laser cladding technology to be widely applied in relative industries.

\section{Laser-deduction hybrid cladding technology}

The deduction cladding technology is a new hybrid surface modified technology, and it utilizes the deduction skin turbulence heating principle to clad the fusible alloy on the surface of the work-piece and form the coat with the staying 
quality and anti-corrosion feature. In recent years, this technology has been widely applied in the oil fields, the metallurgy industry, and the industrial boilers (Zhang, 2001).

The deduction heating has high efficiency and little energy consumption, but in the production process, following phenomena still may exist such as the aberrance of the coat is too large, and the substrate is too heated, and the quality of the product can not be easily controlled.

The laser deduction cladding technology is to prepare the alloy powder layer on the substrate of the work-piece, and utilize the alternating electromagnetic field in the deduction loop to produce the turbulence in the work-piece, and melt the coat by virtue of the heats produced by the skin effect of the turbulence, and implement the laser cladding when making deduction heating, and combine the alloy powder layer with the substrate to strengthen the surface of the substrate. But because the turbulence control when implementing the deduction heating is very complex, so the reports about this research domain are very less, so the theoretical research about this aspect is very important.

\section{Laser-thermal spraying hybrid cladding technology}

The thermal spraying technology means a metal surface machining method which heats the spraying material to the melting or half-melting status, and pulverizes and quickens it by the high-speed airflow, and makes it to spray the surface of the work-piece with high-speed, and forms the spraying coat. According to the heating sources, there are four basic methods such as the flame spraying, the electric arc spraying, the plasma spraying and the special spraying. In China, the thermal spraying technology has been used to make the anti-oxidation coat on the copper alloys.

The thermal spraying possess following characters. First, the flame temperature is high, and the heat can be centralized, and the powder materials with high melting point and high hardness can be melted. Second, after spraying, the coat is flat and smooth, and the coat depth can be exactly controlled. Third, the area influencing the surface of the work-piece is very small. Fourth, the technical standard is stable and easy to be operated.

But there are many deficiencies of the thermal spraying on the copper surface. For example, the coat of the thermal spraying gives priority to the mechanical combination, and the surface prepared by the thermal spraying technology is very coarse, and the anti-variance is bad, so the hot impaction will be influenced under high temperature. In addition, the existence of the holes in the coat will induce the failure of the coat under low temperature, and produce cracks and impact the heat barrier feature and the anti-hot corrosion feature under high temperature.

The combination of the thermal spraying technology and the laser cladding technology can effectively solve part problems. The laser cladding can obviously enhance the surface coarseness of the work-piece after thermal spraying, and the air holes in the coat will be obviously reduced, and the structure of the crystal grain will become thin and equal, and the organization will be denser, and the straying quality will be obviously enhanced. However, because the thermal spraying coat and the substrate are combined mechanically, so under bad working conditions such as high temperature and impact, the performances of the coat need to be further studied (Y.J. Liu, 2008, P.373-374 \& 392-395).

\section{Laser-high energy micro-arc deposition hybrid cladding technology}

The high-energy micro-arc deposition technology is a simple and flexible metal surface processing method, and it has been applied in the components in foreign aviation and spaceflight industry. It is a new technique without stress and distortion, and its shortened form is HEMAD. It directly utilizes the electric energy with high-energy density to intensively treat the surface of the work-piece, and by the function of spark discharge, the temperature of the contact part between the electrode and the work-piece in $10^{-6}-10^{-5} \mathrm{~s}$ will achieve $8000-25000^{\circ} \mathrm{C}$, and as the electrodes, the conductive furious materials will be melted into the surface of the metal work-piece, and form the alloyed surface strengthened layer (Zhao, 2001, P.35-36).

Because the alloyed surface deposition layer with electrode materials can improve the material performance, the chemical materials and the mechanical materials of the work-piece surface, and its interior organizational and mechanical performance will not change. The high-energy maintenance deposition possesses not only some characters of the jointing technique and the spraying technique, but some special characters such as small heat input and the combination of the deposition layer and the substrate metallurgy.

At present, the high-energy micro-arc strengthening technique has been widely applied in many industries such as the motor, the electric equipment, the instrument, the light industry, the machine manufacturing, the farming machine, the chemical industry and the traffic transportation, and acquired good economic benefits. The high-energy micro-arc deposition can not only effectively enhance the staying quality, the anti-corrosion feature, the hot-hardness and the high-temperature anti-oxidation feature of the component surface, but also increase the surface coarseness and influence the fatigue performance of the material. In addition, this technology can be used to remedy the small abrasion of the work-pieces such as the molds, measures and components of the machine to maintain the normal operation of the equipments, so it has significantly economic values. Therefore, the manufacturing level and the technical level of the deposition equipment can be further discussed and enhanced, which is very meaningful to expand the application 
domain, enhance the stability, reliability and the production efficiency of the technology (Wang, 2000, P.3-5 \& J.W Li, 2002, P.223-225).

The high-energy micro-arc deposition technology has many advantages, but its machining efficiency is very low, and the depth of the deposition layer is less than $1 \mathrm{~mm}$, so it is very difficult to prepare the deposition layer with certain depth on the copperplate, and the laser-high energy micro-arc deposition hybrid cladding technology can compensate the deficiencies of the micro-arc deposition technology, but in the production process, the laser cladding on the thin surface of the deposition can largely enhance the production efficiency. At the same time, for the laser cladding of the deposited work-piece, the crystal grain of the deposition layer is thin and equal, and the organizational structure of the cladding layer is denser, and the material shows that the staying quality and the hardness will be obviously enhanced.

Though the deposition layer and the copper substrate can form the metallurgy combination, but the combination area will have obvious cracks and air holes, which is decided by the micro-arc deposition principle, and these deficiencies can not been completely eliminated, so the performances under many bad working conditions such as high temperature and strike should be further studied.

\section{Foreground and expectation}

In the article, the combination of the traditional surface strengthening technology and the laser cladding technology is proposed, and by reasonable technical design, the cladding coat with even and dense organization and good staying quality can be prepared under the condition of high-power laser quick scanning. This research not only possesses good industrialized application foreground, and important scientific research values, but can improve the development of the advanced laser cladding technology.

\section{References}

E.H Beyer, B. Brenner and S. Nowotny. (2004). Proceedings of the $1^{\text {st }}$ Pacific International Conference on Application of Lasers and Optics, P. 1-6.

Guan, Zhenzhong et al. (1998). Handbook of Laser Machining Technology. Beijing: China Measuring Press. No. 265.

J.W Li, Z.Y Wang and J.L Zhu. (2002). Journal of Shenyang Arch. and Civ. Eng. Univ. (Natural Science), July 2002, Vol. 18, No. 3. P. 223-225.

Shepeleva L, Medres B, Kaplan W D, et al. (2000). Laser cladding of turbine blades. Surface and Coatings Technology, No. 125(1). P. 45-48.

Wang, Zhenmin, Huang, Shisheng, Wen, Jinlin \& Zhang, Zhongli. (2000). Developing Status of Electric Spark Surface Hardening Technology. Tool Engineering, No. 34(5). P. 3-5.

Y.J. Liu, Y.S. Wang, X.C. Yang. (2008). Study on Wear Resistance of Plasma Sprayed Coating Re-melted by Laser. Key Engineering Materials. P.373-374 \& 392-395.

Zhang, Zengzhi. (2001). High-efficient and Quick Deduction Cladding and Spraying Technology. Beijing: Metallurgical Industry Press.

Zhao, Shuping. (2001). Analysis of Deposited Coating Depth and the Surface Finish Degree of Electric Sparks. Heat Treatment of Metals Abroad, No. 22(6). P. 35-36. 


\title{
Investigation on the Hydration Properties of the Rice Husk Ash Cement Using Ftir and Sem
}

\author{
G. Sivakumar (Corresponding Author) \\ Centralised Instrumentation and Service Laboratory (CISL) \\ Department of Physics, Annamalai University \\ Annamalai nagar 608 002, Tamilnadu, India \\ Tel: 91-986-560-9800 E-mail: gsk_cisl@yahoo.com \\ R. Ravibaskar \\ Material Science Research Laboratory \\ Department of Physics, Annamalai University \\ Annamalainagar 608 002, Tamilnadu, India \\ Tel: 91-984-208-8302 E-mail: rrbaskarphy@ymail.com
}

\begin{abstract}
Effect of Rice husk ash on hydration properties of rice husk ash cement paste are reported in this paper. Rice Husk Ash (RHA) is used to replace $20 \%$ of Portland cement and water to solid ratio is 0.4 . The hydration products observed due to rice husk ash addition were confirmed using the characteristic peak of Fourier Transform Infrared (FTIR) spectra and the micro structural changes were noted using Scanning Electron Microscope (SEM) micrographs. The rice husk ash cement paste gains more strength due to the production of more Calcium Silicate Hydrate (CSH) gel (pozzolanic reaction products).
\end{abstract}

Keywords: Rice Husk Ash, Cement, FTIR, SEM

\section{Introduction}

Rice husk ash cement is formed by the combination of Ordinary Portland Cement (OPC) with rice husk ash (RHA). Rice husk ash (RHA) is an end product of the combustion of rice husk (or hull). Unlike other pozzolanic materials, the concrete incorporating the RHA shows excellent strength development at early-age even without steam-cure (Wada I. et al., 2000). Burned rice husk give $14-20 \%$ ash by weight which contains approximately $90 \%$ by weight silica and minor amounts of other elements.

Many researchers, have investigated the possible addition of rice husk ash (10\% to $30 \%)$ as a supplementary cementitious material. RHA is a mineral admixture for concrete and a lot of mechanical data (Ganesan et al., 2008; Gemma Rodriguez de Sensale, 2006; Saraswathy and Ha-Won Song, 2006) has been published. The literature regarding the effect of the RHA on molecular vibration and micro structural is vague. Therefore, the main objective of this study is to evaluate and compare the effect of rice husk ash in rice husk ash cement paste with the OPC using FTIR and SEM.

\section{Materials and Methods}

The materials used in this investigation consist of market available Ordinary Portland Cement (ASTM type I) and Rice Husk Ash (RHA) collected from Modern Rice Mill, Erukur, Tamil Nadu, India. The chemical composition of OPC and RHA are given in Table. 1. It reveals the highly siliceous $\left(\mathrm{SiO}_{2}-92.78 \%\right)$ nature of the ash. The partial replacement of cement by rice husk ash in weight percentage is carried out for OPC $+0 \% \mathrm{RHA}$ and $\mathrm{OPC}+20 \% \mathrm{RHA}$. The samples were hydrated with distilled water at the water to solid ratio (w/s) is 0.4 and different hydration intervals. 
Setting time of the OPC and rice husk ash cement samples were measured by the penetration resistance method in accordance with the ASTM C 403 using the standard procedure and strength measurement was conducted for the samples using ASTM C 349 method and its results are given in Fig. 1(a) and (b).

The Infrared spectra are recorded using Perkin Elmer model RX-1 FTIR spectrometer for the powdered samples are made to a pellet by mixing with KBr. For SEM study, a thin layer of fractured surface of sample is mounted on the stub using double sided adhesive carbon tape. The specimens are coated with the help of gold coater (JEOL auto fine coater model JFS-1600, coating time is 120 seconds with $20 \mathrm{~mA}$ ). The micrographs are recorded using JEOL SEM model JSM-5610 LV available at CISL, Annamalai University, Tamil Nadu, India.

\section{Results and discussion}

\subsection{FTIR study}

FTIR spectra of the hydrated OPC and OPC $+20 \%$ RHA samples are shown in Fig. 2 and 3. In the 1hour OPC spectrum (Fig. 2a), the $\mathrm{OH}$ stretching band at $3640 \mathrm{~cm}^{-1}$, symmetric stretching $\left(v_{1}\right) \mathrm{H}_{2} \mathrm{O}$ at $3415 \mathrm{~cm}^{-1}$, asymmetric stretching vibrations $\left(v_{3}\right)$ carbonate at $1460-1420 \mathrm{~cm}^{-1}, v_{3}$-sulphate doublet at1090 and $1150 \mathrm{~cm}^{-1}$ and $v_{3}$-silicate at $917 \mathrm{~cm}^{-1}$ and out-plane $\left(v_{4}\right)$ carbonate at $874 \mathrm{~cm}^{-1}, v_{4}$-sulphate at $660 \mathrm{~cm}^{-1}$ and $v_{4}$-silicate at $519 \mathrm{~cm}^{-1}$ and in-plane bending vibrations $\left(v_{2}\right)$ $\mathrm{H}_{2} \mathrm{O}$ at $1610 \mathrm{~cm}^{-1}, v_{2}$-sulphate at $610 \mathrm{~cm}^{-1}$ and $v_{2}$-silicate at $462 \mathrm{~cm}^{-1}$ bending vibrations are present (Harchand et al., 1980; Mollah et al., 1999; Hassaan M Y \& Abdel N. Hakeem, 1989; Mollah et al., 2000; Ghosh S N \& Chatterjee A K, 1974; Hanna et al., 1995). The $v_{3}$ sulphate doublet bands transform to a singlet $\left(1102 \mathrm{~cm}^{-1}\right)$ on 1 day hydration (Taylor H F W, 1990). It is indicative of early faster dissolution of gypsum and other alkali sulphates, and ettringite formation. Water stretching band at $3415 \mathrm{~cm}^{-1}$ has grown in intensity with a shift $\left(3438 \mathrm{~cm}^{-1}\right)$ compared to 1 hour, while the intensity of $v_{4}$ and $v_{2}$ sulphates have reduced. The shift of water stretching band may be due to conversion of ettringite to monosulphate (Sivakumar et al., 2009)

$$
\begin{array}{rr}
\mathrm{C}_{3} \mathrm{~A}+\underset{(\text { Gypsum })}{3 \mathrm{C} \overline{\mathrm{S}} \mathrm{H}_{2}+26 \mathrm{H}} \rightarrow & \multicolumn{1}{c}{\mathrm{C}_{6}{\mathrm{~A} \overline{\mathrm{S}_{3}} \mathrm{H}_{32}} \rightarrow} \\
& \text { (Ettringite) } \\
2 \mathrm{C}_{3} \mathrm{~A}+\mathrm{C}_{6} \mathrm{~A}_{3} \mathrm{H}_{32}+4 \mathrm{H} \rightarrow & 3 \mathrm{C}_{4} \mathrm{~A} \overline{\mathrm{S}} \mathrm{H}_{12} \\
& \text { (Monosulfate) }
\end{array}
$$

The shifting of $v_{3}$ silicate towards higher frequency $\left(917 \mathrm{~cm}^{-1}\right.$ to $\left.980 \mathrm{~cm}^{-1}\right)$ with an intensity variation may be attributed to precipitation of colloidal suspension of amorphous CSH (Flores-Velez L M A \& Dominguez O, 2002), as a result of reaction of $\mathrm{C}_{3} \mathrm{~S}$ and $\mathrm{C}_{2} \mathrm{~S}$ with water according to the following reactions,

$$
2 \mathrm{C}_{3} \mathrm{~S}+6 \mathrm{H} \rightarrow \mathrm{C}_{3} \mathrm{~S}_{2} \mathrm{H}_{3}+3 \mathrm{CH}
$$

$$
2 \mathrm{C}_{2} \mathrm{~S}+4 \mathrm{H} \rightarrow \mathrm{C}_{3} \mathrm{~S}_{2} \mathrm{H}_{3}+\mathrm{CH}
$$

Cement chemistry notation: $\mathrm{C}=\mathrm{CaO} ; \mathrm{S}=\mathrm{SiO}_{2} ; \mathrm{A}=\mathrm{Al}_{2} \mathrm{O}_{3} ; \mathrm{F}=\mathrm{Fe}_{2} \mathrm{O}_{3} ; \mathrm{S}=\mathrm{SO}_{3} ; \mathrm{H}=\mathrm{H}_{2} \mathrm{O}$

The $v_{3}$-silicate shifting through 63 wave numbers indicate the beginning of setting and strength development. This result is well manifested through Fig. 1. The formation of $\mathrm{Ca}(\mathrm{OH})_{2}$ is a by product of $\mathrm{C}_{3} \mathrm{~S}_{\text {and }} \mathrm{C}_{2} \mathrm{~S}$ reaction and has contributed a strong and sharp peak (1day onwards) at $3640 \mathrm{~cm}^{-1}$. The $v_{2}-\mathrm{OH}$ band at $1610 \mathrm{~cm}^{-1}$ has not only grown but also moved to higher frequency $\left(1630 \mathrm{~cm}^{-1}\right)$. This can be attributed to greater restriction of vibration due to incorporation of water molecules into the cement matrix.

The $v_{3}$ silicate band ( $4^{\text {th }}$ week spectra) at $519 \mathrm{~cm}^{-1}$ decreases while $v_{2}$ silicate at $462 \mathrm{~cm}^{-1}$ has an increase in intensity. This is a finger print evidence for the higher degree of silicate polymerization of the precipitated CSH. It indicates the completion of hydration in this stage and well coincide with the compressive strength results.

Hydrated RHA cement (OPC+20\% RHA) sample (Fig.3) have the same mode of vibration of oxides as that of control. However they observe some differences, the characteristic RHA band at $1095 \mathrm{~cm}^{-1}$ gets a stronger intensity at 1 hour spectrum. From 1 day a decreasing trend in intensity is observed. It indicates the starting of pozzolanic reaction. The RHA peak at $1095 \mathrm{~cm}^{-1}$ fades with time but consistently consumed to yield CSH hydrate according to the following reaction (pozzolanic reaction),

$$
2 \mathrm{SiO}_{2}+3 \mathrm{Ca}(\mathrm{OH})_{2} \rightarrow 3 \mathrm{CaO} \cdot 2 \mathrm{SiO}_{2} \cdot 3 \mathrm{H}_{2} \mathrm{O}
$$

From 1 day, the relative intensity changes between $v_{4}$ and $v_{2}$ silicate bands are also faster in rice husk ash cement. The $v_{3}$ silicate band $(\mathrm{CSH})$ has higher energy with strong intensity in rice husk ash cement. The pozzolanic reaction is higher in rice husk ash cement at 28 days which accelerates the rate of reaction and enhances the strength. 


\subsection{SEM Study}

Hydrated SEM micrographs of OPC and rice husk ash cement sample are shown in Fig. 4 \& 5 respectively. From 1hour OPC micrograph (Fig.4a), the anhydrous cement particles appear much brighter than hydrated products. The initial hydration has produced textural changes on the surface due to formation of a discontinuous layer of some hydration product. At 1 day (Fig.4b) micrograph, the hydration products of ettringite (E) needles are seen on the cement grains. After 1 day the initial frame work of ettringite needles start to disappear and it is replaced by tightly packed oriented long rods indicating $\mathrm{CH}$ crystals.

From the 1week micrograph (Fig.4c), the ettringite needles are not shown. The hexagonal shaped $\mathrm{CH}$ crystals $\left(\mathrm{Ca}(\mathrm{OH})_{2}\right)$ with large crystalline particles and the foil honey-comb structure of calcium silicate hydrate (CSH) are present in the micrograph. It is indicate that the hydration reaction. Since the CSH and $\mathrm{CH}$ comprised over $75 \%$ of the hydrated cement paste, it plays a major role in determining the strength of the cement. As time passes (after 1week onwards), a better crystallization of the CSH formation is observed in the $4^{\text {th }}$ weeks (Fig. 4d) micrograph. This massive structure (Mohanraj et al., 2007) has more rigidity. It is evidence for a higher degree of silicate polymerization of the precipitated CSH in the later periods. These observations well coincide with the compressive strength results.

The hydration product of the rice husk ash cement sample is similar to the OPC sample. The surface of the RHA particles are covered by hydration products and more unreacted RHA are seen with cement grains in 1 hour micrographs Fig. 5a. From 1 day (Fig.5b) microstructure of Rice Husk Ash cement, AFm phases, CH and CSH products are observed. Probably a shift from AFt to AFm phases might have been occurred. The ettringite needles disappear and the CH crystals diminish due to the pozzolanic reaction. In 1week micrograph (Fig.5c) the pores are being filled with CSH and by product of AFm phases, thereby AFm phases occupy more space. As time passes the rate of hydration reaction is faster than OPC and thus producing more secondary $\mathrm{CSH}$.

Micrographs of matured age $\left(4^{\text {th }}\right.$ week $)$ have more compact dense microstructure than OPC. The volumes of $\mathrm{Ca}(\mathrm{OH})_{2}$ crystal are reduced and higher volume of CSH than OPC are seen and consequently accelerates and enhances the hydration (Papadakis, V.G. and E.J. Perdersen., 1999).

\section{Conclusion}

From the above results, the indication of pozzolanic reaction is evolving and that part of the amorphous silica in the ash is released into the matrix, combining available $\mathrm{CH}$ and forming a second generation $\mathrm{CSH}$ improving the strength of the system. The pozzolanic activity of rice husk ash produces more amount of CSH in the rice husk ash cement sample. Hence rice husk ash acts as a good pozzolanic material and can be blended with cement.

\section{References}

Flores-Velez L M A \& Dominguez O. (2002). J Mater Sci, 37, 983-988.

Ganesan, K., K. Rajagopal and K. Thangavel. (2008). Con. Build. Mat., 22: 1675-1683.

Gemma Rodriguez de Sensale. (2006). Cem. Concr. Compos., 28: 158-160.

Ghosh S N \& Chatterjee A K. (1974). J Mater Sci, 10, 1574-1584.

Hanna R A, Barrie P J, Cheeseman C R, Hills C D, Buchler D.M \& Perry R. (1995). Cem Concr Res, 25(7), 1435-1444.

Harchand K S, Vishwamittar \& Chandra K. (1980). Cem. Concr. Res, 20, 243 -252.

Hassaan M Y \& Abdel N. Hakeem. (1989). J Mater Sci Lett, 8, 578-580.

Mohanraj. K., R. Ravibaskar, B. Shanthi and G. Sivakumar. (2007). Eco-Chronicle, 2, 91-96.

Mollah M Y A, Thomas R. Hess, Yung-Nian Tsai \& Cocke D L. (1999). Cem Concr Res, 23, 773-784.

Mollah M Y A, Wenhong Yu, Robert Schennach \& David L. Cocke. (2000). Cem Concr Res, 30, 267-273.

Papadakis, V.G. and E.J. Perdersen. (1999). Cem. Concr. Res., 30: 291.

Saraswathy, V and Ha-Won Song. (2006). Con. Build. Mat.

Sivakumar, G., K. Mohanraj and S. Barathan. (2009). E. Journal of Chemistry, 6(1), 231-236.

Taylor H F W. (1990). Cement Chemistry. Academic Press, Inc., New York.

Wada I., T. Kawano, M. Kawakami and N. Maeda. (2000). Proceedings of the Fifth CANMET/ACI International conference on Durability of Concrete, vol. I, SP-192, Barcelona Spain, pp. 205-222. 
Table 1. Results of chemical analysis of OPC and RHA

\begin{tabular}{|c|c|c|c|c|c|c|c|c|c|c|}
\hline \multirow{2}{*}{ Composition } & $\mathbf{C a O}$ & $\mathrm{SiO}_{2}$ & $\mathrm{Al}_{2} \mathbf{O}_{3}$ & $\mathbf{F e}_{2} \mathbf{O}_{3}$ & $\mathbf{S O}_{3}$ & $\mathbf{M g O}$ & $\mathbf{N a}_{2} \mathbf{O}$ & $\mathbf{K}_{2} \mathbf{O}$ & LOI & others \\
\hline OPC & 63.0 & 21.79 & 5.75 & 3.25 & 2.35 & 1.97 & 0.50 & 0.28 & 1.0 & 0.11 \\
\hline RHA & 1.05 & 92.78 & 0.20 & 0.38 & 0.35 & 0.45 & 0.58 & 1.26 & 1.98 & 0.97 \\
\hline
\end{tabular}

(a)

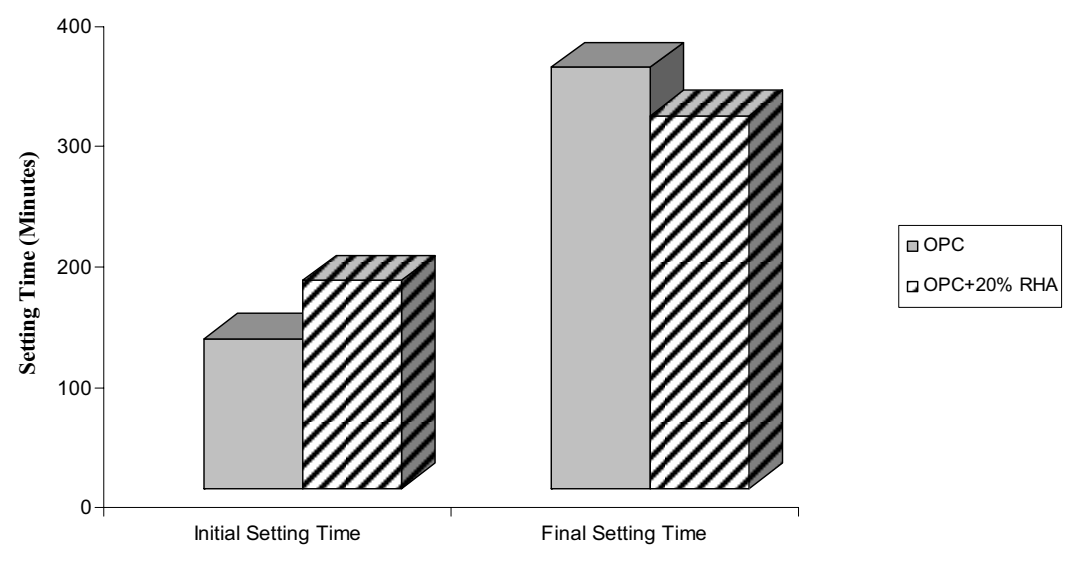

Figure 1. (a) Setting time of the samples

(b)

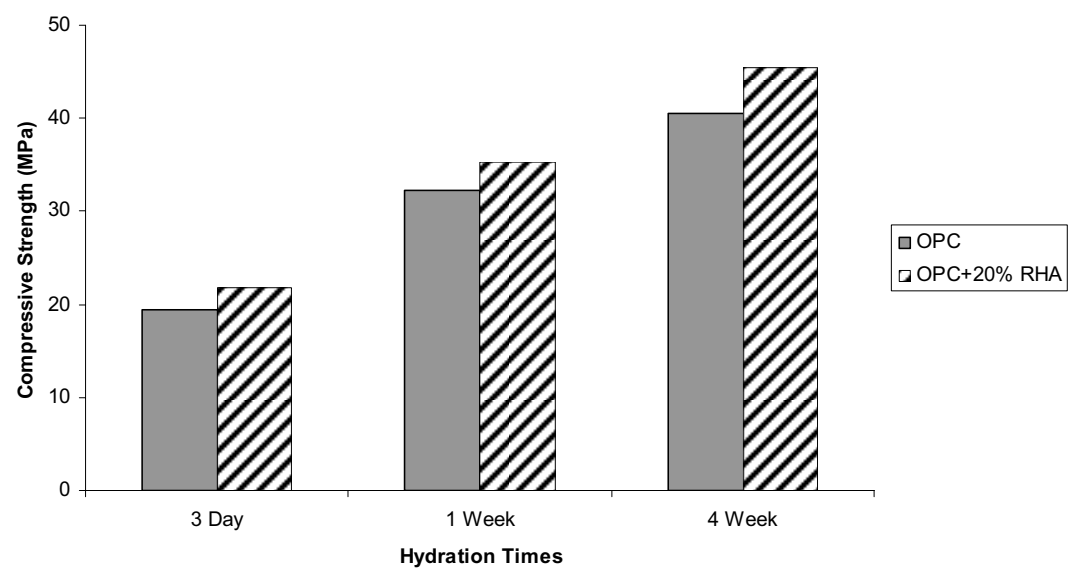

Figure 1. (b) Compressive strength of the samples 


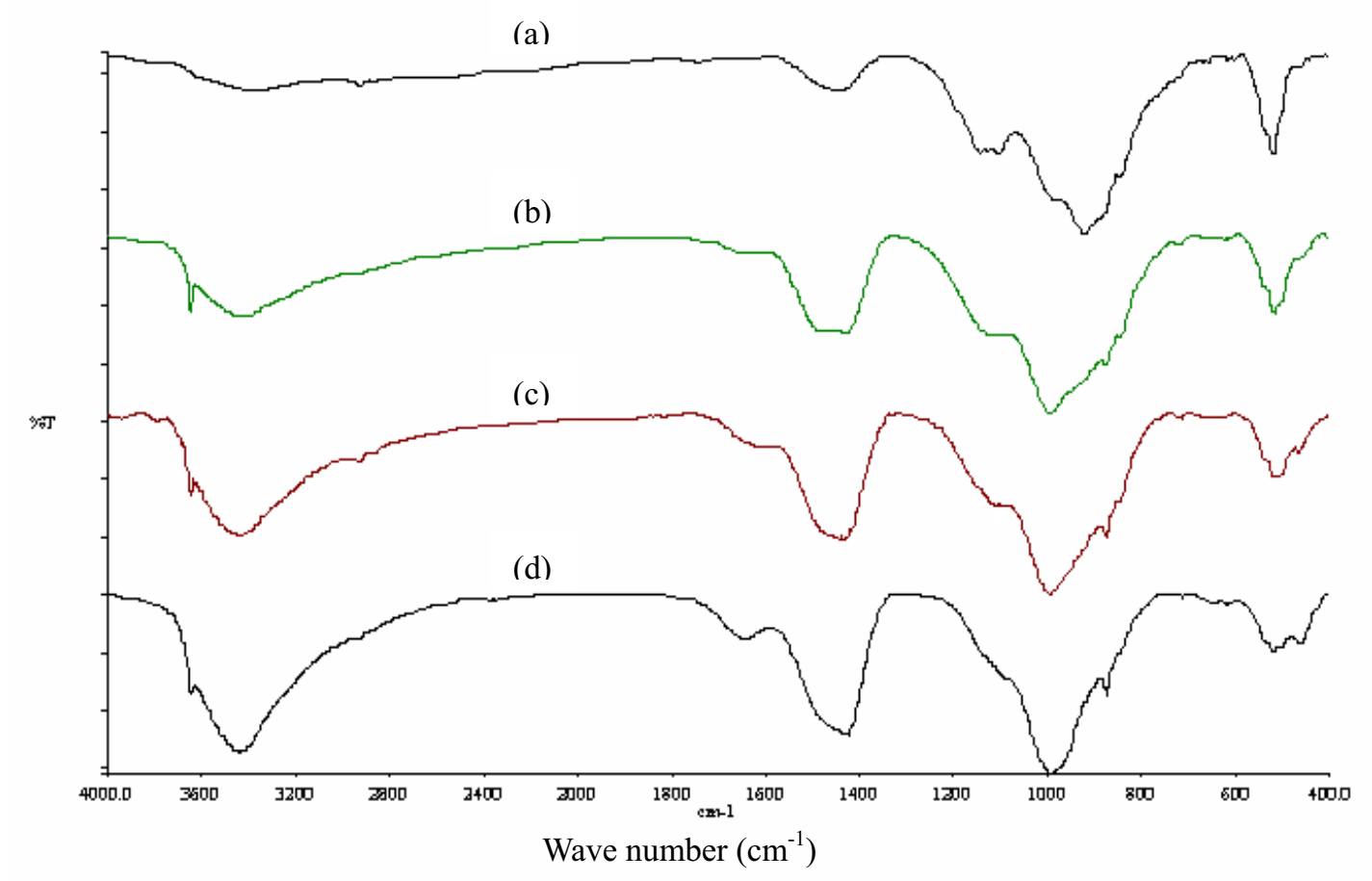

Figure 2. FTIR spectra of OPC sample hydrated for (a) 1hour, (b) 1day, (c) 1week and (d) 4weeks

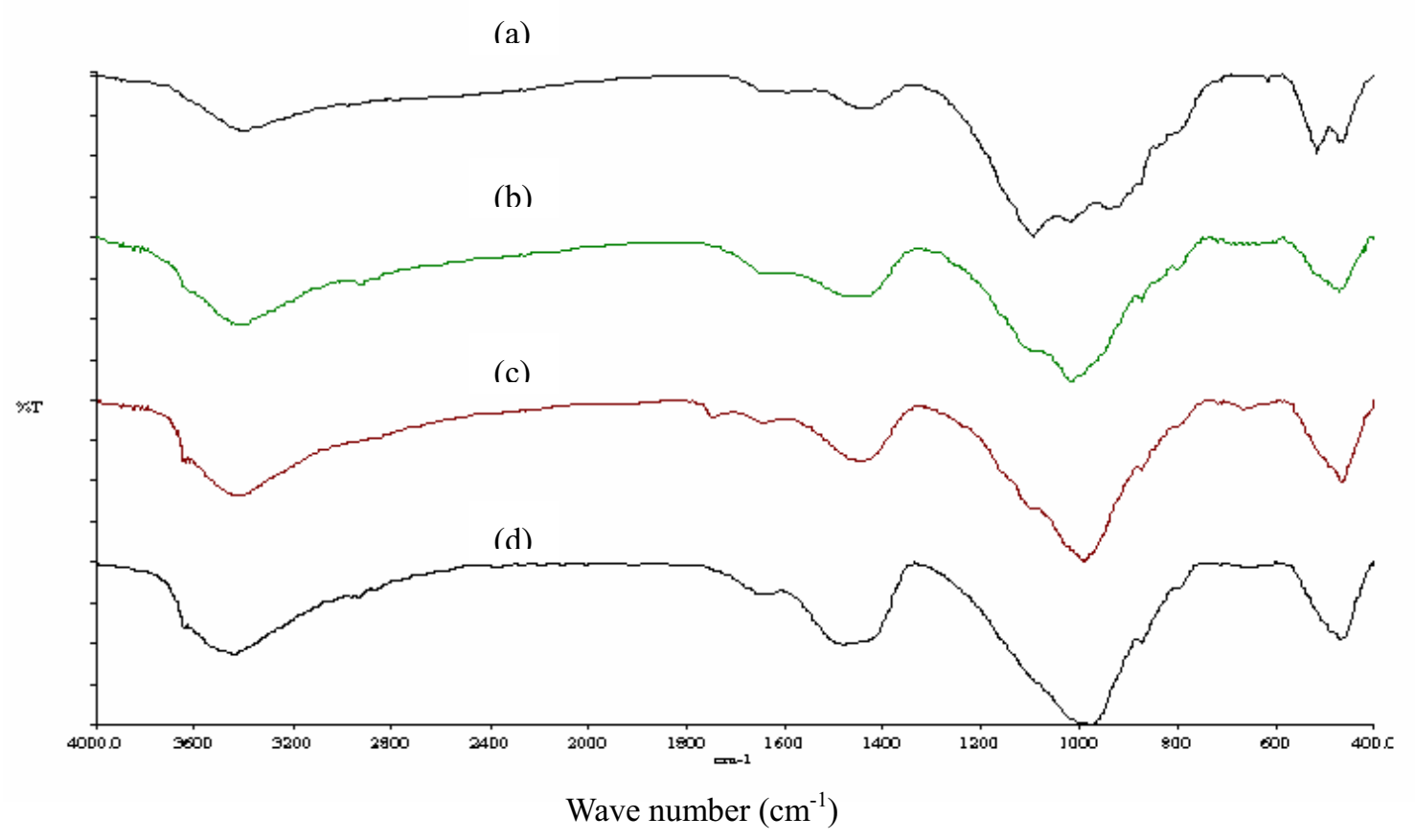

Figure 3. FTIR spectra of OPC $+20 \%$ RHA at (a) 1hour, (b) 1day, (c) 1week and (d) 4weeks 

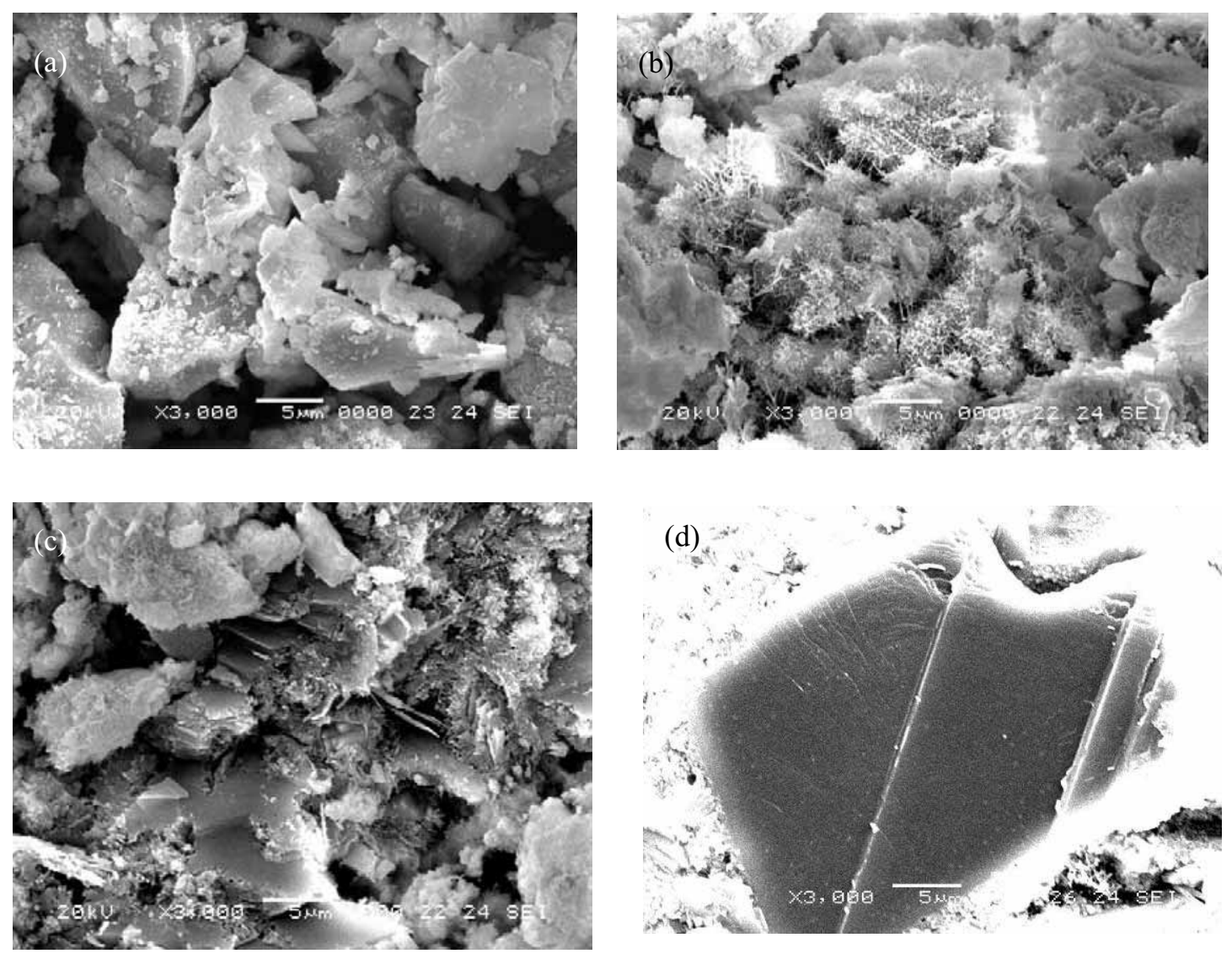

Figure 4. SEM micrographs of OPC at (a) 1hour, (b) 1day, (c) 1week and (d) 4weeks 

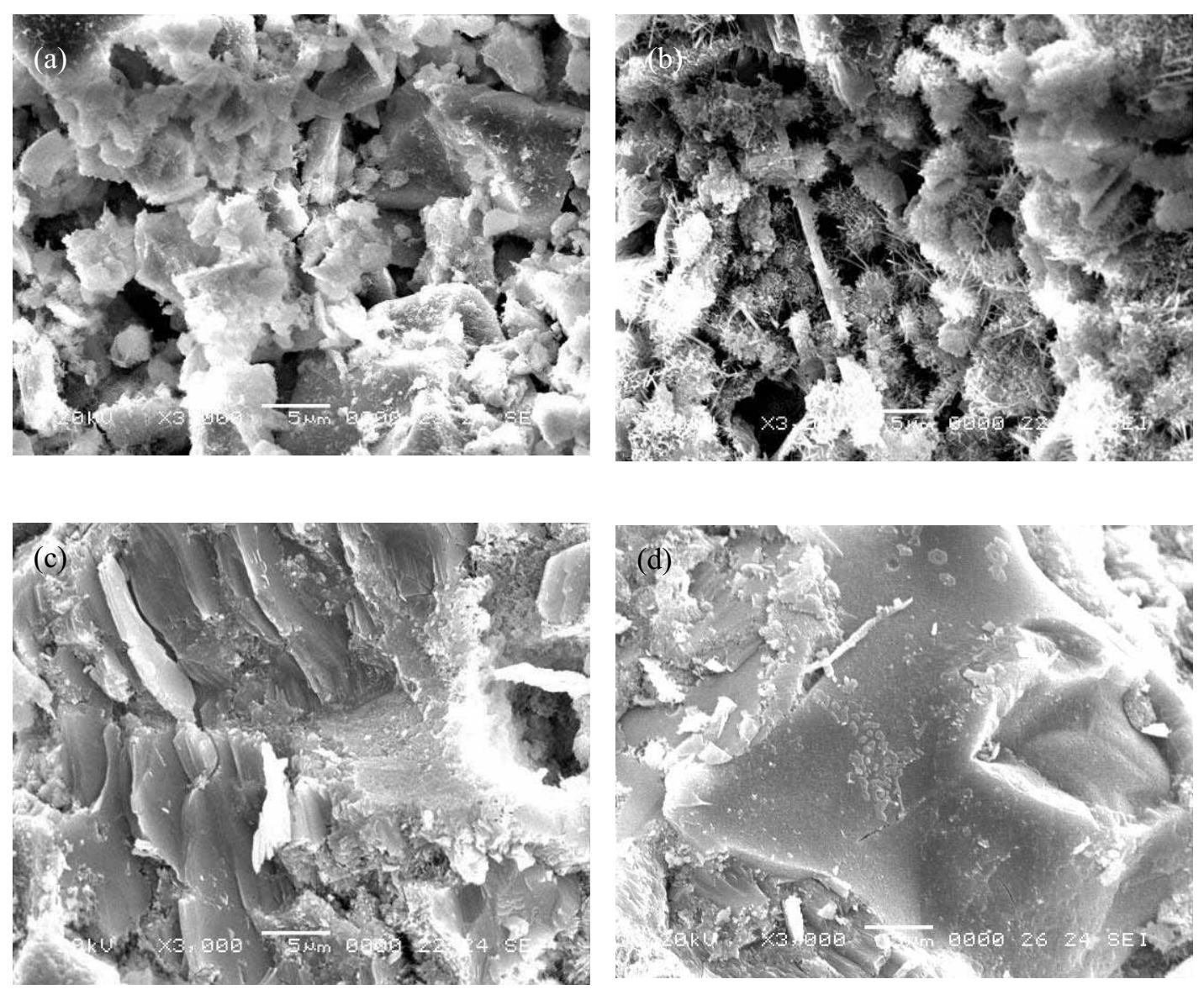

Figure 5. SEM micrographs of hydrated Blended samples at (a) 1hour, (b) 1day, (c) 1week and (d) 4weeks 


\title{
Study on Wet Etching of AAO Template
}

\author{
Guofeng Hu, Haiming Zhang, Wenwen Di \& Tingting Zhao \\ School of Science, Tianjin Polytechnic University, Tianjin 300160, China \\ E-mail: hugf2009@163.com
}

\begin{abstract}
The highly ordered anodic aluminum oxide (AAO) template was prepared with two-step anodization. The AAO template was carried out wet etching process using a mixture of phosphoric acid and chromic acid, $\mathrm{NaOH}$, and $\mathrm{H}_{3} \mathrm{PO}_{4}$ solutions. The relationship between mass loss of AAO template and etching time was studied. The results indicate that 3 wt $\% \mathrm{H}_{3} \mathrm{PO}_{4}$ solution is a more mild and effective etchant comparing with these etchants, and the mass loss is linear with etching time. SEM investigations show that alumina nanowires were obtained with high yield by etching AAO template. And, the growth of alumina nanowires was closely related to the etching time.
\end{abstract}

Keywords: Porous Anodic aluminum oxide, Wet etching, $\mathrm{H}_{3} \mathrm{PO}_{4}$, Alumina nanowires

\section{Introduction}

Recently, One-dimensional (1 D) nanomaterials have stimulated great attention due to their optical and electronic properties. The template-assisted method has played an important role in the field of fabrication of $1 \mathrm{D}$ nanomaterials. The AAO template has uniform pore sizes, a high pore density, and a high aspect ratio (Masuda, 1995, pp. 1466-1468). These structural features of AAO template are controlled readily by appropriate choice of anodizing solutions, voltage or current density, solution temperature, and pore widening ( $\mathrm{Li}, 1998$, pp. 6023-6026). The AAO template has become an ideal template for these advantages. Nanowires or nanotubes of a variety of materials including metals (Sauer, 2002, pp. 3243-3247) (Sarkar, 2007, pp. 271-290), semiconductor materials (Yang, 2004, pp. 65-68) (Seo, 2007, pp. 241-244), and polymer materials (Steinhart, 2002, pp. 1997) (Pan, 2007, pp. 015302-015307), have been fabricated by using AAO template. Carbon nanotubes have also been created in the AAO nanopores (Hu, 2001, pp. 3083-3085). But the nanodevices combined with AAO template are rare in the literature. The nanowires or nanotubes fabricated using AAO template have a highly ordered structure and a high aspect ratio. But when the AAO template was removed, the nanowires or nanotubes are easy to fall down together or form clusters for their high surface tension. This phenomenon has adversely affected the fabrication of nanodevices (Pan, 2005, pp. 1559-1564).

Therefore, the quantificational etching of AAO template has become a very urgent task. There will be a great breakthrough of fabrication of nanodevices based on AAO template, on condition that the length of exposed nanowires or nanotubes could be precise controlled by making from partial removal of AAO template via wet etching process. To obtain the highly ordered nanoarrays is of great significance in the fabrication of gas sensors and field emission devices by keeping the nanowire or nanotube arrays upright with the support of remaining AAO template (Hwang, 2005, pp. 850-858).

To date, the controllable wet chemical etching to remove partial AAO template is rare in the literature. And, the aqueous $\mathrm{NaOH}$ solution, the most common etchant, is available for etch AAO template (Chen, 2007, pp. 306-310) (Shankar, 2004, pp. 1312-1316). But the reaction between $\mathrm{NaOH}$ and AAO template always is too severe to control the progress of wet etching process. In this paper, we report a much milder wet etching of AAO template using the common $\mathrm{H}_{3} \mathrm{PO}_{4}$ solution. The wet etching effect by different etchants has been studied to achieve quantificational etching of AAO template.

\section{Experiment}

\subsection{Porous aluminum oxide template preparation}

High-purity aluminum foils (99.999\%) were employed in our experiment to fabricate the AAO template. The Al foil was first annealed at $500{ }^{\circ} \mathrm{C}$ for $2 \mathrm{~h}$, degreased using acetone and alcohol, then rinsed in distilled water. Al foil was electropolished in a mixed solution of $\mathrm{HClO}_{4}: \mathrm{C}_{2} \mathrm{H}_{5} \mathrm{OH}=1: 4(\mathrm{~V} / \mathrm{V})$ for 5 min to provide a smooth surface, then promptly rinsed with distilled water. Afterwards, the clean $\mathrm{Al}$ foil was anodized at $40 \mathrm{~V}$ DC voltage in $0.3 \mathrm{M}$ oxalic acid solution. 
After $6 \mathrm{~h}$ anodization, the sample was immersed in a mixture of phosphoric acid and chromic acid to remove the porous aluminum oxide formed in the first anodization. The remaining $\mathrm{Al}$ foil was anodized for a second time under the same conditions for $8 \mathrm{~h}$. Then the sample was etched by $\mathrm{CuCl}_{2}$ solution to remove the aluminum substrate.

\subsection{Process of wet etching of AAO template}

A number of clean and dry AAO templates which were removed aluminum substrate were weighted and immersed in different etchants respectively, until completely dissolved at room temperature. During the etching process, the AAO templates were taken out of etchants at regular intervals, rinsed with distilled water, dried and weighted. The etchants were used in our experiment including mixture of phosphoric acid and chromic acid $\left(6 \mathrm{wt} \% \mathrm{H}_{3} \mathrm{PO}_{4}\right.$ and 1.8 wt $\%$ $\left.\mathrm{H}_{2} \mathrm{CrO}_{4}\right), 3 \mathrm{M} \mathrm{NaOH}, 3$ wt $\% \mathrm{H}_{3} \mathrm{PO}_{4}, 5$ wt $\% \mathrm{H}_{3} \mathrm{PO}_{4}$, and $10 \mathrm{wt} \% \mathrm{H}_{3} \mathrm{PO}_{4}$.

The effect of wet etching of AAO template was studied with use of FESEM (LEO 1530VP).

\section{Results and Discussion}

\subsection{Wet etching of AAO template}

The component of AAO template is amorphous alumina. It is an amphoteric oxide which has reactions as both a base and an acid. The chemical equations for the etching reaction are as follows.
$2 \mathrm{OH}^{-}+\mathrm{Al}_{2} \mathrm{O}_{3}$
$\longrightarrow 2 \mathrm{AlO}_{2}^{-}+\mathrm{H}_{2} \mathrm{O}$
$6 \mathrm{H}^{+}+\mathrm{Al}_{2} \mathrm{O}_{3}$
$\longrightarrow 2 \mathrm{Al}^{3+}+3 \mathrm{H}_{2} \mathrm{O}$

It can be seen from Figure 1. that the reaction rate was rapid when AAO template was etched in $\mathrm{NaOH}$ solution. The AAO template was thinned rapidly, curled, and disappear in solution. The wet etching process in $3 \mathrm{M} \mathrm{NaOH}$ solution lasted only $7 \mathrm{~min}$. It is difficult to control the etching process of AAO template to obtain the appropriate length of exposed nanoarrays at such a rapid etching rate. In addition, $3 \mathrm{M} \mathrm{NaOH}$ could be available for a fast reagent to release nanostructures embedded in AAO template for its rapid dissolution rate of alumina.

Figure 2. shows the etching curve of AAO template in the mixture solution of phosphoric acid and chromic acid. The AAO template needs about $180 \mathrm{~min}$ to be completely dissolved. And the etching rate is obviously slower comparing to the rapid etching rate in $\mathrm{NaOH}$ solution.

Figure 3. shows the etching curves of AAO template in 3 wt $\% \mathrm{H}_{3} \mathrm{PO}_{4}, 5$ wt $\% \mathrm{H}_{3} \mathrm{PO}_{4}$, and $10 \mathrm{wt} \% \mathrm{H}_{3} \mathrm{PO}_{4}$. These curves are similar. The mass loss changed little within the first $30 \mathrm{~min}$, then increased rapidly with time and was linear with etching time. It may be due to the AAO template used in our experiment without removing barrier layer, phosphoric acid reacted with the barrier layer at first, and the etching rate is slow at the beginning. After approximately $30 \mathrm{~min}$, the pores of AAO template were opened, it allows more etchant permeated into AAO template free from the open pores, accelerated and made the etching rate linear.

There's no doubt that the etching rate is connected with the active etching component $\mathrm{H}^{+}$in $\mathrm{H}_{3} \mathrm{PO}_{4}$ solution, and the etching rate is proportional to its concentration. From the wet etching studies, the etching rate in $10 \mathrm{wt} \% \mathrm{H}_{3} \mathrm{PO}_{4}$ is higher than that in $5 \mathrm{wt} \% \mathrm{H}_{3} \mathrm{PO}_{4}$, both of which are higher than the etching rate in $3 \mathrm{wt} \% \mathrm{H}_{3} \mathrm{PO}_{4}$. The etching time of AAO template in $10 \mathrm{wt} \% \mathrm{H}_{3} \mathrm{PO}_{4}, 5 \mathrm{wt} \% \mathrm{H}_{3} \mathrm{PO}_{4}$, and $3 \mathrm{wt} \% \mathrm{H}_{3} \mathrm{PO}_{4}$ are $180 \mathrm{~min}, 330 \mathrm{~min}$ and $360 \mathrm{~min}$, respectively. And, the etching rate of $10 \mathrm{wt} \% \mathrm{H}_{3} \mathrm{PO}_{4}$ is similar to that in mixture of phosphoric acid and chromic acid. During the wet etching process, the AAO templates remained the robust state as before, not curly. The slower etching rate enable the precise control of wet etching time to expose the length of nanoarrays, and the etching time in $3 \mathrm{wt} \% \mathrm{H}_{3} \mathrm{PO}_{4}$ is more proper.

We have discovered that AAO templates would become ultrathin, and would be curled near terminal time. This phenomenon is similar to that in $\mathrm{NaOH}$ solution. It is hard to measure so thin an AAO template.

\subsection{Characterization of AAO template and Alumina nanowires}

Topography of the AAO template is shown in SEM images in Figure 4. The AAO template was formed with highly ordered hexagonal arrangement of $50 \mathrm{~nm}$ in diameter and the distance between neighboring pores was about $100 \mathrm{~nm}$ by anodization. And the pore density can reach $10^{10} \mathrm{~cm}^{-2}$, which is suitable for fabrication of large-scale uniform nanowire arrays.

It is shown in Figure 5. that the effect of wet etching of AAO template in mixture solution of phosphoric acid and chromic acid. It is clearly seen that the fallen nanowires on AAO template are disorder and with a high aspect ratio. The upper section of AAO template after wet etching is alumina nanowires clusters and the lower section also is AAO template.

\subsection{The mechanism of fabrication of alumina nanowires}

The alumina nanowires would be produced on the AAO template after wet etching whatever the etchant is a base or an acid. We attribute the fabrication of alumina nanowires to reason that the etchant react with the pore wall of AAO 
template (Zhang, 2005, pp. 1254-1258). When the etchant solution diffuses into the pores, the pore wall are dissolved for the active etching component $\mathrm{H}^{+}$or $\mathrm{OH}^{-}$reacts with the pore wall. Figure 6 . shows that the fabrication procedure of the alumina nanowires in the wet etching process. The thinnest of pore wall of two neighboring pores were etched away at first. Since the juncture of three neighboring pores is the thickest portion of alumina, the wet etching will produce alumina nanowires. The nanowires could fall down together without the support of the pore wall.

In the middle of wet etching process, the fabrication of alumina nanowires results in the acceleration of etching rate. Meantime, the mass loss of AAO template shows good linearity with the etching time.

It is because the active etching components can diffuse into the pores from the opposite end of the pore after barrier layer removal. It would accelerate the dissolution of the pore wall in AAO template. On the one hand, the alumina nanowires have ultrahigh aspect ratio which will greatly increase surface area of AAO template, and they are easy to be dissolved by etchants. On the other hand, the new alumina nanowires are being produced continuously, while the old nanowires are being dissolved. The dynamic balance between the alumina nanowires production and dissolution make the etching rate steady.

\section{Conclusions}

We have studied the wet etching of AAO template using several etchants, including $\mathrm{H}_{3} \mathrm{PO}_{4}$ solutions, a mixture solution of phosphoric acid and chromic acid and $\mathrm{NaOH}$ solution. The $3 \mathrm{wt} \% \mathrm{H}_{3} \mathrm{PO}_{4}$ solution is the best etchants to precise etch AAO template, comparing $3 \mathrm{M} \mathrm{NaOH}$ solution. And, its wet etching effect indicates that the mass loss of AAO template is good linear with the etching time in the wet etching process. A large number of alumina nanowires have been produced on etchants use. It's a good method to fabricate alumina nanowires. Meanwhile, the production of nanowires has played an important part in keeping a linear relationship between the mass losses of AAO template and etching time.

\section{References}

Chen, D., Song, G. J., Peng, Z. (2007). Preparation of metal nanowire arrays with controllable length using a simple etching method. Journal of Functional Materials and Devices, 13, 306-310

Hu, W., Gong, D., Chen, Z. (2001). Growth of well-aligned carbon nanotube arrays on silicon substrates using porous alumina film as a nanotemplate. Applied Physics Letters, 79, 3083-3085

Hwang, S. K., Lee, J., Jeong, S. H. (2005). Fabrication of carbon nanotube emitters in an anodic aluminium oxide nanotemplate on a Si wafer by multi-step anodization. Nanotechnology, 16, 850-858

Li, A. P., Müller, F., and Birner, A. (1998). Hexagonal pore arrays with a 50-420 nm interpore distance formed by self-organization in anodic alumina. Journal of Applied Physics, 84, 6023-6026

Masuda, H., and Fukuda, K. (1995). Ordered metal nanohole arrays made by a two-step replication of honeycomb structures of anodic alumina. Science, 268, 1466-1468

Pan, C., Zhang, L., Zhu, J. (2007). Surface decoration of anodic aluminium oxide in synthesis of Nafion ${ }^{\circledR}{ }^{-} 115$ nanowire arrays. Nanotechnology, 18, 015302-015307

Pan, H., Sun, H., Poh, C. (2005). Single-crystal growth of metallic nanowires with preferred orientation. Nanotechnology, 16, 1559-1564

Sarkar, J., Khan, G. G., and Basumallick, A. (2007). Nanowires: properties, applications and synthesis via porous anodic aluminium oxide template. Bulletin of Materials Science, 30, 271-290

Sauer, G., Brehm, G., Schneider, S. (2002). Highly ordered monocrystalline silver nanowire arrays. Journal of Applied Physics, 91, 3243-3247

Seo, B. I., Shaislamov U. A., Ha, M. H. (2007). ZnO nanotubes by template wetting process. Physica E, 37, 241-244

Shankar, K. S., and Raychaudhuri, A. K. (2004). Growth of an ordered array of oriented manganite nanowires in alumina templates. Nanotechnology, 15, 1312-1316

Steinhart, M., Wendorff, J. H., Greiner, A. (2002). Polymer nanotubes by wetting of ordered porous templates. Science, 296, 1997

Yang, Y., Chen, J., Chen, H. (2004). Study of CdS nanowires deposited in silicon based porous alumina film by non-aqueous electrochemical deposition. Chinese Journal of Inorganic Chemistry. 20, 65-68

Zhang, L., Yao, S., Zhang, H. (2005). Preparation and fabrication mechanism of alumina nanowires. Acta Physico-chimica Sinica, 21, 1254-1258 


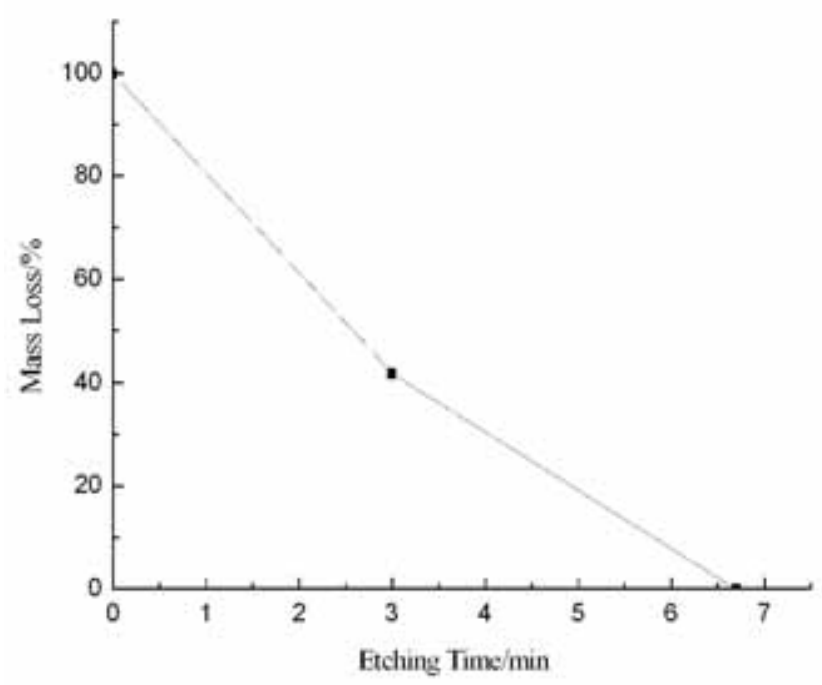

Figure 1. Wet Etching Curve of AAO Template in $3 \mathrm{M} \mathrm{NaOH}$

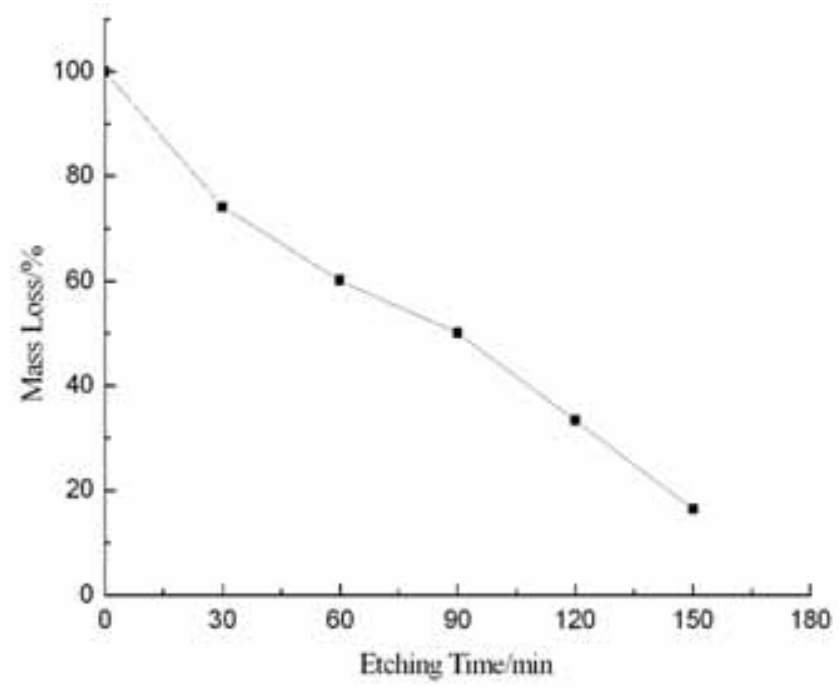

Figure 2. Wet Etching Curve of AAO Template in Mixture of $6 \mathrm{wt} \% \mathrm{H}_{3} \mathrm{PO}_{4}$ and $1.8 \mathrm{wt} \% \mathrm{H}_{2} \mathrm{CrO}_{4}$

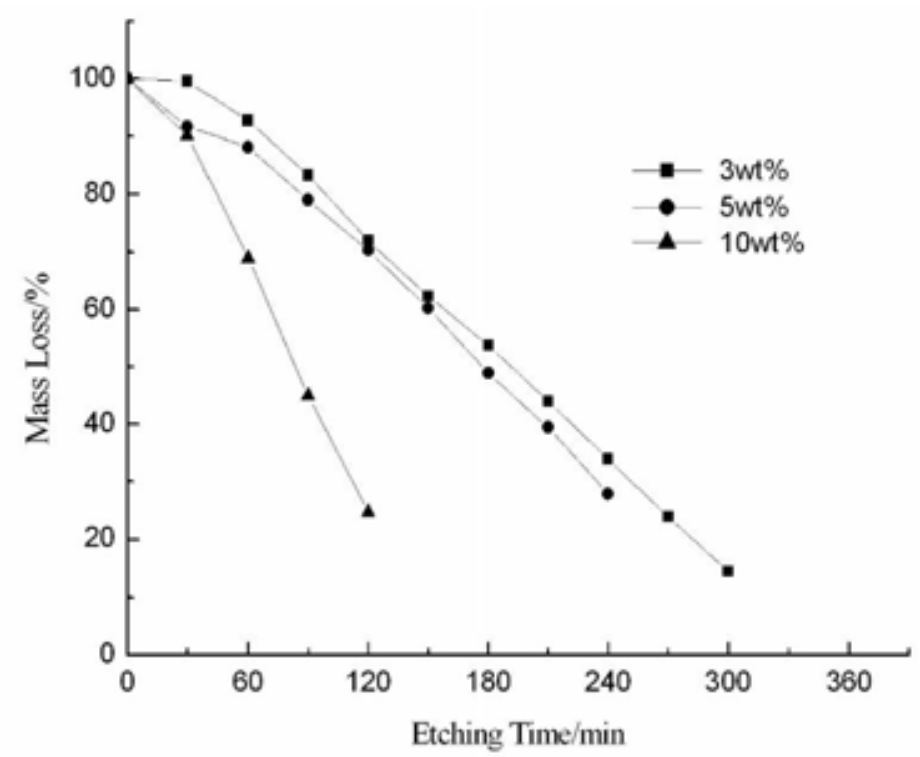

Figure 3. Wet Etching Curves of AAO Template in $\mathrm{H}_{3} \mathrm{PO}_{4}$ Solutions 


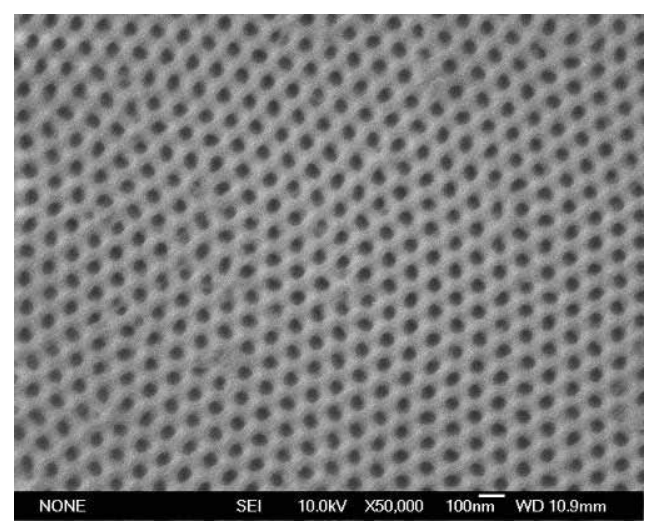

(a)

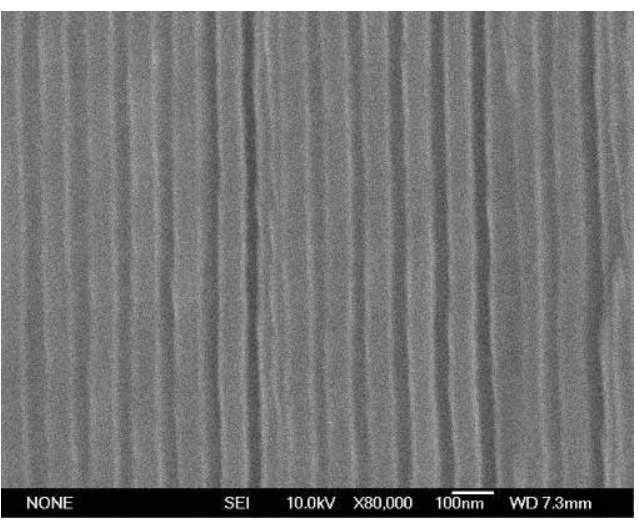

(b)

Figure 4. SEM Images of the AAO (a) Surface (b) Cross Section.

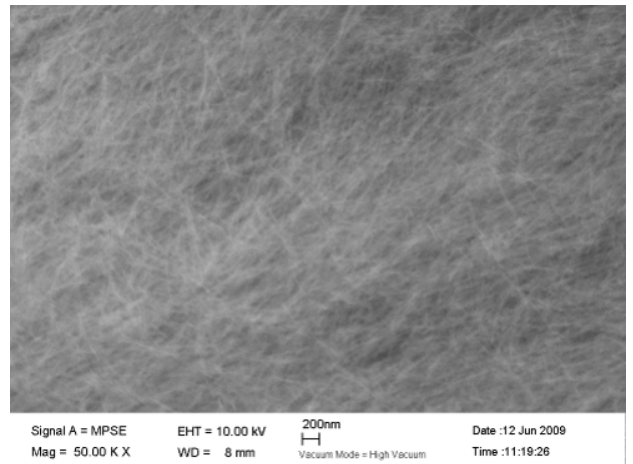

(a)

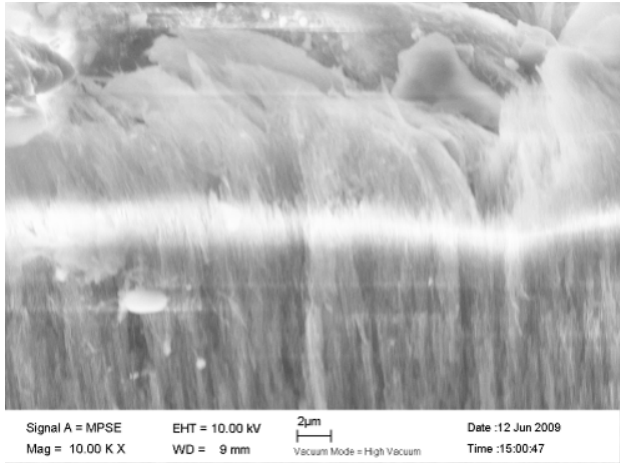

(b)

Figure 5. SEM Images of Alumina Nanowires on AAO Template (a) Surface (b) Cross Section.

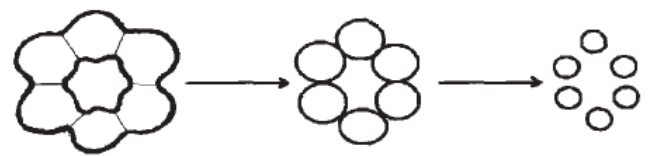

Figure 6. Schematic of Fabrication Procedure of the Alumina Nanowires 


\title{
Ionospheric Correction and Ambiguity Resolution in DGPS with Single Frequency
}

\author{
Norsuzila Ya’acob \\ Department of Electrical, Electronics and Systems Engineering \\ Universiti Kebangsaan Malaysia \\ 43600 UKM Bangi, Selangor, Malaysia \\ Tel: 19-333-0864Ｅ-mail: norsuzilayaacob@yahoo.com \\ Mardina Abdullah and Mahamod Ismail \\ Department of Electrical, Electronics and Systems Engineering \\ UniversitiKebangsaan Malaysia \\ 43600 UKM Bangi, Selangor, Malaysia \\ Tel: 60-3-8921-6304 E-mail: mardina@eng.ukm.my; mahamod@eng.ukm.my \\ Kamaruzaman Jusoff (Corresponding author) \\ Department of Forest Production, Faculty of Forestry \\ Universiti Putra Malaysia, 43400, UPM, Serdang, Selangor, Malaysia \\ Tel: 60-3-8946-7176_E-mail: kjusoff@yahoo.com
}

This research is partly funded by the Malaysian Government through University Kebangsaan Malaysia under the Science Fund 04-01-02-SF191. We are grateful to Jabatan Ukur dan Pemetaan Malaysia (JUPEM) for providing the GPS data (Sponsoring information)

\begin{abstract}
The free electron distributed in the atmospheric region known as the ionosphere produces a frequency dependent effect on the Global Positioning System (GPS) signals, a delay in the pseudorange and advance in the carrier phase. The ionospheric influence is one of the main problems in the real-time ambiguity resolution for the carrier phase GPS data in radio navigation. Real Time Kinematics (RTK) and Malaysian Active Station (MASS) data from JUPEM (Jabatan Ukur dan Pemetaan Malaysia) were used in this analysis. In this study, the effects of initial phase ambiguity at GPS and modeling of ionosphere on base components were researched. To overcome this problem, a correction ionospheric model was used. This correction model could be implemented in single frequency measurements with similar accuracy, which can be obtained from dual frequency.
\end{abstract}

Keywords: Ambiguity Resolution, Ionosphere, Baseline

\section{Introduction}

The ionospheric delay resulting from radio signals traveling through ionosphere is the major source of errors for single-frequency users of the navigation positioning systems based on satellite. Differential GPS (DGPS) enhances the positional accuracy of GPS receivers. It is based on error correction at the signals for satellite data from ground at known locations. DGPS offers positional accuracy down to centimetre level. It provides single-point error correction data based upon the errors experienced at a single reference station. This is then applied to the mobile receiver, which may be up to several hundred kilometres away. Resolving the GPS carrier-phase ambiguity has been a continuing challenge for sub-centimetre level high precision GPS positioning. In general, centimetre-level GPS positioning 
accuracy requires precise tracking of the carrier phase that consists of two parts: a directly measured fractional part (with measurement error at millimetre level) and an unknown integer part, also called the integer ambiguity. Existing ambiguity resolution techniques can be divided into several categories (Donghyun and Richard Langley, 2000). One of the categories comprises of the most abundant group of techniques, which are based on the theory of integer least squares (Hatch, 1990; Frei and Beutler, 1990; Chen, Lachapelle, 1995; and Teunissen, 1995). Parameter estimation in theory is carried out in three steps, the float solution, the integer ambiguity estimation, and the fixed solution. Each technique makes use of the variance-covariance matrix obtained from the float solution step and employs different ambiguity search processes at the integer ambiguity estimation step.

The integer ambiguity is the unknown integer number of whole cycles between satellite and receiver. The receiver can determine only the fractional part of the wavelength but not the integer, so the ambiguity resolution is essential for precise range determination (Donghyun and Richard Langley; 2000). The goal of ambiguity resolution is to resolve phase ambiguities, i.e. to obtain the correct integer numbers (ambiguity fixing), which is possible at the Double Different (DD) level due to the elimination of instrumental biases etc. So a good ionospheric model is essential in order to get unambiguous results or reduced time to resolve for the ambiguities. Resolution strategies can be divided into those for short baselines and long baselines. The ambiguity resolution, which relies on statistical hypotheses and is highly affected by biases e.g. the ionospheric delay, is difficult to process. After the ambiguities are resolved, the variance ratio is larger and the reference variances are smaller (Abdullah et. al, 2008). This resolution problem is a field of research in itself and a good ionospheric model is essential in some circumstances for good ambiguity resolution.

Generally, most observations for accurate positioning in the network use dual frequency receivers and these are considered expensive to implement in the developing countries. However precise measurements are required in poor countries for purposes such as monitoring land slipping. Not only poor countries could not afford to develop an observation network but even buying one reference dual frequency receiver itself might be difficult. Only single frequency receivers might be affordable to make the relative measurements (Cannon et.al, 1993). So, a correction model that is applicable with single frequency receiver is practical in such situation. In all cases, an accurate ionospheric correction model is essential for most accurate positioning since L1 observations are sensitive to ionospheric error and working on this correction error should be done to support third world countries. An algorithm has been developed in this research that only requires L1 carrier phase measurement (Abdullah, 2004). Some methods have been used to determine the systematic effect due to ionospheric refraction in the L1 carrier of single frequency GPS receiver. While data from dual frequency receivers can account for the ionospheric delay directly by the appropriate linear combination of measurements made on both frequencies, data from single frequency receivers cannot be corrected in this way. The ionospheric model can be used to generate 'correction terms', which can then be applied to the single-frequency observations to account for these effects. The data quality was initially checked using TEQC i.e. the multipath noise (Estey and Meertens, 1999). It is hard to determine the phase multipath that could be only millimetre, where the multipath effect on the phase is two orders of magnitude less than that on the code (Seeber, 2003) where the results obtained are contaminated with multipath. According to Leick (2004), the multipath effect for short baseline was likely cancelled in the single difference observables used in this work. The influence of the correction was examined from the quality check resulting from the data processing and its effects on carrier phase ambiguity resolution errors. The model was evaluated by firstly applying the correction to the PRN 19 measurements, then applying it to the PRN 03, PRN 16, PRN 19 and PRN 1 measurements together.

The integer ambiguity is the unknown integer number of whole cycles between satellite and receiver. The receiver can determine only the fractional part of the wavelength but not the integer, so the ambiguity resolution is essential for precise range determination. The goal of ambiguity resolution is to resolve phase ambiguities, i.e. to obtain the correct integer numbers (ambiguity fixing), which is possible at the Double Different (DD) level due to the elimination of instrumental biases etc. So a good ionospheric model is essential in order to get unambiguous results or reduced time to resolve for the ambiguities. In this paper, the ionospheric correction model proposed for single frequency and the data processing strategy are described and the results obtained in an equatorial region are presented.

\section{Materials and method}

\subsection{GPS data Rinex format}

The developed model was evaluated using real GPS data were obtained from Jabatan Ukur dan Pemetaan Malaysia (JUPEM). The observation data was taken from Universiti Teknologi Malaysia, Johor (1'33' 56.934"N,

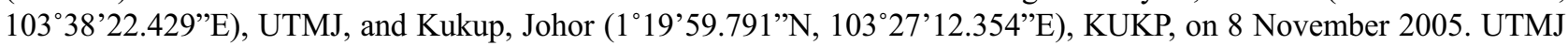
was assumed as a reference station and KUKP was a mobile station giving a baseline of about $33 \mathrm{~km}$.

\subsection{Model application}

The differential ionospheric correction model was applied to GPS carrier phase observables and the results were evaluated. The corrected observation files in RINEX format (Gurtner, 2001) were then used in the processing. GPSurvey software (Trimbel, 1994) was used to process both corrected and uncorrected measurements. In the GPS 
processing software, the quality indicators to evaluate the processing result after the ambiguity is resolved are variance ratio and references variance. They are generated from the statistical results of the observation used. A shorter time was chosen to see how the correction influences the ambiguity resolution. The ambiguity, however, can be resolved for longer periods without applying any ionospheric correction. Both the ratio and the variance distribution can be controlled by the specific level of confidence, which was set to be at $95 \%$. Applying the correction model into the phase measurements should gives better results and this can be evaluated using standard errors of position, ambiguity resolution which is the variance ratio must be larger and the reference variance is smaller.

\section{Results and discussion}

\subsection{Evaluation with PRN 19 measurement corrected}

In this study, only reference station with L1 frequency was used. Within the one hour period from 2:00:00 to 2:59:45, the observed satellites PRNs are 1, 03, 16 and 19 from both stations. The model was evaluated by firstly applying the correction to the PRN 19 measurements, then applying it to the PRN 03, PRN 16, PRN 19 and PRN 1 measurements together.

The ionospheric differential correction was applied to the satellite, namely PRN 19 because this satellite was seen at low elevation angle at the earlier epochs. Firstly, the correction was applied to satellite PRN 19 which had elevation angle of about 28 to 54 degrees.

\subsubsection{Ambiguity not resolved - float solution}

When the processing cannot resolve the ambiguity, it produces a float solution non-integer ambiguity estimate. Figure 1 (a-c) shows that the ambiguity errors of each satellite were plotted. The histogram shows comparison of the errors with uncorrected (without ionospheric correction) and with corrected (with ionospheric correction) measurements at every 10 minutes of processing. The errors are high from the first and decrease to next epochs. (Note1). When the correction was applied to satellite PRN 19, the error decreased a little most of the time but especially for the first 10 minutes of the processing. Figure 2 shows the difference between the errors without correction. When correction was applied in the measurements with respect to the histogram in Fig. 2, it gives an average improvement for PRN 1, followed by PRN 16 and 19. (Note 2). By contrast the standard deviations of baseline components with uncorrected and corrected measurements with float solution are shown in Figure 3. The standard errors of North, East and Up show similar pattern as the ambiguity errors. They reduced over time from about $0.065 \mathrm{~m}$ to $0.015 \mathrm{~m}, 0.6 \mathrm{~m}$ to $0.1 \mathrm{~m}$ and $0.065 \mathrm{~m}$ to $0.2 \mathrm{~m}$ for the North, East and Up respectively. (Note 3, 4). Figure 4 shows that the differences between uncorrected and corrected measurements errors. The East component error reduces to a maximum of about $0.01 \mathrm{~m}$ for the corrected measurements while the other components show smaller reductions. The average reduction with the corrected measurements is about $1 \%$, similar to the difference in the ambiguity errors above.

\subsubsection{Ambiguity resolved- fixed solution}

When the processing can resolve the ambiguity to a correct integer number, it results in a fixed solution. With these 4 satellites, the ambiguities were resolved with the occupation time of 02:54:30. Then by applying the correction model to PRN 19, ambiguities were resolved at 02:53:15 which is about 75 seconds earlier. (Note 5). The improvement can be seen by comparing the variance ratio and reference variance of the processing after the ambiguities were resolved. These are shown in Fig. 5 and Fig. 6 respectively. The ratio in Fig. 5 increases while the reference variance decreases indicating the improvement in the processed results. (Note 6). The difference between the reference variance with no correction and with the correction applied is shown in the Fig. 7. This improvement is quite remarkable by correcting only one satellite in the processing. The difference improves in both the variance ratio and reference variance compared to the uncorrected measurements. (Note 7).

Again, the standard deviations of local position of North, East and Up were compared with the corrected measurements as shown in Fig. 8 (a), (b), and (c). (Note 8) to see how this improvement influences the position. This figure shows a sharp reduction in error compared to that at the time before the ambiguity is resolved as shown in Fig. 2. It can be seen that the standard deviation of the baseline components are changing from the float to fixed solution.

\subsection{Evaluation with PRN 03, PRN 13, PRN 19 And PRN 23 corrected}

Ionospheric corrections were applied to PRN 19, 03, 16 and PRN 01 as well PRN19 for paths with elevation angles of about 28 to 54 degrees, 56 to 76 degrees, 51 to 28 degrees and 57 to 56 degrees respectively. The ambiguity and baseline component errors of the float solution only show improvement with the correction. The duration taken to resolve the ambiguity is reduced to 02:52:30, which is 120 seconds faster.

\subsubsection{Ambiguity not resolved- float solution}

The ambiguity errors of each satellite were plotted in Fig. 9 (a), (b) and (c) in units of cycles. When the processing cannot resolve the ambiguity, it produces a float solution non-integer ambiguity estimate. The histogram shows comparison of the errors with uncorrected and with corrected measurements at every 10 minutes of processing (only 
positive error was plotted in this figure). The errors are high for the first 10 minutes and decrease for the next epochs. During the period from 10 to 50 minutes, the integer part of the decimal ambiguities is not constant. (Note 9,10$)$. When the correction was applied to satellite PRN 19, 3, 16 and PRN 1, the error decreased a little most of the time but especially for the first 20 minutes of the processing. Fig. 10 shows the difference between the errors with no correction and when correction was applied in the measurements with respect to the histogram in Fig. 9. It gives an average improvement for PRN 1, followed by PRN 16 and 19. By contrast the standard deviations of baseline components with uncorrected and corrected measurements with float solution are shown in Fig. 11 (a), (b) and (c) in units of meters. The standard errors of North, East and Up show similar pattern as the ambiguity errors. (Note 11). The differences between uncorrected and corrected measurement errors are shown in Fig. 12. The East component error reduces to a maximum for the corrected measurements while the other components show smaller reductions. The average reduction with the corrected measurements is different in the ambiguity errors above but it still gives an average improvement. (Note 12)

\subsubsection{Ambiguity resolved- fixed solution}

The ratio shows an improvement on average. Even though the ratio increases gradually with the correction, the reference variance does not correspondingly always decrease but increases a little by about 0.2 at 02:57:00 compared to that at 02:55:00. This may be due to other unmodelled errors distorting the solution such as multipath. (Note 13, 14). Both the variance ratio and the reference variance are illustrated in Fig. 15 and show significant improvement with corrected measurements compared to Fig. 13 and Fig.14. The difference between the reference variance with no correction and with correction is shown in Fig. 15 with an increasing trend. (Note 15). Again the standard deviations of local position of North, East and Up were compared with corrected measurements as shown in Figure 16. (Note 16) to see how this improvement influences the position. Figure 16 shows a sharp reduction in error compared to that at the time before the ambiguity is resolved as shown in Fig.9. It can be seen that the standard deviation of the baseline components is changing from the float to fixed solution. Table 1 summarises the ambiguity resolution success rate without and with the correction applied. When the processing cannot resolve the ambiguity, it produces a float solution noninteger ambiguity estimate. Whereas, when the processing can resolve the ambiguity to a correct integer number, it results in a fixed solution. With these 4 satellites, (uncorrected data) the ambiguities were resolved with the occupation time of 02:54:30. By applying the correction model to PRN 19, ambiguities were resolved at 02:53:15, which is 1 minute $15 \mathrm{sec}$ earlier corresponding to uncorrected data and when the correction model was applied to PRN 03, 13, 19 \& 23, ambiguities were resolved at 02:52:30 which is 1 minute $15 \mathrm{sec}$ earlier corresponding to corrected data with PRN 19 only and two minute earlier compared to four satellites (uncorrected data). (Note 17)

The effectiveness of this new technique has been determined by implementing it into real GPS data for short and long baselines. In order to obtain the absolute value of the differential ionospheric delay from the measurements, integer ambiguities have to be resolved. Processing software, have been used to accomplish this task, therefore the model can be validated. The modeled ionospheric delays show good correlation with the computed absolute delay. However, one should note that, in the real world environment, the mobile receivers can be anywhere, such as between the high buildings where multipath is high, which will contaminate the ionospheric induced delay.

Finally, by applying the corrected model, the obtained results compared to uncorrected measurements have indicated that the ambiguity success rate is faster even when only correcting one satellite seen at low elevation angles. This success rate increases by correcting other satellite paths. After the ambiguities are resolved, the variance ratio is larger and the reference variances are smaller. This implies good processing results.

\section{Conclusions}

In this study, the developed differential ionosphere correction model has been evaluated using real GPS measurement. Then the specific topics were considered: float and fixed solution of ambiguity resolution and then effects on the estimated baseline components. This was done by processing the uncorrected and corrected measurements for the given satellites. It was shown that by applying the correction model, the success of ambiguity resolution was achieved earlier when almost all measurements were corrected. For positioning, the standard deviation with respect to the local geodetic component of North, East and Up are significantly reduced.

Implementing this work further would extend the ionospheric correction model to longer baselines for relative measurements at any location with any ionospheric conditions by using only single frequency receivers together with one reference dual frequency receiver. The outcome gives a different approach that could be considered also for current or future GNSS augmentation systems to overcome the ionospheric error.

\section{References}

Abdullah, M., H.J. Strangeways \& D.M.A.Walsh. (2008). Improving ambiguity resolution rate with an accurate ionospheric differential correction. Journal of Navigation-Cambridge Univ. Press, 62 (1), - accepted for publication.

Abdullah, M. (2004). Modelling and Determination of Ionospheric Effect on Relative on GPS Measurements. The University of Leeds School of Electronic and Electrical Engineering. 
Cannon M.E., Lachapelle, G., Lu, G. (1993). Kinematic Ambiguity Resolution with a High Precision C/A Code Receiver", Department of Geomatics Engineering, University of Calgary Calgary, Alberta. Journal of Surveying Engineering, Amer. Soc. Civil Eng, Vol. 119, No. 4 (November).

Chen D, Lachapelle G. (1995). A Comparison of the FASF and Least-Squares Search Algorithms for On-the-Fly Ambiguity Resolution. Navig: J Inst Navig.

Donghyun K., and Richard B. Langley. (2000). GPS Ambiguity Resolution and Validation: Methodologies, Trends and Issues. International Symposium on GPS/GNSS, Seoul.

Estey, L. H., Meertens, C. M. (1999). TEQC: the multi-purpose toolkit for GPS/GLONASS data, GPS Solutions, 3(1), $42-49$.

Frei E, Beutler G. (1990). Rapid Static Positioning Based on the Fast Ambiguity Resolution Approach FARA: Theory and First Result, Manuscr Geod.

Gurtner, W. (2001). RINEX: The Receiver Independent Exchange Format Version 2.10. [Online] Available: http://www.ngs.noaa.gov/CORS/Rinex2.html, accessed on 20 July 2008.

Hatch H. (1990). Instantaneous Ambiguity Resolution, Proceeding of KIS90, Banf.

Leick, A. (2004). GPS Satellite Surveying. Wiley, New Jersey.

Seeber,G.. (2003). Satellite Geodesy. Walter de Gruyter, Berlin.

Teunissen P.J.G. (1995). A New Method for Fast Carrier Phase Ambiguity Estimation. Proceeding of IEEE Position, Location and Navigation Symposium, Las Vegas.

Trimble. (1994). WAVE software user's guide. Sunnyvale,CA,USA: Trimble Navigation Limited

Table 1. Ambiguity resolution success rate

\begin{tabular}{|l|l|l|}
\hline \multirow{2}{*}{$\begin{array}{l}\text { Without } \\
\text { Correction }\end{array}$} & \multicolumn{2}{|l|}{ With Correction } \\
\cline { 2 - 3 } & PRN 19 & $\begin{array}{l}\text { PRN 03, 13, 19 \& } \\
23\end{array}$ \\
\hline $02: 54: 30$ & $02: 53: 15$ & $02: 52: 30$ \\
\hline
\end{tabular}

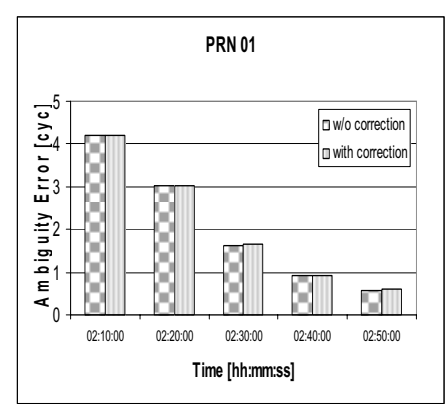

(a)

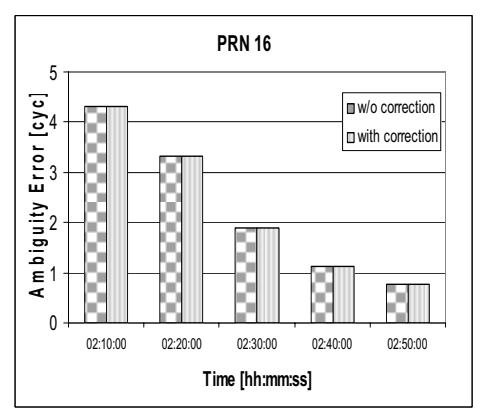

(b)

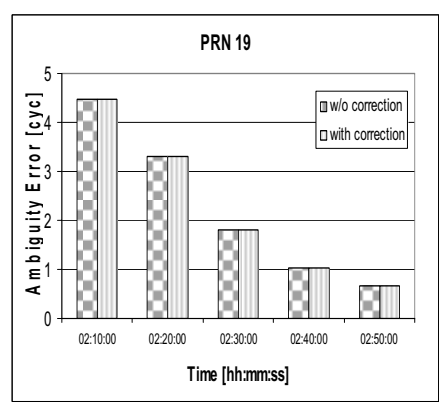

(c)

Figure 1. Ambiguity error of float solution for UTMJ312 and KUKP312

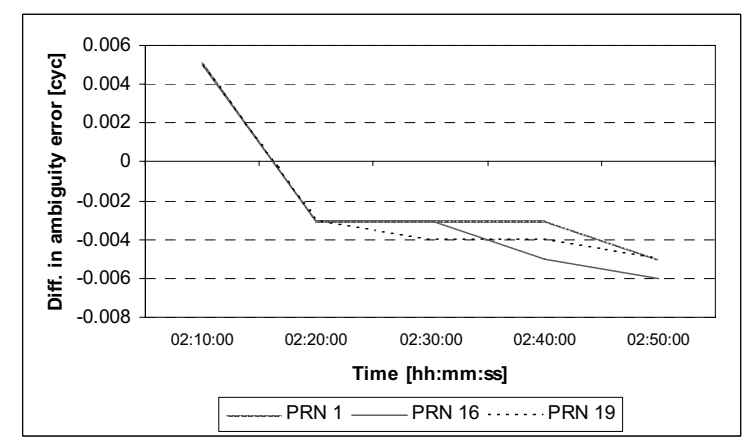

Figure 2. The difference in the ambiguity errors of float solution 


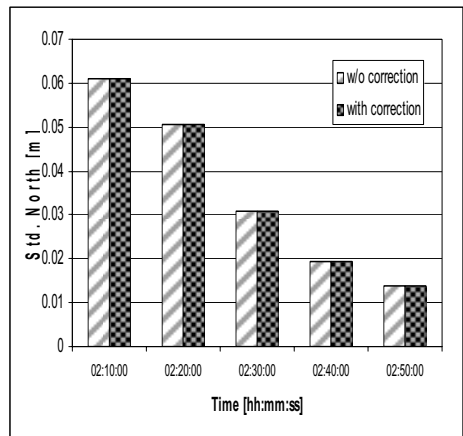

(a)

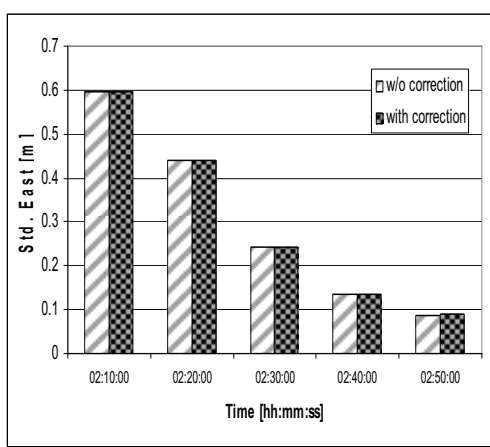

(b)

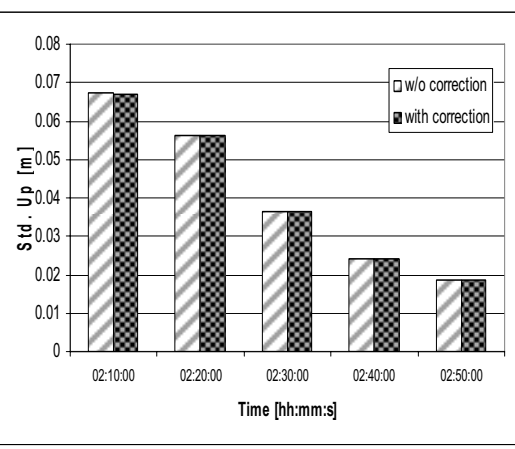

(c)

Figure 3. Standard errors of baseline components (float solution) for UTMJ312 and KUKP312

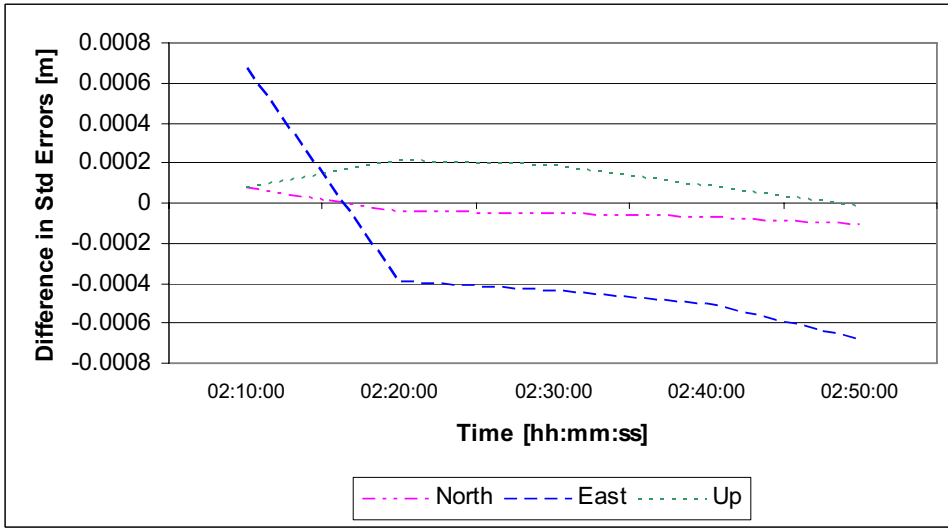

Figure 4. The difference in standard error of float solutions

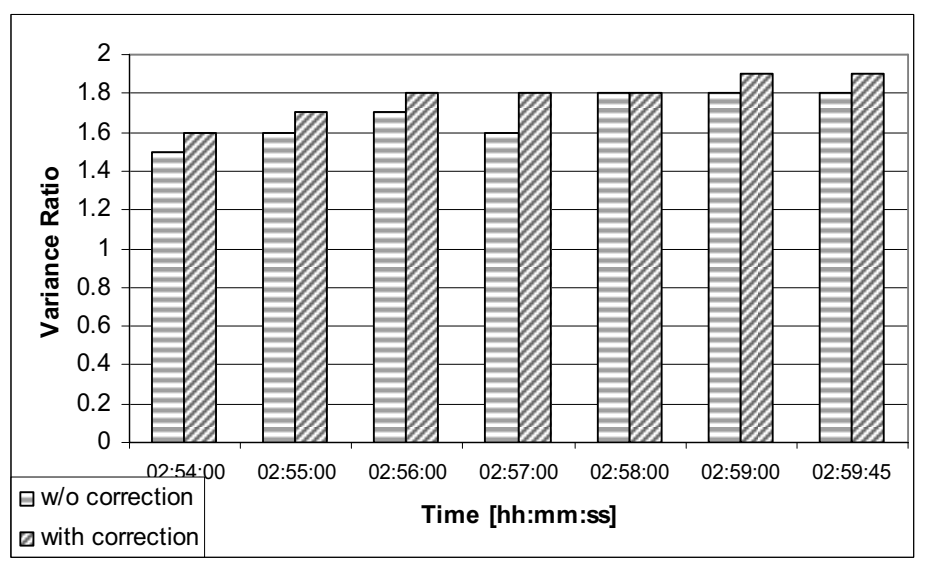

Figure 5. Comparison of Variance Ratio for UTMJ312 and KUKP312 


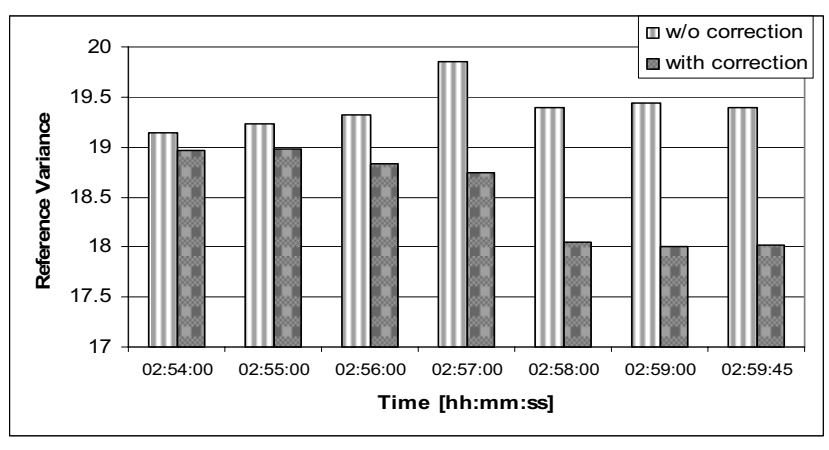

Figure 6. Comparison of Reference Variance for UTMJ312 and KUKP312

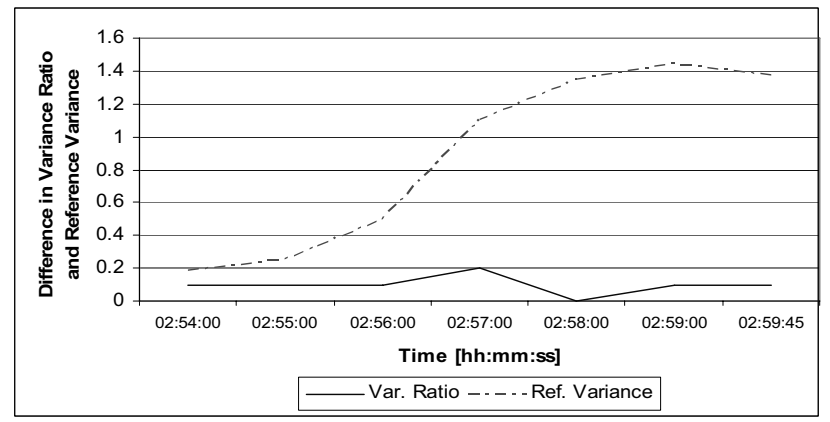

Figure 7. Difference in the reference variance and variance ratio for UTMJ312 and KUKP312

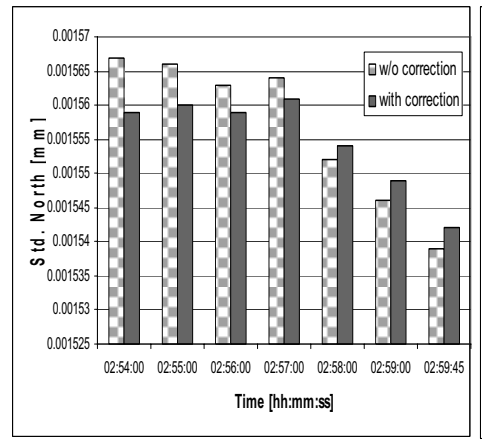

(a)

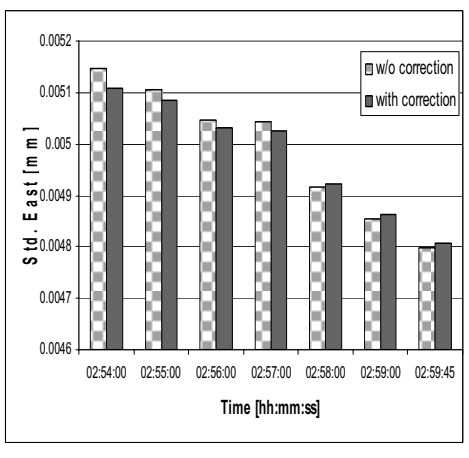

(b)

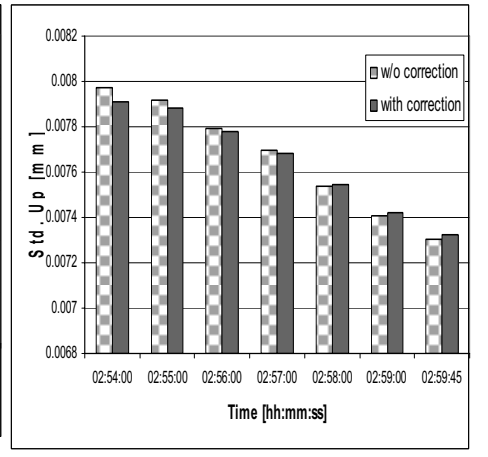

(c)

Figure 8. Standard errors of baseline components (fixed solution) for UTMJ312 and KUKP312

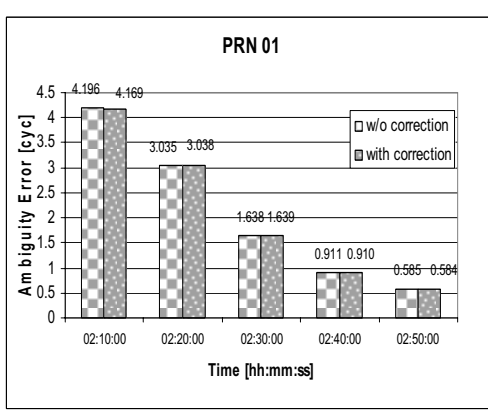

(a)

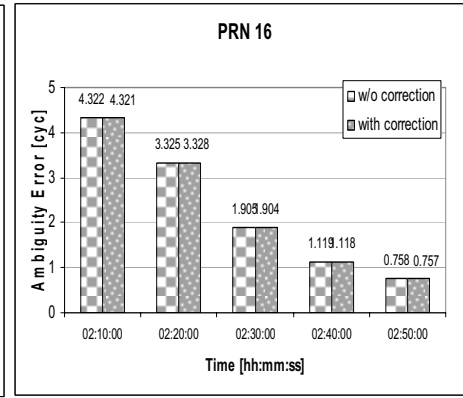

(b)

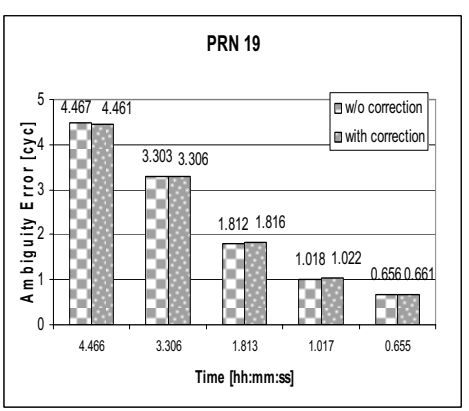

(c)

Figure 9. Ambiguity error of float solution for UTMJ312 and KUKP312 


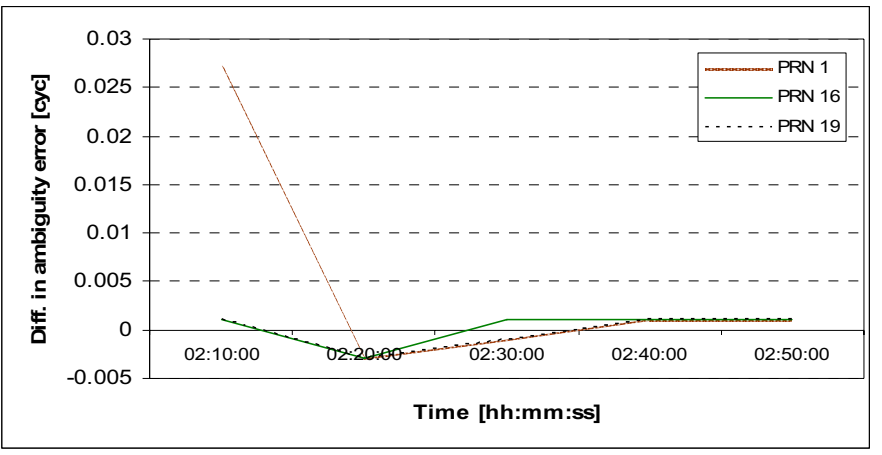

Figure 10. The difference in the ambiguity error of float solution for UTMJ312 and KUKP312

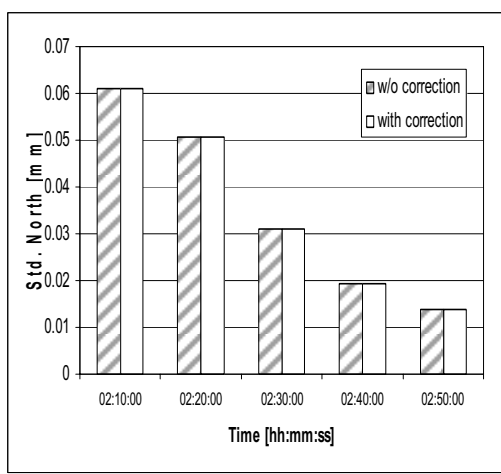

(a)

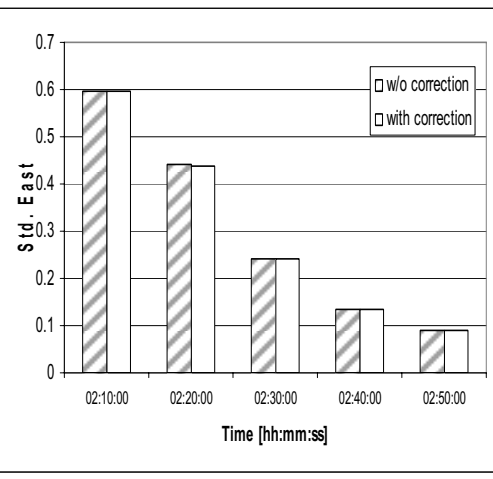

(b)

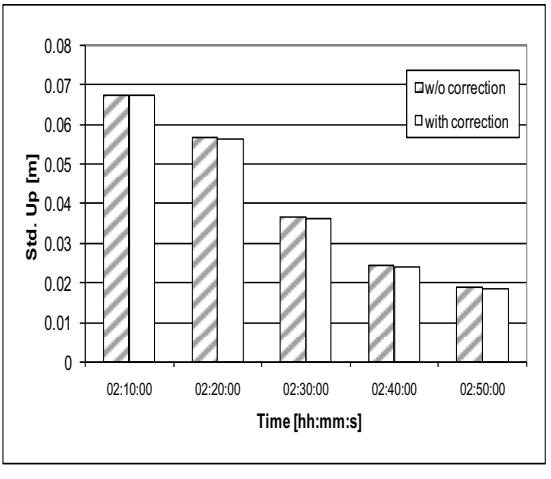

(c)

Figure 11. Standard errors of baseline components (float solution) for UTMJ312 and KUKP312

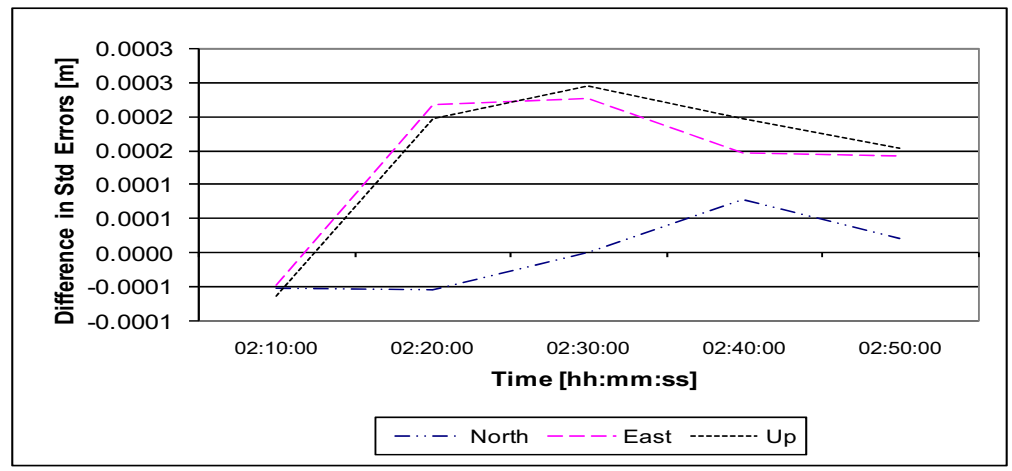

Figure 12. Difference in the standard errors (float solution) for UTMJ312 and KUKP312

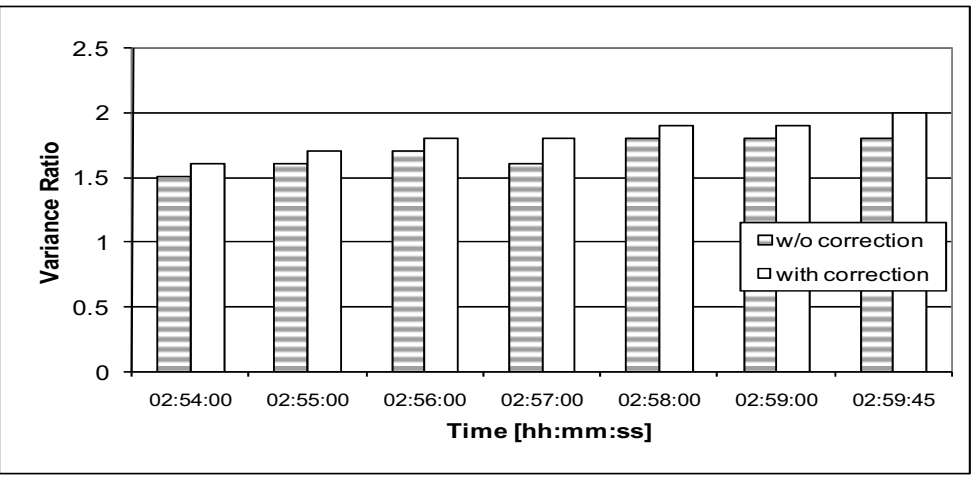

Figure 13. Comparison of Variance ratio for UTMJ312 and KUKP312 


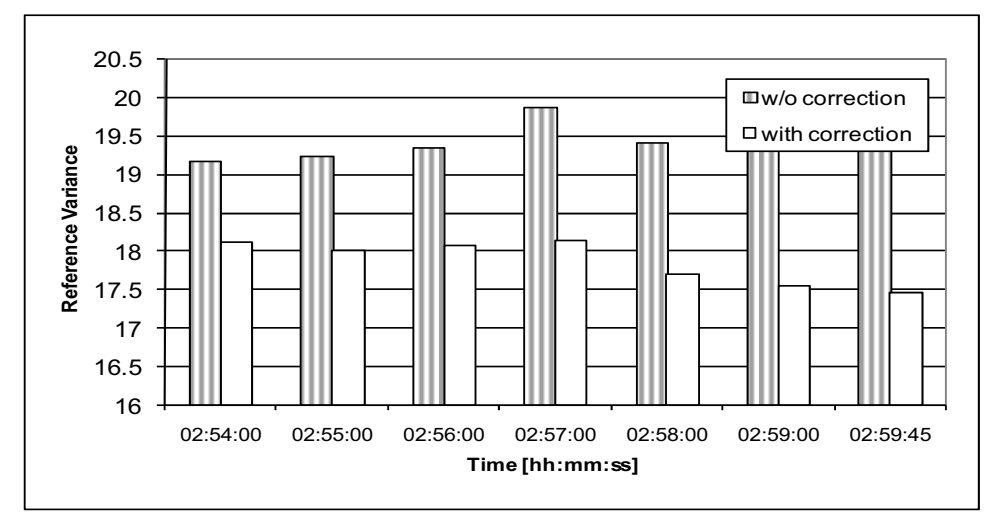

Figure 14. Comparison of Reference Variance for UTMJ312 and KUKP312

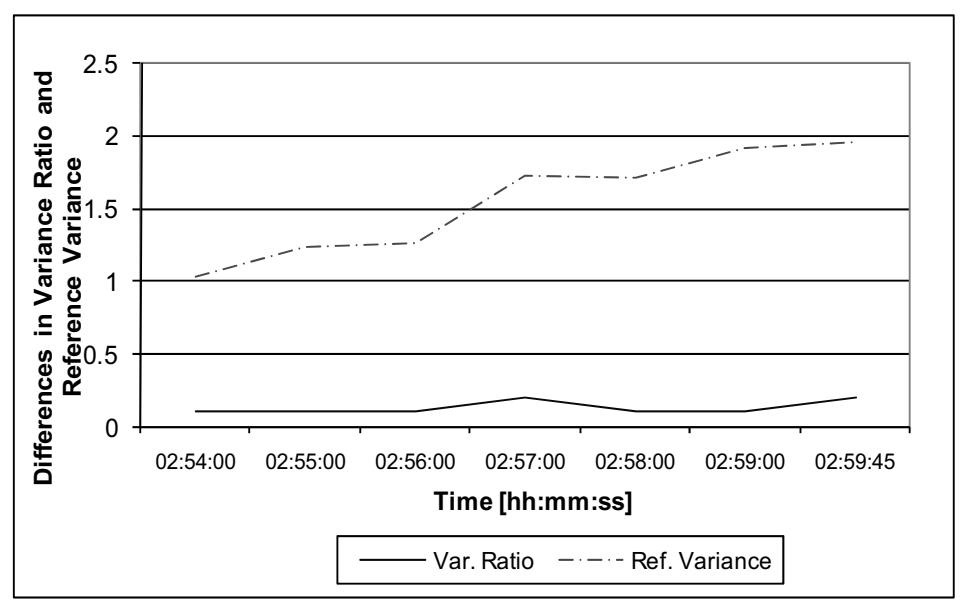

Figure 15. Differences in Variance ratio and Reference Variance for UTMJ312 and KUKP312

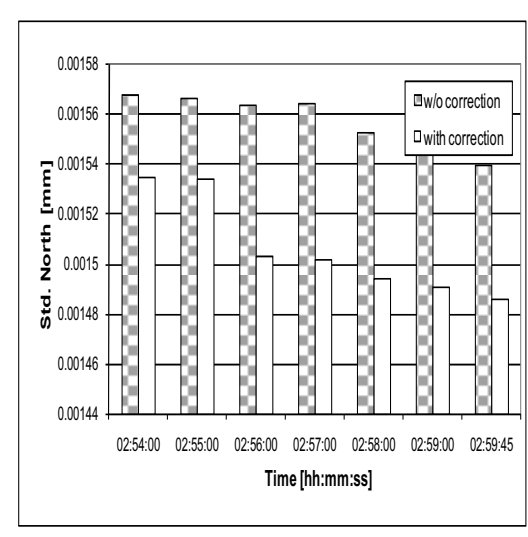

(a)

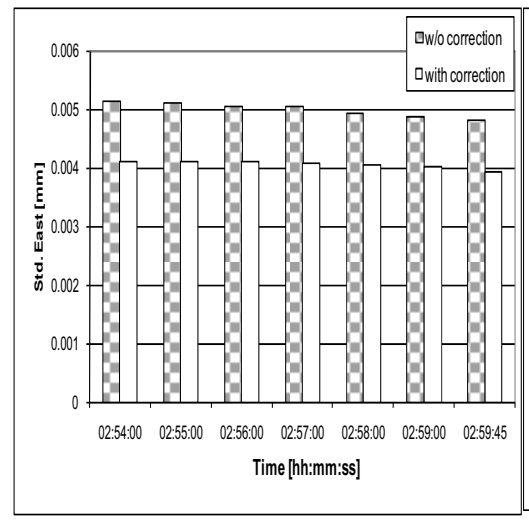

(b)

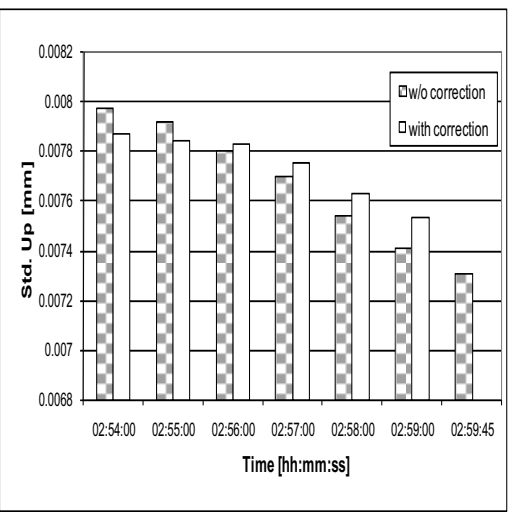

(c)

Figure 16. Standard errors of baseline components (fixed solution) for UTMJ312 and KUKP312 


\title{
Target Strength for Fish Identification Using Echo Sounder
}

\author{
Sunardi (Corresponding author) \\ Electrical Engineering Department, Universitas Ahmad Dahlan \\ Jl. Prof. Soepomo, Umbulharjo 55164, Yogyakarta, Indonesia \\ Tel: 62-274-379-418Ｅ-mail: sunargm@ee.uad.ac.id \\ Jafri Din \\ Electrical Engineering Faculty, Universiti Teknologi Malaysia \\ Skudai 81310, Johor Bahru, Malaysia \\ E-mail: jafri@fke.utm.my
}

Anton Yudhana

Electrical Engineering Department, Universitas Ahmad Dahlan

Jl. Prof. Soepomo, Umbulharjo 55164, Yogyakarta, Indonesia

E-mail: eyudhana@uad.ac.id

Raja Bidin Raja Hassan

Marine Fishery Resources Development and Management Department

Kuala Terengganu 21080, Terengganu, Malaysia

E-mail: rbidin@seafdec.org

The work is supported by the Vote \# 79011 managed by UTM Research Management Center (RMC)

\begin{abstract}
Identification of target strength (TS) of fish species in the South China Sea has been conducted using Furuno FQ- 80 (38/120 kHz echo sounder). This study introduces new experimental method which is combination of in situ and ex situ experiment by applying net cage at undersea. This research involved Selar boops (Oxeye scad) and Megalaspis cordyla (Torpedo scad) in separate net cage at the bottom of the vessel. TS, depth, and position (x-y-z) of fish have been monitored at every ping using echogram. TS of Selar boobs at low and high frequency are $-44.49 \mathrm{~dB}$ for source level $(\mathrm{SL})$ of $236 \mathrm{~dB}$ and $-43.96 \mathrm{~dB}$ for SL of $228 \mathrm{~dB}$. For Megalaspis cordyla, TS are $-45.34 \mathrm{~dB}(\mathrm{SL}=230 \mathrm{~dB})$ and -43.06 $\mathrm{dB}(\mathrm{SL}=225 \mathrm{~dB})$ for low and high frequency respectively. The results show that Megalaspis cordyla produce higher TS whereas the position is deeper and smaller size than Selar boops at low and high frequency.
\end{abstract}

Keywords: Echo sounder, Target strength, FQ-80, Fish identification, Selar boops, Megalaspis cordyla

\section{Introduction}

The ocean is a complex environment with various hidden physical phenomena. One of them is fisheries resources that challenge people to explore. It leads the scientist to establish fisheries acoustic science to study fisheries resources more. Fisheries acoustic then become a particular field hydro acoustic that has significant role on undersea research. As inheritance of hydro acoustic, fisheries acoustic has also two major divisions: active and passive one. Refer to Horne (2000) active acoustic includes subjects such as echo sounder and sonar, where pulses of sound are transmitted into the water and reflect off objects such as fish, submarines, or seabed.

The science of underwater acoustics was given its major impetus by the sinking of Titanic in 1912. This event leaded to the invention of ultrasonic echo ranging devices for iceberg detection. Using the devices with $1100 \mathrm{~Hz}$ frequency for 
projector and receiver, the first underwater echo was received from an iceberg at a range of about 2 miles in 1914. Then, it brought underwater acoustic as the important tools for submarine detection.

Underwater acoustic then had been utilized to detect the fish abundance. The use of echo for fish detection was pioneered by Balls in 1933. Size and reflectivity of sound by the fish are combined into a parameter called the backscattering cross section $\left(\sigma_{b s}\right)$, which is essentially the acoustic size of the object. The backscattering cross section can be expressed as the amount of reflected sound intensity measured one meter away from the target, relative to the amount of energy incident upon the target, as shown in Figure 1. This parameter usually expressed in logarithmic then called the target strength (TS) and expressed in dB (Hydroacoustic, 1989).

Acoustic backscattering by fish depends on fish size, anatomical characteristics, morphology of the body, morphology and composition of swim bladder, location of fish in the acoustic beam, fish behavior and frequency of transducer (Horne, 1998) (Jech, 2002) (Sawada, 2002) (Hazen, 2003). Horne (2003) also identified that the ratio of acoustic wavelength to fish length had influence to acoustic backscattering. Moreover, Horne (2000) divide the factors affecting acoustic backscattering into physical factors such associated with the transmission of sound through a compressible fluid, and the biological factors associated with the location, reflective properties, and behavior of the target. Furthermore, Foote (1990a) and Ona (1990) defined that the biological factors composed of behavioral, morphological, ontogenetic, and physiological factors. The definition of ontogeny is restricted to the development and growth of the fish body and swim bladder. Physiology is restricted to fish feeding and gonad development through the reproductive cycle. Behavior includes the tilt and roll of individual organisms as well as the aggregation and polarized movement (i.e. schooling) by fish groups.

The swim bladder which is an oval-shaped sac found in the fish's abdominal cavity is considered to be responsible for most of the fish's acoustic backscattering energy (Foote, 1990b) and consequently to its TS. Moreover, Horne (1998) identified that acoustic scattering by a swim bladder is four or more times greater than it by fish bodies at any given frequency. At different time, swim bladder can be filled with varying amounts and compositions of gases (same as atmospheric gases; carbon dioxide, oxygen, and nitrogen). The bladder has developed as an extension of the gut wall (Mukai, 1996) (Martin, 2000). Swim bladder varies naturally in volume and shape. It possibly causes the fish TS. The important factors that are assumed to alter the TS significantly are stomach content, gonads, body-fat content, pressure, and tilt angle (Jorgensen, 2003).

The measurement of TS can be conducted both in situ and ex situ. In situ TS measurements for fish detection (Figure 2) incorporate ping-to-ping variability from ensonified organisms but do not permit independent measurement or the manipulation of sources that influence TS. Ex situ one is to measure TS for specific fish with known length in which tilt and depth are controlled.

Kloser (2003), Zhao (2006), Pena (2008) are among others who study of in situ measurement method in the sea using echo sounder for Orange roughly (Hoplostethus atlanticus) from Australia-New Zeland-Namibia, Young hairtail (Trichiurus haumela), and Chilean jack mackerel (Trachurus symmetricus murphyi) respectively. In other side, Abe (2004), Sawada (2004), and Kang (2004) are study of ex situ measurement in the laboratory for Juvenile Walleye pollock (Theragra chalcogramma), Japanese common squid (Todarodes pacificus), and Bluegill (lepomis macrochirus).

The previous literatures show the application of acoustic to study fisheries resources for various fish species. However, the fish involved are very specific associated to its habitat. This research tries to study TS for Selar boops (Oxeye scad) and Megalaspis cordyla (Torpedo scad) that are the most famous and in demand fish in Malaysia. This research also introduces new experimental method which is combination of in situ and ex situ experiment by applying net cage at undersea.

\section{Materials and method}

The location of this research was the South China Sea, north of Redang Island, Terengganu, Malaysia as shown in Figure 3. Two species: Selar boops (Oxeye scad) and Megalaspis cordyla (Torpedo scad) were involved (Figure 4). The detail characteristics of Selar boops and Megalaspis cordyla are listed in Table 1.

This research combined in situ and ex situ methods. The net cage size of $3 \mathrm{~m} \times 3 \mathrm{~m} \times 3 \mathrm{~m}$ was placed at the bottom of the vessel (Figure 5) after calibration set up. The TS measurement of the cage with and without fish has been conducted. Furuno FQ-80 Scientific Echo Sounder was utilized to collect data. FQ-80 is included in the research vessel of KK Senangin II, with dual-frequency capabilities, low-frequency $(38 \mathrm{kHz})$ and high-frequency $(120 \mathrm{kHz})$.TS value, depth, and position of targeted fish can be viewed at every ping by recorded echogram using FQ-80 Analyzer.

TS value, depth, and position (x-y-z) of single fish which detected at every ping at low or high frequency has been observed from Top View of TS as shown in Figure 6. This display shows the direction and depth of single fish. The $\mathrm{x}$-axis is starboard $(+\mathrm{x})$ and port $(-\mathrm{x})$, the $\mathrm{y}$-axis is bow $(+\mathrm{y})$ and stern $(-\mathrm{y})$. Depth recorded is the distance between fish and transducer. The $\mathrm{z}$-axis is angle between fish and center of axis which measured from transducer. 
The transducer is positioned at the bottom of vessel and $2.8 \mathrm{~m}$ from water surface. FQ- 80 must be properly calibrated in order to measure biomass effectively. The calibration is performed using a "calibration sphere," a sphere which has a precise TS value. Calibration allows the determination of backscattering strength or target strength of individual fish. The age of the transducer does not affect the calibration. However, we have to be careful of transducer cleanliness and its damage condition. Since, they affect measurement precision. For this reason, any marine growth, barnacles, and oysters had to be removed from the transducer before performing the calibration. Calibration sphere was $38.1 \mathrm{~mm}$ diameter and bind to the net with nylon string. Deep sea multifilament \#20 was used to the fishing line for the reel. The monofilament \#10 - \#15 was used to bind the calibration sphere. The underwater setup for calibration and calibration ball are shown in Figure 5.

Processor and Analyzer Units were always on-line and displayed the same echo sounder picture (echogram) on the low or high frequency. While watching the Top View of TS display, the position of calibration sphere was adjusted so that the "red ball" on the scope comes to the center of $x-y$ axis. The measured TS should be maintained in the range of \pm 2 $\mathrm{dB}$ from calibration sphere TS or standard TS, i.e. is $-42.30 \mathrm{~dB}$ and $-40.10 \mathrm{~dB}$ for low and high frequency. The detail of TS standard for any frequency and calibration sphere as shown as are listed in Table 2.

\section{Results and discussions}

This section discusses implementation of echo sounder on TS measurement's results included the calibration process and net measurement with or without fish. Table 3 list the parameters used in the calibration process. The calibration ball appearance has been observed and can be viewed from echogram.

The position of calibration ball was varied from 11.36 to $11.61 \mathrm{~m}$ depth from transducer, whereas the transducer was $2.8 \mathrm{~m}$ from the water surface. This different depth of calibration ball has been influenced by sea wave in underwater. The echogram of the calibration ball appearance has been observed and can be viewed in the Figure 7a.

Total pings of echogram are 119 pings. Single fish TS detected are $-46.49 \mathrm{~dB}$ of 97 pings for low frequency and -45.62 $\mathrm{dB}$ of 113 pings for high frequency. Unit conversion from TS $(\mathrm{dB})$ to backscattering cross section must be conducted because the data on $\mathrm{dB}$ unit can not to be average directly. The new Source Level (SL) must be changed as considered in the Table 4.

Position of the upper net and lower net from the transducer are $2.3 \mathrm{~m}$ and $5.3 \mathrm{~m}$ (or $5.1 \mathrm{~m}$ to $8.1 \mathrm{~m}$ from water surface). Total of 79 Selar boops has been put in the net cage 12 hours before TS measurement for adaptation to avoid fish unstable condition. Of 79 fish, only 44 survived and were utilized in this study. The average and range of fork length were $209.59 \mathrm{~mm}$ and $175-233 \mathrm{~mm}$ while the average and range of weight were 165.00 gram and 100-250 gram.

Selar boobs had been detected at 6.98 to 7.69 meters of depth. The echogram of the fish appearance in the net cage is shown in Figure 7b. Fish appearance at low frequency is more than at high frequency because of beam width differences.

For $236 \mathrm{~dB}$ SL, fish TS detected at low frequency has a range of -47.40 to $-38.33 \mathrm{~dB}$. Its average is $-44.49 \mathrm{~dB}$. Otherwise, TS at high frequency varies from -45.19 to $-42.76 \mathrm{~dB}$ for $228 \mathrm{~dB}$ of SL. Its average is $-43.96 \mathrm{~dB}$. It shows that TS of Selar boops at higher frequency is stronger $(0.53 \mathrm{~dB})$ than it of lower frequency. If the $8 \mathrm{~dB}$ differences between SL at high frequency and low frequency is considered then this difference becomes more significant. TS data sample of Selar boops TS recorded are displayed in Table 5.

Total of 9 Megalaspis cordyla were used in this study. They have fork length of 133-155 mm with 144 mm of average. The average of weight is 30 gram which the range is 15-40 gram. This size is smaller than selar boops. Megalaspis cordyla were detected at 8.44 to 10.99 meters of depth. This position is deeper than Selar boops.

The average of TS at low and high frequency for Megalaspis cordyla are $-45.34 \mathrm{~dB}(\mathrm{SL}=230 \mathrm{~dB})$ and $-43.06 \mathrm{~dB}(\mathrm{SL}=$ $225 \mathrm{~dB})$. It shows that TS of Megalaspis cordyla at higher frequency is stronger $(2.28 \mathrm{~dB})$ than it at lower frequency. If the $5 \mathrm{~dB}$ differences between SL at high frequency and low frequency is considered then this difference will be more significant.

These results of TS have no significantly differences for both fish, but Megalaspis cordyla need less of SL. It shows that Megalaspis cordyla produce higher TS whereas the position is deeper and smaller size than Selar boops at low and high frequency. The details data of this comparison can be shown in Table 6.

\section{Conclusion}

TS for fish identification of Selar boops and Megalaspis cordyla at the bottom of the vessel using FQ-80 echo sounder have been conducted. TS value, depth, and position (x-y-z) of fish targeted can be monitored from echogram using FQ-80 Analyzer. Megalaspis cordyla produce higher TS whereas the position is deeper and smaller size than Selar boops at low and high frequency. 


\section{References}

(1989). Hydroacoustics Manual. Biosonic, Inc. USA, pp: 1-15.

(2004). Fishbase: a Global Information System on Fishes. World Fish Center. [Online] Available: http://www.fishbase.org

(2004). Furuno FQ-80 Scientific Echo Sounder, Furuno Electric, Co. Ltd. Nishinomiya, Japan.

Abe, K., Sadayasu, K., Sawada, K., Ishii, K., and Takao, Y. (2004). Precise target strength measurement and morphological observation of juvenile walleye pollock (Theragra chalcogramma). OCEAN'04.MTTS/IEEE TECHNO-OCEAN'04, Japan, Vol. 1, pp. 370-374.

Foote, K.G. (1990a). Averaging of Fish Target-Strength Functions. Journal of the Acoustical Society of America, 67: 504-515.

Foote, K.G. (1990b). Importance of the Swimbladder in Acoustic Scattering by Fish: a Comparison of Gadoid and Mackerel Target Strengths. Journal of the Acoustical Society of America, 67: 2084-2089.

Gauthier, S. and Horne, J.K. (2004). Potential Acoustic Discrimination within Boreal Fish Asemblages. ICES Journal of Marine Science, 61: 836-845.

Hazen, E.L. and Horne, J.K. (2003). A method for Evaluating the Effects of Biological Factors on Fish Target Strength. ICES Journal of Marine Science, 60: 555-562.

Horne, J. K. (2000). Acoustic Approaches to Remote Species Identification: a Review. Fisheries Oceanography, 9(4): 356-371.

Horne, J. K. and Clay, C. J. (1998). Sonar Systems and Aquatic Organisms: Matching Equipment and Model Parameters. Can. J. Fish. Aquat. Sci. 55: 1296-1306.

Horne, J.K. (2003). The Influence of Ontogeny, Physiology, and Behavior on Target Strength of Walleye pollock (Theragra chalcogramma). ICES Journal of Marine Science, 60: 1063-1074.

Jech, J. M. and Horne, J. K. (2002). Three-dimensional Visualization of Fish Morphometry and Acoustic Backscatter. ARLO, 3(1): 35-40.

Jorgensen, R. (2003). The Effects of Swimbladder Size, Condition, and Gonads on the Acoustic Target Strength of Mature Capelin. ICES Journal of Marine Science, 60: 1056-1062.

Kang, D., Iida, K., Mukai, T., and Hwang, D. (2004). Acoustic target strength of Japanese common squid, Todarodes pacificus, and important parameter influencing its TS: swimming angle and material properties. OCEAN'04.MTTS/IEEE TECHNO-OCEAN'04, Japan, Vol. 1, pp. 364-369.

Kloser, R.J., and Horne, J.K. (2003). Characterizing uncertainty in target-strength measurements of a deepwater fish: orange roughly (Hoplostethus atlanticus). ICES Journal of Marine Science, 60: 516-523

Martin. (2000). Anphys Courses. [Online] Available: http://www.bio.division.edu

Mukai, T. and Iida, K. (1996). Depth Dependence of Target Strength of Live Kokanee Salmon in Accordance with Boyle's Law. ICES Journal of Marine Science, 53: 245-248.

Ona, E. (1990). Physiological Factors Causing Natural Variations in Acoustic Target Strength of Fish. Journal of the Marine Biological Association of the United Kingdom, 70: 107-127.

Pena, H. (2008). In Situ Target Strength Measurements of Chilean Jack Mackerel (Trachurus symmetricus murphyi) Collected with a Scientific Echosounder Installed on a Fishing Vessel. ICES Journal of Marine Science, 2008: 594-604.

Sawada, K., Mukai, T., and Sadayasu, K. (2004). Estimation of the Variation in Target-Strength of Fish under Pressure Condition. OCEAN'04.MTTS/IEEE TECHNO-OCEAN'04, Japan, Vol. 1, pp. 389-400.

Sawada, K., Takao, Y., and Miyanohana, Y. (2002). Introduction of the Precise Target Strength Measurement for Fisheries Acoustics. Turk J Vet Anim Sci. 26: 209-214.

Zhao, X. (2006). In Situ Target Strength Measurement of Young Hairtail (Trichiurus haumela) in the Yellow Sea. ICES Journal of Marine Science, 63: 46-51. 
Table 1. Fish characteristics

\begin{tabular}{|c|c|c|}
\hline & Selar boops & Megalaspis cordyla \\
\hline Family & Carangidae & Carangidae \\
\hline Order & Perciformers & Perciformers \\
\hline Class & Actinopterygii & Actinopterygii (ray-finned fishes) \\
\hline Fish base name & Oxeye scad & Torpedo scad \\
\hline Max. size & $30.0 \mathrm{~cm}$ & $80.0 \mathrm{~cm}$ \\
\hline Environment & Reef-associated; marine; depth: $35-500 \mathrm{~m}$ & $\begin{array}{l}\text { Reef-associated; brackish; marine; depth: } \\
\text { 20-100 m }\end{array}$ \\
\hline Climate & Subtropical; $19^{0} \mathrm{~N}-22^{0} \mathrm{~S}$ & Tropical; $47^{\circ} \mathrm{N}-22^{\circ} \mathrm{S}, 40^{\circ}-156^{\circ} \mathrm{E}$ \\
\hline Importance & $\begin{array}{l}\text { Fisheries: commercial; price category: } \\
\text { medium; price reliability: very questionable: } \\
\text { based on ex-vessel price for species in this } \\
\text { family }\end{array}$ & $\begin{array}{l}\text { Fisheries: highly commercial; price reliability: } \\
\text { high }\end{array}$ \\
\hline Resilience & $\begin{array}{l}\text { High, minimum population doubling time less } \\
\text { than } 15 \text { months }(\mathrm{K}=1.90)\end{array}$ & $\begin{array}{l}\text { Medium, minimum population doubling time } 1.4 \\
-4.4 \text { years }(\mathrm{K}=0.13-0.35)\end{array}$ \\
\hline Distribution & $\begin{array}{l}\text { Pacific Ocean: Andaman islands to Vanuatu, } \\
\text { North to the Philippines, South to Northern } \\
\text { Australia }\end{array}$ & $\begin{array}{l}\text { Indo-West Pacific: East Africa to Japan and } \\
\text { Australia. }\end{array}$ \\
\hline Morphology & $\begin{array}{l}\text { Dorsal spines (total): 9-9; dorsal soft rays } \\
\text { (total): 23-25, anal spines: } 3 \text {, anal soft rays: } \\
\text { 19-21, Color blue-green above, silvery to } \\
\text { silver-gold below. Very large eyes. Usually } \\
\text { shows yellow band. Lower margin of gill } \\
\text { opening with a deep furrow. Operculum with } \\
\text { black spot. Breast fully scaled. } 43-46 \text { large } \\
\text { and strong scutes. First } 2 \text { anal fin spines } \\
\text { detached; pectoral fins falcate. }\end{array}$ & $\begin{array}{l}\text { Dorsal spines (total): } 9 \text { - 9; Dorsal soft rays } \\
\text { (total): } 18 \text { - 20; Anal spines: } 3 \text {; Anal soft rays: } 16 \\
\text { - 17. Color bluish grey to green dorsally; silvery } \\
\text { below; dark fins. Opercula with a large black } \\
\text { spot. } 51-59 \text { strong, very large scutes. Anal fin } \\
\text { with } 2 \text { detached spines. Numerous dorsal and } \\
\text { anal finlets are distinct. }\end{array}$ \\
\hline Biology & $\begin{array}{l}\text { Occurs inshore. Forms schools. Feeds on } \\
\text { planktonic and benthic invertebrates. }\end{array}$ & $\begin{array}{l}\text { Primarily oceanic, lives near the surface of } \\
\text { coastal waters. Forms schools and feeds mainly } \\
\text { on fishes. Generally marketed fresh. }\end{array}$ \\
\hline
\end{tabular}

This fish characteristics is published by World Fish Center (2004) and online available at the http://www.fishbase.org.

Table 2. TS standard for calibration

\begin{tabular}{|l|c|c|}
\hline & Frequency $38 \mathrm{kHz}$ & Frequency $120 \mathrm{kHz}$ \\
\hline Radius of calibration sphere & $38.10 \mathrm{~mm}$ & $38.10 \mathrm{~mm}$ \\
\hline TS of calibration sphere & $-42.30 \mathrm{~dB}$ & $-40.10 \mathrm{~dB}$ \\
\hline
\end{tabular}

This standard is available in the Furuno FQ-80 Scientific Echo Sounder (2004). 
Table 3. Parameters for calibration

\begin{tabular}{|l|c|c|}
\hline \multicolumn{1}{|c|}{ Parameters } & Low frequency & High frequency \\
\hline Frequency $(\mathrm{kHz})$ & 38 & 120 \\
\hline Sound speed $(\mathrm{m} / \mathrm{s})$ & 1500 & 1500 \\
\hline SL $(\mathrm{dB})$ & 229.9 & 229.5 \\
\hline ME $(\mathrm{dB})$ & -190 & -190 \\
\hline Gain $(\mathrm{dB})$ & 146.69 & 146.69 \\
\hline Absorption $(\mathrm{dB} / \mathrm{km})$ & 10 & 44 \\
\hline Beam width $(\mathrm{dB})$ & -22.9 & -23.3 \\
\hline Pulse length $(\mathrm{ms})$ & 0.228 & 0.142 \\
\hline TVG line $(\mathrm{dB} / \mathrm{V})$ & 60 & 60 \\
\hline Noise level $(\mathrm{dB})$ & -150 & -150 \\
\hline TD radius $(\mathrm{m})$ & 0.4 & 0.1 \\
\hline TD distance $(\mathrm{m})$ & 0.32 & 0.10 \\
\hline 3dB beam width $($ degree $)$ & 3.1 & 3.1 \\
\hline
\end{tabular}

These parameters must be adjusted in the calibration process in order to appearance of ball and fish is clearly detected and monitored by echogram.

Table 4. Example of calibration results

\begin{tabular}{|l|c|c|}
\hline Parameters & Low frequency $(\mathrm{dB})$ & High frequency $(\mathrm{dB})$ \\
\hline SL & 229.90 & 229.50 \\
\hline TS(f) & -42.30 & -40.10 \\
\hline Measured TS & -46.49 & -45.62 \\
\hline Measured TS - TS(f) & -4.19 & -5.52 \\
\hline New SL & $229.9+(-4.19)=225.71$ & $229.5+(-5.52)=223.08$ \\
\hline
\end{tabular}

The result of calibration process is new Source Level (SL) considered this calculation.

Table 5. Example of various fish detected of Selar boops

\begin{tabular}{|c|c|c|c|c|c|}
\hline & $\begin{array}{c}\text { Depth } \\
(\mathrm{m})\end{array}$ & $\begin{array}{c}\mathrm{x} \\
(\mathrm{deg})\end{array}$ & $\begin{array}{c}\mathrm{y} \\
(\mathrm{deg})\end{array}$ & $\begin{array}{c}\mathrm{z} \\
(\mathrm{deg})\end{array}$ & $\begin{array}{c}\mathrm{TS} \\
(\mathrm{dB})\end{array}$ \\
\hline \multirow{2}{*}{ Low frequency } & 4.86 & 26.20 & -50.10 & -2.09 & -46.64 \\
\cline { 2 - 6 } & 4.82 & 32.70 & -25.30 & -1.05 & -46.60 \\
\hline \multirow{2}{*}{ High frequency } & 4.61 & 48.20 & -55.70 & -2.32 & -43.92 \\
\cline { 2 - 6 } & 4.61 & 23.80 & -18.20 & -0.76 & -45.19 \\
\hline
\end{tabular}

This table shows that TS of Selar boops obtained from low and high frequency. TS recorded of higher frequency is stronger than it at lower frequency whereas depth is no significantly differences. 
Table 6. Comparison of Selar boops and Megalaspis cordyla

\begin{tabular}{|l|c|c|}
\hline Parameters & Selar boops & Megalaspis cordyla \\
\hline Total of sample & 44 & 9 \\
\hline Range of fork length $(\mathrm{mm})$ & $175-233$ & $133-155$ \\
\hline Average of fork length $(\mathrm{mm})$ & 209.59 & 144 \\
\hline Range of weight $(\mathrm{gram})$ & $100-250$ & $15-40$ \\
\hline Average of weight $(\mathrm{gram})$ & 165.00 & 30 \\
\hline Depth from water surface $(\mathrm{m})$ & $6.98-7.69$ & $8.44-10.99$ \\
\hline Average of TS at low frequency $(\mathrm{dB})$ & $-44.49(\mathrm{SL}=236)$ & $-45.34(\mathrm{SL}=230)$ \\
\hline Average of TS at high frequency $(\mathrm{dB})$ & $-43.96(\mathrm{SL}=228)$ & $-43.06(\mathrm{SL}=225)$ \\
\hline
\end{tabular}

This table shows comparison for both fish in this study and its results

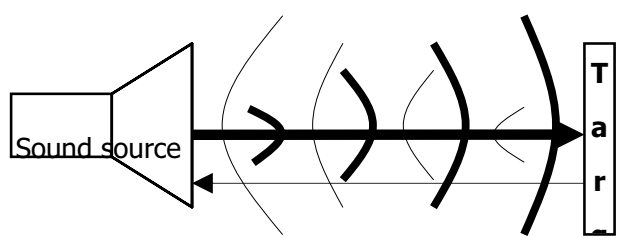

(a) Reflection of sound

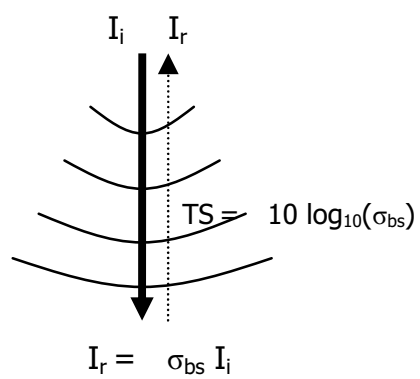

(b) Target strength

Figure 1. Sound reflection and target strength

When the sound wave encounters a density difference (i.e. target), an echo propagates radially outward from the target back to a receiver (a). Size and reflectivity of sound are combined into a parameter called the backscattering cross section $\left(\sigma_{b s}\right)$, which expressed as the amount of reflected sound intensity measured one meter away from the target, relative to the amount of energy incident upon the target. This parameter usually expressed in logarithmic then called the target strength (TS) (b). 


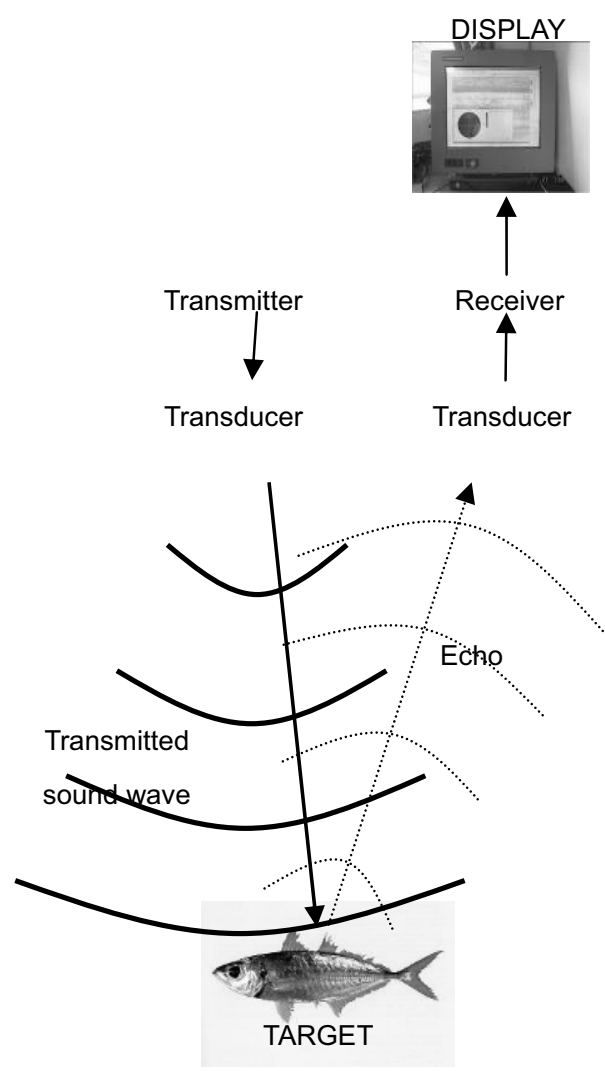

Figure 2. Fish detection using echo sounder

Transmitter of an echo sounder sends out a beam of sound through a transducer. Sound then reflected off objects and the echoes are detected back at transducer and displayed.

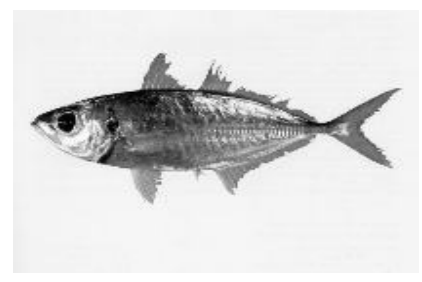

(a) Selar boops

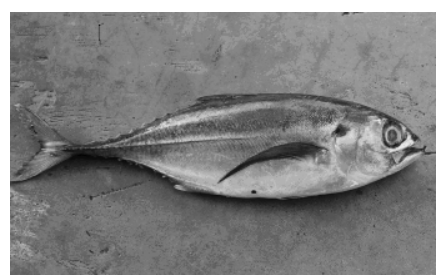

(b) Megalaspis cordyla

Figure 3. Fish studied

This figure captures two of most famous and in demand fish species in Malaysia Selar boops (a) and Megalaspis cordyla (b) 


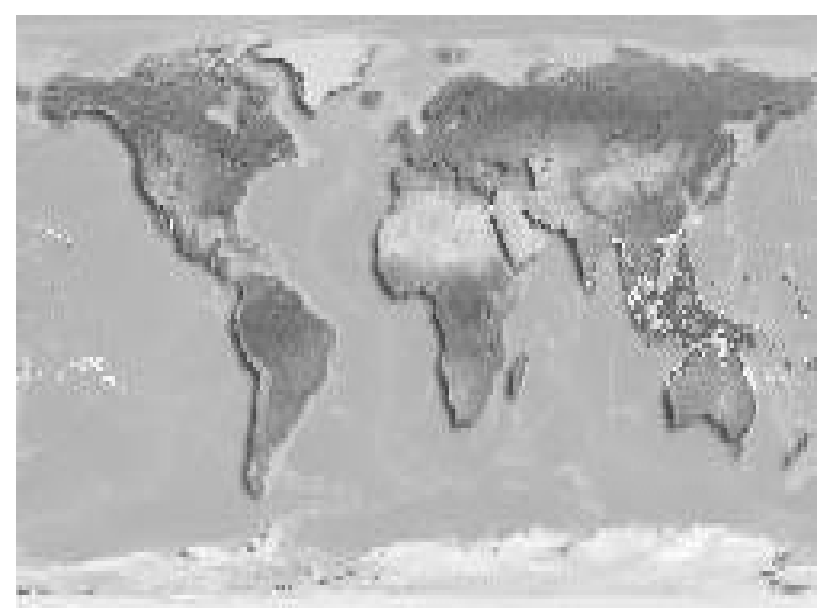

(a) Distribution of fish studied in the world

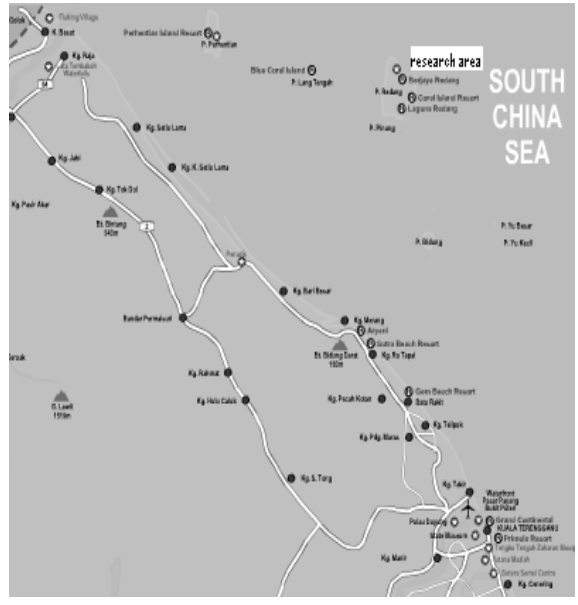

(b) Research location in Malaysia

Figure 4. Fish distribution and research location

World map of distribution of Selar boops and Megalaspis cordyla in the Pacific Ocean: Andaman islands to Vanuatu, North to the Philippines, South to Northern Australia and Indo-West Pacific: East Africa to Japan and Australia (a). Location of research is near of Redang Island, Terengganu, Malaysia (b).

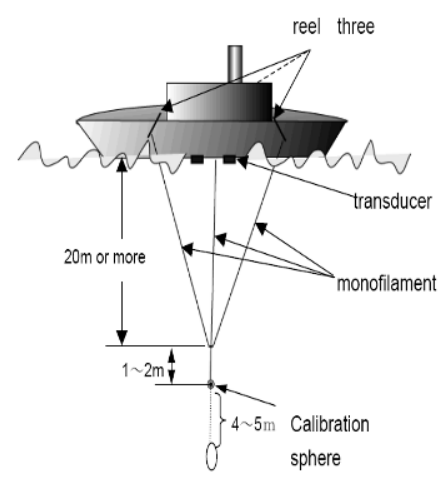

(a) Calibration setup

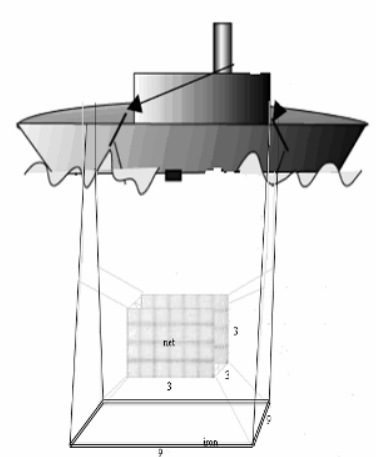

(b) Net cage setup

Figure 5. Setup for Calibration and net cage underwater

The transducer is positioned at the bottom of vessel and $2.8 \mathrm{~m}$ from water surface. FQ- 80 must be properly calibrated using a "calibration sphere" (a). The net cage size of $3 \mathrm{~m} \times 3 \mathrm{~m} \times 3 \mathrm{~m}$ was placed at the bottom of the vessel for fish habitat (b). 


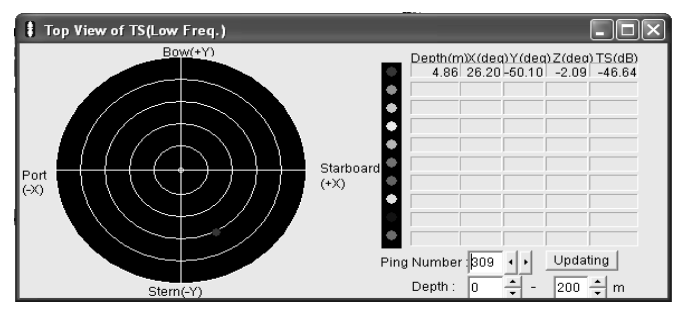

(a) View of single fish detected (one ping)

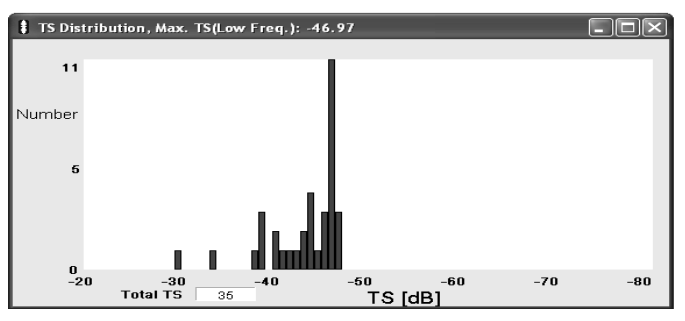

(b) View of TS data (one file)

Figure 6. Echogram view

Depth, position (x-y-z), and TS of fish detected ping-by-ping can be monitored by Top View of TS (a), whereas total of TS data at file-by-file can be shown by Distribution of TS (b).
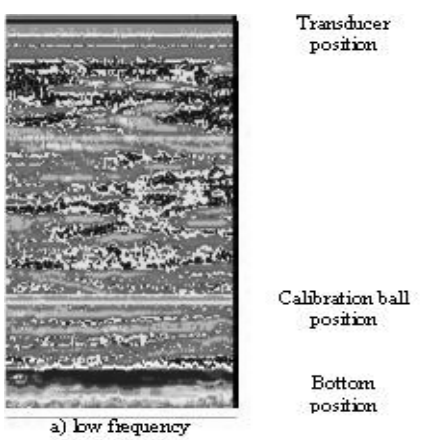

(a) Echogram of calibration ball position
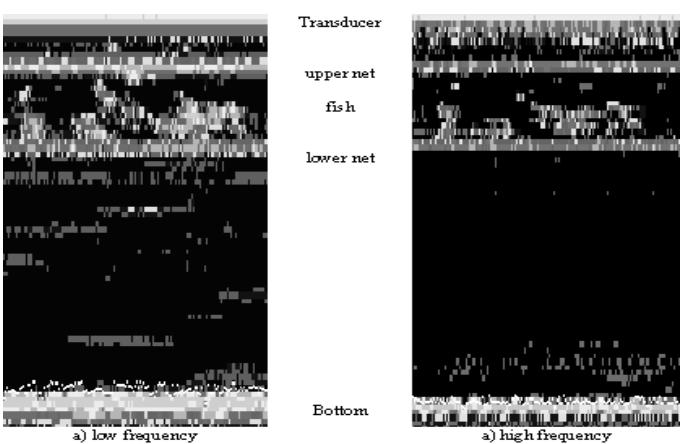

(b) Echogram of fish in the net cage

Figure 7. Recorded echogram.

The position of seabed and calibration ball from transducer (a) and fish abundance in the net cage (b) can be monitored using echogram. 


\title{
Study on Fault Diagnosis of Fuel Injection Based on Vibration
}

\section{Signal Analysis of High-pressure Fuel Injection Pipe}

\author{
Zhiqiang Wang \\ School of mechanical and electronic engineering, Tianjin polytechnic university \\ Tianjin 300160, China \\ E-mail: XiaoKing_ky@yahoo.com.cn
}

\begin{abstract}
An accurate fuel injection advance angle is an important parameter to obtain better fuel combustion index and emission index. Fuel injection advance angle is always deranged because of the wear of the injection nozzle matching parts, which has serious impact on diesel engine performance. How to measure the fuel injection advance angle easily and accurately is a problem for fault diagnosis of high-pressure fuel injection pipe. In this paper, the vibration signals of high-pressure fuel injection pipes' nozzle of different cylinders with different fuel injection advance angles were measured by external oil pressure sensor. Through the theoretical analyzing and calculating the above-mentioned experimental data, the characteristic curves were established, which described the relationship between the fuel injection advance angles and the vibration characteristic quantities of high-pressure fuel injection pipes' nozzle. The characteristic curves were the judgment basis of fuel injection system fault diagnosis. It can be applied to diagnose the fault that caused by fuel injection advance angle change which induced by improper adjustment and matching parts abrasion.
\end{abstract}

Keywords: Fuel injection advance angle, Fault diagnosis, Vibration signal, Frequency analysis

\section{Introduction}

The diesel engine has been widely used in freight cars and some private cars because of its good economy and dynamic performance. An accurate fuel injection advance angle not only is very important for diesel engine to obtain good combustion and normal working condition but also is an important parameter to obtain better fuel combustion index and emission index, so it has great influence on the overall performance of diesel engine. If the fuel injection advance angle is too large, the air temperature in cylinder will be lower, the mixture formation condition will become worse, and the combustion preparing time will get longer, accompanied with the increase of fuel consumption, the reduction of power and the unstable idle speed. However, if the fuel injection advance angle is too small, the fuel combust incompletely at the top dead center and the posterior combustion period get longer. Furthermore, the combustion temperature increase and the pressure in cylinder decrease. Ultimately, the thermal efficiency of diesel engine decreased significantly (Sen, Souling, Zhang, Yingtang, \& Zhen, Haiqi, 1999, pp.48-52. Bai, Shuzhan, 2007, pp.49-52. Shiozaki \& Matsumoto, 1987, pp.521-533. Kang, Jing, \& Hu, Hongying, 2004, pp.127-129). Therefore, the accurate measurement of the fuel injection advance angle is an important part of diesel engine fault diagnosis.

In this paper, the vibration signal of the high-pressure fuel injection pipe's nozzle was measured by external oil pressure sensor. Then through signal processing and analysis, an important parameter - the fuel injection advance angle was extracted, which was used to identify the state of fuel injection. In a word, a new method was presented to measure the fuel injection advance angle, which achieve the nondestructive detection and fault diagnosis of diesel engine without disintegration.

\section{Experimental principle}

\subsection{The measurement of fuel injection advance angle $\alpha$}

As shown in figure 1 (John, 1988, chapter 6), the fuel injection advance angle is the interval between the fuel injection starting point from the top dead center. During this process, the injection rate raise continuously. That is to say, when the crankshaft rotates to top dead center, the fuel injection rate and the corresponding nozzle pressure are maximum. In 
another word, the time history that the nozzle pressure raises continuously from zero to maximum is the time corresponding to fuel injection advance angle. It is very difficult to measure the time corresponding to fuel injection advance angle directly. In this paper, a new method was presented. The $i$ th cylinder's fuel injection advance angle was measured by extracting the duration $\Delta \mathrm{t}_{\mathrm{i}}$ from the first cylinder starting work to the $i$ th cylinder finishing work. During this process, the crankshaft-flywheel rotates with homogeneous angular speed, so the value of crank angle $\beta_{\mathrm{i}}$ from the first cylinder beginning work to the $i$ th cylinder finishing work is proportional to $\Delta \mathrm{t}_{\mathrm{i}}$. The angle is $720^{\circ}$ corresponding to the time of crankshaft rotating two circles, so the relationship is given as follows

$$
\frac{\beta_{\mathrm{i}}}{\Delta t_{i}}=\frac{720^{\circ}}{T}(\mathrm{i}=1,2,3,4,5,6)
$$

Because WD615.77 diesel engine is four-stroke engine, the crankshaft rotated every two circles is one working cycle, and every injection pump supplies oil to combustion chamber once. The working order of cylinders is 1-5-3-6-2-4. Therefore, the crank angle from the 1st cylinder beginning doing work to each other cylinder beginning doing work are $\varphi_{1}=0^{\circ}, \varphi_{2}=480^{\circ}, \varphi_{3}=240^{\circ}, \varphi_{4}=720^{\circ}, \varphi_{5}=120^{\circ}, \varphi_{6}=360^{\circ}$, respectively. Then the fuel injection advance angle $\alpha$ can be obtained as following:

$$
\alpha=\beta_{\mathrm{i}}-\varphi_{\mathrm{i}}
$$

Where $\varphi_{\mathrm{i}}$ is the crank angle from the first cylinder begin doing work to the $i$ th cylinder begin doing work, and the $\beta_{\mathrm{i}}$ is the crank angle from the first cylinder begin doing work to the $i$ th cylinder finish doing work.

\subsection{The extraction of $\Delta t_{i}$}

The high-pressure fuel injection pipe connected to fuel injection pump and injector. The fuel pressure in pump chamber of fuel injection pump is pulse load, so the exciting force of fuel injection pump also has pulse duration properties, and the vibration frequency as equation (3) (Tang, Daming, 1993, chapter 3).

$$
f_{k}=\frac{m j}{60 \tau} k \quad(k=1,2,3 \cdots n)
$$

Where $k$ is the harmonic number, $m$ is the crankshaft speed of diesel engine, $j$ is the number of cylinder (in the experiment, $j=6$ ), and $\tau$ was coefficient of stroke (the diesel engine WD615.77 is four-stroke, so $\tau=2$ ).

Fundamental vibration frequency of high-pressure fuel pipe's nozzle is mainly caused by the harmonic which produced by fuel injection pump's pulse exciting force. The Fourier transformation of the vibration signal X(t) of the $i$ th cylinder's nozzle is expressed as

$$
X(f)=\int_{-\infty}^{\infty} X(t) e^{-j \omega t} d t
$$

The Parseval's equation is given as (Alan, V. O., 2005, chapter 4)

$$
E=\int_{-\infty}^{\infty} f^{2}(t) d t=\frac{1}{2 \pi} \int_{-\infty}^{\infty}|F(j \omega)|^{2} d \omega
$$

According to equation (5), it can be known that the energy of the same signal in time-domain and frequency-domain is equivalent. A new correlation of amplitude spectrum $|X(f)|$ with power spectrum $S_{x}(f)$ was derived as following

$$
S_{x}(f)=\frac{1}{T}|X(f)|^{2}
$$

Where $\mathrm{T}$ was sample length of signal $\mathrm{X}(\mathrm{t})$. Because $S_{x}(f)$ is even function, so its values is symmetric at origin. Therefore the power spectrum can be expressed as equation $(7)$ in the frequency range of $(0, \infty)$.

$$
G_{x}(f)=2 S_{x}(f)
$$

Where $S_{x}(f)$ and $G_{x}(f)$ are the bilateral power spectrum and unilateral power spectrum, respectively. In engineering practice, the root-mean-square spectrum $\sqrt{G_{x}(f)}$ is usually adopted. The $\sqrt{G_{x}(f)}$ can be calculated by combing equation (4), (5) and (6), then it was filtered by using the Chebyshev I low-pass filter. The characteristic function of Chebyshev I low-pass filter is given as

$$
|H(j \omega)|^{2}=\frac{1}{1+\varepsilon^{2} V_{N}^{2}(x)}
$$

Where $\mathrm{N}$ is the filter order, $\varepsilon$ is the ripple factor that determines the magnitude of pass-band ripple fluctuation. $V_{N}(x)$ is defined as:

$$
V_{N}(x)= \begin{cases}\cos \left(N \cos ^{-1} x\right) & x \leq 1 \\ \cosh \left(N \cosh ^{-1} x\right) & x \geq 1\end{cases}
$$


By substitution of the simulation technology indexes into the equation (9), the Chebyshev I low-pass filter which meets the requirement of the performance indicator was established. It was used to extract the first harmonic from $\sqrt{G_{x}(f)}$, denoted by $g_{x}(f)$. Further, with the help of the inverse Fourier transform of $g_{x}(f)$, the corresponding time-domain signal $g(t)$ was obtained according to the equation (10).

$$
g(t)=\frac{1}{2 \pi} \int_{-\infty}^{\infty} g_{x}(f) e^{j \omega t} d \omega
$$

The time when the first peak of $g(t)$ appears is the duration from the first cylinder starting work to the $i$ th cylinder finishing work, namely $\Delta \mathrm{t}_{\mathrm{i}}$. The corresponding crank angle calculated from equation (1). Finally, the fuel injection advance angle $\alpha$ was gained according to equation (2).

\section{Example}

WD615.77 Bosch pump diesel engine was used in this experiment. Its normal fuel injection advance angle $\varphi$ is $20 \pm 2^{\circ}$. The vibration signal of high-pressure fuel pipe was measured by external oil pressure sensor, and then was analyzed by dynamic signal analyzer called RT Pro Focus. The whole test flowchart is shown in figure 2.

As shown in figure 3, the external oil pressure sensor is fixed on the high-pressure fuel injection pipe's nozzle of the fifth cylinder to obtain the vibration signal. In the experiment, the engine speed is $800 \mathrm{r} / \mathrm{min}$ and the sample frequency is $20000 \mathrm{~Hz}$. The vibration signal X(t) of fuel injection pipe's nozzle is presented in figure 4 .

The vibration of the fuel injection pipe's nozzle is mainly caused by the harmonic response generated by the pulse exciting force of fuel injection pipe. Normally, the second vibration harmonic or higher harmonic can be ignored because of its weak influence on the whole vibration, so only the first order harmonic of pulse exciting force is considered. The method stated in section 2 is used to establish the root-mean-square spectrum $\sqrt{G_{x}(f)}$ of $\mathrm{X}(\mathrm{t})$. Then the Chebyshev I band-pass filter is used to filter out the first and the second order harmonic of $\sqrt{G_{x}(f)}$, which is shown in figure 5

As shown in figure 5, the frequency of the first and second order harmonic is $39.1 \mathrm{~Hz}$ and $58.6 \mathrm{~Hz}$, respectively, which gives the same results as that of equation (3). So the first order harmonic of $ل_{G_{x}}(f)$ is caused by the pulse exciting force of fuel injection. The time-domain signal $g(t)$ (shown in figure 6) is obtained according to equation (9). It showed that the value of $\Delta \mathrm{t}_{5}$ is $0.029 \mathrm{~s}$ (the time from the first cylinder beginning doing work to the fifth cylinder finishing doing work). Finally, the injection advance angle $\alpha$ of the fifth cylinder is calculated to be $20^{\circ}$ by combing equation (1) and equation (2). Because the test result is the same as the normal state of WD615.77, the fifth cylinder's fuel injection advance angle is without any faults. Continuing to collect the vibration signals of others cylinders' nozzle, and the injection advance angles were calculated by using the method stated in section 2.1 2.2. The results listed in Table 1 .

According to the results, the following conclusions can be reached:

1) The 1st, 3rd, 4th, 5th cylinder's injection advance angle are healthy.

2) The 2nd cylinder's injection advance angle is smaller than the normal value;

3) The 6th cylinder's injection advance angle is larger than the healthy value.

The above-mentioned results are agreed with the real state of experiment.

\section{Conclusion}

(1). In this paper, a novel fault monitor technique for diesel engine was presented. The time-frequency characteristic of the nozzle's vibration signal was used to identify the fault modes of fuel injection advance angle. It is found that the time of fuel injection advance angle can be extracted from the first harmonic caused by pulse exciting force of fuel injection.

(2). The proposed method is verified by experiments. The results of these studies show that the method can be applied in engineering practice as well as develop a process for nondestructive detecting techniques for diesel engine

\section{References}

Alan, V. O. (2005). Signals and systems. Beijing: Tsinghua University Press, (Chapter 4).

Bai, Shuzhan. (2007). Analysis of damage of engine fuel injection pipe based on vibration test. I.C.E\&Powerplant, 163, 49-52.

John, H. (1988). Internal combustion engine fundamentals. New York, (Chapter 6).

Kang, Jing, \& Hu, Hongying. (2004). Vibration detection \& diagnosis for high-pressure fuel pipe of diesel engineer. International conference on information acquisition, pp.127-129.

Sen, Souling, Zhang, Yingtang, \& Zhen, Haiqi. (1999). Study on fuzzy diagnosis for fuel injection system fault of diesel 
engine using wavelet analysis. Vehicle Engine, 19(4), 48-52.

Shiozaki, T., \& Matsumoto, T. (1987). Low emission combustion influences durability of fuel injection pipe line and treatment of the pipe. SAE international off-highway \& powerplant congress \& exposition. USA, pp.521-533.

Tang, Daming. (1993). Vibration control of internal combustion engine. ChenDu: Southwest Jiaotong University Press, (Chapter 3).

Table 1. The diagnosis results of each cylinder's fuel injection advance angle

\begin{tabular}{|c|c|c|c|c|c|c|}
\hline $\begin{array}{c}\text { Fuel injection } \\
\text { advance angle }\end{array}$ & $\begin{array}{c}1^{\text {st }} \\
\text { cylinder }\end{array}$ & $\begin{array}{c}2^{\text {nd }} \\
\text { cylinder }\end{array}$ & $\begin{array}{c}3^{\text {rd }} \\
\text { cylinder }\end{array}$ & $\begin{array}{c}4^{\text {th }} \\
\text { cylinder }\end{array}$ & $\begin{array}{c}5^{\text {th }} \\
\text { cylinder }\end{array}$ & $\begin{array}{c}6^{\text {th }} \\
\text { cylinder }\end{array}$ \\
\hline $\begin{array}{c}\text { Experimental } \\
\text { value }\end{array}$ & $20^{\circ}$ & $16^{\circ}$ & $21^{\circ}$ & $18^{\circ}$ & $20^{\circ}$ & $25^{\circ}$ \\
\hline Normal value & \multicolumn{7}{|c|}{$20^{\circ}$} \\
\hline
\end{tabular}

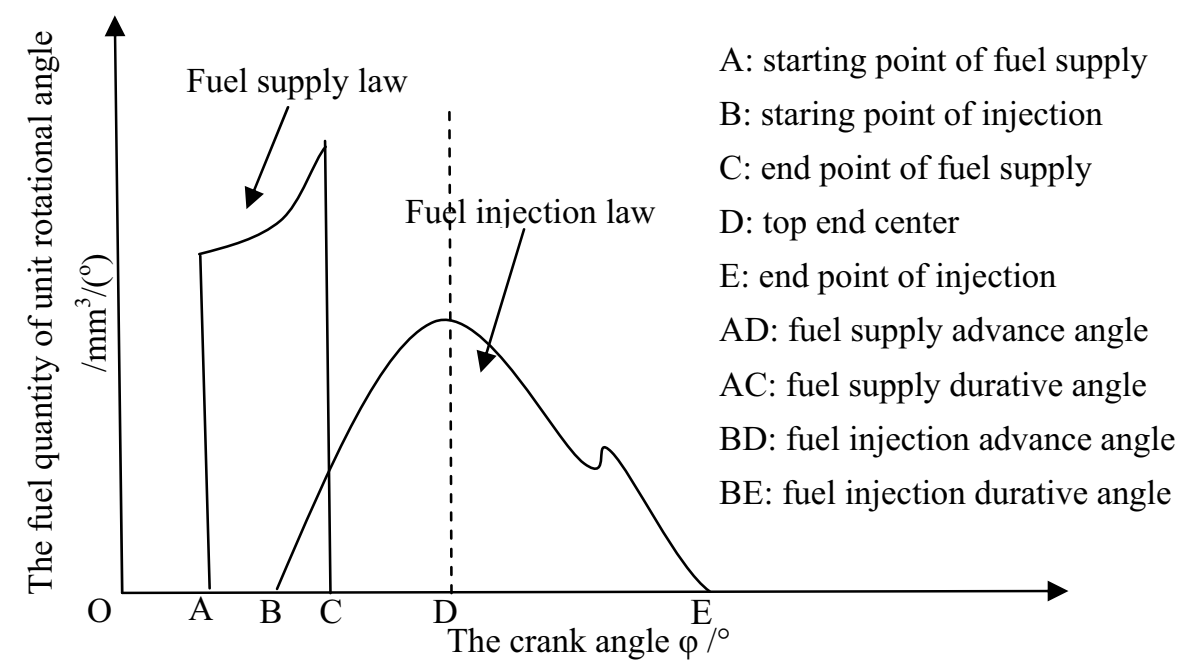

Figure 1. The Fuel Supply Law and Fuel Injection Law

\begin{tabular}{|c|c|c|c|}
\hline High-pressure & External oil & Dynamic & Data analysis \\
\hline fuel injection & pressure sensor & signal analyzer & and processing \\
\hline
\end{tabular}

Figure 2. The Test Flowchart 


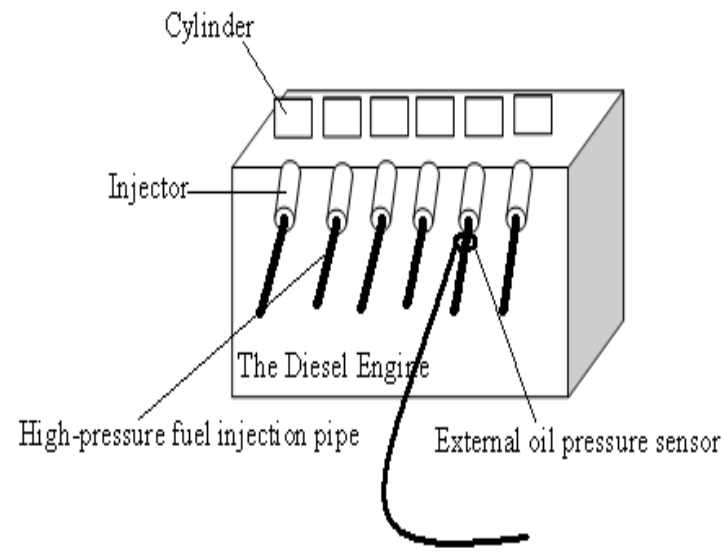

Figure 3. The Location of Sensor

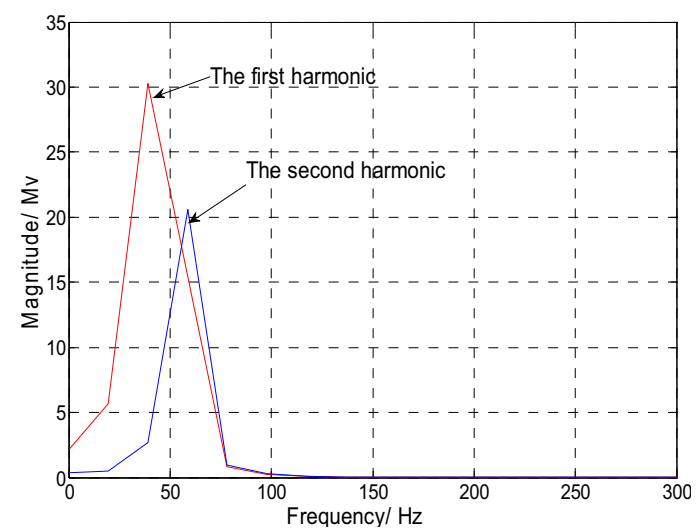

Figure 5. The First and Second Order Harmonic

$$
\text { of } \sqrt{G_{x}(f)}
$$

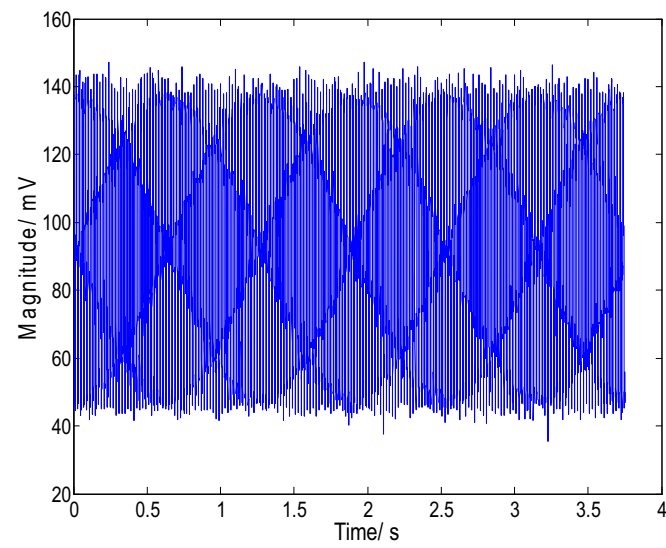

Figure 4. The Vibration Signal X(t) of Fuel Injection Pipe's Nozzle

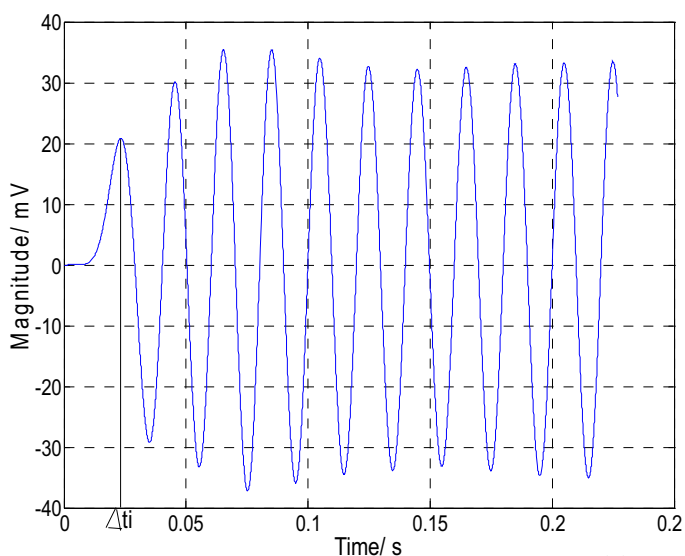

Figure 6. The Time-domain Signal $g(t)$ 
A journal archived in Library and Archives Canada

A journal indexed in Canadiana

A journal indexed in AMICUS

A journal included in Ulrich's

A journal indexed in Google Scholar

A journal indexed in Genamics JournalSeek

A journal indexed in DOAJ

A journal included in PKP Open Archives Harvester

\section{Applied Physics Research}

Semiannual

Publisher Canadian Center of Science and Education

Address 4915 Bathurst St. Unit \# 209-309, Toronto, ON. M2R 1 X9

Telephone 1-416-208-4027

Fax 1-416-208-4028

E-mail apr@ccsenet.org

Website www.ccsenet.org

Printer William Printing Ine.

Price CAD.\$20.00

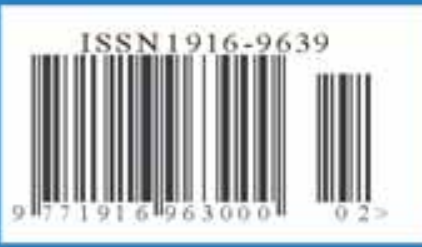

